\title{
Seaside, Oregon Tsunami Pilot Study- Modernization of FEMA Flood Hazard Maps
}

By Tsunami Pilot Study Working Group

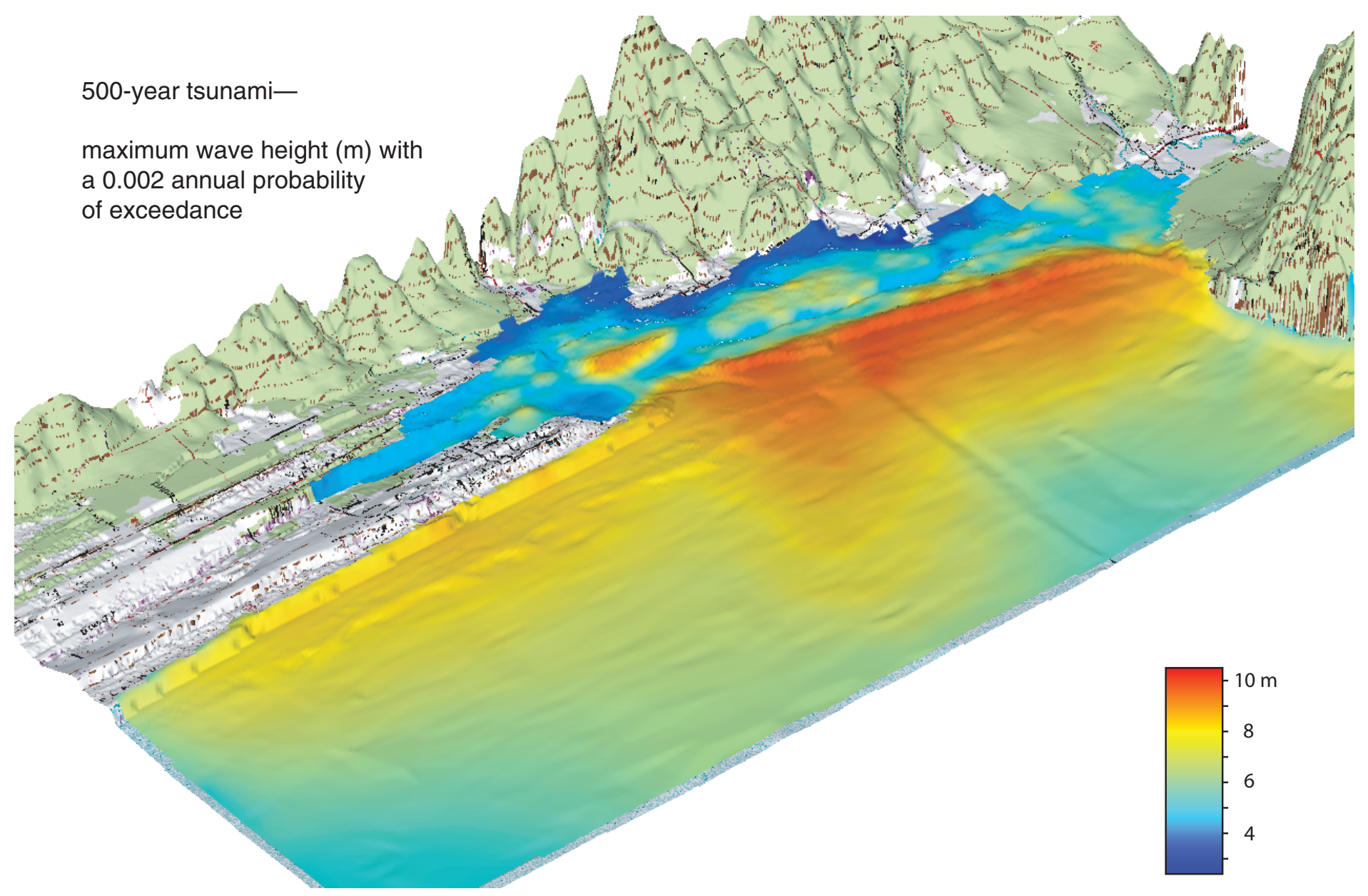

Joint NOAA/USGS/FEMA Special Report

U.S. National Oceanic and Atmospheric Administration

U.S. Geological Survey

U.S. Federal Emergency Management Agency
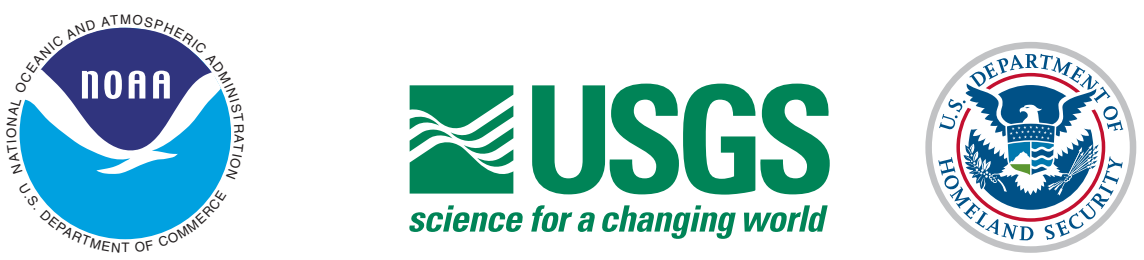



\section{Seaside, Oregon Tsunami Pilot Study- Modernization of FEMA Flood Hazard Maps}

\section{Tsunami Pilot Study Working Group:}

Frank I. González ${ }^{1}$, Eric Geist ${ }^{2}$, Costas Synolakis ${ }^{3}$, Diego Arcas $^{4}$, Douglas Bellomo ${ }^{5}$, David Carlton ${ }^{5}$, Thomas Horning ${ }^{6}$, Bruce Jaffe $^{2}$, Jeff Johnson ${ }^{7}$, Utku Kanoglu ${ }^{8}$, Harold Mofjeld ${ }^{1}$, Jean Newman ${ }^{4}$, Thomas Parsons ${ }^{2}$, Robert Peters ${ }^{2}$, Curt Peterson ${ }^{9}$, George Priest ${ }^{10}$, Vasily Titov ${ }^{4}$, Angie Venturato ${ }^{4}$, Joseph Weber ${ }^{5}$, Florence Wong ${ }^{2}$, Ahmet Yalciner ${ }^{8}$

\footnotetext{
${ }^{1}$ NOAA, Pacific Marine Environmental Laboratory, Seattle, WA

${ }^{2}$ U.S. Geological Survey, Menlo Park and Santa Cruz, CA

${ }^{3}$ University of Southern California, Los Angeles, CA

${ }^{4}$ Joint Institute for the Study of Atmosphere and Ocean (JISAO), University of Washington, Seattle, WA

${ }^{5}$ FEMA, Department of Homeland Security, Washington, D.C. and Bothell, WA ${ }^{6}$ Horning Geoscience, Seaside, OR

${ }^{7}$ Northwest Hydraulics Consultants, Seattle, WA

${ }^{8}$ Middle East Technical University, Ankara, Turkey

${ }^{9}$ Portland State University, Portland, OR

${ }^{10}$ Oregon Dept. of Geology and Minerals, Newport, OR
}

\section{Joint NOAA/USGS/FEMA Special Report}

U.S. National Oceanic and Atmospheric Administration

U.S. Geological Survey

U.S. Federal Emergency Management Agency 


\section{NOTICE from NOAA}

Mention of a commercial company or product does not constitute an endorsement by NOAA/OAR. Use of information from this publication concerning proprietary products or the tests of such products for publicity or advertising purposes is not authorized. Any opinions, findings, and conclusions or recommendations expressed in this material are those of the authors and do not necessarily reflect the views of the National Oceanic and Atmospheric Administration.

\section{This report should be cited as:}

Tsunami Pilot Study Working Group (2006): Seaside, Oregon Tsunami Pilot StudyModernization of FEMA flood hazard maps. NOAA OAR Special Report, NOAA/OAR/PMEL, Seattle, WA, 94 pp. +7 appendices.

\section{Also available as:}

Tsunami Pilot Study Working Group (2006): Seaside, Oregon Tsunami Pilot StudyModernization of FEMA flood hazard maps. U.S. Geological Survey Open-File Report 20061234 [available on the World Wide Web at http://pubs.usgs .gov/of/2006/1234/].

Cover: Perspective view of 500-year tsunami in the Seaside/Gearhart, Oregon, pilot study area. Tsunami wave heights $(\mathrm{m})$ with a $0.2 \%$ annual probability of exceedance. Wave heights include the effects of tides. Vertical exaggeration 10×; view looks southeastward.

Contribution No. 2975 from NOAA/Pacific Marine Environmental Laboratory

Also available from the National Technical Information Service (NTIS)

$$
\text { (http://www.ntis.gov) }
$$




\section{Contents}

$\begin{array}{ll}\text { Executive Summary } & 1\end{array}$

1 Background and Introduction $\quad 5$

2 Previous Methods Used for FIRM Tsunami Maps 9

2.1 Tsunami Sources . . . . . . . . . . . . . . . . . . . 9

2.2 Trans-Pacific and Nearshore Numerical Models . . . . . . . . . . 10

2.3 Predicted Tides . . . . . . . . . . . . . . . . . . . . . . 11

2.4 Computing the 100- and 500-Year Tsunami Runup Heights . . . . 11

2.5 Application to Seaside, Oregon . . . . . . . . . . . . . . . 12

3 Development of GIS Database $\quad 15$

3.1 Digital Elevation Model . . . . . . . . . . . . . . . . . . . 16

3.2 Historical Tsunami Event Data . . . . . . . . . . . . . . . 19

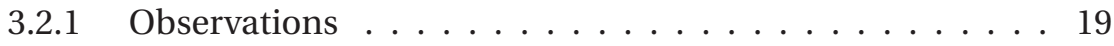

3.2 .2 Shoreline . . . . . . . . . . . . . . . 19

3.3 Model Output . . . . . . . . . . . . . . . . . . . . . . . 19

4 Tsunami Deposits $\quad 23$

4.1 Methods . . . . . . . . . . . . . . . . . . . . . 24

4.2 Results . . . . . . . . . . . . . . . . . . 24

$4.2 .1 \quad 1964$ tsunami deposits . . . . . . . . . . . . . . . . 28

4.2 .21700 tsunami deposits . . . . . . . . . . . . . 28

4.2 .3 Older tsunami deposits . . . . . . . . . . . . 31

4.2.4 Paleo-tidal inlet . . . . . . . . . . . . . . . . 31

4.3 Discussion of Tsunami Deposit Results . . . . . . . . . . . 33

5 Probabilistic Method $\quad 35$

5.1 PTHA Overview . . . . . . . . . . . . . . . . 35

5.1 .1 Previous PTHA studies . . . . . . . . . . 35

5.1.2 Application of PTHA to FIRM specifications . . . . . . . . 36

5.2 Source Specification . . . . . . . . . . . . . . . . 39

5.2 .1 Source magnitude and geometry . . . . . . . . . 39

5.2 .2 Far-field earthquakes . . . . . . . . . . . . . . 40

5.2.3 Cascadia Subduction Zone earthquakes . . . . . . . . . . 44

6 Propagation and Inundation Modeling $\quad 51$

6.1 Numerical Model . . . . . . . . . . . . . . . . . . . 51

6.1 .1 Mathematical formulation . . . . . . . . . 52

6.1.2 Moving boundary condition . . . . . . . . . 53 
6.1.3 Tsunami propagation model . . . . . . . . . . . . . . 54

6.1 .4 Model verification . . . . . . . . . . . . . . . . . 54

6.2 Model Sources . . . . . . . . . . . . . . . . . . . . . . . 55

6.2 .1 Far-field sources . . . . . . . . . . . . . . 56

6.2 .2 Near-field sources . . . . . . . . . . . . . . . 56

6.3 Numerical Model Setup and Testing . . . . . . . . . . . . . . 58

6.4 Database of Model Runs . . . . . . . . . . . . . . . . . . 61

6.4.1 Discussion of model simulation results . . . . . . . 61

7 Evaluating Tsunami Impact Metrics $\quad 69$

7.1 Forces on Structures $\ldots \ldots \ldots$. . . . . . . . . 70

8 Results $\quad 77$

$8.1 \quad 100$-Year Tsunami Map . . . . . . . . . . . . . . . . . . . 77

8.2500 -Year Tsunami Map . . . . . . . . . . . . . . . . . . . 77

9 Discussion: Resolvable Issues Through Future Research 83

9.1 Tsunami Earthquakes . . . . . . . . . . . . . . . . . . . . 83

9.2 Smaller Cascadia Subduction Zone Earthquakes . . . . . . . . . . . . . . . . . 83

9.3 Other Sources of Epistemic Uncertainty . . . . . . . . . . . . . . 84

10 Recommendations $\quad 87$

10.1 Scientific/Technical Recommendations . . . . . . . . . . . . 87

10.2 Policy/Programmatic Recommendations . . . . . . . . . . . 88

11 Acknowledgments $\quad 88$

12 References $\quad 89$

Appendices $\quad 95$

A: Background tides and sea level variations at Seaside, Oregon

B: A digital elevation model for Seaside, Oregon

C: Summary of eyewitness observations from 1964 Alaska Tsunami in Seaside, Oregon

D: Location of sites used in this study and presence of 1964, 1700, and older tsunami deposits

E: Incorporating tides into probability calculations

F: Determining earthquake recurrence rates

G: Surface and area calculation for the 100-year and 500-year floods 


\section{Executive Summary}

$\mathrm{F}$

EMA Flood Insurance RATE MAP (FIRM) guidelines do not currently exist for conducting and incorporating tsunami hazard assessments that reflect the substantial advances in tsunami research achieved in the last two decades; this conclusion is the result of two FEMA-sponsored workshops and the associated Tsunami Focused Study (Chowdhury et al., 2005). Therefore, as part of FEMA's Map Modernization Program, a Tsunami Pilot Study was carried out in the Seaside/Gearhart, Oregon, area to develop an improved Probabilistic Tsunami Hazard Assessment (PTHA) methodology and to provide recommendations for improved tsunami hazard assessment guidelines. The Seaside area was chosen because it is typical of many coastal communities in the section of the Pacific Coast from Cape Mendocino to the Strait of Juan de Fuca, and because State Agencies and local stakeholders expressed considerable interest in mapping the tsunami threat to this area. The study was an interagency effort by FEMA, U.S. Geological Survey, and the National Oceanic and Atmospheric Administration, in collaboration with the University of Southern California, Middle East Technical University, Portland State University, Horning Geoscience, Northwest Hydraulics Consultants, and the Oregon Department of Geological and Mineral Industries. Draft copies and a briefing on the contents, results, and recommendations of this document were provided to FEMA officials before final publication.

\section{Methodology}

The study methodology consisted of a number of important components, each of which was essential to successfully developing 100- and 500-year tsunami inundation products required by FEMA for Flood Insurance Rate Maps, including flooding depth and high velocity zones ( $V$-zones). These components were:

- Source Specification. Review of literature; consultation with expert colleagues; development of a database of quantitative probabilistic models of local and far-field earthquake tsunami sources in the Cascadia Subduction Zone (CSZ), the Alaska-Aleutian Subduction Zone (AASZ) and the Peru-Chile Subduction Zone (PCSZ).

- Data Acquisition. Performance of a paleotsunami deposit mapping and interpretation study; acquisition of historical records and eyewitness reports.

- Model Development, Testing, and Application. Development of a highresolution Digital Elevation Model (DEM) based on the latest available 
topography, bathymetry, and tidal information; development of a stateof-the-art, site-specific tsunami inundation model; testing of the model with all available tsunami field observations, including paleotsunami data, historical records, and eyewitness reports; application of the model, using the source database, to generate the corresponding tsunami inundation database.

- Probabilistic Computations. Development of a systematic procedure to process the study data and compute the distributions of 0.01 and 0.002 annual rates of occurrence (100- and 500-year) quantities, including the effect of ocean tides; application of the procedure to create the sitespecific tsunami hazard maps.

- Study-Specific Database Development. Development and documentation of a comprehensive, study-specific, GIS-compatible database that includes sources, DEM, model output, field observations, and other information relevant to the study; creation of web-based interface for database access.

- Analyses and Interpretation. Use of the GIS database for quality control and error-checking, and to analyze and interpret the primary study results; exploratory analyses and interpretation of various tsunami impact indices to generalize the concepts of tsunami hazard levels in general, and tsunami high-velocity flood zones ( $V$-zones) in particular.

\section{Results}

Although Seaside suffered inundation and damage as a result of the tsunami generated by the Great 1964 Prince William Sound earthquake, little inundation is indicated by the 100-year tsunami hazard map. The interpretation of this result is that, on the 100 -year time scale, Seaside is threatened primarily by tsunamis generated by far-field earthquakes that are not generally as destructive as those generated locally. In contrast, on the 500-year time scale, Seaside is threatened by large, destructive tsunamis generated locally by great earthquakes on the Cascadia Subduction Zone, which lies just offshore. As a consequence, the 500-year tsunami hazard map reflects very large regions of Seaside inundated to significant depths.

Details of the methodology developed during the course of this project, a discussion of older tsunami assessment methods, data sources, literature references, results, and other recommendations are provided in the body of the report.

\section{Recommendations}

Some important factors influenced our recommendations, as follows. First, the methodology for probabilistic tsunami hazard assessment (PTHA) developed by this study, while preliminary, is nonetheless a major advance over previous methods, and should therefore be applied to upgrade assessments 
in other coastal areas. However, considerable work remains to improve the methodology, and these follow-on studies should also be designed to refine and improve the methodology, as discussed in the report. Also, truly disastrous local events will inevitably devastate U.S. coastal communities near known subduction zones, such as the Cascadia and the Alaska-Aleutian Subduction Zones; though infrequent, the impact of such events are so catastrophic that they must somehow be taken into account. Time limitations did not allow development of a "Credible Worst Case" methodology during the course of this study. However, our results lay the groundwork for the development of this method which, essentially, answers two fundamental questions: "What is the scientifically defensible and credible worst case scenario?" and "What is the probability of occurrence of this scenario?" This simple concept has great intuitive appeal and should have very high practical value as an actuarial tool. Finally, adequate PTHA for all U.S. coastlines is a long-term, challenging effort that requires an integrated, sustainable national approach, including the establishment and maintenance of Federal agency partnerships, in collaboration with State agencies, academic, and other institutions. Our specific recommendations are therefore grouped as Scientific/Technical and Policy/Programmatic, as follows.

\section{Scientific/Technical Recommendations}

- Include all reasonable epistemic and aleatory sources of uncertainty in each Probabilistic Tsunami Hazard Assessment, using the best available science.

- Utilize tsunami hydrodynamic models that meet NOAA standards, to ensure consistency of Federal agency products.

- Test all earthquake and tsunami models by extensive field studies to gather and exploit all possible paleogeography and paleotsunami data, historical tsunami measurements, eyewitness reports, and other types of field observations.

- Develop and maintain a comprehensive GIS database of all field data, model results, and a comprehensive site- and source-specific tsunami/ earthquake bibliography for the region as an essential and invaluable analysis and product development tool.

- Publish a report for each PTHA project that documents procedures, data sources, and results, that includes a bibliography, and that is reviewed for consistency with FEMA standards.

- Publish PTHA results either as a separate Federal Insurance Rate Map, or include PTHA information as separate, tsunami-specific items on FIRMs. In either case, include: (a) the 100-year and 500-year events, (b) tsunamispecific $V$-zones, (c) measurements available for the worst case historical and/or paleotsunami events, and (d) the "Credible Worst-Case Scenario" event. 


\section{Policy/Programmatic Recommendations}

- Establish a formal FEMA/NOAA/USGS partnership to address national needs for tsunami hazard assessment products in a federally consistent and cost-effective manner.

- Apply PTHA to additional Cascadia Subduction Zone communities as NOAA inundation models are completed.

- Conduct pilot studies to adapt PTHA to other tsunami regimes in the Pacific, Caribbean, Atlantic, and Gulf, using a preliminary assessment of uncertainty.

- Apply PTHA to additional Pacific, Caribbean, Atlantic, and Gulf communities as the corresponding pilot studies and NOAA inundation models are completed.

- Establish a systematic maintenance and improvement program to integrate scientific and technical advances into the PTHA methodology. 


\section{Background and Introduction}

$\mathrm{F}$ EMA Flood Insurance Rate Map (FIRM) guidelines do not currently exist for conducting and incorporating tsunami hazard assessments that reflect the substantial advances in tsunami research achieved in the last two decades. Thus, current FIRMs rely heavily on the science, technology, and methodologies developed in the 1970s, such as that of Houston and Garcia (1974) and Houston (1980). This work is generally regarded as groundbreaking and state-of-the-art for its time, but is now superseded by modern methods (Table 1).

Two recent FEMA workshops were held to help develop plans for updating the existing FIRMs. The approximately 40 workshop participants included FEMA management, coastal engineering and scientific experts, floodplain management professionals, and study contractors. FEMA guidance at the first workshop encouraged a regional approach, in recognition that "one shoe seldom fits all" and that somewhat different methodologies are frequently required to properly account for regional differences. The second workshop concentrated on reviewing "Focused Study" plans developed by Technical Working Groups, including the Tsunami Focused Study.

Table 1: Comparison of pre-1990 and post-1990 tsunami hazard assessment.

\begin{tabular}{|c|c|c|}
\hline Component & Pre-1990 & Post-1990 \\
\hline Runup modeling & No & Yes \\
\hline Far-field sources & $\begin{array}{l}\text { Earthquakes. Surface deformation } \\
\text { based on simple elliptic analytic } \\
\text { idealizations. }\end{array}$ & $\begin{array}{l}\text { Earthquakes and landslides. } \\
\text { Surface deformation based on } \\
\text { geophysical models. }\end{array}$ \\
\hline Near-field sources & No. Importance not recognized. & $\begin{array}{l}\text { Yes. Importance now recognized } \\
\text { as a result of numerous studies. }\end{array}$ \\
\hline Bathymetry and topography & $\begin{array}{l}\text { Low quality coverage and } \\
\text { availability. Deep ocean modeled } \\
\text { as constant-depth basin. Shallow } \\
\text { coastal features not adequately } \\
\text { resolved. }\end{array}$ & $\begin{array}{l}\text { Improved quality, coverage, and } \\
\text { availability of Pacific deep and } \\
\text { coastal bathymetry and } \\
\text { topography. }\end{array}$ \\
\hline Computational grids & Coarse-resolution. & Fine-resolution, where required. \\
\hline Probabilistic methodology & $\begin{array}{l}\text { Based on short-term historical } \\
\text { tsunami record. }\end{array}$ & $\begin{array}{l}\text { Based on long-term paleoseismic } \\
\text { and paleotsunami records and } \\
\text { short-term, historical earthquake } \\
\text { and tsunami records. }\end{array}$ \\
\hline Hazard zone identification & $\begin{array}{l}\text { Qualitative estimates inferred } \\
\text { from offshore height only. }\end{array}$ & $\begin{array}{l}\text { Indices can be computed, based } \\
\text { on both runup heights and } \\
\text { currents. }\end{array}$ \\
\hline
\end{tabular}


Tsunamis generated by seismic or other sources near or far from a site of interest are termed, from the point of view of that site, near-field (or local) and far-field (or distant) tsunamis, respectively. The Tsunami Focused Study (Tsunami Focused Study Team, 2005) identified two general types of sources as the most common generators of destructive tsunamis: earthquakes, which might be local or distant from the area of interest; and slides, which might be coseismic or aseismic, subaerial or subaqueous.

Earthquake sources generally produce a zone of destructive tsunami energy over a larger geographic scale than slide sources. Differences in the relative importance of local and distant earthquake sources serve to identify five distinct Pacific Tsunami Regimes:

A. Southern and Central California. Local offshore fault systems; distant Subduction Zones

B. Cascadia (Northern California to Northern Washington and Straits of Juan de Fuca). Local Cascadia Subduction Zone; distant subduction zones

C. Puget Sound. Local Seattle, Tacoma, and other fault systems

D. Alaska. Local Alaska-Aleutian Subduction Zone

E. Hawaii. Distant subduction zones

Slide sources in all regions can also generate tsunamis that produce destructive zones, but on a smaller geographical scale, with variations in the type and potential threat. Upon review and discussion by workshop participants of the Tsunami Focused Study plan, the following recommendation was made:

"The recommended approach is to perform a comprehensive probabilistic tsunami hazard assessment at a pilot site in California or Oregon or Washington [that includes]: (1) recurrence interval estimate[s] of forcing functions and (2) propagation of tsunamis from Pacific Seismic subduction zones, (3) inundation calculations, [and] (4) probability distributions and integration."

Subsequently, after a site selection study, this interagency project-the Seaside Tsunami Pilot Study —was funded by the FEMA Map Modernization Program. The purpose of the study was to develop methods and preliminary guidelines for future tsunami components of FEMA FIRMs. These specific guidelines would apply to coastal communities along the coast of the Cascadia Tsunami Regime, extending from Cape Mendocino to the Strait of Juan de Fuca. Existing FEMA Flood Insurance Studies and the resulting FIRM maps for this region do not include tsunamis as a flooding hazard. During the 1970s, a Type 16 Flood Insurance Study was carried out for this region by Houston and Garcia (1978). Their study was based on the assumption that only farfield tsunamis impacted this region. Furthermore, their computations did not include actual inundation of the land. Since that study, compelling evidence from earthquake and paleotsunami research has shown that great earthquakes occur in the Cascadia Subduction Zone and that these earthquakes generate 
major tsunamis. These local Cascadia events, although infrequent, are not rare. Furthermore, they would cause such widespread and severe devastation that they need to be considered in developing new FIRM maps for this coastal region.

The site for the Pilot Study includes the communities of Seaside and Gearhart, Oregon, and the adjacent unincorporated areas. The site was chosen because it is typical of coastal communities in the region with development on sand spits and other low-lying areas near the ocean and with coastal rivers flowing through the communities. The study area was also recommended by Oregon Emergency Managers, who need the results of the Study for tsunami evacuation planning and public education. Furthermore, stakeholders in the Seaside/Gearhart area are very interested in tsunamis, due in part to the flooding and damage caused by the 1964 Alaska tsunami and other recent tsunamis that struck these communities. There is also increased awareness that major Cascadia Subduction Zone tsunamis have struck this area in the past.

This pilot study directly addresses Task Item 16, "Probabilistic Hazard Assessment for the open and non-open coastlines of the Pacific States," and Task Item 20, "Tsunami structure debris interaction to define hazard zones," identified in a series of workshops in 2004 that were held to plan the development of new tsunami hazard mapping guidelines for FEMA's National Flood Insurance Program. A methodology was recommended for a comprehensive probabilistic tsunami hazard assessment for the Cascadia Region, considering both far-field events and near-field events triggered by seismic sources. For both types of events, the tsunamis are generated by coseimic seafloor displacement and submarine landslides. Far-field events are defined as those generated a long distance away by sea floor displacement during earthquakes, such as the 1964 Alaska and 1960 Chile earthquakes; near-field events are those generated by sea floor displacement from Cascadia Subduction Zone earthquakes. An example of the latter is the 1992 Cape Mendocino tsunami that was incident on the northern California coast (González et al., 1995).

FEMA's policy has been to incorporate tsunami-induced hazards and other storm-related coastal hazards into one coastal high-hazard zone, which is defined in the Code of Federal Regulations, Title 44, Part 59.1 as:

Coastal high hazard area means an area of special flood hazard extending from offshore to the inland limit of a primary frontal dune along an open coast and any other area subject to high velocity wave action from storms or seismic sources.

During the course of the present study, it became imperative to address not only the statistical aspects of tsunami generation but also the associated geological, numerical modeling, regulatory, and institutional aspects as well as the available resources in NOAA, USGS, and academic institutions participating in this study. 



\section{Previous Methods Used for FIRM Tsunami Maps}

$\mathrm{F}$

OR The FEMA PILOT Study, it is helpful to understand the procedures used by Houston and Garcia (1978) to develop the previous set of FIRM tsunami maps for the U.S. West Coast. Like the goals of the new Pilot Study, their procedures produced 100- and 500-year tsunami runup elevations using numerical models and probabilistic approaches to both the distribution of tsunami sources, in terms of their intensity and location, and the effects of tides and other background water levels on the elevations. The purpose of this section is to summarize the assumptions and methodology used by Houston and Garcia (1978) in order to provide background for the Pilot Study and to provide a perspective when comparing their results with those generated by the Pilot Study. Only a few references are given in this section; an extensive bibliography can be found in the 1978 report.

When Houston and Garcia (1978) did their study for the Federal Insurance Administration in the Department of Housing and Urban Development, regional tsunami sources in the Cascadia Subduction Zone had not been identified as the most likely to dominate the 100- and 500-year tsunami runup elevations along the middle and northern portions of the West Coast. Local landslides in the Southern California Bight had also not been identified as important sources for that region. However, Houston and Garcia (1978) state that important local sources might eventually be found but that such sources are outside the scope of their study. The sources they use are limited to the Alaska-Aleutian and Peru-Chile Subduction Zones, justified by the historical record of damaging tsunamis along the West Coast.

\subsection{Tsunami Sources}

The tsunamis striking the West Coast are assumed by Houston and Garcia (1978) to be teletsunamis from the Alaska-Aleutian and Peru-Chile Subduction Zones. Using observed tsunamis in the source regions, the tsunami intensities $i=\log _{2}\left(2^{1 / 2} R_{\text {avg }}\right)$ are first computed from the average runup height $R_{\text {avg }}$ in meters using the Imamura-Iida intensity scale as modified by Soloviev (1970). (Runup is strictly defined as the wave height at maximum inundation. As used in this case, runup is a more general term that also describes wave height measurements within the inundation zone.) A least-square fit to the historical data along the Peru-Chile Subduction Zone then gives $n(i)=0.074 \mathrm{e}^{-0.63_{i}}$ as the probability of occurrence in a given year for a tsunami of intensity $i$. (The Houston and Garcia (1978) technical report lacks the minus sign 
in the exponential term, which is needed since the probability $n(i)$ should decrease with increasing tsunami intensity.) Since there is much less historical information on tsunamis occurring in the Alaska-Aleutian Subduction Zone, an assumed exponent coefficient -0.71 is used, i.e., $n(i)=0.113 \mathrm{e}^{-0.71_{i}}$, based on large $(i=$ or $>3.5)$ tsunamis in the Alaska-Aleutian Subduction Zone and observed coefficients of other tsunamigenic regions around the Pacific (Soloviev, 1970). The probabilities are assumed to be uniform along the respective subduction zones.

The Alaska-Aleutian Subduction Zone is divided into 12 segments and the Peru-Chile Subduction Zone into 3 segments. The fine segmentation along the Alaska-Aleutian Subduction Zone honors the observation that the heights of tsunamis along the West Coast are very sensitive to the location of earthquake in the Alaska-Aleutian Subduction Zone, whereas this is much less true for the Peru-Chile Subduction Zone. The coseismic uplift patterns due to the tsunamigenic earthquakes are assumed to be ellipses oriented parallel to the subduction zone trench and are centered on the respective segment.

The shapes and sizes of the uplift ellipses are "standardized" because there is often a disparity between the intensity, observed uplift extent, and the tsunami heights that occur at impact site. Houston and Garcia (1978) discuss this issue using the 1946 and 1957 Aleutian tsunamis, in which the modest 1946 earthquake had a relatively small uplift area but large tsunami, whereas the great 1957 earthquake had a very large extent but a much smaller teletsunami. Other issues and their implication for tsunami generation are also discussed.

For each segment, seven tsunami intensities in the range $i=2-5$ (in increments of 0.5) are used. Here, $i=2$ is considered a lower limit for dangerous tsunamis along the West Coast; and $i=5$ is a credible upper limit based on the history of Pacific tsunamis. The 15 earthquake segments (12 for the Alaska-Aleutian and 3 for the Peru-Chile Subduction Zones) then lead to a total of 105 tsunami sources used in the study by Houston and Garcia (1978), each with its own probability of occurrence.

\subsection{Trans-Pacific and Nearshore Numerical Models}

A linear finite difference model $\left(1 / 3^{\circ} \times 1 / 3^{\circ}\right)$ is used to propagate the tsunamis from each source across the Pacific to the vicinity (about the depth contour of $500 \mathrm{~m}$ ) of the West Coast. The details of the trans-Pacific model are given in Houston and Garcia (1974). A finer-scale nearshore finite difference model $\left(2^{\prime} \times 2^{\prime}\right)$, driven by tsunami time series at the open boundaries, is then used to estimate runup along a vertical-wall coast. The nearshore model is based on that of Leendertse (1967) and includes advective terms and quadratic drag.

The West Coast is divided into four overlapping segments, each with its own nearshore model applied to a rectangular domain. Variable bathymetry is used out to the $500 \mathrm{~m}$ depth contour, beyond which the depth is set to $500 \mathrm{~m}$. Each domain has a normal-to-shore width of approximately 1.5 wavelengths of a 30min tsunami. This width is chosen so that at least three waves of a major trans- 
Pacific tsunami have a chance to reach the coast before re-reflection can occur at the open seaward boundary.

While the southern domain extends across half of the Southern California Bight, only results for the region west of Santa Barbara are reported. However, 100- and 500-year tsunami maps for the Southern California Bight are given by Houston and Garcia (1974). Likewise, Garcia and Houston (1975) show analogous maps for Monterey and San Francisco Bays and Puget Sound.

Verification of the model time series is limited to a comparison at Crescent City and Avila Beach (Port San Luis), California. There is significant disagreement at Crescent City, but this station had only a partial tide gage record. The agreement at Avila Beach (largest tsunami amplitude reported from uninterrupted 1964 tide gage records along the West Coast) is good and is taken to be justification for the modeling procedures.

\subsection{Predicted Tides}

To include the effects of the tides on the maximum tsunami runup elevation, Houston and Garcia (1978) use as tidal input 15-min sampled time series of predicted tides for stations along the West Coast. Observed NOAA harmonic constants were used to compute the predicted tides where these were available. Presumably the predicted tides were either zoned (constant within a coastal section) or interpolated to give the coastal tides at the nearshore model grid points. The tidal time series are for the year 1964, during which nodal factors modifying tidal heights are at or near their average values during the 18.6-year nodal cycle. Clearly, these are also convenient series to use when discussing the 1964 Alaska tsunami.

\subsection{Computing the 100- and 500-Year Tsunami Runup Heights}

For each of the 105 tsunami time series at each coastal grid point of the nearshore model, a 24-hr tsunami series is prepared by adding a sinusoidal series (with an amplitude equal to $40 \%$ of the maximum height of the first model waves) to the $2 \mathrm{hr}$ of directly modeled series representing the first waves of the tsunami. The factor of 0.4 was determined from observed tsunamis along the West Coast that are observed to decay slowly in time. Adding a given tsunami time series sequentially to the predicted tide, stepping every $15 \mathrm{~min}$, and then computing the maximum height of the combined tsunami and tide, leads to a year-long series of maximum runup heights. The largest of these is selected to give the tsunami runup elevation for that coastal grid point and that tsunami source location and intensity. This is under the assumption that the linear sum of the tsunami and tidal time series adequately represents the actual water levels for that tsunami impacting the coast as the tides vary in time.

The 100- and 500-year tsunami runup heights are computed numerically by Houston and Garcia (1978) from the maximum runup heights and probabilities 
Table 2: 100- and 500-yr tsunami runup heights at Seaside, Oregon (latitude of $46^{\circ} 0.00^{\prime} \mathrm{N}$ ) relative to various tidal datums. The heights are computed from the Houston and Garcia (1978) results relative to mean sea level (MSL), using observed tidal datums interpolated in latitude between Hammond $\left(46^{\circ}\right.$ $\left.12.1^{\prime} \mathrm{N}, 123^{\circ} 56.7^{\prime} \mathrm{W}\right)$ and Garibaldi $\left(45^{\circ} 33.3^{\prime} \mathrm{N}, 123^{\circ} 45.7^{\prime} \mathrm{W}\right)$.

\begin{tabular}{lccc}
\hline & Datum (m)* & 100-Year Runup (m) & 500-Year Runup (m) \\
\hline MHHW & 2.5 & 2.1 & 4.7 \\
MHW & 2.3 & 2.3 & 4.9 \\
MTL & 1.4 & 3.2 & 5.9 \\
MSL & 1.3 & 3.2 & 5.9 \\
MLW & 0.4 & 4.2 & 6.9 \\
MLLW & 0.0 & 4.6 & 7.3 \\
\hline
\end{tabular}

*1983-2001 Tidal Epoch

associated with the corresponding source segment and tsunami intensity. For a given coastal grid location, the probabilities are summed over decreasing heights starting with the maximum one for that location. When the sum reaches $1 / 500$, this is the 500-year runup height for that coastal location. The summing of the individual probabilities downward in height then continues until the summed probability reaches $1 / 100$, yielding the 100-year runup height. Once this is done for all the coastal grid points along the West Coast, smooth curves are drawn through these to give the alongshore distributions of the 100- and 500-year runup heights that are shown in Plates 1-30 of Houston and Garcia (1978).

\subsection{Application to Seaside, Oregon}

Shown in Table 2 are the 100- and 500-year tsunami runup heights computed from Plate 26 of Houston and Garcia (1978) for Seaside, Oregon, which is the site location for the FEMA FIRM Pilot Study. The heights are for the open coast at lat. $46^{\circ} 00.0^{\prime} \mathrm{N}$, which passes through Seaside. The original heights are in feet relative to mean sea level (MSL). For the purposes of the Pilot Study and for other applications, Table 2 also contains heights relative to other tidal datums on the open coast.

Mean high water (MHW) was used as the background water level for all inundation modeling performed in the current study. A check on the consequences of fixing the background water level at MHW was made by performing a statistical analysis based on linearly superimposed tsunami wavetrains by predicted tides at Seaside. The tsunami wavetrains are assumed to decay exponentially in time with an e-folding decay coefficient of 2.0 days, consistent with observed Pacific teletsunamis (Van Dorn, 1984; Mofjeld et al., 2000). Assuming a linear superposition may be regarded as a first step toward a fuller analysis that includes the dynamical interaction between tsunamis and the tides. The details of the linear analysis are given by Mofjeld et al. (in press). It is consistent with the way the Seaside tides are included in the estimation of the 0.01- and 0.002-probability wave heights in this present study (see Appendix E). 
Table 3: Representative maximum tsunami wave heights when the background water level in the tsunami inundation model was set to mean high water (MHW) and when the equivalent mean height for the tsunami wavetrain was superimposed linearly on predicted Seaside tides (1992).

\begin{tabular}{clccccc}
\hline \multirow{2}{*}{ Annual Prob. } & Location & $\begin{array}{c}\text { Background: MHW } \\
(\mathbf{m})\end{array}$ & $\begin{array}{c}\text { Adjusting for Tides } \\
(\mathbf{m})\end{array}$ & $\begin{array}{c}\text { Difference } \\
(\mathbf{m})\end{array}$ & $\begin{array}{c}\text { Difference } \\
(\mathbf{\%})\end{array}$ \\
\hline \multirow{2}{*}{0.01} & Coastal & 4.0 & 3.6 & 0.4 & 10 \\
& Estuarine & 3.0 & 2.8 & 0.2 & 8 \\
& Coastal & 10.0 & 9.3 & 0.7 & 8 \\
& Estuarine & 7.0 & 6.5 & 0.5 & 7 \\
\hline
\end{tabular}

Briefly summarizing the results of the Mofjeld et al. (in press) analysis, the probability distribution functions (pdfs) of maximum wave height for small tsunamis $(<0.5 \mathrm{~m}$ amplitudes) are tightly concentrated around the sum of the tsunami amplitude and mean higher high water (MHHW). Hence, using MHW as the background water level in modeling these small-amplitude tsunamis introduces a slight downward bias relative to the mean height of the pdfs. At Seaside, this bias amounts to MHHW-MHW $=0.23 \mathrm{~m}$. As the amplitude of the incident tsunami increases, the pdf changes both in mean maximum height and vertical spread. The total mean is the sum of the tsunami amplitude at each location and an effective height. The latter decreases from MHHW to mean sea level (MSL) with increasing amplitude. For very large tsunami amplitudes, the largest tsunami wave simply selects the stage of the tide at the time of the wave crest. Statistically, the pdf then represents the probability distribution of the tide itself.

For the 0.01- and 0.002-probability wave heights shown in Figs. 26 and 28, the effect of not allowing the tides to vary in the tsunami modeling gives an upward bias (Table 3) of $0.2-0.7 \mathrm{~m}(7-10 \%)$ based on the linear analysis. The bias will be less at other locations where the tsunami amplitude is less, so the values in Table 3 are estimates of the maximum bias.

There is a need for future research on non-linear tide/tsunami interactions and their effects on wave heights, inundation, and current strength. Research is also needed on issues of tsunami-caused erosion during the first waves that might alter the access of tsunamis and tides to estuaries and coastal rivers. 



\title{
3. Development of GIS Database
}

\begin{abstract}
N extensive amount of relational spatial data was collected and develA oped for the study. A geographic information system (GIS) was built to 1 organize these data for analysis (Wong et al., 2006). The GIS database consists of data descriptions, preview images, virtual globe (Google Earth@) views, metadata, and downloadable files (Table 4). Except for data sets strongly tied to the study, such as historic inundation lines and existing FEMA Flood Insurance Rate maps, the GIS serves only data developed in the course of building the tsunami model.
\end{abstract}

The majority of the data were built using ESRI ArcGIS@ software products. All were georeferenced to the following parameters:

Coordinate system: Geographic decimal degrees or Universal Transverse Mercator Zone 10 where indicated

Vertical units: $\quad$ Meters

Horizontal datum: North American Datum of 1983

Vertical datum: $\quad$ Mean High Water

Table 4: Summary of GIS database layers.

\begin{tabular}{|c|c|}
\hline Category & Dataset \\
\hline Digital elevation model development & $\begin{array}{l}\text { Coastal tide stations } \\
\text { Modeling grid limits } \\
\text { Historic shorelines } \\
\text { Vertical control data } \\
\text { Seaside digital elevation model }\end{array}$ \\
\hline Historical tsunami events & $\begin{array}{l}\text { Alaska } 1964 \text { event deposits, observations, and } \\
\text { inundation } \\
\text { Cascadia } 1700 \text { event deposits and inundation } \\
\text { Photographs of field sites }\end{array}$ \\
\hline Tsunami propagation and inundation modeling & $\begin{array}{l}\text { Far- and near-field earthquake sources } \\
\text { Maximum tsunami velocity zones based on far- } \\
\text { and near-field sources } \\
\text { Coseismic vertical displacement fields for } \\
\text { near-field sources } \\
\text { Maximum wave heights based on far- and } \\
\text { near-field sources }\end{array}$ \\
\hline Probabilistic tsunami hazard assessment model & $\begin{array}{l}\text { Probability surfaces for maximum wave heights } \\
\text { of } 0.5 \text { to } 10.5 \mathrm{~m} \\
\text { Maximum tsunami wave heights for } 100 \text { - and } \\
500 \text {-year floods }\end{array}$ \\
\hline
\end{tabular}


The horizontal datum was based on the latest accepted geodetic references. Mean High Water (MHW) was used as the constant background water level for the tsunami inundation modeling, and this is the reference datum for the tsunami heights in this report. Current FEMA FIRM maps are based on the horizontal and vertical datums of the North American Datum of 1927 and the National Geodetic Vertical Datum of 1929, respectively. Mofjeld et al. (2004) provide more information on the determination of vertical datum values for Seaside (Appendix A).

\subsection{Digital Elevation Model}

An accurate digital elevation model (DEM) is critical to accurate model results. The DEM for inundation modeling should consist of the best available elevation data at a resolution of $50 \mathrm{~m}$ or less (González et al., 2005). Elevation data available from Federal, State, and local agencies often consist of disparate horizontal and vertical datums that must be rectified through accepted conversion methods (see Appendix A).

Three nested DEMs were created for the MOST model to simulate tsunami generation at the offshore source, wave propagation nearshore, and inundation in the region of interest (Fig. 1, Table 5). The source and propagation DEMs consist solely of bathymetric values with land set to a "no data" value. The inundation DEM consists of both bathymetric and topographic values.

These DEMs were developed using a standard four-step process:

1. Data collection

2. Data assessment

3. DEM development

4. Quality assessment

The best available bathymetric, topographic, orthophotographic, and control data were obtained from various government agencies and converted to modeler parameters. Datasets were analyzed for accuracy and consistency. The best available data were used to build the DEMs.

The inundation DEM was compared to fifteen vertical control points to yield a RMS error of $0.135 \mathrm{~m}$. Detailed procedures, methodologies, and quality assurance analyses are available in Venturato (2005) (Appendix B).

Significant shoreline differences were discovered when comparing the inundation DEM with historical shorelines. Coastlines extracted from regional

Table 5: DEM summary.

\begin{tabular}{lcc}
\hline \multicolumn{1}{c}{ Region } & Resolution & SW/NE Corner Extents \\
\hline $\begin{array}{c}\text { Pacific Northwest } \\
\text { (bathymetry only) }\end{array}$ & 36 arc-seconds $(\sim 1 \mathrm{~km})$ & SW: $-132.00,43.00 ;$ NE: $-122.00,53.00$ \\
$\begin{array}{c}\text { Washington-Oregon Border } \\
\text { (bathymetry only) }\end{array}$ & 6 arc-seconds $(\sim 180 \mathrm{~m})$ & SW: $-124.5,45.36 ;$ NE: $-123.5,47.36$ \\
Seaside & $1 / 3$ arc-seconds $(\sim 10 \mathrm{~m})$ & SW: $-124.04,45.90 ;$ NE: $-123.89,46.08$ \\
\hline
\end{tabular}




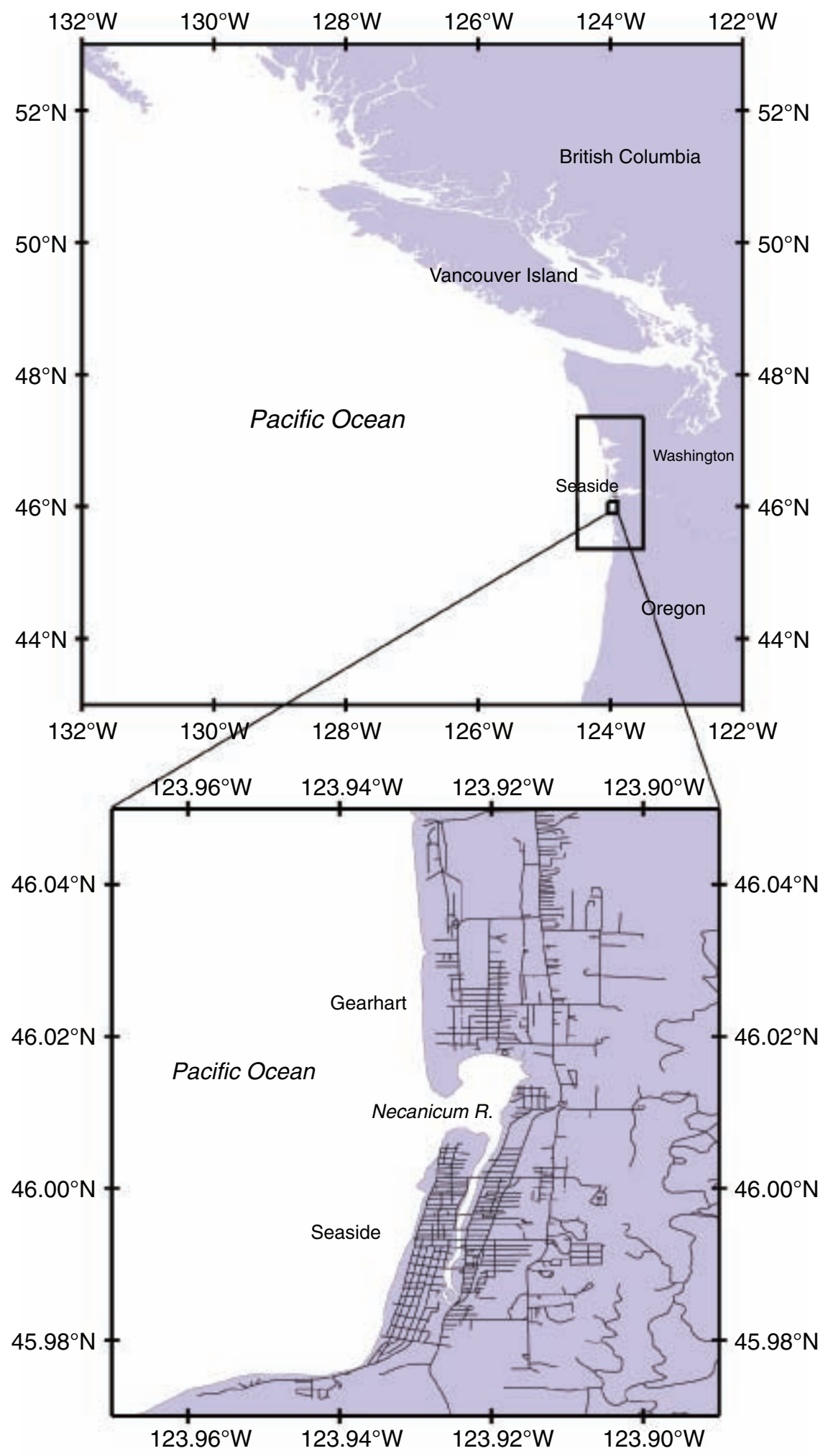

Figure 1: Study area of the FEMA FIRM pilot project for Seaside, Oregon. Top panel displays nested grids used by the model. Bottom panel details the study region. 

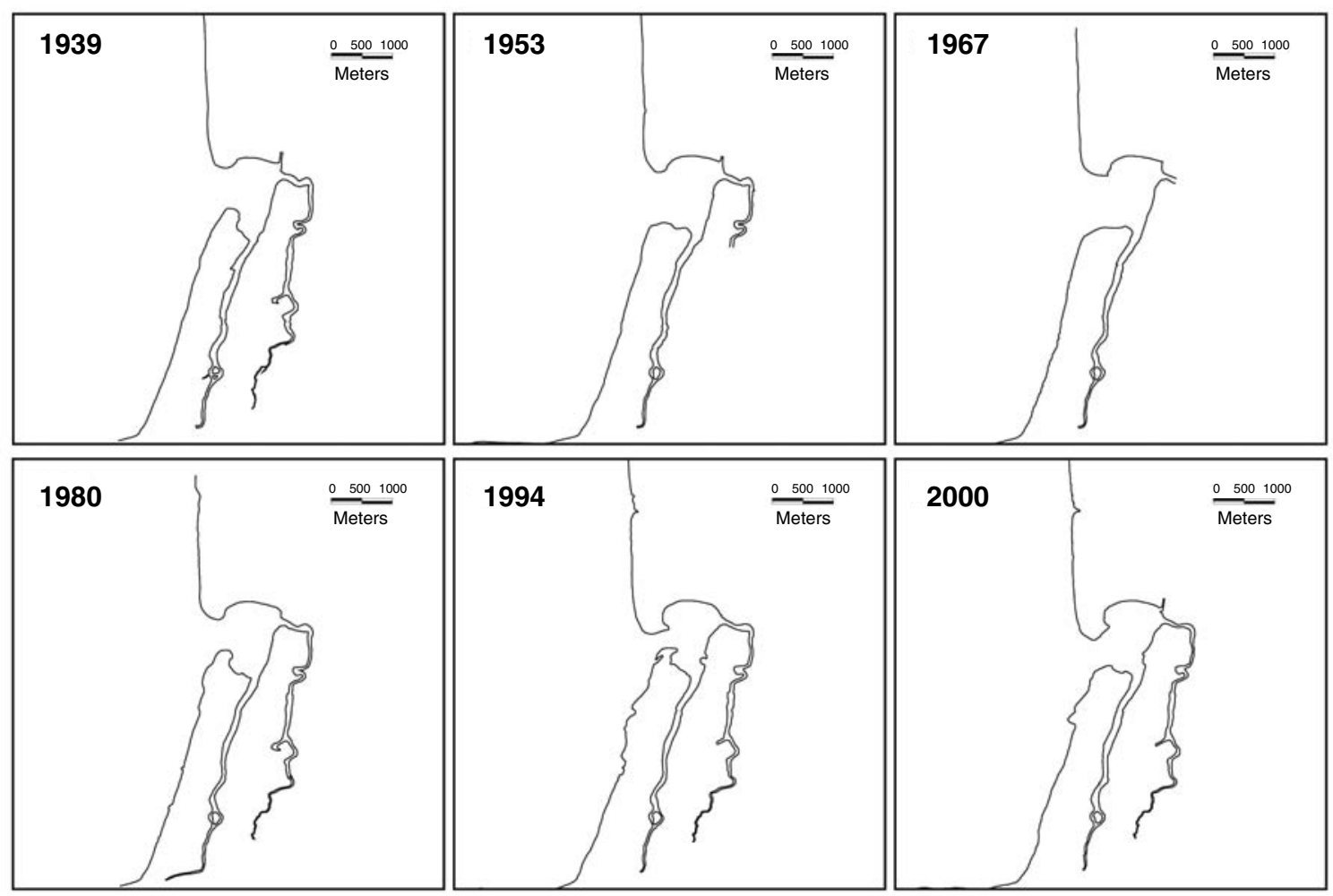

Figure 2: Historical shoreline depicting the apparent Mean High Water line based on orthophotography from various Federal and State agencies.

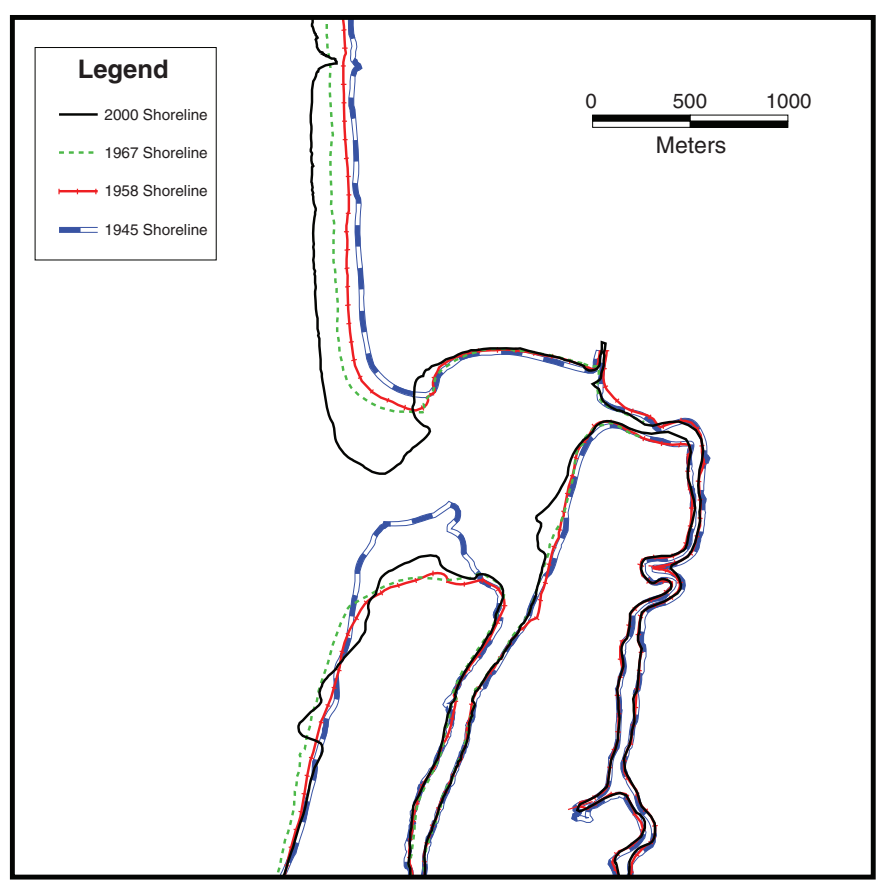

Figure 3: Accretion and erosion trends of the Necanicum River mouth $(3.2 \mathrm{~m} / \mathrm{y})$. 
historical aerial photography obtained from the University of Oregon show a general trend of accretion averaging $3.2 \mathrm{~m} / \mathrm{yr}$ on the outer coast north of the Necanicum River mouth (Fig. 2) (Appendix B).

A cyclic pattern of erosion and accretion within the Necanicum River mouth along its northern and southern Mean High Water extents is apparent (Fig. 3). The northern extent generally shows an accretion rate of approximately $7 \mathrm{~m} / \mathrm{yr}$ since 1939. The southern extent varies between accretion and erosion over an estimated 15-year cycle. The river mouth cycled from a minimum width of $300 \mathrm{~m}$ to a maximum width of $800 \mathrm{~m}$ over the 65-year period (Appendix B).

The final DEMs were distributed in an ASCII raster format to the modeler. The modeler converted the DEMs to a format compatible with the model, clipped the DEM to cover the inundation area, and applied an algorithm to smooth the bathymetry using a predetermined steepness threshold (refer to the Section 6, "Propagation and Inundation Modeling").

\subsection{Historical Tsunami Event Data}

Tsunami deposits, observations, and inundation lines were collected to compare with model results. Deposits collected in the field (see Tsunami Deposits section) were converted to GIS files for comparison with model results. Estimated inundation lines were subsequently created for the 1964 Gulf of Alaska and the 1700 Cascadia Subduction Zone events. Summaries of observations and historic shoreline are discussed below.

\subsubsection{Observations}

Over 70 observations at Seaside of the 1964 Gulf of Alaska event were added to the GIS database for comparison (Fiedorowicz, 1997) (see also Appendix C). These observations include estimated runup/wave height values and type (Fig. 4).

\subsubsection{Shoreline}

The apparent Mean Lower Low Water line was digitized (Fig. 5) from orthophotos nearest in time to significant historical tsunami events (1946 East Aleutian Islands, $\mathrm{AK}, 7.3 \mathrm{M}_{\mathrm{s}}$; 1960 Central Chile, $8.5 \mathrm{M}_{\mathrm{s}}$; and 1964 Gulf of Alaska, 8.5 $\mathrm{M}_{\mathrm{s}}$ ). The Necanicum River mouth migrates northward from 1946 to 1964 and then southward from 1964 to 2000. The dynamic nature of the shoreline in this region could vary tsunami inundation patterns over time.

\subsection{Model Output}

Model runs from the Model Database (see Section 6, "Propagation and Inundation Modeling") were converted to GIS-compatible formats and added to the GIS database. Model setup of the inundation grid introduced a rounding error 
(a)

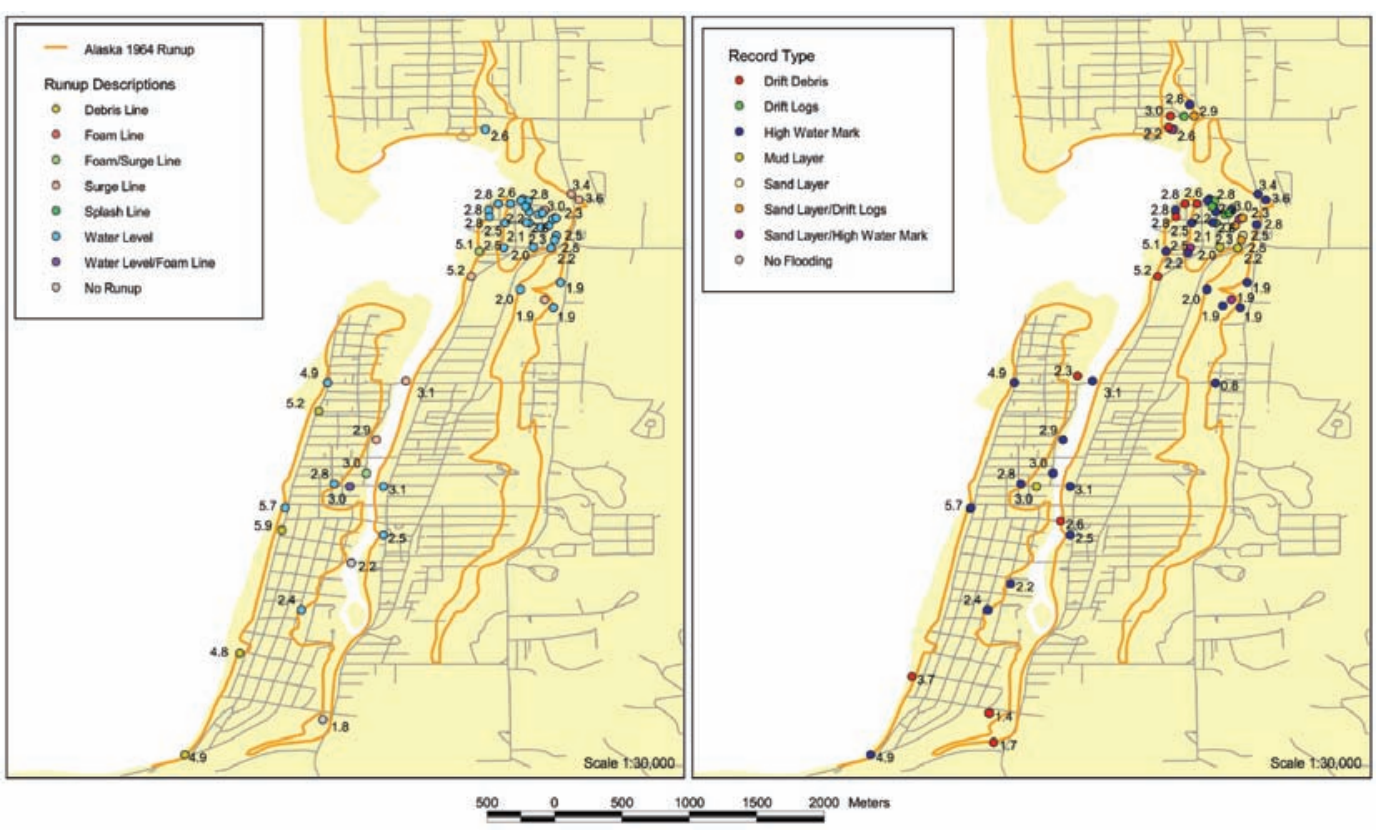

(c)

(b)

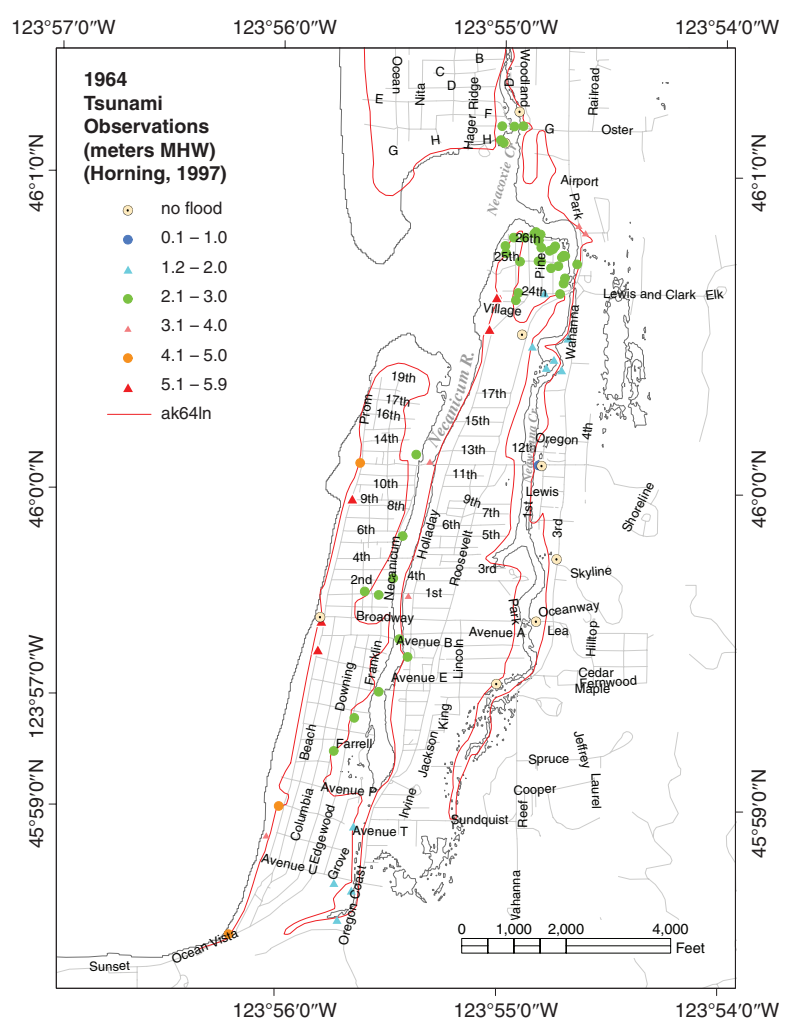

Figure 4: Observations of the Alaska 1964 tsunami event as described in Fiedorowicz (1997) and updated by Horning (see Appendix C). The runup line is based on observations (a) and tsunami deposits (b). The values associated with each observation represent runup elevation in meters based on a vertical datum of Mean High Water. Meaning of different eyewitness runup indicators listed in (a) described in Appendix C. Locations of possible tsunami sand and mud layers are provided in (b). (c) Major streets in Seaside and Gearhart shown with tsunami observation locations. 

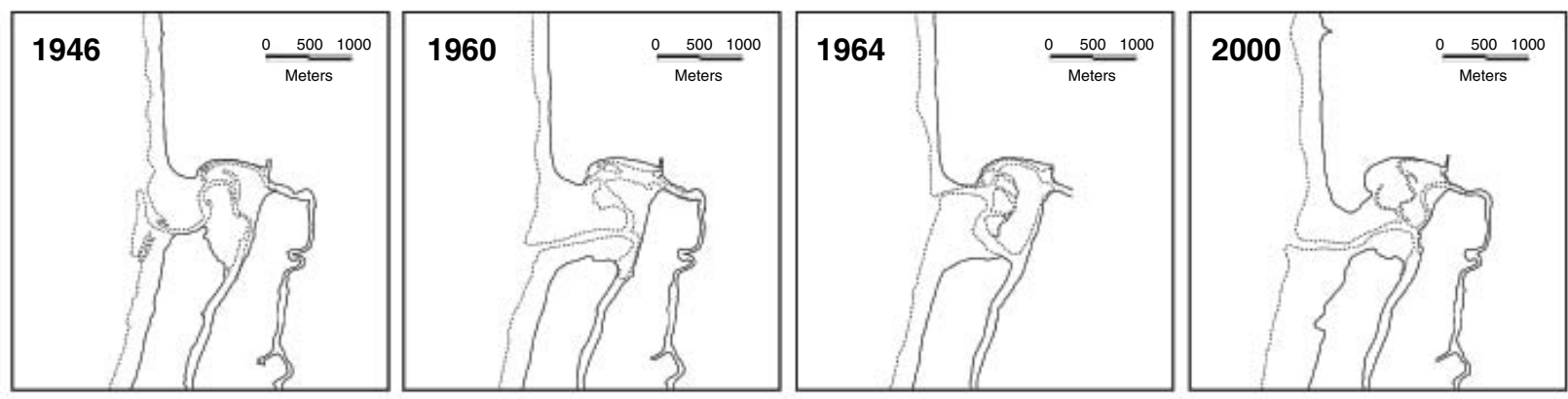

Figure 5: Estimated shoreline during historic tsunami events depicting Mean High Water (solid) and Mean Lower Low Water (dashed). Shoreline from the most recent orthophoto (2000) also displayed in rightmost panel.

(RMS error $0.000901 \mathrm{~m}$ ), which is reflected in the model runs. Additional error (total RMS error $0.001267 \mathrm{~m}$ ) was created during the conversion of the model runs to GIS. This error is considered insignificant in this study. Probabilistic tsunami wave height data were derived as described in the "Probabilistic Method" part of this report. 



\section{Tsunami Deposits}

SUNAMIS FLOODING SEASIDE have left behind distinctive sheets of sand
(hereafter referred to as tsunami deposits) that can be interpreted to
reconstruct the history of tsunamis. These tsunami deposits are similar in appearance to those found by other researchers studying tsunamis along the Cascadia margin (Peters et al., 2003). The spatial distribution of tsunami deposits in Seaside is hard evidence of tsunamis that establishes minimum inundation areas (Jaffe and Gelfenbaum, 2002). Tsunami deposit age, combined with this spatial distribution, can be used to estimate the relative magnitude of near- and far-field tsunamis and to determine the frequency and magnitude of tsunami inundation.

The value of incorporating a tsunami deposit component in probabilistic tsunami hazard assessments is underscored by the fact that the only record of tsunamis generated by earthquakes on the Cascadia Subduction Zone impacting Seaside are from tsunami deposits. Tsunami deposits verify the ability of the Cascadia Subduction Zone to generate large tsunamis that impacted Seaside in the past. Tsunami deposits define the lower limit of the inland extent of inundation. In this study, we have not interpolated between these point measurements, although in some locations it would be justified because they are close together. The spatial distribution and ages of tsunami deposits were used in this study for validation of the hydrodynamic model runs. The focus of tsunami deposit validation for modeling was on two events-the near-field 1700 Cascadia tsunami and the far-field 1964 Alaska tsunami.

Tsunami deposits also are tangible evidence of tsunamis in Seaside that the public is able to relate to. Locations of known tsunami deposits overlain on an inundation map, or, for this study, on a map showing the 100- and 500year tsunami flooding lines, validate study results for the public, emergency planners, and managers. Digging a hole and seeing a tsunami deposit makes believers out of even the most skeptical—a tsunami flooded this location.

This study benefited from extensive research on tsunami deposits in Seaside conducted by Curt Peterson and his students in the 1990s (Darienzo and Peterson, 1995; Darienzo et al., 1994; Fiedorowicz, 1997; Fiedorowicz and Peterson, 2002; Peterson, 1993). It is possible to generate a tsunami deposit record for use in a probabilistic tsunami hazard assessment without previous studies. When the geometry of the site is simple, there is less need for preexisting tsunami deposit data. In the case of Seaside, which has a complex geometry (two shore-parallel rivers bounded by high beach ridges), without preexisting data the tsunami deposit component of this study would require additional effort and would not have produced as complete a record of past tsunamis. 


\subsection{Methods}

The methods used in the tsunami deposit component of this study are standard for the geologic tsunami research community. These methods can be transported to other sites where FEMA requires a probabilistic tsunami hazard study. It is essential that scientists performing a tsunami deposit study have experience identifying tsunami deposits and knowledge of geologic environments where tsunami deposits are likely to be formed and preserved. Without such experience and knowledge, the quality of a tsunami deposit study is compromised and the results of such a study are of limited usefulness.

We used a combination of preexisting sedimentary data and new sedimentary data collected specifically for this study to map out the distribution of past tsunami inundation in the Seaside area. We examined and re-evaluated logs of cores, trenches, and cut banks from previous work done in Seaside during 1996 by Brooke Fiedorowicz and Curt Peterson (Fiedorowicz, 1997; Fiedorowicz and Peterson, 2002). The existing data set, collected at 236 sites in the 1990s, was supplemented by additional fieldwork to increase the data density, provide data where existing data was not available or clear, and to extend the boundaries of the survey farther inland and farther to the south of Seaside. Cores, trenches, and cutbacks were examined and logged from 76 locations in the Seaside area during the summer and fall of 2004 (Fig. 6). Overall, data from 312 locations were included in the survey (Fig. 7).

In addition to sedimentary data, we used a database that contains 66 observations by Seaside, Oregon residents of inundation, runup, and water levels from the 1964 tsunami in Seaside, recorded by Tom Horning, and included in the master's thesis of Brooke Fiedorowicz (1997). Other locations of possible tsunami sand layers and tsunami mud layers based on these eyewitness observations were also noted and categorized as locations where the 1964 tsunami was known to have inundated. We included an additional five observations of areas with no sedimentary deposits that are presumed to have not been inundated by the 1964 tsunami.

The ages of the deposits were determined using a combination of radiocarbon dating, stratigraphic context and, for 1964 tsunami deposits, historical documentation. Correlations between deposits were based on stratigraphic context and lateral continuity between deposits. Tsunami deposits stratigraphically below the 1700 event were deposited by earlier tsunamis.

\subsection{Results}

Deposits from five tsunamis in the past 2000 years were found at 167 sites located as far as $2 \mathrm{~km}$ inland along the $5-\mathrm{km}$ stretch of coast at Seaside. Deposits were found primarily in marshes fringing the Necanicum River and Neawanna Creek, which flow parallel to the coast between beach ridges that are 5 to $10 \mathrm{~m}$ high.

Tsunami deposits in the Seaside area usually occur as anomalous sand layers within mud or peat layers (Fig. 8). The following additional criteria were established for the Seaside area to determine whether a sand layer had 
(a)

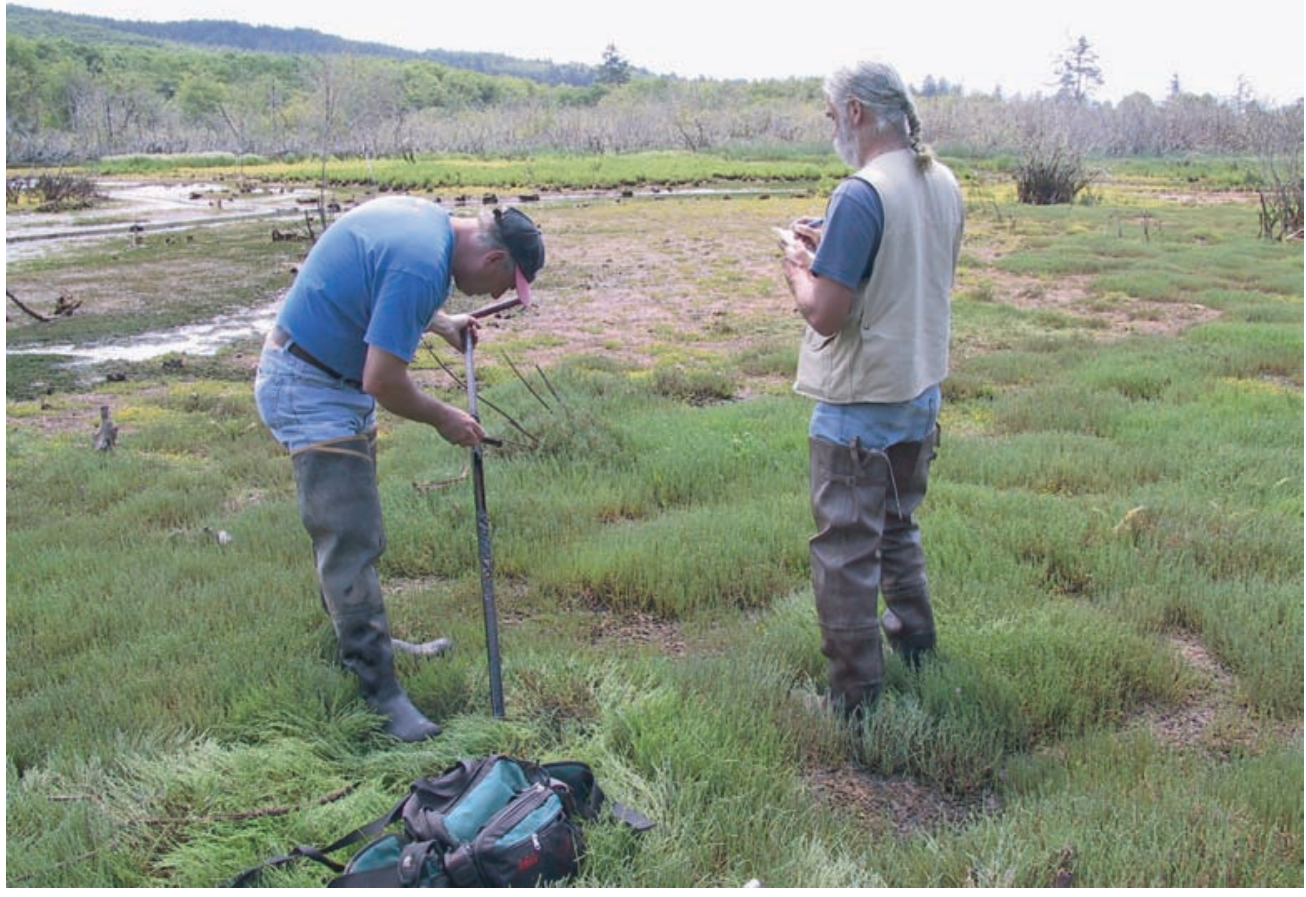

(b)

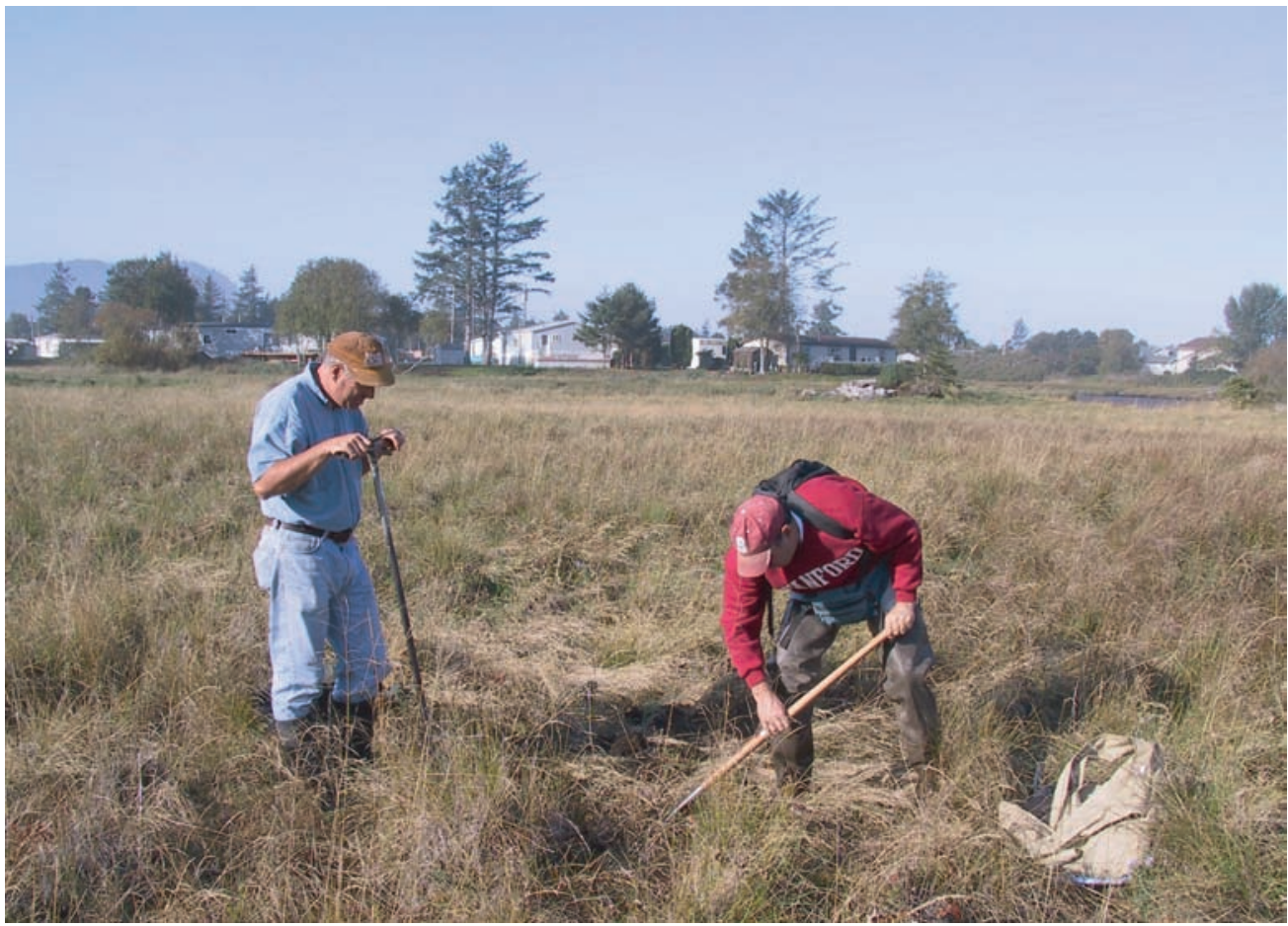

Figure 6: (a) Bob Peters and Curt Peterson coring at Stanley Lake; (b) Bruce Jaffe digs a trench while Curt Peterson cores along Neawanna Creek. 


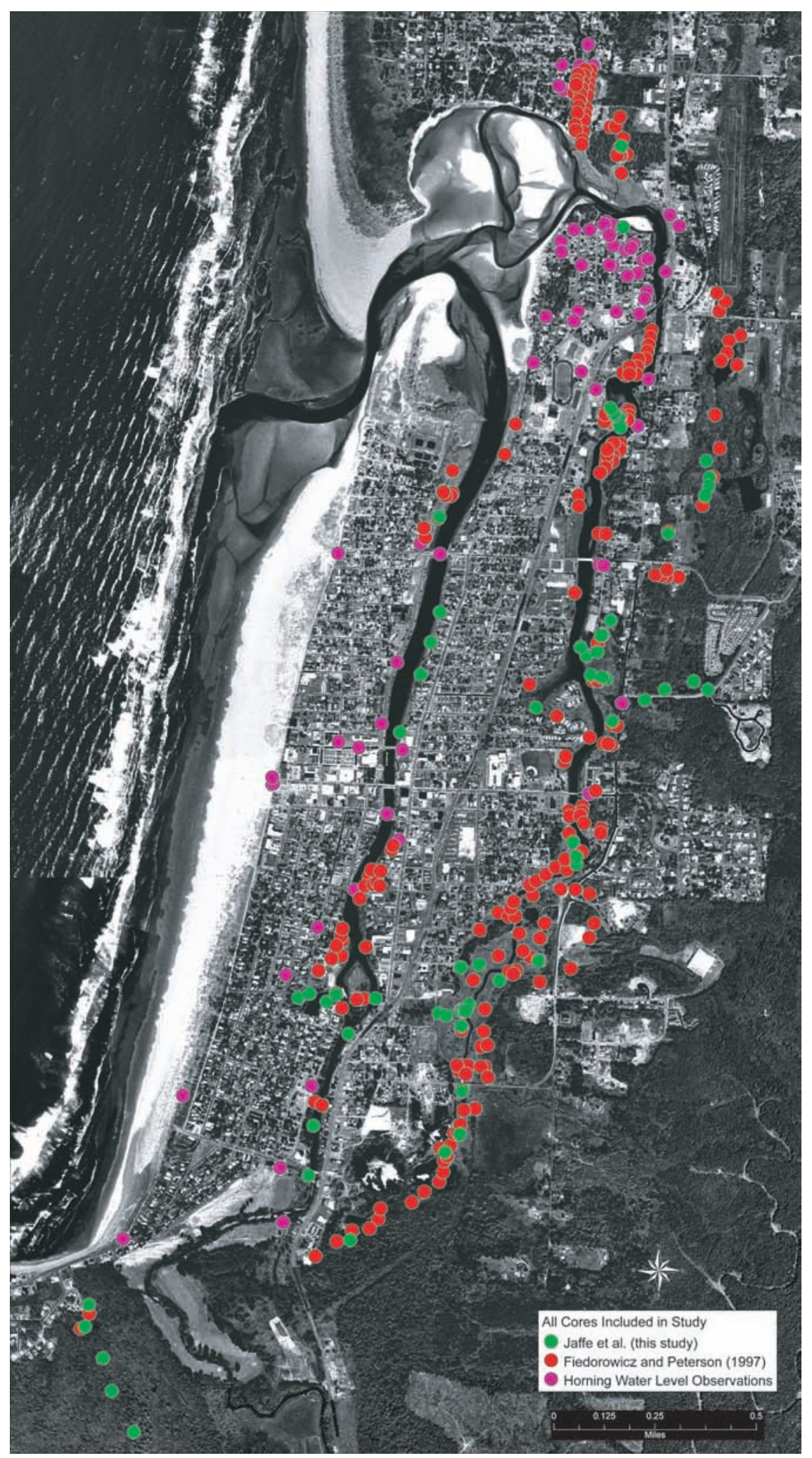

Figure 7: Locations of gouge core and trench sites visited by Tom Horning (1996), Fiedorowicz and Peterson (1997), and Jaffe et al. (2004). 
(a)

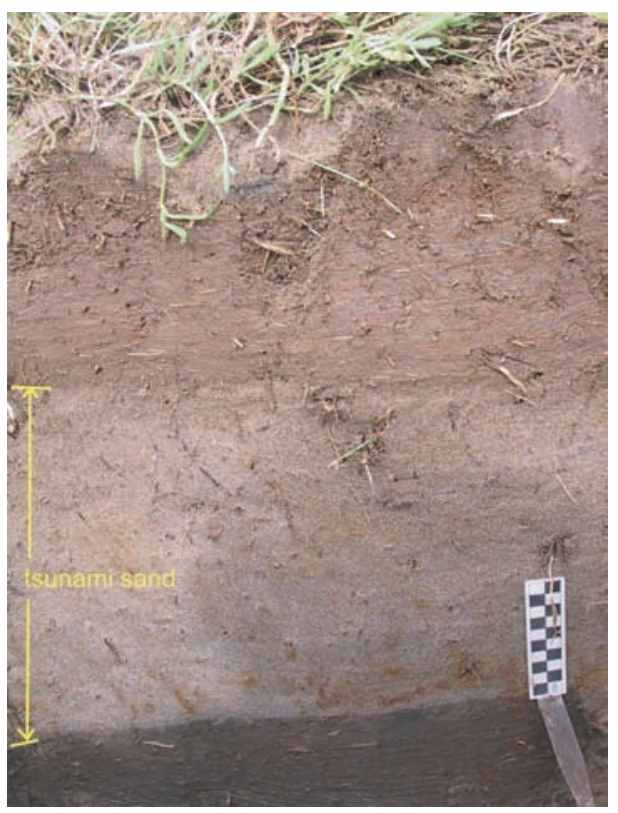

(b)

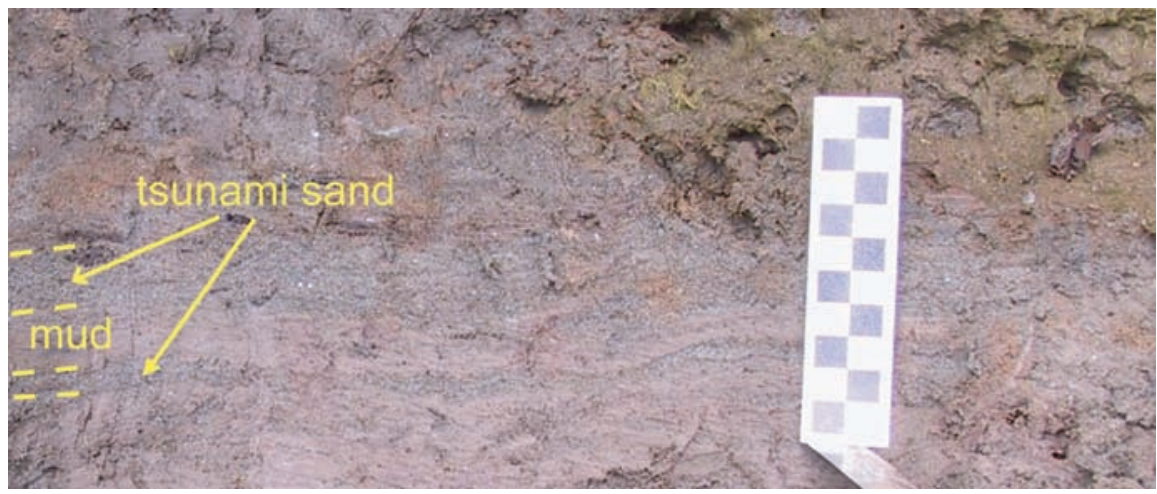

Figure 8: (a) Deposit from 1964 tsunami in Neawanna Creek trench; (b) Deposit from 1700 tsunami exposed in Neawanna Creek cutbank.

a tsunami origin: normal grading, presence of organic detritus, particularly as a detrital cap; a noticeable decrease in the amount of peat from the underlying material to the overlying material; lateral continuity; presence of rip-up clasts; presence of sand/mud couplets; and historical documentation. With the exception of historical documentation, no single criterion is wholly diagnostic. A combination of stratigraphic context and lateral context, combined with one or more of the identifying criteria, were used to assign a tsunami origin to a particular deposit. See Peters et al. (2003) for a discussion of tsunami identification criteria.

We focused on defining tsunami inundation from tsunami deposits for the 1964 far-field and 1700 near-field tsunamis to develop a dataset for validating hydrodynamic models. 


\subsubsection{4 tsunami deposits}

Tsunami deposits from the 1964 tsunami were identified at 116 sites (Fig. 9; Appendix D). Tsunami deposits from the 1964 Alaskan tsunami were typically found within a few tens of centimeters of the surface. In contrast, tsunami deposits from the 1700 Cascadia tsunami were typically covered by more than $0.5 \mathrm{~m}$ of sediment. The stratigraphic features of the 1964 tsunami deposits are very different than those of a storm deposit (Morton et al., in press), allowing discrimination between the two types of deposits. Inundation during the 1964 tsunami was primarily up channels. Tsunami deposits were limited to the banks of channels, primarily the Necanicum River, Neawanna Creek, and Neacoxie Creek. Along Neacoxie Creek, deposits were found as far upstream as the G Street Bridge in Gearhart (Fig. 4c). Residents observed tsunami inundation over the bridge and beyond it. There was a log jam at the bridge and the water backed up behind the bridge. In Seaside, deposits from the 1964 tsunami are found along Neawanna Creek as far south as 16th Avenue. Residents observed the tsunami as far south as the 12th Avenue Bridge. Tsunami deposits from 1964 on the Necanicum River are found as far south as Avenue Q. Eyewitness observations indicate that the 1964 tsunami inundation reached the golf course south of Avenue U (Fig. 4c).

Tsunami deposits were found primarily within the inundation line determined from eye-witness reports (Appendix C, Figs. 4 and 9). The distribution of 1964 tsunami deposits was a close approximation of the area of inundation along the Necanicum River determined from historical observations, but significantly underestimated the area of inundation along Neawanna Creek.

\subsubsection{0 tsunami deposits}

Deposits from the 1700 tsunami were present at 119 sites in the Seaside area (Fig. 10; Appendix D). The 1700 tsunami deposit is usually found approximately 0.5-1 $\mathrm{m}$ below the surface and in many places forms sand sheets that are laterally continuous for tens to hundreds of meters. The sites available for investigation were limited to those not developed or otherwise disturbed since 1700. Long stretches of the banks of the Necanicum River and Neawanna Creek have been covered with fill so that residential or commercial structures could be built or to create pasture land. Armoring of the banks also made many areas possibly inundated by the 1700 tsunami inaccessible for coring or trenching.

Deposits from the 1700 tsunami east of Neawanna Creek were found at Stanley Lake and along Shore Terrace Road as far east as the trailer park. Fiedorowicz (1997) reconstructed the geography present during the 1700 tsunami by interpreting geologic deposits. The tsunami probably entered Stanley Lake through the outlet at the north end of the lake. The deposits along Shore Terrace Road are best explained by the tsunami overtopping the dune ridge that separates Neawanna Creek from the lowlands to the east. Deposits from the 1700 tsunami were found along the banks of the Necanicum River as far south as Avenue $U$ and along the banks of Neawanna Creek in the reaches south of the millponds. In Gearhart, deposits from the 1700 tsunami were also found 


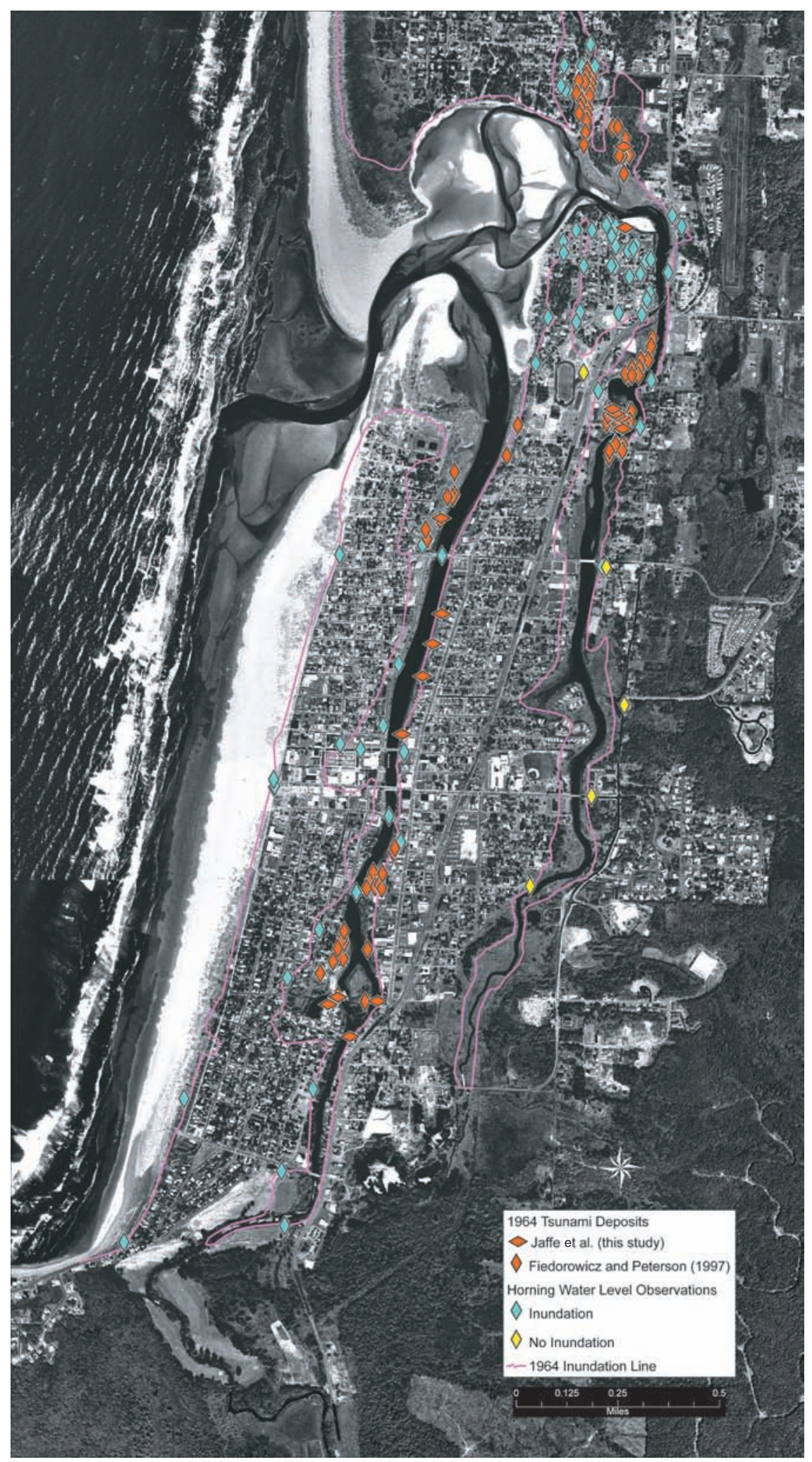

Figure 9: Sites containing 1964 tsunami deposits. 


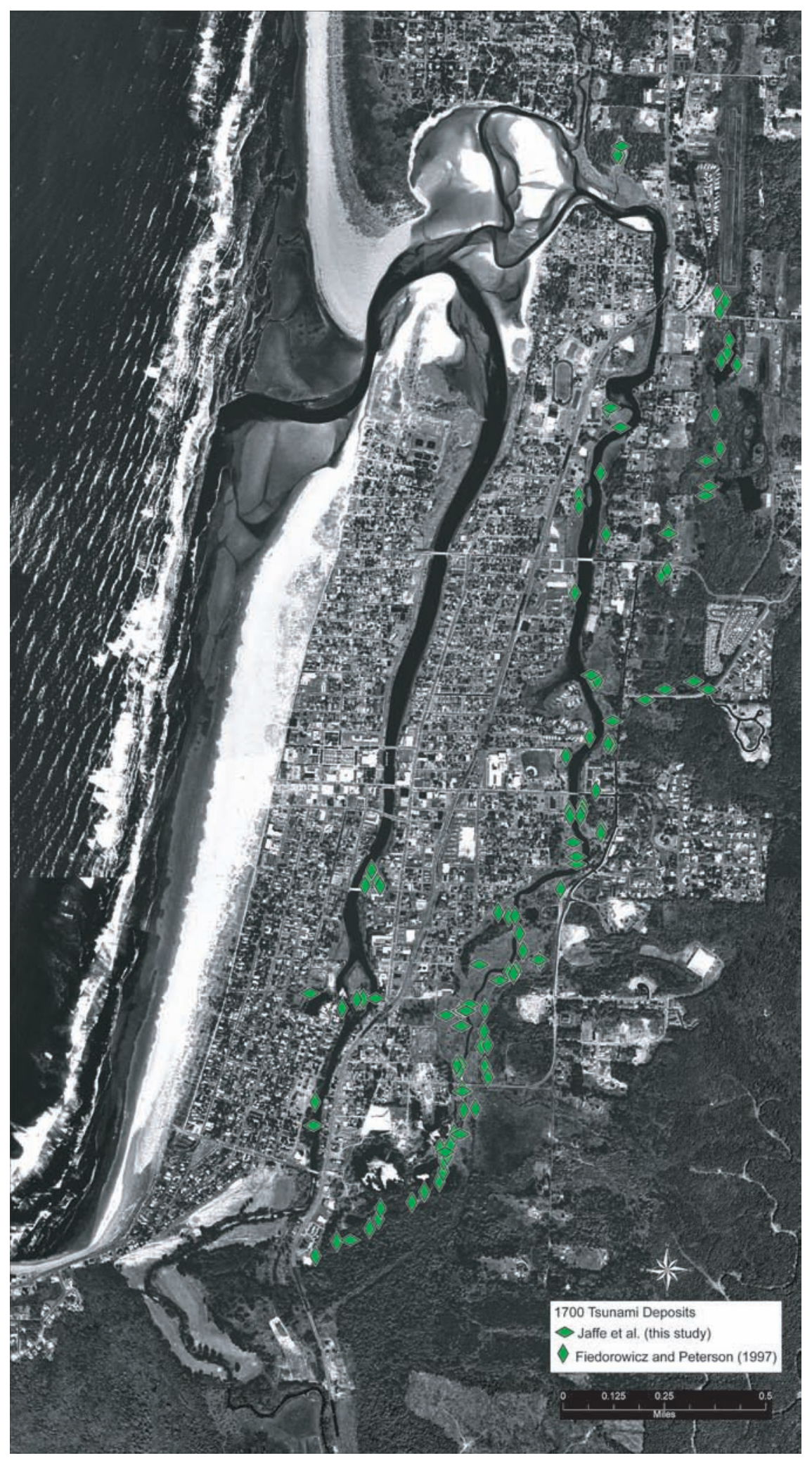

Figure 10: Sites containing 1700 tsunami deposits. 
along the banks of the small creek east of the present Neacoxie Creek, but no deposits from the 1700 tsunami were found along Neacoxie Creek. Geological evidence suggests that Neacoxie Creek is younger than 1700 (Fiedorowicz and Peterson, 2002).

The 1700 tsunami may have overtopped the narrow gravel ridge between the Necanicum River and Neawanna Creek north of Avenue P. It may also have overtopped the considerably wider gravel ridge complex at 4th Avenue.

\subsubsection{Older tsunami deposits}

Deposits from tsunamis older than the 1700 tsunami are also found in the Seaside area (Fig. 11). Deposits from tsunamis older than the 1700 event were found at 36 sites. Of particular interest are deposits dated at $1230 \pm 30$ years B.P. and 2770 years B.P. that are located south of the bend in the Necanicum River south of Seaside. These radiocarbon dates are based on spruce cones found within the deposits. This area may have been a paleo-outlet for the Necanicum River. Deposits from events older than the 1700 event are also found along the banks of the southern portions of Neawanna Creek. In the vicinity of Avenue P, north of the Avenue S Bridge, a deposit from a tsunami that occurred prior to 1700 can be seen at low tide along the cut banks of Neawanna Creek. This deposit lies stratigraphically below the 1700 deposit. Deposits from tsunamis older than 1700 are also found in cores from the Stanley Lake region.

\subsubsection{Paleo-tidal inlet}

The distribution of the 1700 tsunami deposits and morphological features prompted us to hypothesize that the inlet was located further south than its present location when the 1700 tsunami impacted Seaside. A preliminary investigation using Ground Penetrating Radar (GPR) found a sediment-filled valley between the Necanicum River and the Pacific Ocean that could have been formed by an inlet approximately 1 to $1.5 \mathrm{~km}$ south of its present location.

North-south GPR lines collected along Downing Street and the full length of Front St. (north-south parallel to Necanicum River) detected the banks and the bottom of the paleo-inlet. Curt Peterson and David Percy (Portland State University) ran additional north-south GPR lines to confirm location of the paleo-inlet and west-east lines to check for channel fill versus beach progradation strata. At the southern portion of the sediment fill, north-dipping reflectors indicate a northward migration of the paleo-inlet. Change from northward-dipping reflectors to flat or landward-dipping reflectors occur at approximately $50 \mathrm{~m}$ south of A Street, marking the southern extent of the paleo-inlet. Paleo-tidal inlet depth was a maximum of $5 \mathrm{~m}$ below mean sea level. The inlet fill is approximately $1.3 \mathrm{~km}$ wide; the size of the paleo-inlet was less because the fill is created by migration or narrowing of the inlet. For comparison, the widest portion of the present inlet is approximately $0.7 \mathrm{~km}$ wide. The north side of the paleo-tidal inlet begins just south of 15th Street in Seaside (on Franklin S-N extension of Downing Street about 3 blocks south of the waste water treatment plant). 


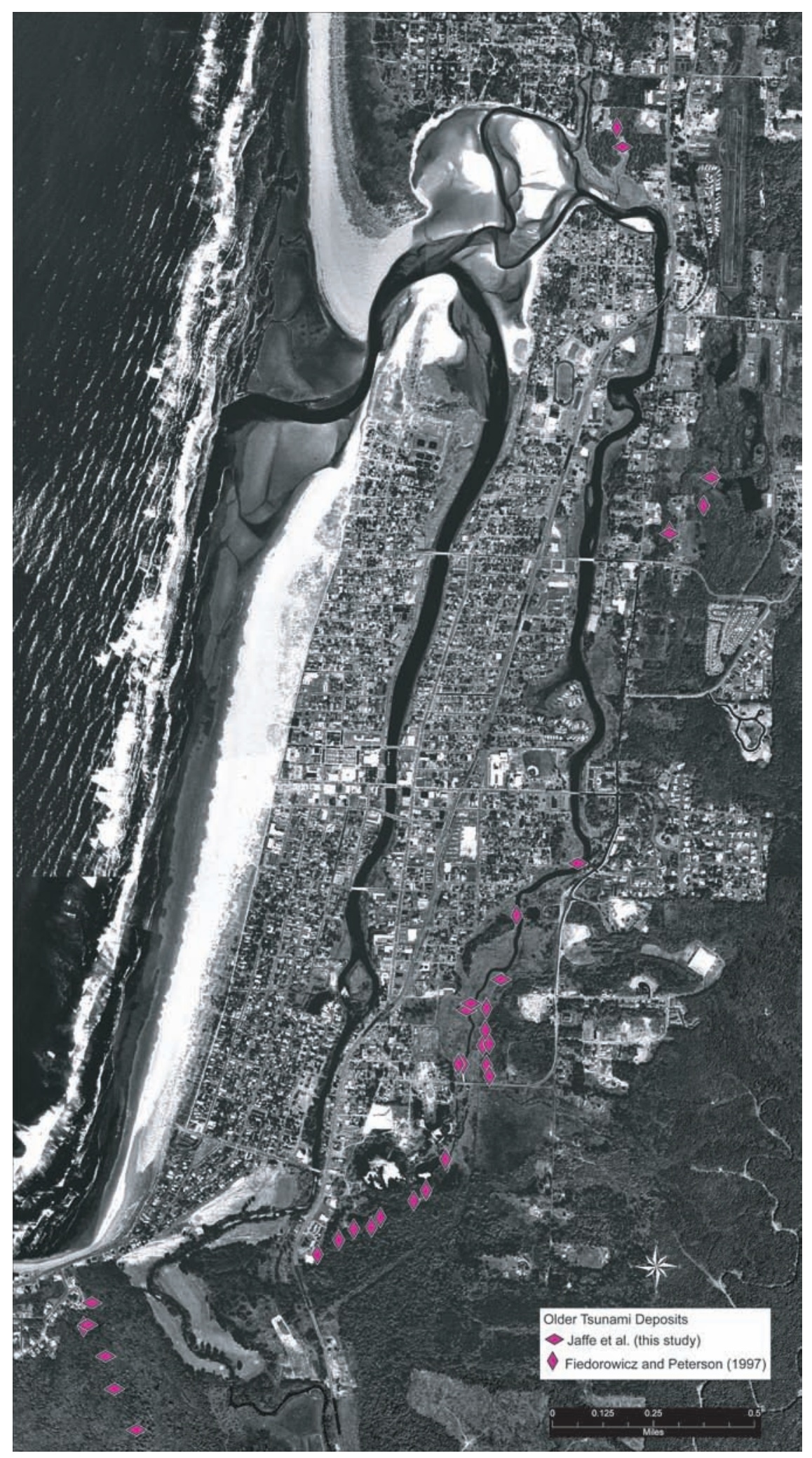

Figure 11: Locations of older tsunami deposits. 
Reflectors imaged by GPR constrain the history of the inlet. At 1st Street, a progradational beach facies (seaward dipping reflectors) starts $50 \mathrm{~m}$ east of the present landward extent of the beach (the boardwalk), indicating that the closing off of the inlet and building out of the beach there is relatively recent. Moderately-deep reflectors dipped south (toward the paleo-inlet channel) at the northern end of the inlet fill, confirming that the channel "jumped" to its present position (north of the waste-water treatment plant) rather than by a gradual migration north, which would have left north dipping reflectors. The jump may have occurred immediately after the catastrophic flooding by the 1700 AD tsunami event.

\subsection{Discussion of Tsunami Deposit Results}

The tsunami deposit record for Seaside establishes that near-field tsunamis generated by great Cascadia Subduction Zone earthquakes are significantly larger than the 1964 far-field Alaska tsunami. Deposits from the 1700 tsunami are found up to $2 \mathrm{~km}$ inland near the base of the hills on the east side of town (Fig. 10). The spatial distribution and characteristics of 1700 tsunami deposits indicates that the 1700 tsunami overtopped the ridge east of Neawanna Creek - the 1700 tsunami was large even this great distance inland. Geological and archeological evidence indicates that this and other high gravel ridges have been present in Seaside for many centuries (Fiedorowicz, 1997). In contrast to the extensive spatial distribution of 1700 tsunami deposits, deposits from the 1964 tsunami are confined to the margins of Neawanna Creek and the Necanicum River-indicating a smaller tsunami that was not able to overtop the high gravel ridges at Seaside. Geological and archeological evidence indicates that this and other high gravel ridges have been present in Seaside for many centuries (Fiedorowicz, 1997). In contrast to the extensive spatial distribution of 1700 tsunami deposits, deposits from the 1964 tsunami are confined to the margins of Neawanna Creek and the Necanicum Riverindicating a smaller tsunami that was not able to overtop the high gravel ridges at Seaside. The presence of tsunami deposits older than 1700 far inland is evidence that the 1700 tsunami is not an outlier in terms of size. The Seaside area has been inundated by large tsunamis many times in the past.

The inundation zones derived from the tsunami deposit data in this report are minimums because of limitations inherent in deriving inundation from tsunami deposits and limitations in the scope of this study. Where there is a suitable environment for deposition and preservation of tsunami deposits, data from modern tsunamis (Gelfenbaum and Jaffe, 2003; Jaffe et al., 2003) indicate that the inland extent of tsunami deposits and of flooding are usually within $50 \mathrm{~m}$ - using tsunami deposits as proxy for limit of inundation does not introduce significant error. However, inundation extent is underestimated if a deposit never formed because there was not a source of sediment. A larger source of error in mapping inundation using only tsunami deposits, especially for tsunamis that occurred hundreds or thousands of years ago, is erosion of tsunami deposits. Preservation potential must be carefully evaluated in a probabilistic analysis of inundation and used as a filter for evaluating tsunami 
deposit data. Although a large number of sites (312) have been examined in Seaside for tsunami deposits, it is probable that further investigations will increase the estimate of the area of inundation, especially for older tsunamis.

Changes in topography or bathymetry need to be accounted for in using tsunami deposits to estimate the magnitude of past tsunamis. For Seaside, inlet location is a primary control on tsunami inundation. Deposits from the 1964 tsunami extended farthest inland at the inlet, indicating that it served as a conduit for the tsunami. Preliminary investigations using Ground Penetrating Radar (GPR) found a sediment-filled valley that could have been formed by an inlet to the south of its present location. If this inlet was open when the 1700 tsunami impacted Seaside, tsunami deposits could be expected to extend farther directly inland of the inlet. Additional studies are needed to determine the time when it was open to the sea.

Shoreline stability must also be taken into account when using tsunami deposits in a probabilistic tsunami hazard study. Change in shoreline position was observed but not accounted for in the Pilot Study and does not introduce large errors into the analysis of the 1700 and 1964 tsunamis, but could for older tsunamis. Estimates of inundation from tsunami deposits at a site where there is an eroding (prograding) shoreline underestimates (overestimates) tsunami inundation. For tsunami deposits to be most useful for validation of hydrodynamic models, paleoshorelines, paleotopography, and paleobathymetry should be established.

Because of its geologic setting, complex topography, and inlet migration history, Seaside is not a good location to develop tsunami recurrence intervals. Sites with simple topography and a coastal geologic setting that favors deposition and preservation of tsunami deposits are best used for developing tsunami recurrence intervals. Tsunami recurrence intervals have been established for Cannon Beach (Peterson et al., 2004), which is $13 \mathrm{~km}$ south of Seaside. If a sitespecific tsunami recurrence interval based on deposits were required for this study, it could have been developed using a combination of the Cannon Beach and Seaside tsunami deposit records. Use of tsunami deposit records from nearby locations is acceptable for developing tsunami recurrence intervals in a probabilistic tsunami hazard study.

Even with the complexities encountered in the study of tsunami deposits at Seaside, we were able to develop a robust tsunami record using standard geologic tsunami research methods. This record established minimum inundation zones from past tsunamis and was the only data available for validation of near-field tsunamis generated during Cascadia Subduction Zone earthquakes. An additional benefit of a tsunami deposit component to this study is that tsunami deposits were useful as an educational tool for the general public, emergency planners, and managers. 


\section{Probabilistic Method}

\subsection{PTHA Overview}

\subsubsection{Previous PTHA studies}

$\mathrm{P}$

ROBABILISTIC TSUNAMI HAZARD ANALYSIS (PTHA) is derived from and closely allied to probabilistic seismic hazard analysis (PSHA); the latter, developed originally by Cornell (1968) and subsequently described in several reports (including Senior Seismic Hazard Analysis Committee (SSHAC), 1997). Lin and Tung (1982), Rikitake (1988), and Downes and Stirling (2001) modified PSHA to develop a PTHA that calculates wave heights using a simple source specification. In a related effort, a recent Puerto Rico Sea Grant report (Natural Disaster Research, 2001) used both traditional cumulative runupfrequency statistics and rank-order statistics (Sornette et al., 1996) derived from hydrodynamic modeling for calculating wave heights at Aguadilla, Puerto Rico. Included in this Sea Grant report were 1\% annual probabilities of exceedance (i.e., according to the FIRM specification) as well as a specification of the $10 \%$ probability of exceedance in 50 years.

Geist and Parsons (2005) recently expanded these efforts by comparing empirical analysis of tsunami probabilities with computational PTHA. For a site such as Seaside that lacks an extensive historic record of tsunamis, computational PTHA provides a valuable tool for assessing tsunami risk. For the Cascadia region, Geist and Parsons (2005) compare end-member models of earthquake magnitude distributions: characteristic and Gutenberg-Richter. The latter involves a Monte Carlo simulation where hypocentral location and slip distribution is randomized in the process of building a tsunami hazard curve (tsunami amplitude vs. probability). They also compare an empirical estimate of far-field probabilities with the computational PTHA estimates for local tsunamis. For this study, tsunamis from a characteristic $\mathrm{M} \sim 9$ Cascadia earthquake are part of the PTHA for the Seaside pilot study.

The PTHA methods described in these previous studies are expanded for the Seaside tsunami pilot study to develop, for the first time, a probabilistic tsunami inundation map. In this case, rather than calculating a hazard curve for a point on the coastline, a high-resolution grid is developed for the region around Seaside (see Section 3, "Development of GIS Database") and a hazard curve is computed for each grid cell. For each grid cell hazard curve, the exceedance wave heights for the $1 \%$ and $0.2 \%$ annual probabilities are interpolated and the results mapped using GIS software. 


\subsubsection{Application of PTHA to FIRM specifications}

The central point in developing the PTHA maps is determining the joint recurrence rate for different sources of tsunamis. This problem has been previously addressed in the development of FIRMs near the mouth of a river where there is combined riverine and coastal flooding as described in a Tetra Tech Inc. report (1981) to FEMA. If riverine flooding at a given elevation $(\eta)$ occurs at an average recurrence rate of $1 / m$ and coastal flooding at $\eta$ occurs at an average recurrence rate of $1 / n$, then the joint recurrence rate is simply $\frac{1}{q}=\frac{1}{m}+\frac{1}{n}$. We can think of this in terms of probabilities such that

$$
P_{\text {river }}(\eta, T)=1-\exp \left(-\frac{1}{m} T\right)
$$

and

$$
P_{\text {coastal }}(\eta, T)=1-\exp \left(-\frac{1}{n} T\right)
$$

where $P$ is the Poisson, time-independent probability of exceedance and $T$ is the exposure time.

The combined probability from both sources of flooding is given by

$$
P(\eta, T)=1-\left(1-P_{\text {river }}\right)\left(1-P_{\text {coastal }}\right)=1-\exp \left[-\left(\frac{1}{m}+\frac{1}{n}\right) T\right]
$$

Thus, the apparent recurrence rate for the combined source is $\frac{1}{m}+\frac{1}{n}$. A similar approach to determine the probability of ground shaking from multiple sources is described by Ward (1994).

We can adopt the same methodology (Tetra Tech Inc., 1981) to determine the joint recurrence rate for multiple tsunami sources. Suppose that in a given source region (with position vector $\mathbf{r}_{\mathbf{0}}$ ), we can determine the rate at which a tsunamigenic source with source parameter set $\left(\psi_{s}\right)$ occurs: $\dot{n}\left(\mathbf{r}_{\mathbf{0}}, \psi_{s}\right)$. Typically, in PTHA the objective is to determine the total rate $\dot{N}\left(\mathbf{r}, \eta_{\text {crit }}\right)$ at which wave height exceeds a risk tolerance value $\left(\eta_{\text {crit }}\right)$ at a specific coastal site $(\mathbf{r})$. In general, this involves a double integral over the parameter space for a given source and over all source locations (for example, Anderson and Brune, 1999; Ward, 2001):

$$
\dot{N}\left(\mathbf{r}, \eta_{\text {crit }}\right)=\int_{A} \int_{\psi_{s}^{\text {crit }}\left(\mathbf{r}, \mathbf{r}_{\mathbf{0}}\right)} \dot{n}\left(\mathbf{r}_{\mathbf{0}}, \psi_{s}\right) d \psi_{s} d A\left(\mathbf{r}_{\mathbf{0}}\right)
$$

For our probabilistic inundation map at Seaside, the source locations will include far-field tsunamis from major subduction zone segments around the Pacific and local sources near Seaside. Focusing first on the far-field sources, for a given subduction zone there will be a range of source locations (for example, a $M=8.0$ earthquake could happen anywhere along the subduction zone), tsunamigenic magnitudes, and recurrence intervals. For a range of tsunamigenic earthquake magnitudes $\left(M_{\text {low }}<M<M_{\text {max }}\right)$, each magnitude will be associated with an average recurrence rate according to the GutenbergRichter relationship $\log (\dot{n}(\mathrm{M}))=a-b M$, where $a$ and $b$ are empirical constants. $M_{\text {low }}$ is the lower cutoff magnitude that would produce a significant tsunami at 
Seaside. $M_{\max }$ is the maximum earthquake magnitude that can occur along a particular subduction zone or subduction zone segment.

Ideally, we would like to produce many inundation maps for a range of earthquake magnitudes $M_{\text {low }}-M_{\max }$ for each subduction zone. We note, however, that if we just estimate the $M_{\max }$-recurrence pair for each subduction zone, this will provide adequate constraint for high recurrence rate-low wave height tsunamis (that is, $P>0.01$ ). Additional inundation runs for smaller magnitude earthquakes will not significantly constrain the $P=0.01$, $P=0.002$ exceedance wave heights. The possible exceptions are smaller earthquakes $M<M_{\max }$ in the Prince William Sound segment of the AleutianAlaska Subduction Zone that are optimally oriented in terms of wave focusing at Seaside. It is possible that these earthquakes can produce larger tsunamis than $M_{\max }$ earthquakes along other subduction zones. $M_{\max }$-recurrence pairs are specified for adjacent regions along all subduction zones considered. For each earthquake source specification, an inundation map is produced. The production of inundation maps for these far-field sources is facilitated by the fact that NOAA/PMEL has pre-computed the open-ocean tsunami wavefield for these sources as part of the FACTS database. Uncertainty in recurrence rates and $M_{\max }$ is discussed in the Section 8, "Results."

Once a set of far-field and local inundation maps are prepared, Fig. 12 illustrates how we can determine the $1 \%$ annual probability inundation line, using GIS software. To create a map, a hazard curve is calculated for each $(x, y)$ point. As shown below, the tsunami hazard curve plots cumulative frequency of exceedance (ordinate) as a function of exceedance wave height (abscissa). The exceedance wave height incorporates the combined tidal and tsunami wave heights as described in Appendix E. Aggregating the results from all of the inundation runs, at each $(x, y)$ point there would be discrete values plotted in wave height/recurrence rate space. This is shown graphically in Fig. 12, where a hazard curve is derived from all of the inundation runs at each $(x, y)$ point. A regression analysis is run to fit a straight or other parametric line to determine each of these hazard curves. The wave height corresponding to the $0.01 \mathrm{yr}^{-1}$ recurrence rate is determined from the hazard curve at each $(x, y)$ point and contoured over $x$ - $y$ space to produce a probabilistic exceedance wave-height map. A similar procedure is used to also produce the $0.002 \mathrm{yr}^{-1}$ exceedance wave-height map.

PTHA can also accommodate a comprehensive treatment of uncertainties in much the same way as PSHA (Senior Seismic Hazard Analysis Committee (SSHAC), 1997). For convenience, two types of uncertainty are often considered: aleatory and epistemic. In simple terms, aleatory uncertainty is often associated with the natural complexity of the physical process itself, whereas epistemic uncertainty is associated with incomplete knowledge about the physical process that can be lessened through the collection of additional data. Aleatory uncertainty is sometimes called external, objective, random, or stochastic uncertainty, whereas epistemic uncertainty is sometimes called internal, subjective, or functional uncertainty (National Research Council (NRC), 2000). A comprehensive treatment of uncertainty requires scientific guidance from a broad range of scientific experts. In the past, this has been performed through a Technical Integrator or Technical Integrator/Facilitator (Senior Seis- 


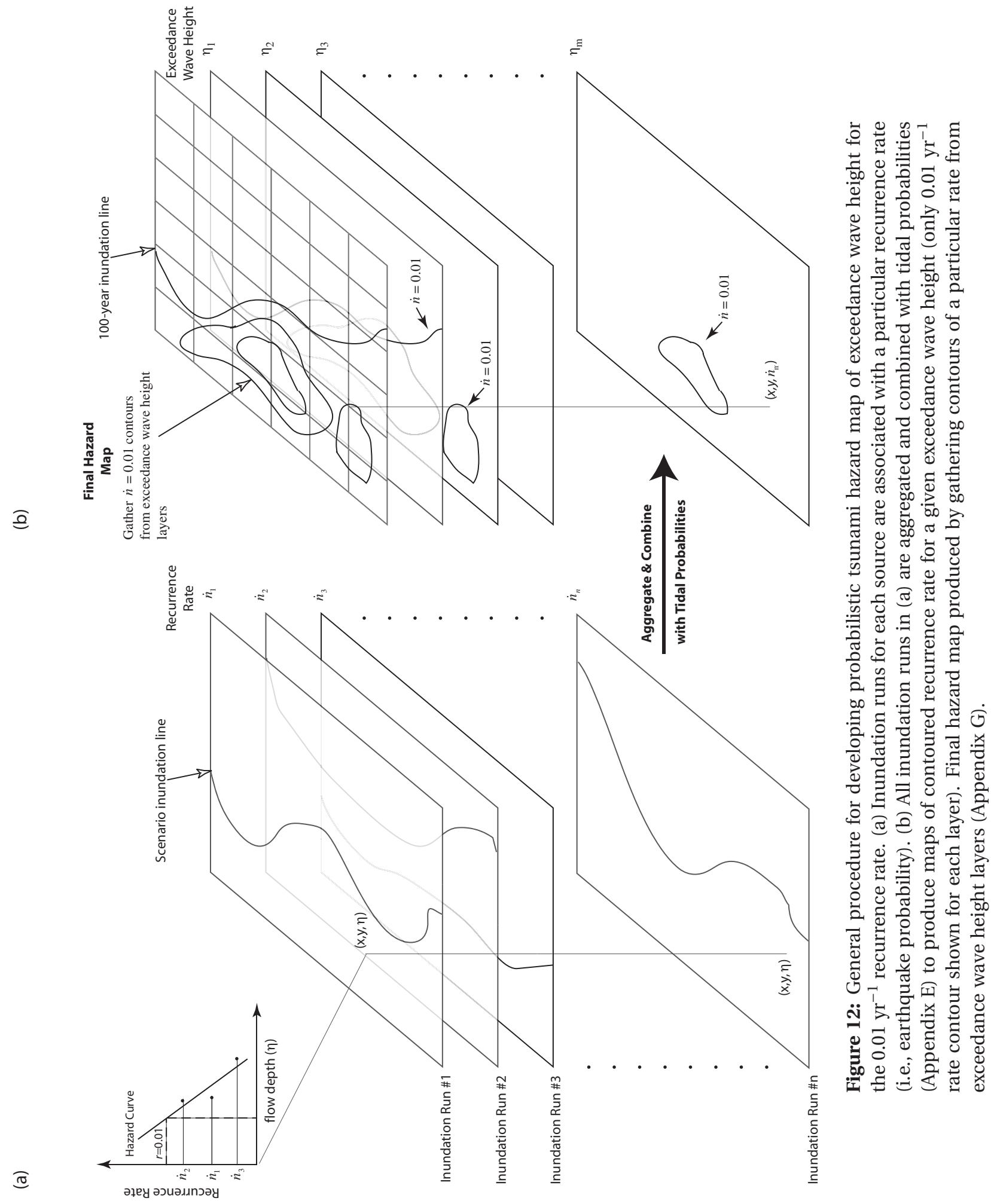


mic Hazard Analysis Committee (SSHAC), 1997) process that determines the "legitimate range of technically supportable interpretations" and "the relative importance or credibility that should be given to the differing hypotheses across that range."

For this preliminary study, however, we focus on including those uncertainties that are readily quantifiable. These are primarily aleatory uncertainty of tsunami arrival time relative to the tidal stage (Appendix E) and the slip distribution of the earthquake. The only epistemic uncertainty we consider is the two earthquake models for the Aleutian-Alaska Subduction Zone set forth by Wesson et al. (1999). We compare the probabilistic results using different rupture models and estimates of recurrence rates for a local Cascadia earthquake, but do not explicitly include this uncertainty in the probabilistic calculations. Other possible sources of epistemic uncertainty are indicated in Section 9, "Discussion," of this report, but not included in this study. To include these sources of uncertainty would require the assignment of relative weights in a logic-tree approach and hence, the consensus among a wide range of scientific experts. It is recommended that the level of uncertainty analysis be related to the specific objectives of the probabilistic study as described in Section 3 of the SSHAC (1997) report entitled "Structuring and Implementing a PSHA."

\subsection{Source Specification}

\subsubsection{Source magnitude and geometry}

\subsubsection{Typical interplate thrust earthquakes}

Earthquake source parameters used in this study include primarily the largest earthquakes (that is, $M=M_{\max }$ ) along major north Pacific Subduction Zones and the southern Chile Subduction Zone, site of the $1960 \mathrm{M}=9.5$ earthquake and trans-oceanic tsunami. The rationale for choosing the largest earthquakes is that, even though the recurrence rate for each event is low, when combined these earthquakes (along with local Cascadia earthquakes) should be sufficient to specify the tsunami at Seaside from any source with an average return time of 100 years and 500 years. Inclusion of smaller magnitude and more frequent earthquakes will likely not add significantly more information with which to constrain the 100-year exceedance wave heights. The exception is inclusion of smaller earthquakes in the Prince William Sound segment of the Aleutian-Alaska Subduction Zone, that can result in larger runup values than $M=M_{\max }$ earthquakes in other subduction zones. In using this set of source parameters, it will appear that we are adopting a characteristic earthquake distribution model (Appendix F). This may be the case, for example, in the 1964 Alaska source region. In most cases, however, we are choosing an earthquake magnitude that is at the extreme tail of a continuous distribution of earthquake magnitudes (that is, that of a modified Gutenberg-Richter distribution; see Appendix F). 
The primary source parameters that are provided are magnitude, width, length, and slip. Because we are relying on pre-computed solutions from NOAA/PMEL's FACTS database for the far-field sources, it is assumed that other source parameters such as depth, dip, strike, and slip direction have already been determined from the best available sources. Except for local events, it will be assumed that variations in slip distribution patterns from event to event will have minimal effect on far-field tsunami amplitudes (see Titov et al., 1999). Wherever possible, published references will be provided for estimates of these source parameters. It should be noted, however, that for the objectives of the probabilistic study, these source parameters will not be based strictly on historic events but on events that are thought to be representative of the $M=M_{\max }$ earthquake for each subduction zone. Average earthquake return times may be cited for different cases, though it is important to note that these are estimates subject to epistemic uncertainty. The Alaska-Aleutian, Kamchatka, Kuril, and southern Chile Subduction Zones are discussed in the sections below.

Table 6 below summarizes the earthquake source parameters and recurrence rates used in this study. Horizontal dimensions have been adjusted according to the pre-set parameters in the FACTS database constrained by the seismic moment relationship. Details of each source region are given in the next section.

\subsubsection{Far-field earthquakes}

\subsubsection{Alaska-Aleutian Subduction Zone}

Because the probabilistic tsunami hazard assessment for the Tsunami Pilot Study closely follows similar efforts used in the National Seismic Hazard Mapping Program, it is judicious to take advantage of previous work in determining likely source parameters. The seismic hazard maps for Alaska are described by Wesson et al. (1999). They consider two hazard models (I and II) for the AlaskaAleutian megathrust: Model I consists of a western and an eastern seismic zone in which earthquakes as large as $\mathrm{M}=9.2$ can occur. The delineation between the zones occurs approximately at the site of the 1946 Aleutian earthquake. Model II consists of a western Aleutian seismic zone (Zone A) as in Model I, but a smaller eastern Alaska seismic zone (Zone C) with a western boundary coincident with the rupture boundary for the 1964 earthquake.

Because the intervening zone (Zone B) that includes the Shumagin seismic gap (Nishenko, 1991) and the source area for the 1938 earthquake can only accommodate earthquakes up to magnitude 8.5, there is a saddle (low region) in the expected seismic hazard near Zone B. For the purposes of far-field tsunamis, Model I is probably more representative of the long-term zonation for large earthquakes. Near the source region for the 1964 earthquake, paleoseismic studies indicate that return times of great earthquakes is roughly 600-800 years (Combellick, 1992; Gilpin and Carver, 1992; Wesson et al., 1999). Average return times for $M=9.2$ earthquakes along the Aleutian part of the subduction zone are probably similar, but more work is needed to constrain these times. The tsunami models for the largest earthquakes would closely 
Table 6: Source specification for earthquakes used in this study.

\begin{tabular}{|c|c|c|c|c|c|c|c|}
\hline $\begin{array}{l}\text { Source } \\
\text { Number }\end{array}$ & Location & $\mathbf{M}$ & $\begin{array}{l}\text { Length } \\
(\mathbf{k m})\end{array}$ & $\begin{array}{c}\text { Width } \\
(\mathbf{k m})\end{array}$ & $\begin{array}{l}\text { Slip } \\
(\mathrm{m})\end{array}$ & $\begin{array}{l}\text { Mean Inter-event } \\
\text { Time (yr) }\end{array}$ & FACTS Specification \\
\hline 1 & Alaska-Aleutian & 9.2 & 1000 & 100 & 17.7 & 1,313 & $\begin{array}{l}\text { A0-A9 \& B0-B9 (Tsunami } \\
\text { model 1-western zone) }\end{array}$ \\
\hline 2 & Alaska-Aleutian & 9.2 & 1100 & 100 & 18.1 & 750 & $\begin{array}{l}\text { A9-A19 \& B9-B19 } \\
\text { (Tsunami model 1-mid } \\
\text { source) }\end{array}$ \\
\hline 3 & Alaska-Aleutian & 9.2 & 600 & 100 & - & 750 & $\begin{array}{l}\text { Distributed slip: } \\
15 \mathrm{~m} \star(\mathrm{A} 20+\mathrm{B} 20)+ \\
20 \mathrm{~m} \star(\mathrm{A} 21+\mathrm{B} 21)+ \\
25 \mathrm{~m} \star(\mathrm{A} 22+\mathrm{B} 22)+ \\
30 \mathrm{~m} \star(\mathrm{A} 23+\mathrm{B} 23+\mathrm{A} 24+\mathrm{B} 24) \\
(\text { Tsunami model } \\
1 \text {-eastern zone })\end{array}$ \\
\hline 4 & Alaska-Aleutian & 9.2 & 1200 & 100 & 16.3 & 1,133 & $\begin{array}{l}\text { A0-A11 \& B0-B11 } \\
\text { (Tsunami model } \\
\text { 2-western zone) }\end{array}$ \\
\hline 5 & Alaska-Aleutian & 9.2 & 1200 & 100 & 14.8 & 750 & $\begin{array}{l}\text { A12-A23 \& B12-B23 } \\
\text { (Tsunami model } \\
\text { 2-western zone) }\end{array}$ \\
\hline 6 & Alaska-Aleutian & 8.2 & 300 & 100 & 2.1 & 875 & A17-A19 \& B17-B19 \\
\hline 7 & Alaska-Aleutian & 8.2 & 300 & 100 & 2.1 & 661 & A20-A22 \& B20-B22 \\
\hline 8 & Alaska-Aleutian & 8.2 & 300 & 100 & 2.1 & 661 & A23-A25 \& B23-B25 \\
\hline 9 & Kamchatka & 8.8 & 500 & 100 & 9.8 & 100 & A1-A5 \& B1-B5 \\
\hline 10 & Kamchatka & 8.8 & 500 & 100 & 9.8 & 100 & $\mathrm{~A} 6-\mathrm{A} 10$ \& B6-B10 \\
\hline 11 & Kuril & 8.5 & 300 & 100 & 5.8 & 500 & A11-A13 \& B11-B13 \\
\hline 12 & Kuril & 8.5 & 300 & 100 & 5.8 & 500 & A14-A16 \& B14-B16 \\
\hline 13 & Kuril & 8.5 & 300 & 100 & 5.8 & 500 & A17-A19 \& B17-B19 \\
\hline 14 & Southern Chile & 9.5 & 1000 & 100 & 40.0 & 300 & A35-A45 \& B35-B45 \\
\hline $15-26$ & Cascadia & 9.1 & Var. & Var. & Var. & 520 & $\begin{array}{l}\text { High-resolution fault } \\
\text { model (Flück et al., 1997) }\end{array}$ \\
\hline
\end{tabular}

follow the seismic Model I above. The first tsunami model consists of three $\mathrm{M}=9.2$ earthquakes, with adjacent rupture areas as shown in Fig. 13. One of the $\mathrm{M}=9.2$ ruptures would correspond in location to the 1964 rupture, whereas the other two rupture areas would not correspond to any historic event. The middle event also spans what some may believe is a tectonic segment boundary at the tip of the Alaska Peninsula. It is important that the rupture areas for the three events do not overlap-this would violate an important seismic moment balance along the subduction zone.

For the purpose of accounting for radiation pattern changes with alongstrike shifts of the rupture area (see Fig. 2, gage 3 in Titov et al., 1999), Tsunami Model 2 is introduced with two $\mathrm{M}=9.2$ earthquakes (Fig. 14). The western rupture area approximately corresponds to the 1957 rupture area, whereas the eastern rupture spans the 1946, 1938, and the western part of the 1964 rupture area. Tsunami Models 1 and 2 are weighted (50\% each) and combined to form a composite model. The result would be combined as separate, weighted branches of a logic tree. For each of Models 1 and 2, we are operating under the 
Tsunami Model 1

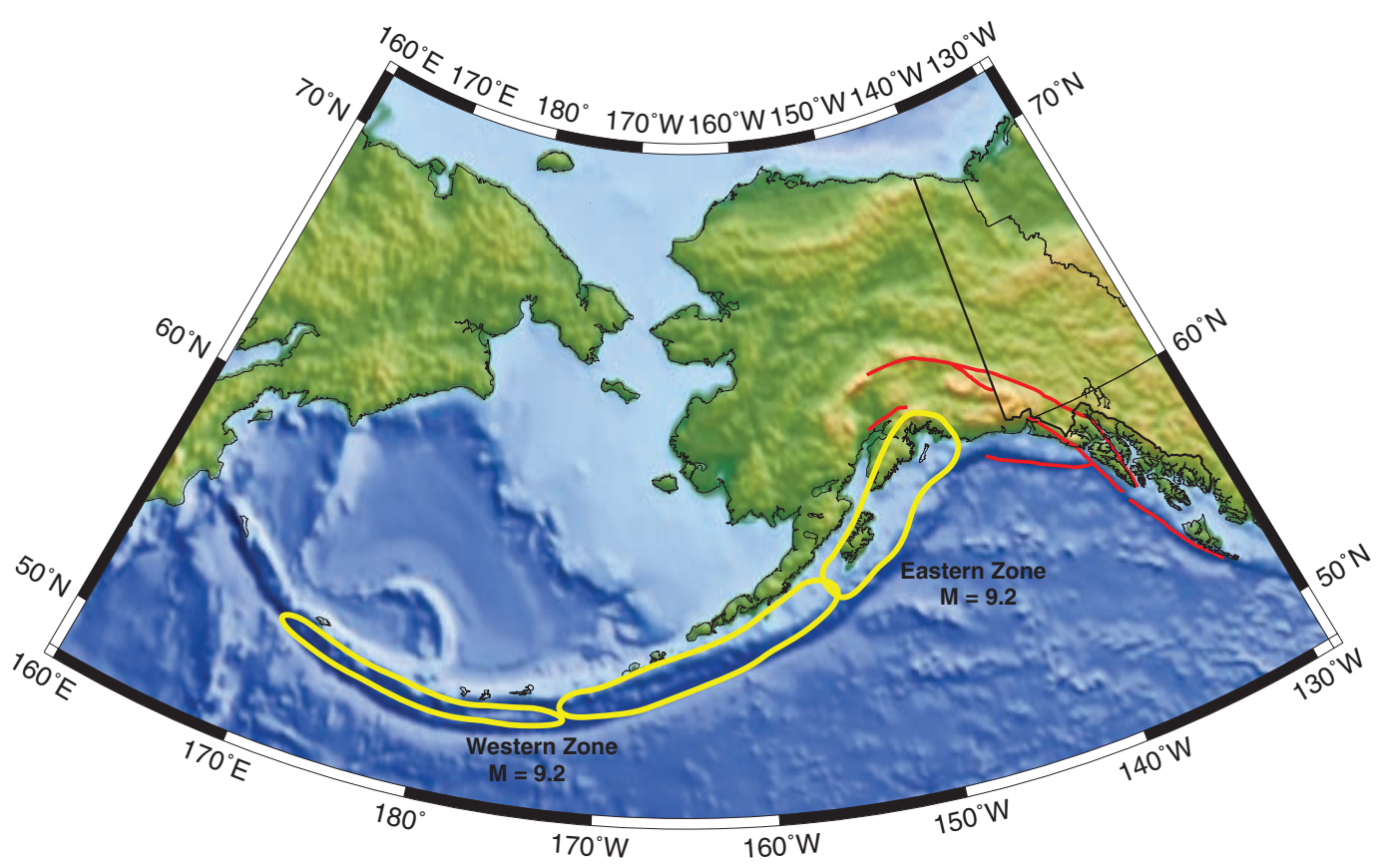

Figure 13: Model 1 for location of $M=9.2$ earthquakes along the Aleutian-Alaska Subduction Zone. Red lines: faults with predominantly strike-slip motion.

Tsunami Model 2

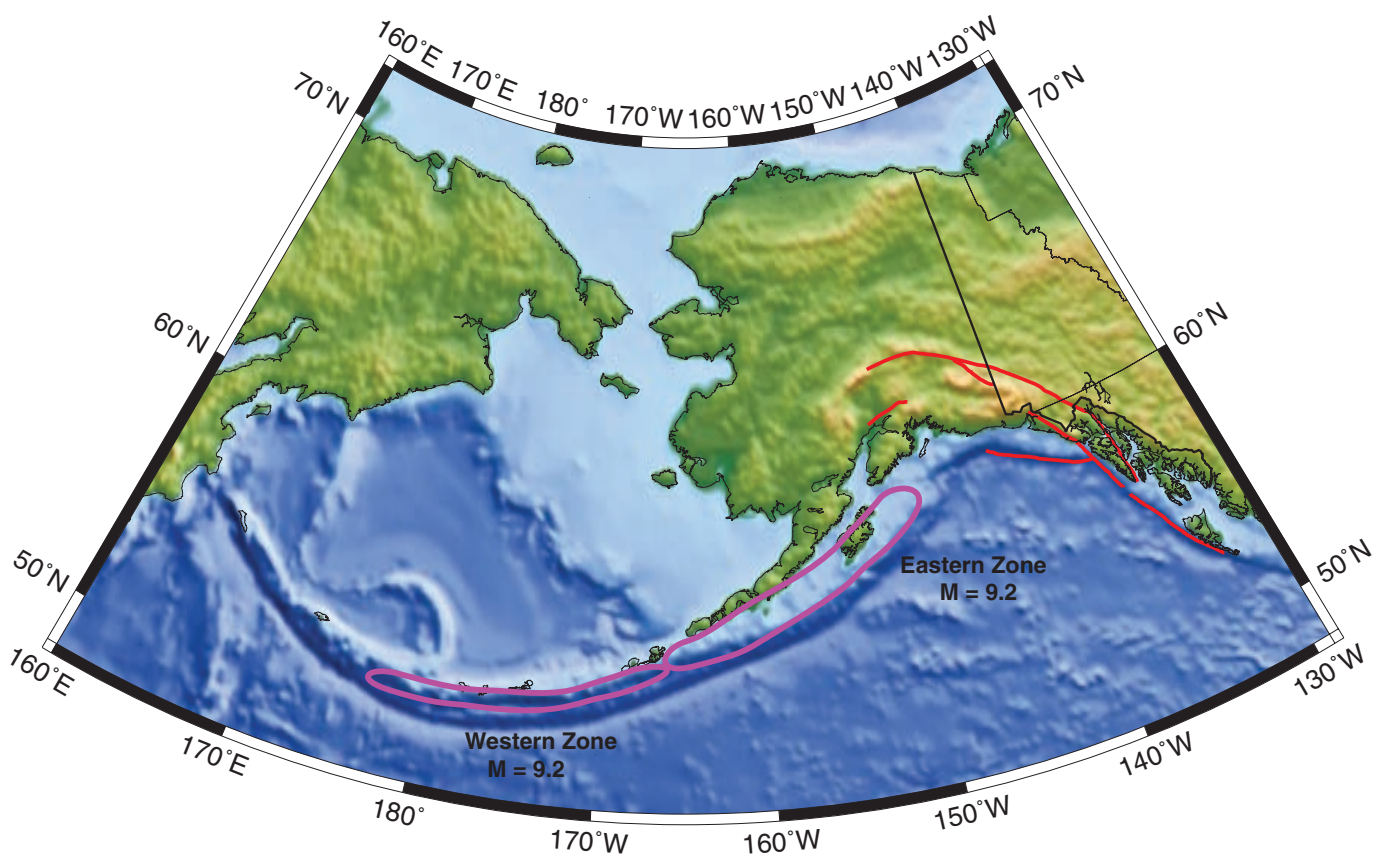

Figure 14: Model 2 for location of $M=9.2$ earthquakes along the Aleutian-Alaska sbuduction zone. Red lines: faults with predominantly strike-slip motion. 


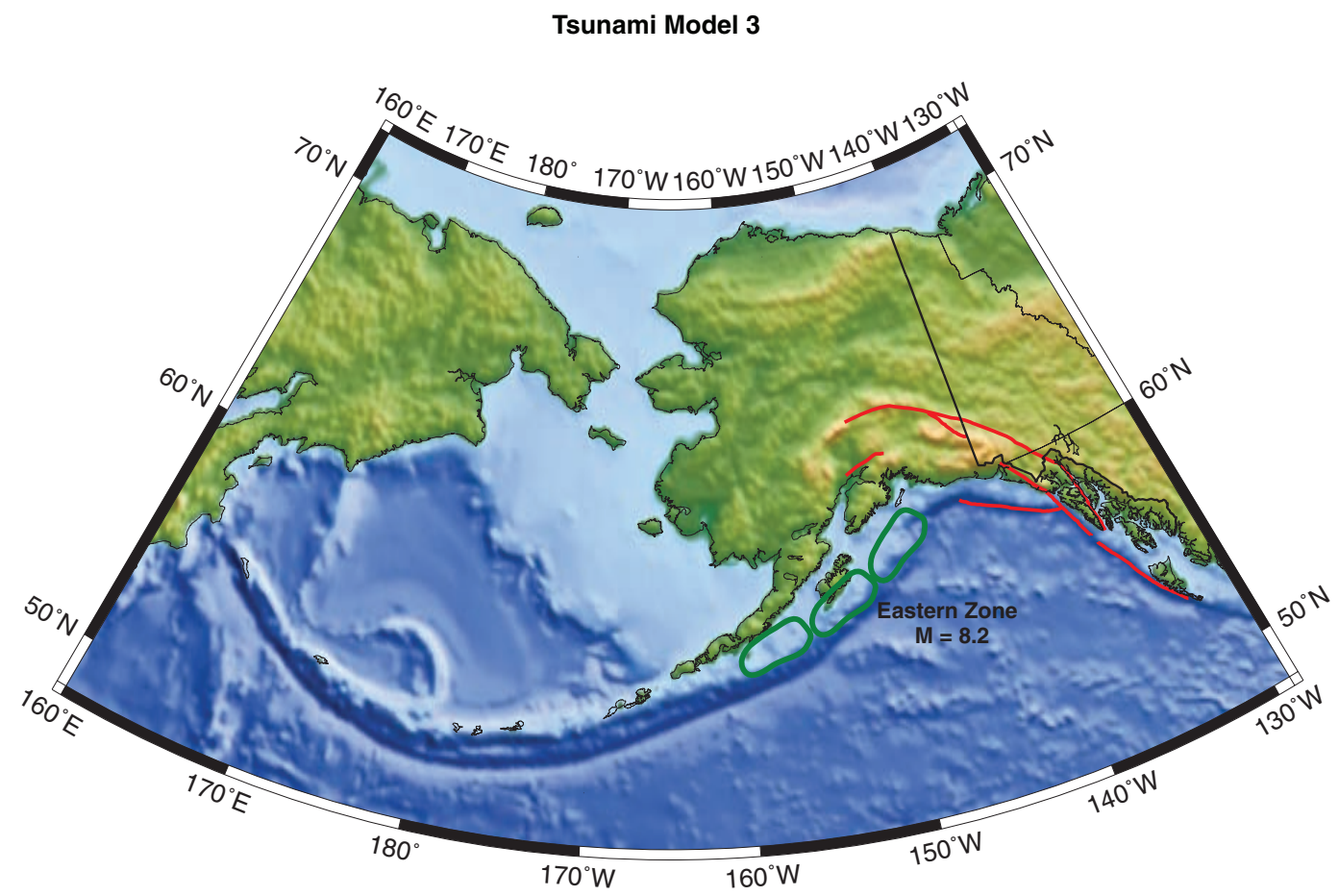

Figure 15: Model 3 for location of $M=8.2$ earthquakes along the Aleutian-Alaska Subduction Zone in the Prince William Sound region. Red lines: faults with predominantly strike-slip motion.

hypothesis that large earthquakes (and even small earthquakes; Tanioka and González, 1998) will rupture across segment boundaries defined by tectonic and geologic structures.

Finally, to accommodate the possibility that a smaller magnitude earthquake $(\mathrm{M}=8.2)$ in Prince William Sound may cause larger inundation at Seaside than other earthquakes considered in this initial set of source parameters, a third tsunami model (Fig. 15) is included that consists of three adjacent $\mathrm{M}=8.2$ ruptures, similar to the 1938 rupture. The recurrence rates for the $\mathrm{M}=8.2$ ruptures are again derived from Wesson et al. (1999).

For the Alaska-Aleutian Subduction Zone, eight inundation runs have been completed: three for Model 1, two for Model 2, and three for Model 3.

\subsubsection{Kamchatka Subduction Zone}

Like the Alaska-Aleutian Subduction Zone, large earthquakes have occurred along the Kamchatka Subduction Zone (KSZ) with noticeable frequency. Pinegina et al. (2003) recently concluded that Kamchatka has been impacted by large tsunamis at a rate of 1 every 100 years for the past 3,000 years, though not all are from local sources ( 10-20\% far field). Of note, the $\mathrm{M}_{\mathrm{W}}=8.81952$ (Johnson and Satake, 1999) and the $M_{t}=8.81923$ (Abe, 1979) earthquakes are probably representative of the largest earthquakes of this subduction zone. A tsunami model for Kamchatka can be constructed as done for the Alaska Tsunami Model 1 above, where two adjacent $M=8.8$ earthquakes fill the entire subduction zone. 


\subsubsection{Kuril Subduction Zone}

Continuing south along the Kuril Subduction Zone, the maximum magnitude earthquake is likely to be slightly smaller than for the Kamchatka Subduction Zone, primarily because of a change in tectonic regime for the overriding plate. From the analysis of the 13 October 1963 Kuril Islands earthquake (there was also a tsunami earthquake in the Kuril Islands on 20 October 1963) which Ward (1982) and Ruff and Kanamori (1983) placed at $\mathrm{M}_{\mathrm{W}}=8.5$ and recent evidence of multi-segment rupture in the southern part of the Kuril Subduction Zone by Nanayama et al. (2003), it is reasonable to characterize this subduction zone with a series of $\mathrm{M}=8.5$ earthquakes. Nanayama et al. (2003) indicates that the average return time for these earthquakes is approximately 500 years. Approximately three $\mathrm{M}=8.5$ earthquakes would fill the Kuril Subduction Zone up to the southern extent of the Kamchatka Subduction Zone.

\subsubsection{Southern Chile Subduction Zone}

Earthquakes along the Chilean Subduction Zone are also considered, primarily because of the size of the $M=9.5-9.61960$ earthquake (Cifuentes, 1989; Cifuentes and Silver, 1989) and observations of the associated tsunami along the west coast of North America. The amount of slip that occurred during the 1960 tsunami is difficult to ascertain because of the complexity of the event. The geodetic models of both Linde and Silver (1989) and Barrientos and Ward (1990) result in average amounts of slip that correspond to significantly lower seismic moment estimates than determined from seismic waveform data, though still at a $\mathrm{M} \sim 9.5$ level. Average slip estimates vary from $17 \mathrm{~m}$ to $20 \mathrm{~m}$, though the variable slip models indicate significantly higher amounts of slip, as much as $40-50 \mathrm{~m}$, are predicted for the offshore extent of rupture and even small earthquakes (Barrientos and Ward, 1990; Linde and Silver, 1989). For comparison, Liu et al. (1995) use $24 \mathrm{~m}$ of slip in their far-field tsunami model.

Chile has been struck by giant earthquakes and tsunamis in the past, including the 1570s, 1730s, 1837, and the $\mathrm{M} \sim 9.51868$ earthquake in northern Chile. These dates are not representative of return times for $\mathrm{M} \sim 9.5$ earthquakes from purely a moment-balance perspective (Barrientos and Ward, 1990) and from recent paleoseismologic analysis by Salgado et al. (2003). The latter study suggests an average return time for great earthquakes in Chile of $\sim 250$ years. Even so, if the average slip per event is $\sim 20 \mathrm{~m}$, this results in a seismic slip rate of $8 \mathrm{~cm} / \mathrm{yr}$ - close to the relative plate convergence rate of $8.4 \mathrm{~cm} / \mathrm{yr}$. Although the southern Chile Subduction Zone is considered the most highly coupled subduction zone in the world in terms of seismic efficiency (Scholz, 1990), the repeat time should not be much smaller, nor the average slip per event be much greater, than these estimates to satisfy the moment balance.

\subsubsection{Cascadia Subduction Zone earthquakes}

This part of the pilot study is of particular importance because M $~ 9$ earthquakes along the Cascadia Subduction Zone will likely produce the worst-case 
tsunami inundation and be the defining event for the 500-year tsunami flood standard. We first discuss how the coseismic displacement field can be calculated for variable slip (Geist, 2002), building on previous inundation mapping efforts (Priest et al., 1997). Not only does the coseismic displacement field provide the initial conditions for tsunami propagation, but it will also affect inundation estimates because of coseismic subsidence of coastal regions. We will then discuss different approaches to incorporating uncertainties caused by incomplete knowledge of rupture geometry and by different slip distribution patterns into the probabilistic calculations. Discussion of recurrence rates and time-dependent probability calculations is presented by Petersen et al. (2002).

\subsubsection{Specification of Cascadia earthquake magnitudes}

There is mounting evidence that the last major Cascadia Subduction Zone earthquake in the year 1700 had a magnitude approximately equal to $\mathrm{M} \sim 9$ (Satake et al., 2003). Available paleoseismic data indicate that other major earthquakes have struck the Cascadia margin, though it is unclear whether these earthquakes were "characteristic" $\mathrm{M}=9$ events or whether they also included smaller magnitude earthquakes. The method that the National Seismic Hazard Mapping program employed to characterize earthquakes along the interplate thrust was to use two equally weighted scenarios: (1) a $\mathrm{M}=9.0$ characteristic earthquake with an average repeat time of 500 years and (2) a series of $\mathrm{M}=8.3$ earthquakes that fill the seismogenic region of the interplate thrust every 500 years, resulting in a repeat time of 110 years for a $\mathrm{M}=8.3$ earthquake to occur anywhere in the seismic zone (Frankel et al., 1996; Frankel et al., 2002; Petersen et al., 2002). These two scenarios represent epistemic uncertainty that is included in the probabilistic calculations for the seismic hazard maps.

One could now argue, however, that this either/or option has been superseded with recent analysis of the Japan tsunami records that indicate the 1700 event had a magnitude of $\mathrm{M}=8.7-9.2$ and ruptured approximately $1100 \mathrm{~km}$ (Satake et al., 2003). That is, the epistemic uncertainty regarding magnitude posed in the National Seismic Hazard maps has essentially been resolved with the collection of new data (that is, tsunami records in Japan). This does not exclude the possibility of $\mathrm{M}<9$ earthquakes occurring along the interplate thrust. Instead, the epistemic uncertainty may now be whether the magnitude distribution is characteristic or a Gutenberg-Richter (G-R) distribution (Appendix F). Toward this end, Geist and Parsons (2005) consider two end-member cases of a characteristic $M=9$ earthquake and a modified G-R distribution of earthquakes for demonstrating methods to calculate tsunami probabilities. Because of a lack of information to define a G-R distribution for the Cascadia Subduction Zone (see Discussion), we focus primarily on $\mathrm{M}=9$ events as specified by Satake et al. (2003) and Leonard et al. (2004), though this is certainly a topic open for future research and inclusion in future PTHA studies. 


\subsubsection{Calculation of coseismic displacement field}

To calculate the coseismic displacement field, we can take advantage of previous work performed by Priest et al. (1997) in developing deterministic tsunami inundation maps. The source discretization currently implemented in FACTS may not be fine enough to accommodate slip pattern variations. Optimally, it is best to modify the fault grid developed by Flück et al. (1997) and used by Priest et al. (1997). This grid includes 105 quadrilateral elements with varying dip and strike.

The stochastic source model is modified from that of Herrero and Bernard (1994) as described by Geist (2002). In basic terms, the model computes a stochastic slip distribution that conforms to a specific amplitude spectrum in the wavenumber domain that is constrained by earthquake physics and observations. Randomizing the phase spectrum and transforming to the spatial domain yields a wide variety of slip distribution patterns. Scaling constants are adjusted so that the average slip for all slip distributions produced by the model equal the specified seismic moment or independent slip estimates from far-field tsunamis and/or coastal subsidence. The slip distribution then can be mapped to the fault grid without too much distortion of the wavenumber spectrum. It is important to recognize that the stochastic source is specifically designed to estimate the aleatory uncertainty related to slip for a given seismic moment. Any single slip distribution has a low probability of occurring and should not be considered as a characteristic slip distribution (i.e., one which represents the slip distribution for each earthquake, with little uncertainty) (cf., Schwartz, 1999). Such a model, not considered here, is tightly constrained by the overall convergence rate and time since the last event.

An important consideration is how to deal with slip in the transition zone (Flück et al., 1997) and uncertainty in the rupture width. In past coseismic displacement studies, slip is assumed to taper in the transition zone from full slip adjacent to the locked zone to zero at the downdip edge of the transition zone (Flück et al., 1997; Leonard et al., 2004). In Satake et al. (2003), three long-rupture models are considered for the 1700 C.E. earthquake that are compatible with both the tsunami records and coastal subsidence estimates: a "Long-Narrow" model with uniform slip in the locked zone and slip tapered to zero half-way down the transition zone; a "Long-Splayed" model like the Long-Narrow model, but with a seaward-vergent splay fault at the updip edge of rupture; and a "Long-Wide" model with uniform slip throughout both the locked and transition zones.

Because the Satake et al. (2003) study could not resolve between the LongNarrow and Long-Wide rupture models at a reasonable level of confidence, there is still uncertainty related to the rupture width. The National Seismic Hazard Maps handle this uncertainty by considering five different rupture widths that extend through the transition zone (Petersen et al., 2002). We make the case that uncertainty related to the effective width of the rupture zone is in part aleatory uncertainty associated with slip distribution patterns. The slip distributions used for the local tsunami models are based on the Long-Wide rupture geometry. Using this geometry, regions where slip is concentrated updip, for example, will have a narrow effective rupture width. Even so, there 
is still a level of epistemic uncertainty related to the region where slip can occur for a Cascadia Subduction Zone earthquake. If we limit variable slip to a narrow zone consistent with the Long-Narrow rupture geometry, mean tsunami amplitudes are larger (Geist, 2005). For this pilot study, we did not consider this latter case.

The uncertainty in rupture width is also related to how well the coastal subsidence predicted using the slip distributions for the local tsunami models compare to the observations. The event for which there are the most abundant paleoseismic observations is the 1700 C.E. earthquake (Leonard et al., 2004). Recognizing that the stochastic slip distributions represent a range of possible rupture modes (i.e., they are not representative of one particular event) and that there is significant uncertainty associated with the paleoseismic subsidence measurements themselves, most of the slip distributions tend to overpredict subsidence in comparison to the estimates from the 1700 C.E. earthquake (Leonard et al., 2004). There are, however, individual slip distributions that provide an adequate comparison to the observed subsidence observations. Moreover, reductions in rupture width as little as $12.5 \%$ (still greater than the Long-Narrow geometry) greatly reduce the subsidence predictions. Thus, for the Cascadia geometry, coastal subsidence is more sensitive to uncertainty in rupture width than average slip. Tsunami generation, on the other hand, is more sensitive to average slip and slip distribution.

Finally, we estimate how many model runs it may take to capture that natural variability in runup heights caused by variations in slip distribution patterns. To do this, we track variation in peak nearshore tsunami amplitude (PNTA) at the $100 \mathrm{~m}$ isobath, which can be quickly computed using linear propagation models. In Fig. 16, both the standard deviation of PNTA (blue) offshore Seaside and the difference between maximum and minimum PNTA values (magenta) are shown as a function of the number of model runs. As is typical with this type of computational effort, representational gains in modeling the physical system die off exponentially with the number of model runs. In this case, a minimum of about 12 model runs would be needed to capture the natural variability in PNTA.

\subsubsection{Specification of earthquake recurrence rates}

In the Cascadia region, numerous paleoseismic investigations have been conducted to determine the recurrence record of great earthquakes (for example, Atwater and Hemphill-Haley, 1997; Atwater et al., 2004; Kelsey et al., 2002; Witter et al., 2003). In this section, we show how empirical parameters that define the regional probability distributions can be determined, taking into account uncertainty in age-dating methods and the open time intervals before the first and after the last earthquake dated in the geologic record (Ogata, 1999). We also show how the method for determining empirical distribution parameters can be applied directly to establishing tsunami probability distributions.

The age range of geologic horizons representing great earthquakes is a result of dating samples from multiple sites, each with an associated uncertainty related to the age dating technique used. These age ranges, as well as open intervals before the first and after the last geologic horizon and a 


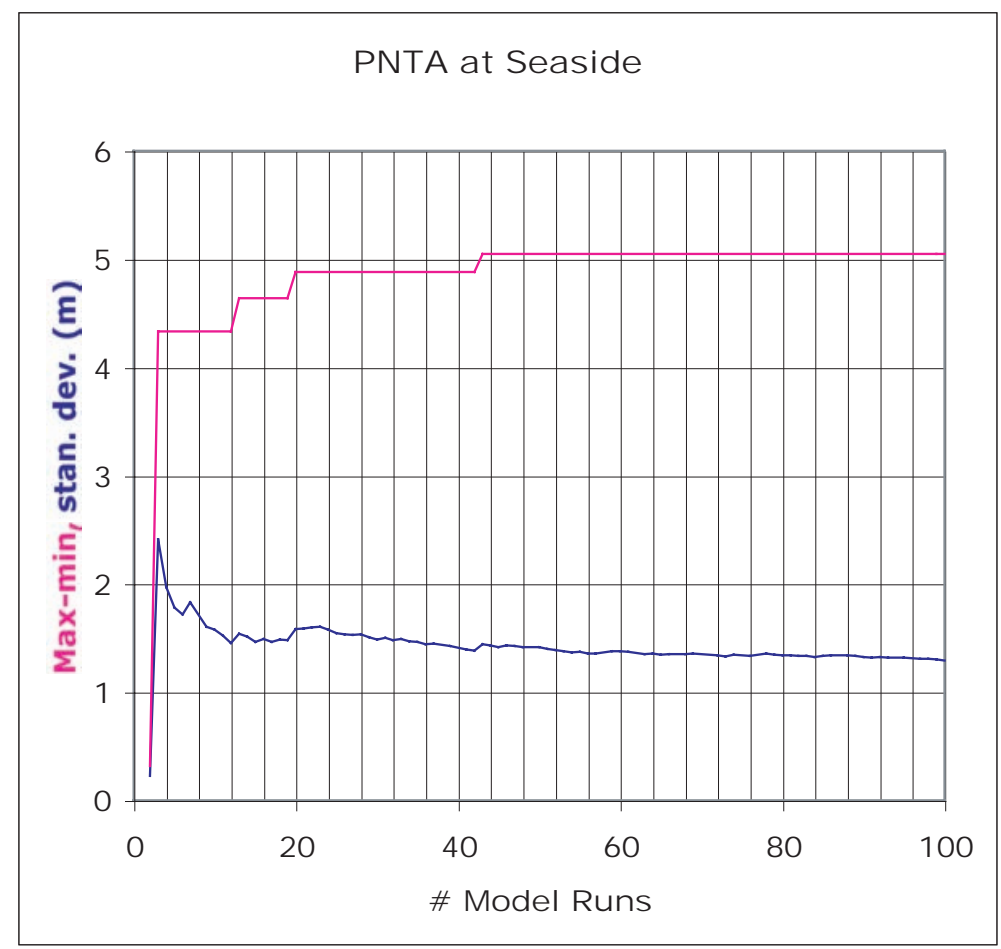

Figure 16: Level of variability in peak nearshore tsunami amplitudes (PNTA) offshore Seaside as a function of the number of stochastic slip distributions used. Pink: difference in maximum and minimum values of PNTA. Blue: standard deviation of PNTA values.

(a)

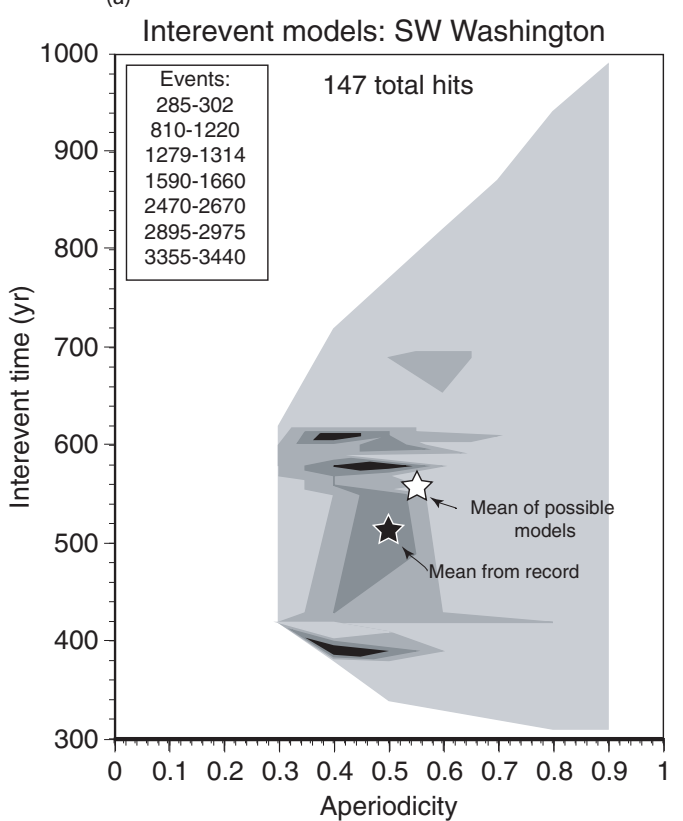

(b)
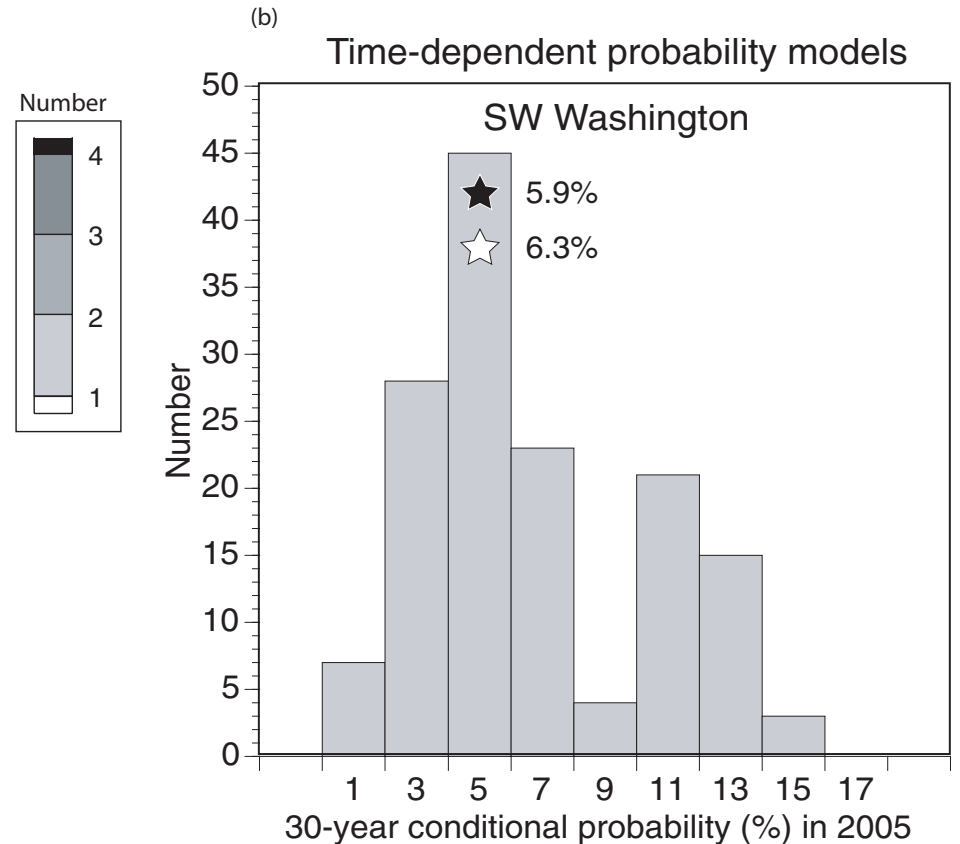

Figure 17: Results of Monte Carlo analysis of inter-event times and aperiodicity, using paleoseismic horizons identified and dated by Atwater et al. (2004). 
limited sampling of earthquake recurrence history, introduce uncertainty in determining the mean inter-event time and aperiodicity. To determine the range of distributions that are consistent with available paleoseismic data, a Monte Carlo simulation is performed in which a random sample of earthquake times is drawn from a specified probability distribution with varying mean inter-event times $(\mu)$ and aperiodicities $(\alpha)$ (Parsons, 2004, submitted). Either mean values of $\mu$ and $\alpha$ for all random samples that fit the observations can be used, or a range of values can be carried through the probability calculations enabling an estimate of parameter sensitivity.

Results using paleoseismic data from southwest Washington (Atwater et al., 2004) are shown in Fig. 17. The event table shows the age ranges (calibrated years B.P.) for the identified horizons and the plots show the successful distributions defined in $\mu$ - $\alpha$ parameter space that produce hits in the age ranges for the events. The histogram shows the 30 -year conditional probability resulting for all successful hits, using the Brownian Passage Time probability distribution (Matthews et al., 2002). The probability corresponding to the mean of the successful hits is shown by the white star ( $\mu=566$ years, $\alpha=0.55)$. 



\section{Propagation and Inundation Modeling}

$\mathrm{D}$

EVELOPING QUANTITATIVE ESTIMATES for site-specific tsunami hazard assessments requires substantial modeling efforts to simulate potential tsunami impacts. For most locations, the use of historical data alone is not sufficient to derive long- and short-term hazard estimates. Such studies demand additional model data to fill in the gaps in the historical records. Even if a wealth of historical data is available, extra modeling estimates are warranted to account for changes of coastal infrastructure and/or for probable but non-historical events. The goals of numerical modeling for such studies differ substantially from the goals of a typical hindcast simulation, where the model results are compared with various field data for a specific historical event. In probabilistic modeling, comparison with historical data is only the first preliminary step of the study, to ensure reliability of multiple model estimates for probable events. In this respect, the probabilistic simulations are similar to forecast modeling, which employs a similar methodology for model use. This section presents the methods, modeling results, and discussions of the modeling study for Seaside, Oregon. This modeling effort produced a model database for probabilistic tsunami hazard assessment. Multiple simulations have been performed for a large number of potential far- and nearfield tsunami sources using the MOST numerical model (Titov and González, 1997; Titov and Synolakis, 1996). Unlike previous tsunami probabilistic studies, high-resolution numerical grids are employed to resolve details and internal structure of the computed flood zones for each modeled event. Although Seaside does not have a tide gage to record historical tsunamis, some historical tsunami inundation data is available in the form of inundation zone estimates and tsunami sediment data for a limited number of historical events. The numerical model was tested against available historical tsunami measurements. Full numerical solutions for the high-resolution grid are retained for each model run to form a model database that can be used to perform various analyses and probabilistic estimates.

\subsection{Numerical Model}

NOAA's MOST numerical model (Titov and González, 1997; Titov and Synolakis, 1995,1997 ) was utilized to produce inundation and propagation simulations for this study. This model has been extensively tested against a number of laboratory experiments and was successfully used for many historical tsunami simulations (Bourgeois et al., 1999; Titov and Synolakis, 1995, 1996, 1997, 1998; 
Yeh et al., 1995). The model includes simulation of inundation dynamics by implementing moving boundary conditions that allow calculation of the flow dynamics of a wave climbing up dry topography and water withdrawing from the initial coastline. The employed numerical scheme also handles wave breaking that has been verified by comparison with a number of laboratory experiments and historical tsunami observations.

Details of the numerical implementation and testing of the MOST model are described in Titov and Synolakis $(1995,1996,1997,1998)$ and Titov and González (1997). Here, we present a brief description of the model and its application for this study.

\subsubsection{Mathematical formulation}

Two-dimensional shallow-water-wave equations (SW) are used to model this phenomenon. Despite certain limitations, these equations have proven capable of modeling many important physical characteristics of tsunami propagation, including wave breaking and bore runup on mild and steep beaches (Peregrine, 1966; Kobayashi et al., 1987). Recent studies (Titov and Synolakis, 1995) have shown that this approximation works reasonably well even in the case of relatively short (length to depth ratio less then 10) breaking waves. Although the equations cannot resolve the specific pattern of the breaking front, they adequately model the overall wave behavior and give accurate estimations of the runup values in a wide range of wave parameters.

The shallow-water-wave equations are

$$
\begin{gathered}
h_{t}+(u h)_{x}+(v h)_{y}=0 \\
u_{t}+u u_{x}+v u_{y}+g h_{x}=g d_{x} \\
v_{t}+u v_{x}+v v_{y}+g h_{y}=g d_{y}
\end{gathered}
$$

where $h=\eta(x, y, t)+d(x, y, t), \eta(x, y, t)$ is the wave amplitude, $d(x, y, t)$ is the undisturbed water depth, $u(x, y, t), v(x, y, t)$ are the depth-averaged velocities in the $x$ and $y$ directions, respectively.

For arbitrary topography and bottom displacement the system of equations has to be solved numerically. We use a finite-differences algorithm based on the splitting method (Titov and Synolakis, 1998). This method reduces the numerical solution of the two-dimensional problem into the consecutive solution of two locally one-dimensional problems. The splitting technique allows effective implementation of a variety of boundary conditions, including moving boundary conditions, to account for tsunami inundation of dry topography.

Note that, with regards to wave breaking, the equations cannot resolve the specific pattern of the breaking front. However, the equations do adequately model the overall wave behavior and give accurate estimation of the runup values in a wide range of wave parameters. The MOST model handles wave breaking by modeling it as a shock wave within the shallow-water wave approximation (without simulating the details of the breaking front). The numerical dissipation qualities of the scheme allow for stable computation of the shock dynamics, conserving mass and momentum with good accuracy. The 


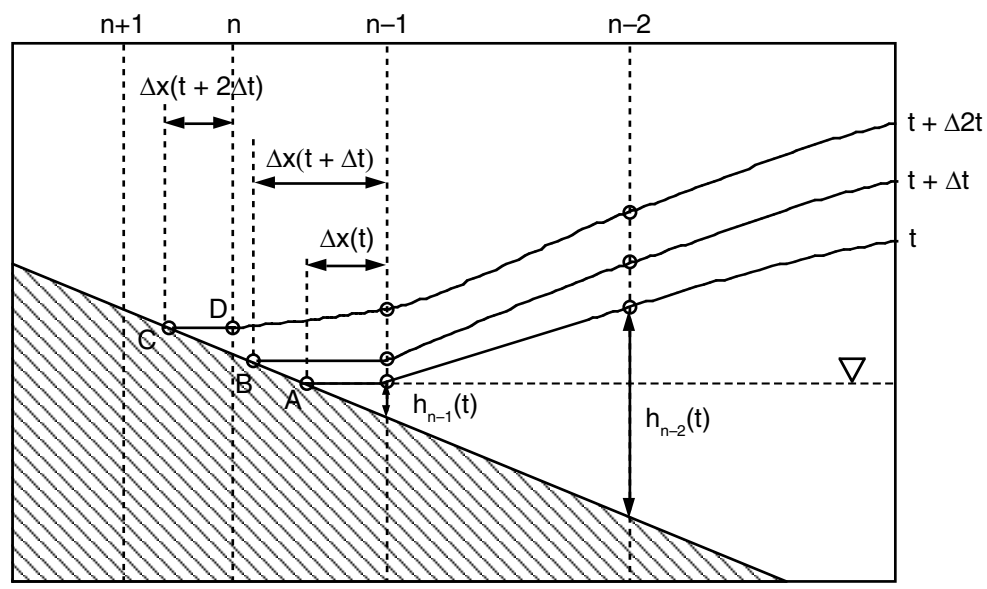

Figure 18: Definition sketch for the shoreline boundary computation.

amplitudes of the simulated breaking waves compare well with a number of laboratory experiments.

\subsubsection{Moving boundary condition}

To calculate tsunami evolution on a dry bed, it is necessary to use moving boundary conditions. The Froude number may be greater than 1 near the shoreline point, implying that all characteristic families have the same inclination in this region. Hence, it is impossible to use the direct relationships between the Riemann invariants, as is done for fixed boundary approximations (Titov and Synolakis, 1995). Therefore, approximations of the boundary values from previous space nodes are used. This is described in Fig. 18.

The shoreline algorithm uses a time-dependent space step $\Delta x(t)$ of the last node of the computational area. The objective is to maintain the shoreline boundary point (represented consecutively by A, B, or C on Fig. 18) on the surface of the beach during the computation. We therefore adjust the length of the last space step $\Delta x(t)$ every time step, so that the shoreline point (A) is at the intersection of the beach with the horizontal projection of the last "wet" point, for example, $n-1$ node on Fig. 18. The value of the velocity on the shoreline node is equal to the velocity on the previous "wet" point.

We introduce additional grid points as follows. Referring to Fig. 18, at the time interval between times $t$ and $t+\Delta t$, there are $n$ grid points $(n-1$ fixed grid points and the instantaneous shoreline, points A or B) in the computation. At time $t+2 \Delta t$, when the shoreline point (C) reaches beyond the next fixed grid point ( $n$-th fixed node of the constant dry bed grid), this $n$-th fixed point is introduced between the shoreline point $(C)$ and the previous internal fixed node $(n-1)$ and $\eta(D)=\eta(D)$. Now there are $n+1$ grid points in the computational area and we repeat the process. During rundown, we reduce the number of dry grid points sequentially in an analogous manner. 


\subsubsection{Tsunami propagation model}

To account for a spherical earth during tsunami propagation, the SW equations are solved in spherical coordinates. The MOST propagation code uses the nonlinear shallow water equation in spherical coordinates with Coriolis force and a numerical dispersion scheme to take into account the different propagation wave speeds with different frequencies. The equations, shown below, are numerically solved using a splitting method (Titov and González, 1997):

$$
\begin{gathered}
h_{t}+\frac{(u h)_{\lambda}+(v h \cos \phi)}{R \cos \phi}=0 \\
u_{t}+\frac{u u_{\lambda}}{R \cos \phi}+\frac{v u_{\phi}}{R}+\frac{g h_{\lambda}}{R \cos \phi}-\frac{u v \tan \phi}{R}=\frac{g d_{\lambda}}{R \cos \phi}-\frac{C_{f} u \sqrt{u^{2}+v^{2}}}{d}+f v \\
v_{t}+\frac{u v_{\lambda}}{R \cos \phi}+\frac{v v_{\phi}}{R}+\frac{g h_{\phi}}{R}+\frac{u^{2} \tan \phi}{R}=\frac{g d_{\phi}}{R}-\frac{C_{f} v \sqrt{u^{2}+v^{2}}}{d}-f u
\end{gathered}
$$

where

$$
\begin{array}{ll}
\lambda & =\text { longitude } \\
\phi & =\text { latitude } \\
h & =\eta(\lambda, \phi, t)+d(\lambda, \phi, t) \\
\eta(\lambda, \phi, t) & =\text { amplitude } \\
d(\lambda, \phi, t) & =\text { undisturbed water depth } \\
u(\lambda, \phi, t) & =\text { depth averaged velocity in longitude direction } \\
v(\lambda, \phi, t) & =\text { depth averaged velocity in latitude direction } \\
g & =\text { gravity } \\
R & =\text { radius of the Earth } \\
f & =2 \omega \sin \phi, \text { Coriolis parameter } \\
C_{f} & =g n^{2} / h^{1 / 3}, n \text { is Manning coefficient }
\end{array}
$$

To account for changing spatial scales during tsunami propagation, several telescoping grids are used for propagation simulations with dynamic data exchange at the boundaries. The highest resolution grid simulation includes inundation modeling with moving boundary conditions applied. The MOST model handles wave breaking by modeling it as a shock wave within the shallow-water wave approximation (without simulating the details of a breaking front). The numerical dissipation qualities of the scheme allow for stable computation of the shock dynamics, conserving mass and momentum with good accuracy. The amplitudes of the simulated breaking waves compare well with a number of laboratory experiments (Titov and Synolakis, 1995).

\subsubsection{Model verification}

MOST model testing against a variety of data is documented in many publications (see, for example, Bourgeois et al., 1999; Titov and Synolakis, 1995, 1996, 1997, 1998; Yeh et al., 1995). 

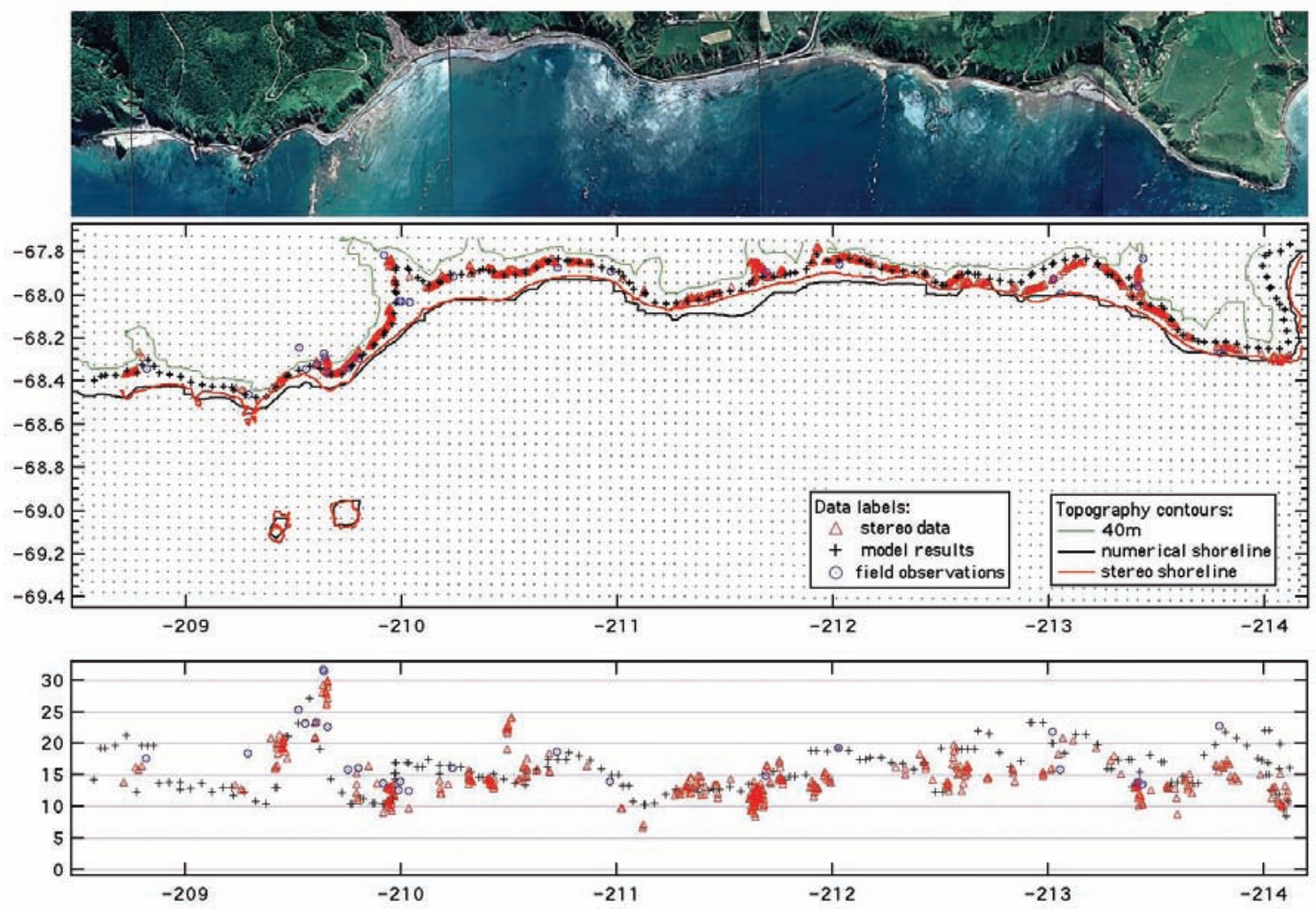

Figure 19: Comparison of the 1993 Okushiri tsunami inundation model (crosses) with field observations (circles) and stereo photo data (triangles). Top frame shows aerial photo of the modeled area used for the stereo analysis of the inundation data. Middle frame illustrates the numerical grid used for the simulation of the same area (dots are computational nodes, contours show topography data) and compares inundation distances. Bottom frame compares maximum vertical runup for the same shoreline locations.

Here, verification of the inundation computations is presented for one historical tsunami to illustrate the accuracy of inundation estimates using the MOST model. As a partial test of inundation forecast capability of the MOST model, the simulation of the 1993 Hokkaido-Nansei-Oki tsunami has been compared with an independent dataset. The model scenario of this event is based on the field survey data (Takahashi, 1996). An independent, much denser dataset of tsunami inundation distances and heights have been obtained at PMEL from stereo photography data of Okushiri Island. Figure 19 shows a comparison of the original MOST simulation (Titov and Synolakis, 1997) with the new stereo data. Inundation values are compared for the west coast of Okushiri Island, where the highest runup was measured for this event. The MOST runup and inundation estimates compare well with both stereo and field data.

\subsection{Model Sources}

Only earthquake-generated tsunamis are assumed for the Seaside probabilistic analysis. Landslide sources can potentially be considered for analyses in the 
future, when the probability of landslide occurrence is better defined for this location.

Tsunamis propagated from distant sources have substantially different dynamics, duration, and intensity when compared with local tsunami events. Simulations of tsunami propagation across the Pacific from far-field sources need to be combined with the local high-resolution inundation computations. On the other hand, deformations from local earthquake sources change the bathymetry and topography of the study area, which needs to be taken into account during the simulation of inundation dynamics. To account for those and other differences, the modeling strategy for the tsunami scenarios of the far-field sources was different from the local sources' modeling.

\subsubsection{Far-field sources}

Seaside inundation modeling from far-field sources was divided into two steps: (1) across-ocean propagation from a source to the U.S. West Coast in the vicinity of Seaside and (2) high-resolution inundation simulation using the tsunami propagation results as input.

A source sensitivity study (Titov et al., 1999) has established that only a few source parameters are critical for the far-field tsunami characteristics, namely the location and the magnitude (assuming some typical mechanism for the displacement and typical size of a given magnitude source). The details of the earthquake deformation are not important for inundation in the far-field. For example, wide-ranging variations of dip and slip (rake) angles of an earthquake source do not lead to significant changes in the farfield tsunami signal. Therefore, assuming simplified uniform slip for each location/magnitude combination of far-field sources accounts for most of the variability of the tsunami inundation at the Seaside (far-field) location for events of certain magnitude from a specified geographical area.

Tsunami propagation scenarios for far-field sources are obtained from PMEL's model tsunami propagation database that includes sources from all major tsunamigenic subduction zones (Titov et al., 2005). The database contains a discrete set of unit sources that can provide the basis for constructing a tsunami scenario from a given source location and magnitude. Numerical solutions of tsunami propagation from these unit sources, when linearly combined, provide arbitrary tsunami propagation simulation. Figure 20 shows the computational area of the propagation simulations and locations of 14 earthquake scenarios considered for this study with earthquake magnitudes varying from $\mathrm{M}_{\mathrm{w}} 8.2$ to 9.2. Details of the earthquake parameters and the methodology for choosing the sources for the Probabilistic Tsunami Hazard Analysis are in Section 5, "Probabilistic Method."

\subsubsection{Near-field sources}

In contrast to tsunamis arriving from the far-field, details of the local earthquake deformation source are important for inundation estimates. The local source model for this study involved a discretized fault surface with variable 


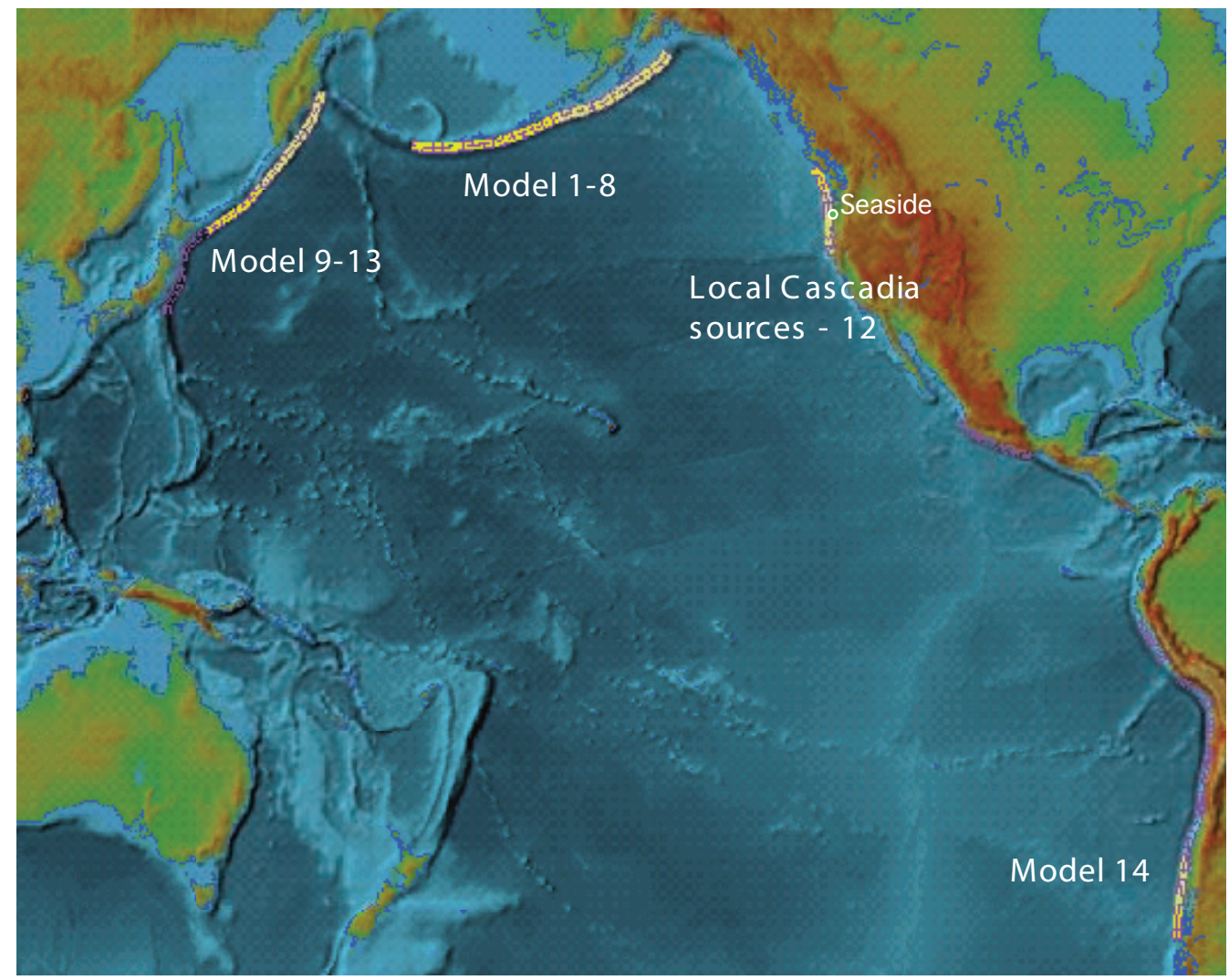

Figure 20: Source regions from FACTS database used for propagation modeling.
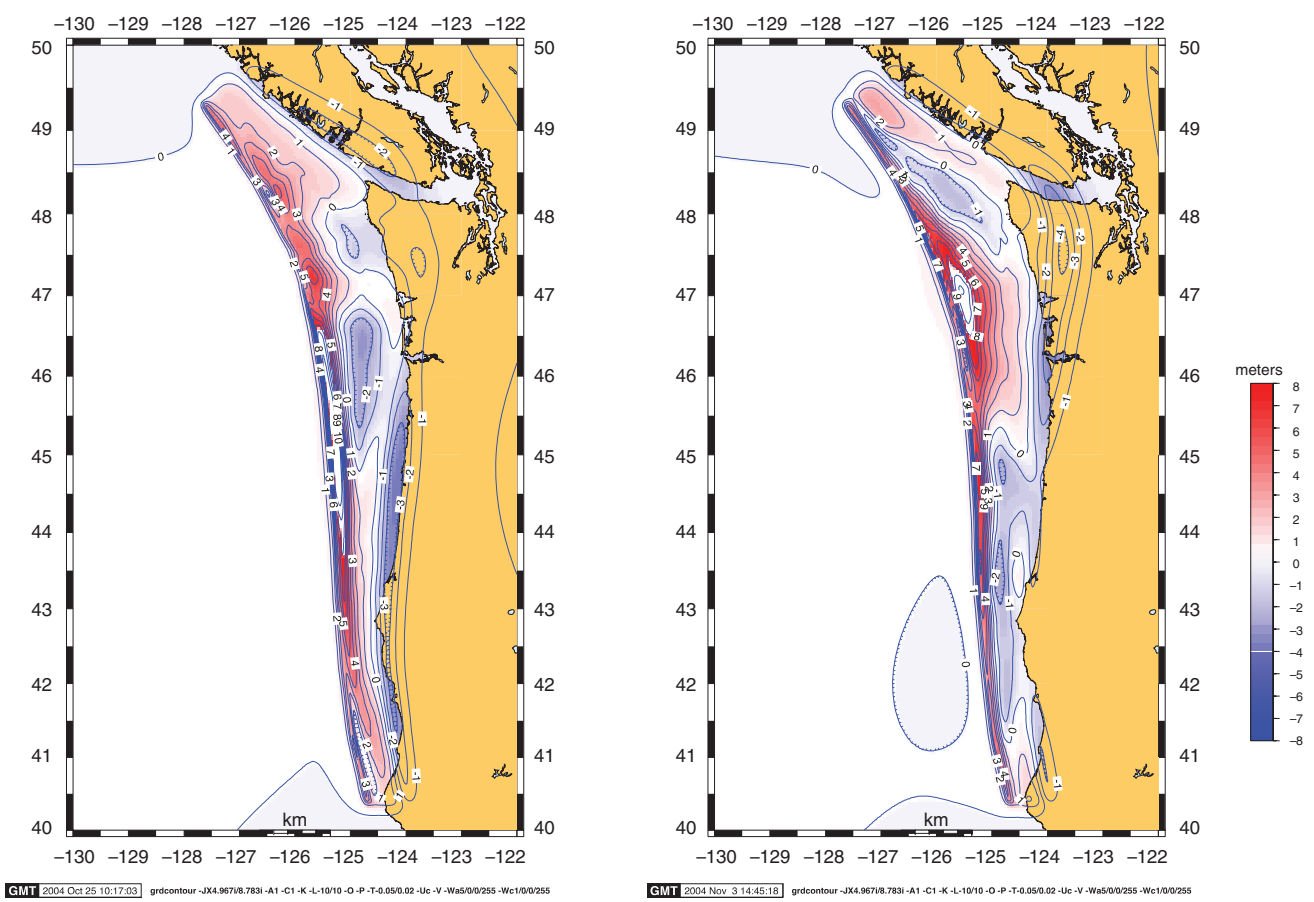

Figure 21: Two examples of coseismic vertical displacement field used as initial conditions for local tsunami modeling. 
dip and strike, using average slip estimates, rupture dimensions, and moment magnitude estimates for the 1700 event. That allowed the use of different slip distribution patterns and different rupture geometries to estimate the range of local tsunamis. Figure 21 shows deformation patterns for two tsunami source scenarios of $\mathrm{M}_{\mathrm{W}} \sim 9$ earthquake used for the Seaside inundation modeling, as an example of source scenario variability. A total of 14 different local source scenarios were considered for the study.

\subsection{Numerical Model Setup and Testing}

Figure 22 illustrates the numerical grid system setup for the tsunami numerical model at Seaside. It shows the location and the resolution of three telescoping grids (grid $\mathrm{A}, \mathrm{B}$, and $\mathrm{C}$ with corresponding resolutions of 36,6 , and $1 / 3$ arc seconds) that are used to compute each simulation of the Seaside tsunami inundation. The propagation results for the far-field sources (1964 propagation model is shown as an example on the Pacific-wide grid) are used as input through the boundary of grid A. The deformation data from local earthquake source scenarios are input directly into all three computational grids; the resulting local tsunamis are computed without additional use of the propagation model.

The MOST numerical model has been extensively tested in many model comparative studies and in various historical tsunami simulations (Titov et al., 2005; Titov and González, 1997; Titov and Synolakis, 1995, 1998). It is known to accurately simulate tsunami propagation and inundation for even extreme tsunami events (Titov and Synolakis, 1995). The goal of the model tests in this study is to verify that the numerical setup for the Seaside, OR location is adequate for the purpose of this study, i.e., the accuracy, size, and the resolution of the numerical grid is sufficient to resolve details of the inundation flow for both the far-field and the near-field tsunamis.

Unfortunately, Seaside does not have a tide gage to record tsunami signals from the 1964 or other smaller tsunamis. It is not feasible to have a standard tide gage at Seaside because this would have to be located inside the very shallow entrance bar to the Necanicum River. To serve the needs of the northern Oregon coastal region, NOAA has installed a tsunami-capable tide gage at Garibaldi, a location that provides more direct observation of incident tsunamis.

Nonetheless, eyewitness reports of the 1964 Alaskan tsunami (compiled by Tom Horning and described in the Appendix $C$ of this report) provide several tsunami runup values for this event at different Seaside locations. These are the best available tsunami field data for this location. The inundation measurements for this largest tsunami at Seaside are important, but they are not a comprehensive dataset to verify model accuracy. Changes in topography and bathymetry since 1964 create an additional difficulty in interpreting comparisons of the model simulations and field data.

The source of the 1964 Alaskan tsunami is modeled as a two-fault rupture with fault geometry and average slip values approximately corresponding to the analysis of Johnson et al. (1996). Detailed modeling of the 1964 event is beyond 


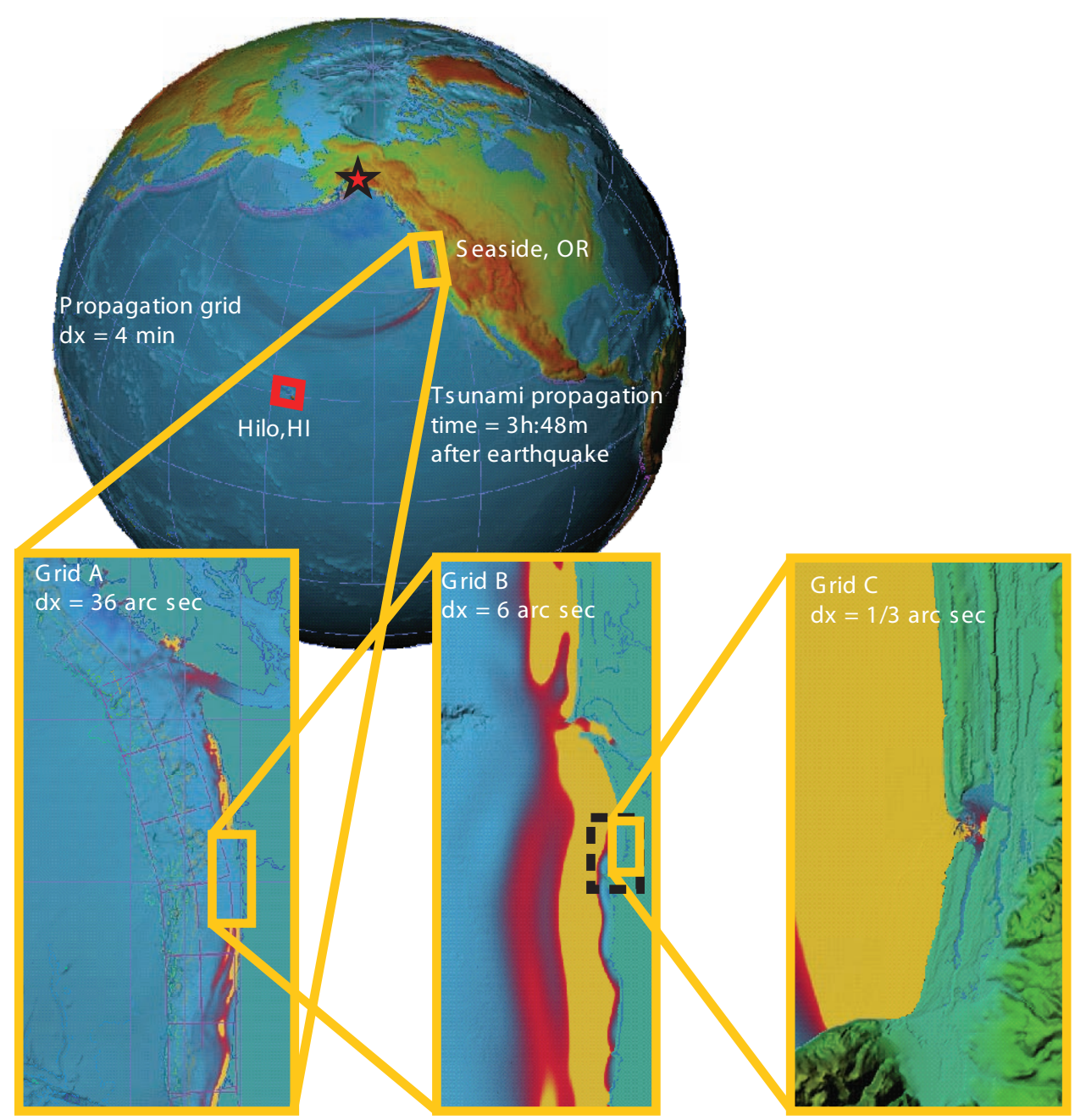

Figure 22: Schematic of nesting grids for Seaside, Oregon, used in numerical computations.

the scope of this study. The goal of this exercise is to accurately reproduce the far-field propagation pattern of this event. The sensitivity study (Titov et al., 1999) implies that a simplified source model for this event that reflects the geometry, location, and magnitude of this source generates a tsunami that accurately reproduces the 1964 Prince William Sound tsunami in the far-field. To verify this assumption, we compared this model of the 1964 tsunami with a tide gage record at Hilo, Hawaii. To accurately reproduce the tsunami dynamics at Hilo, a high-resolution grid was used for the tsunami simulation. The overall model setup was similar to that used for the Seaside model, and consisted of three telescoping grids (Fig. 23) that used propagation model output as input via the outer grid boundary shown in red on Fig. 22. The numerical model setup for Hilo has been tested against many historical events and has been shown to be a reliable reference for verifying general parameters of the tsunami sources. The results shown in Fig. 23 demonstrate that our propagation model of the 1964 tsunami compares well with the tide gage record. The amplitude 


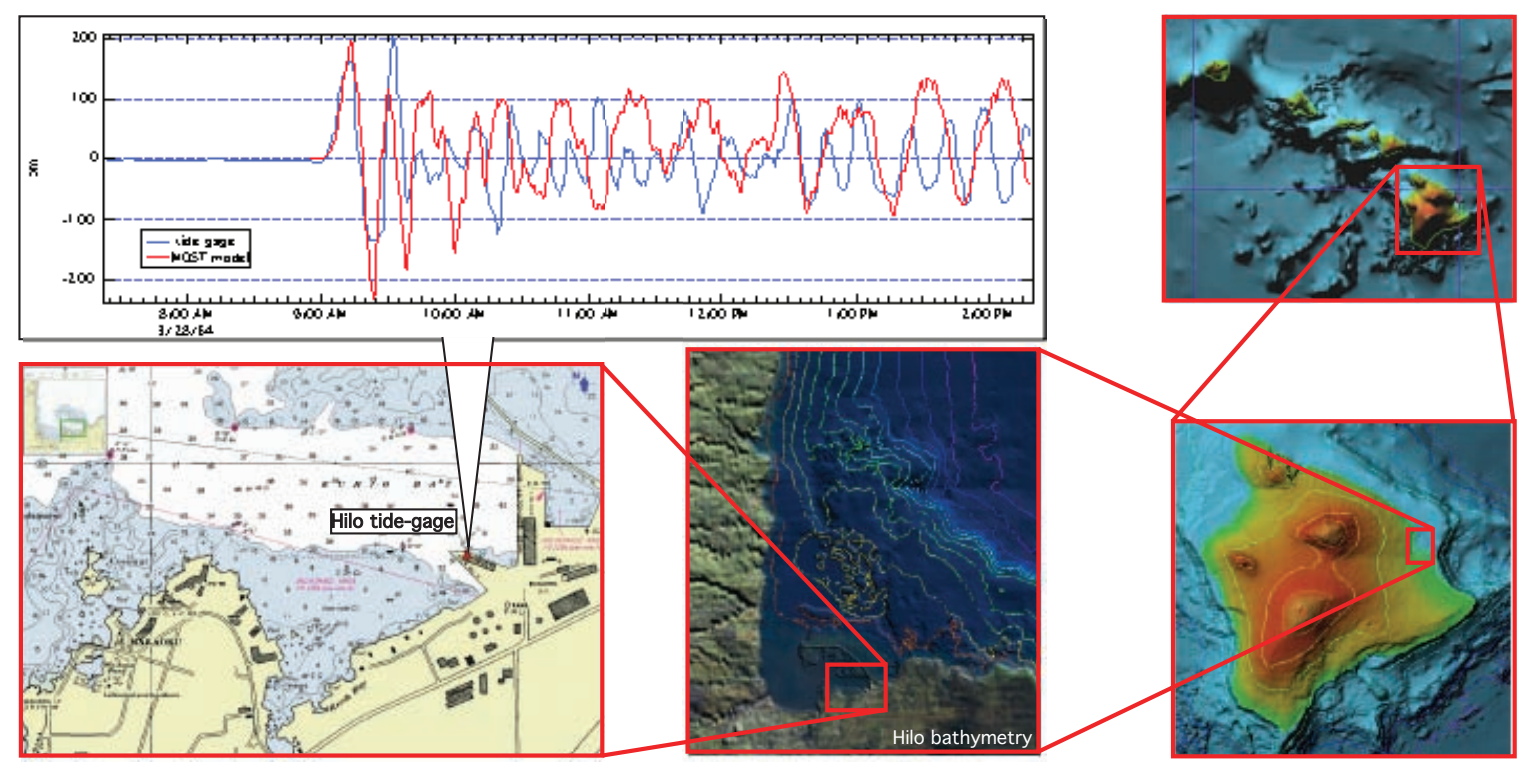

Figure 23: Schematic of nesting grids for Hilo, Hawaii, where the modeled 1964 tsunami is compared with tide gauge records.

and period of the first two waves match with the measured data. The first waves carry most of the information about the tsunami source magnitude and configuration. Therefore, the comparison at Hilo shows that our model source of the 1964 tsunami has proper amplitude and correct location. These are the two most important parameters of the source for reproducing the tsunami amplitude in the far-field (Titov et al., 1999). The good comparison with independent data at Hilo provides additional confirmation of the accurate representation of the 1964 tsunami at Seaside.

The comparison of modeled inundation of the 1964 tsunami at Seaside with the eyewitness accounts shows a qualitatively consistent picture. Figure 24 shows the computed inundation and the inundation inferred from the eyewitness accounts. The computed inundation shows a slightly larger inundated area; however, comparisons of the vertical runup values at the open coast show very good correspondence between measurements and model. The difference between the model inundation extent and the field estimates can be explained by many factors, including slight differences of coastal dune representation in the Digital Elevation Model used for this study and the actual topography in 1964. The most important value for this study is the predicted vertical amplitude values. The predicted runup for the 1964 tsunami compares well with measurements, which ensures the accuracy of the tsunami inundation model predictions. The Seaside inundation model of the 1964 tsunami was computed with two different grid resolutions of $30 \mathrm{~m}$ and $10 \mathrm{~m}$. The comparison of the results shows that computed vertical runup values are very similar for both simulations, while the horizontal extent of the inundation differs. The 30$m$ grid does not represent the coastal dunes accurately enough, which leads to extended inundation areas for waves that have smaller amplitudes than the height of the dunes. Therefore, the 10 -m grid was used for all far-field simulations, in which case the coastal dunes can block the horizontal extent 
of smaller amplitude waves. For the local tsunami sources, where the runup values are much larger, small-scale features like dunes do not make much difference in the horizontal inundation. The 30 - $\mathrm{m}$ grid with coverage of a larger area was used to account for much greater inundation distances.

Data for the 1700 Cascadia tsunami are much scarcer. Tsunami deposit data are the only indication of the size of the tsunami inundation area. Since topography and bathymetry could have changed significantly in 300 years, a direct comparison with the model data is very difficult. Our inundation results for the local tsunami sources (which are all potential scenarios for the 1700 event) show that computed inundation areas encompass the tsunami sediment locations. At least qualitatively, this indicates that our local inundation estimates are within the constraints of the available field data for such events.

\subsection{Database of Model Runs}

Computed tsunami inundation scenarios for Seaside are stored in a WWWaccessible database for further analyses. All computed variables (amplitude and velocity components) are saved at each time-step for the duration of the simulation.

These model data are available via Web interface using Live Access Server (LAS) technology (Fig. 25). The interface provides full access to all computed variables and additional tools for project researchers to conduct additional analyses.

\subsubsection{Discussion of model simulation results}

Analysis of the far-field tsunami source simulations revealed the strong influence of the directivity of tsunami propagation on runup amplitudes at Seaside. Directivity determines both the amplitude and the direction of the incident waves and, therefore, affects the degree of refraction and other effects of local and regional bathymetry and shoreline shape have on the characteristics of tsunamis at Seaside. Potentially important local and regional features include the Astoria Canyon, the bight between the Columbia River and Tillamook Head just south of Seaside, the Juan de Fuca Ridge, and seamount chains farther offshore. These bathymetric features are resolved in the DEM used to model tsunami propagation to Seaside. A detailed analysis of these effects has not been carried out. However, such an analysis would be helpful for interpreting the tsunami response in the Seaside area as a function of the source location.

Figure 26 illustrates the overall effects of different sources by comparing three different simulation results corresponding to Source Numbers 2, 3, and 5 in Table 6. The figure shows that these three simulation scenarios are for tsunami sources at similar locations (epicenters for these three earthquakes could very well be at the same location); all correspond to the same earthquake magnitude of $\mathrm{M}_{\mathrm{w}}=9.2$. Despite the seeming similarities of these source scenarios, the inundation simulations at Seaside show very different amplitudes (lower images). The difference is explained by different propagation directivity patterns for the three sources (upper images). The largest inundation at Sea- 


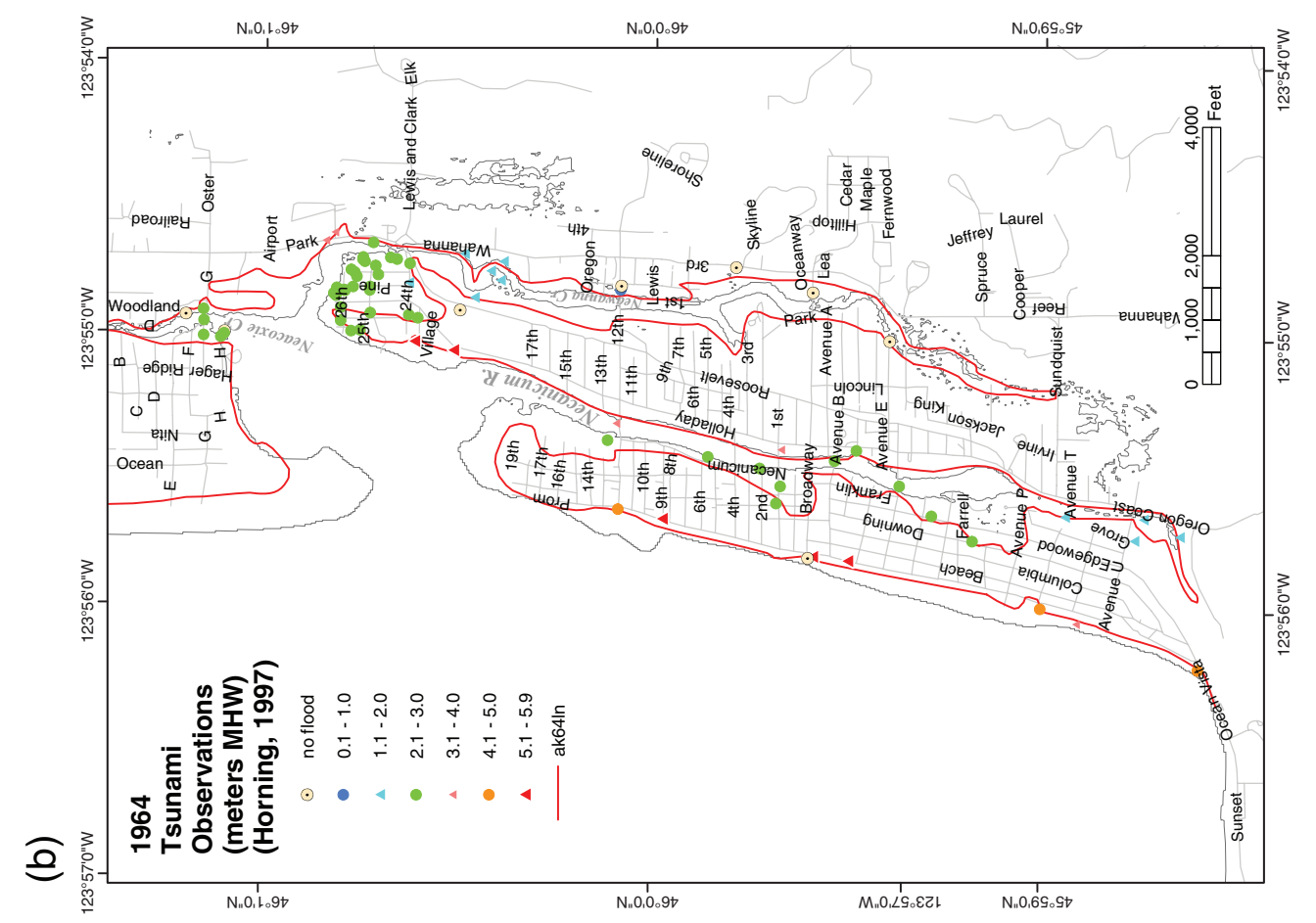

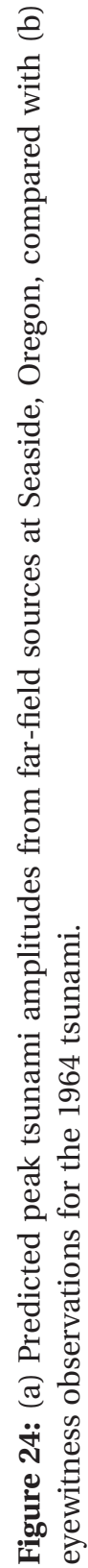

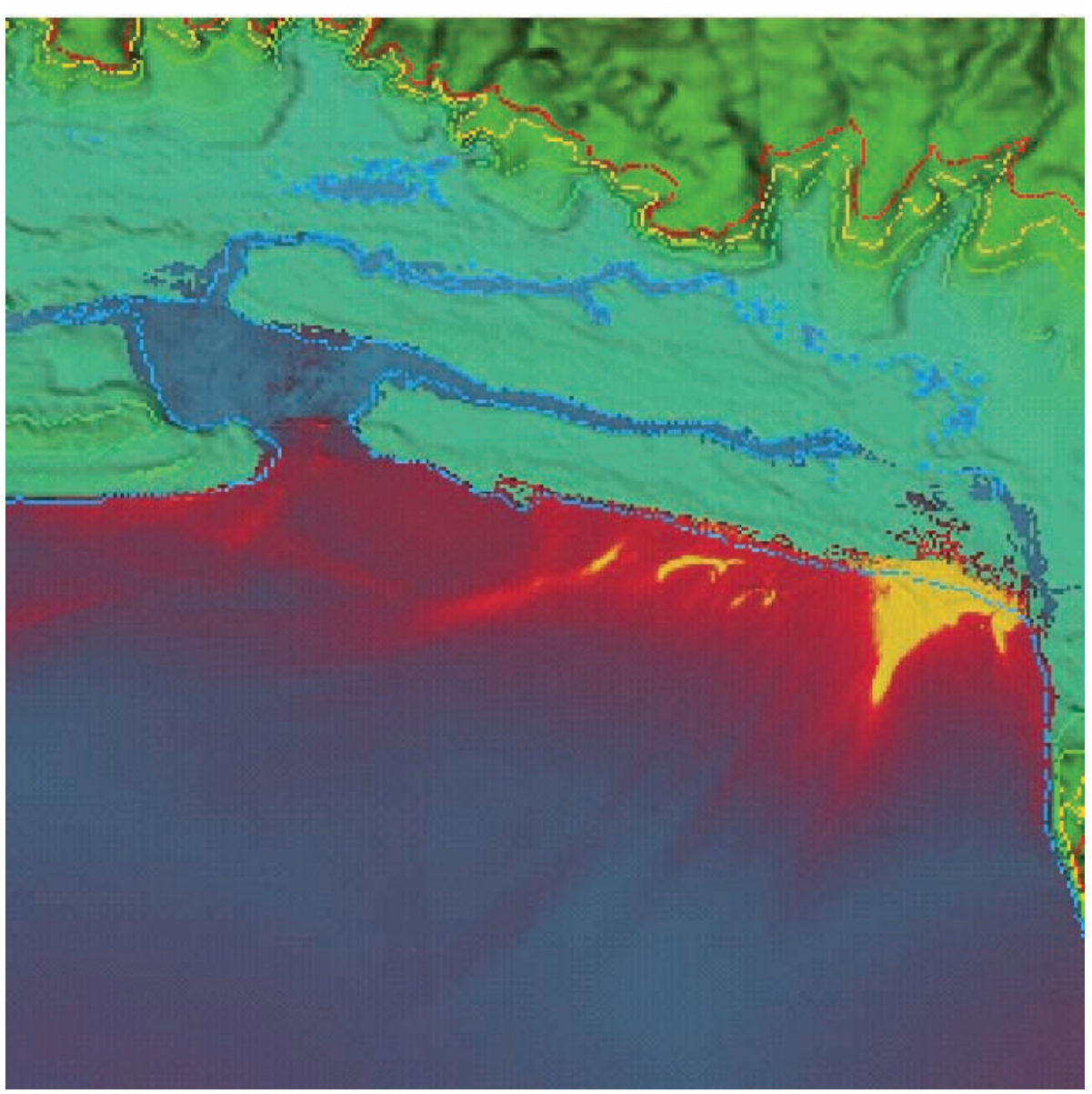



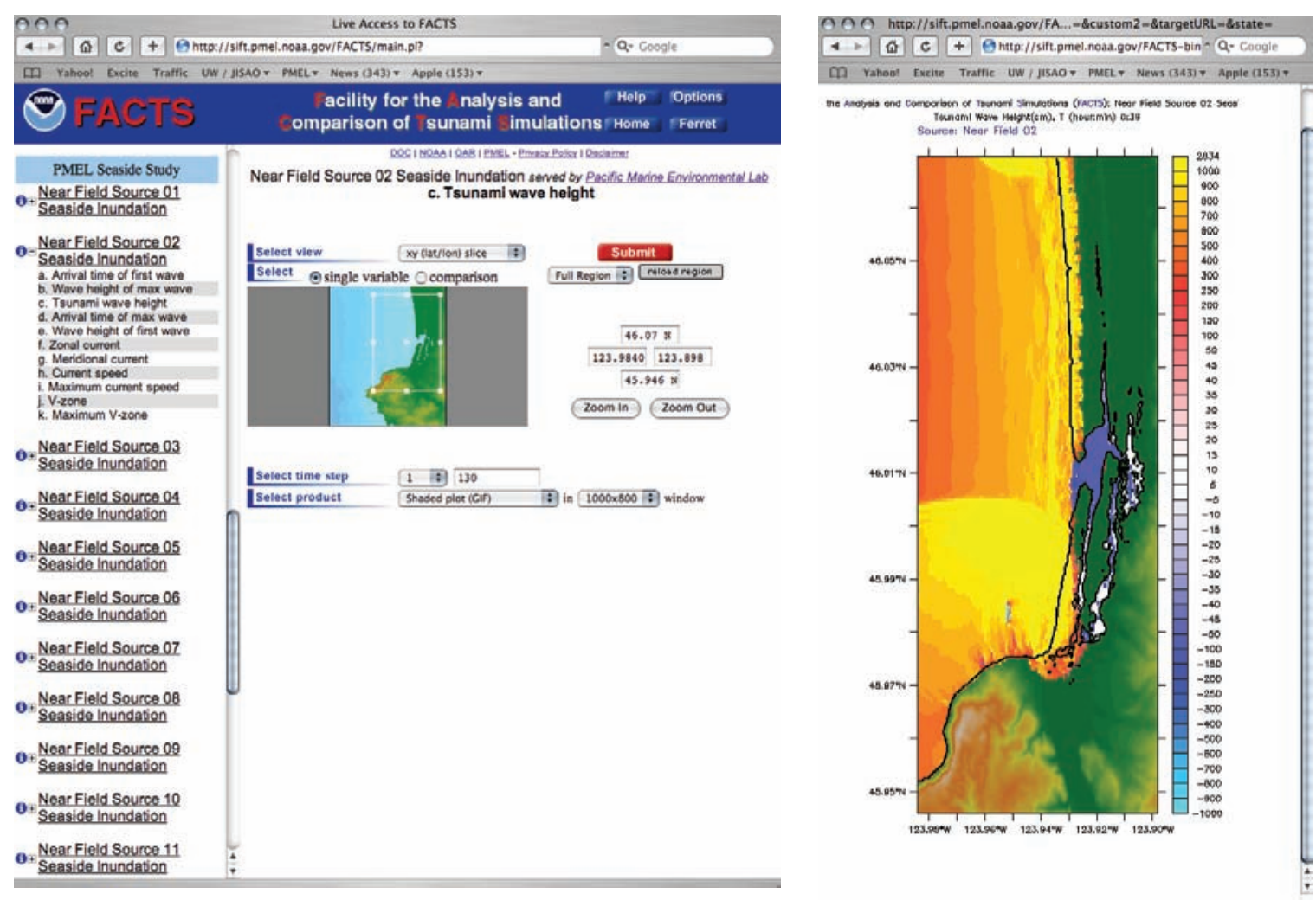

Figure 25: Screen-shot from FACTS database.

side among the chosen far-field sources is produced by the Alaskan source with the fault near Kodiak (the middle images). This source roughly corresponds to the rupture area of the 1964 Prince Williams Sound tsunami but have different slip distribution. This large inundation from the far-field source may not show up in the probabilistic inundation map for Seaside due to the lower probability of such a source. However, it should be noted that tsunami sources from this area in Alaska could produce large inundation at Seaside if this low-probability rupture does occur.

Currents cannot be neglected in tsunami hazard assessments, because the associated kinetic energy can be the most destructive aspect of a tsunami and very high currents can be associated with relatively modest wave height. Figure 27 illustrates this point for the far-field Source Numbers 3 and 5 of Table 6 . Note that regions of high currents frequently do not correspond to regions of high wave heights. The most obvious examples are in the river entrance and the adjacent bay area for both scenarios and, especially in the case of Source Number 3, on the peninsula south of the river entrance. This lack of correspondence between maximum wave heights and currents means that inundation maps of maximum wave height could be dangerously misleadingi.e., the overall tsunami hazard and destructive potential could be seriously underestimated in areas of modest wave height because destructively high currents were not taken into account. A more complete hazard assessment must employ "impact indices" or "impact metrics" that take account of both 

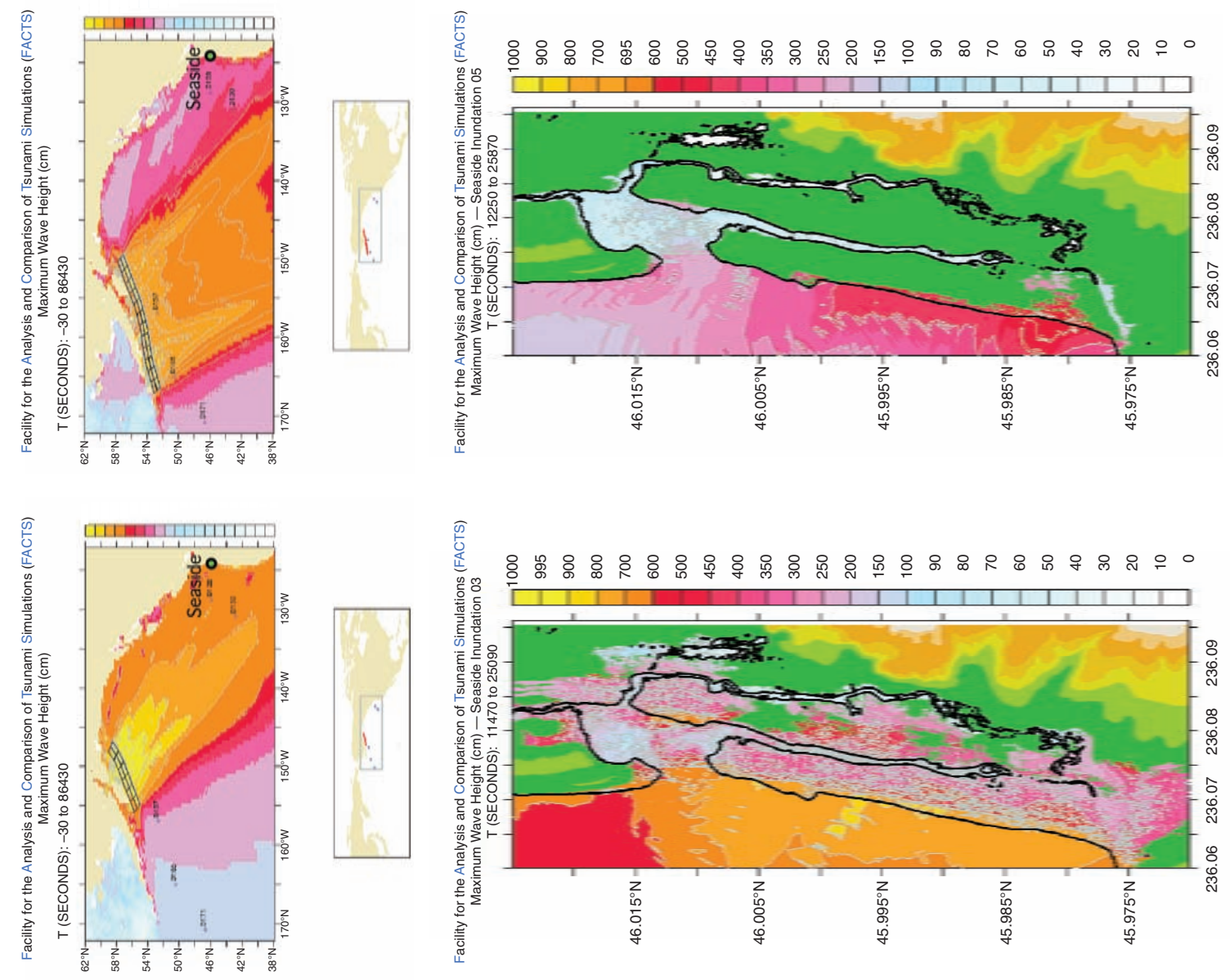

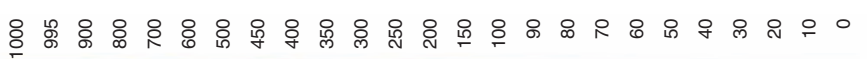
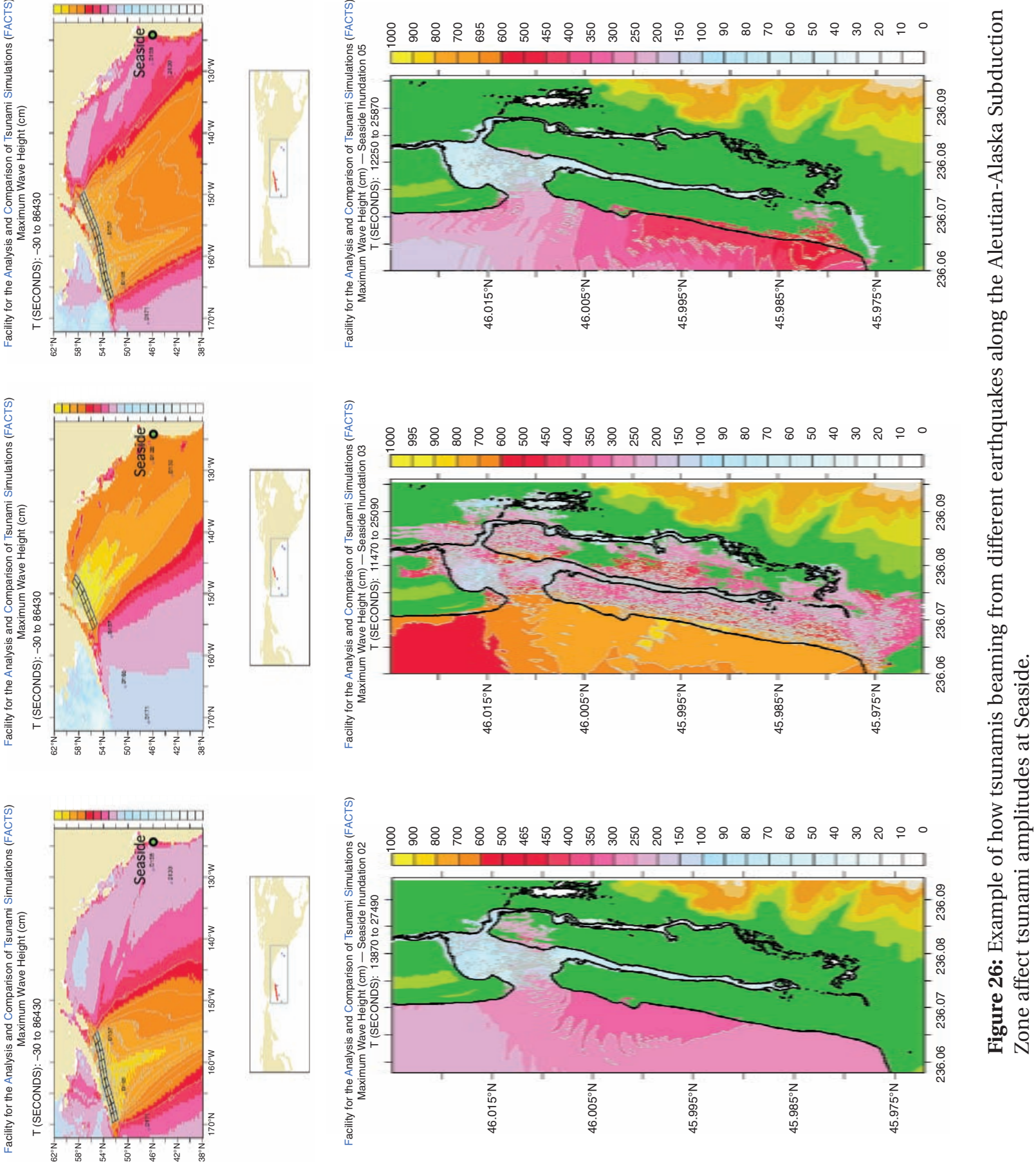
potential and kinetic energy, i.e., both wave height and currents. This topic is explored in Section 7, "Evaluating Tsunami Impact Metrics."

For local sources, in Fig. 28 we compare the inundation map derived from one of the slip distributions used for Cascadia Subduction Zone earthquakes described above to the inundation map derived from a uniform slip rupture model described by Priest et al. (1997) (their Model 1A). Although the magnitudes for these two scenarios is similar and the average slip used in Fig. 28a is similar to the uniform slip used for Fig. 28b, the distributed slip model results in significantly higher maximum wave heights. This is consistent with theoretical results (Geist and Dmowska, 1999) and the comparison presented in Priest et al. (1997) between the uniform slip model and the same model with an added Gaussian asperity (Model 1A-Asperity). The difference between the inundation maps derived from uniform slip and distributed slip source models is shown in Fig. 28c. 
(a)

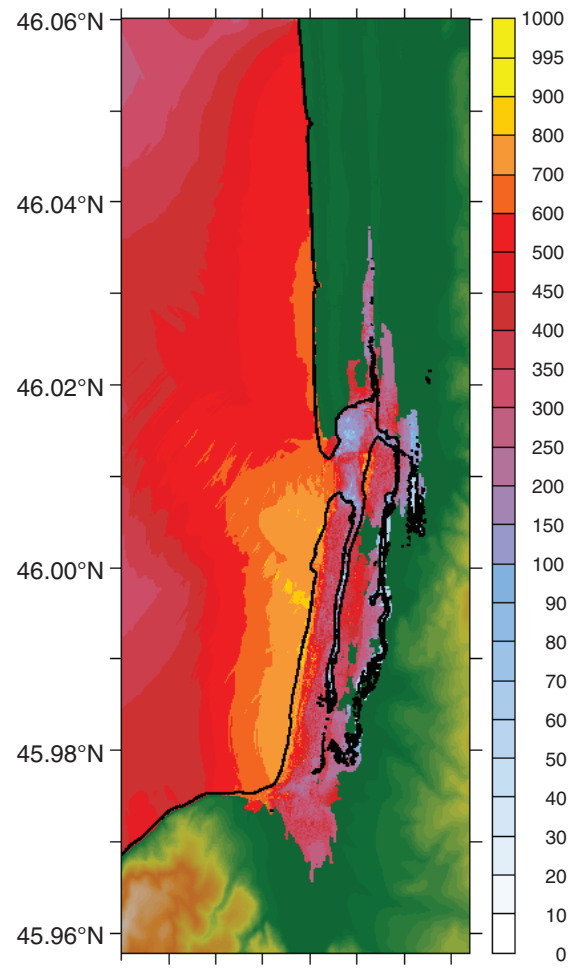

(b)

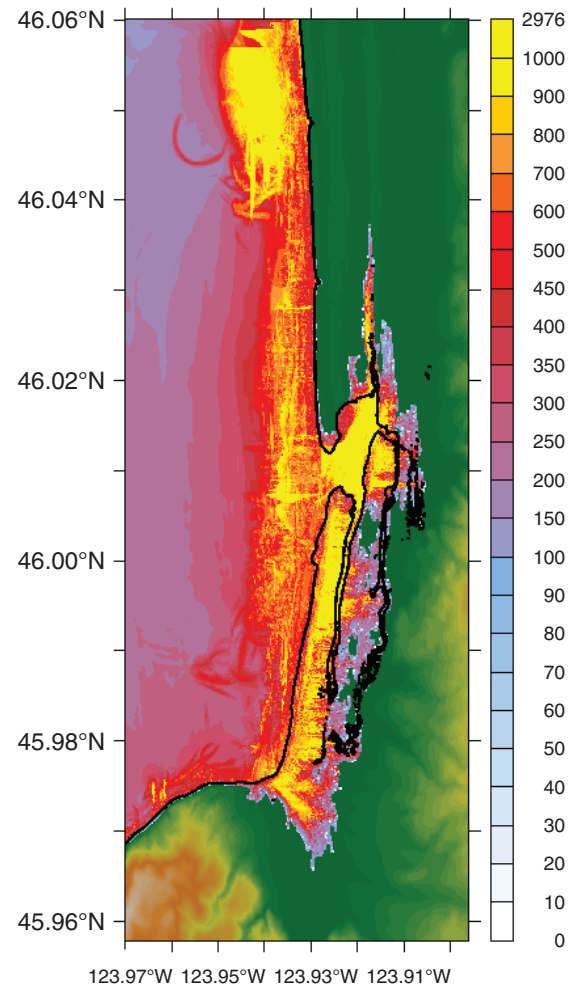

(c)

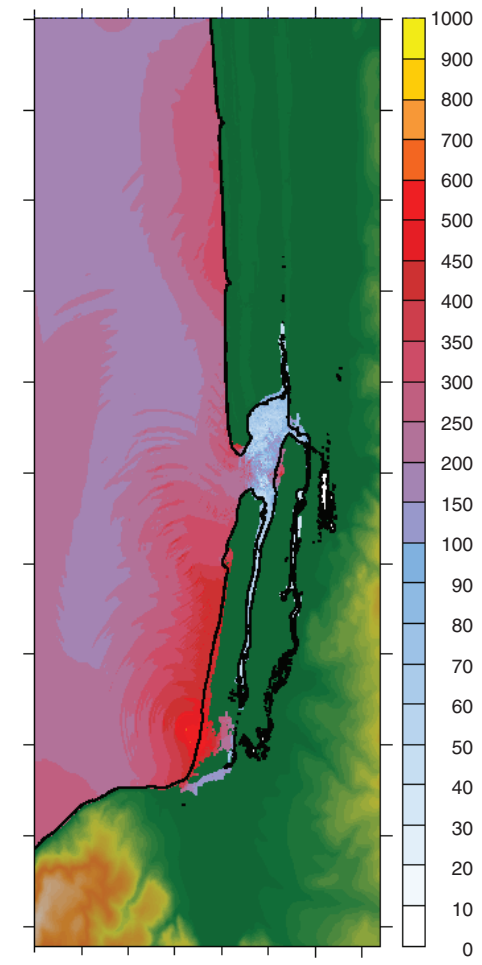

(d)

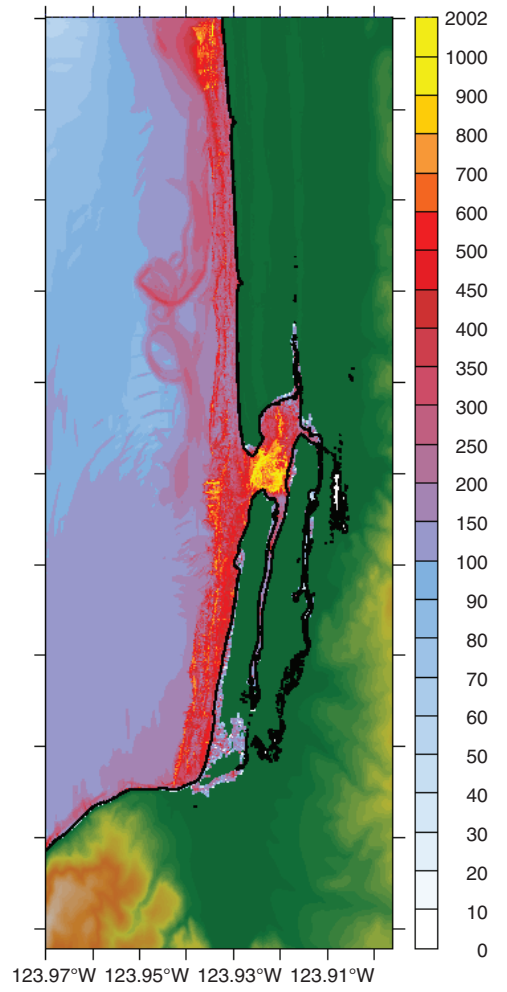

Figure 27: Maximum wave heights and currents for Sources 3 and 5 in Table 6. (a) Source 3 maximum wave height, (b) Source 3 maximum current speed, (c) Source 5 maximum wave height, (d) Source 5 maximum current speed. 
(a)

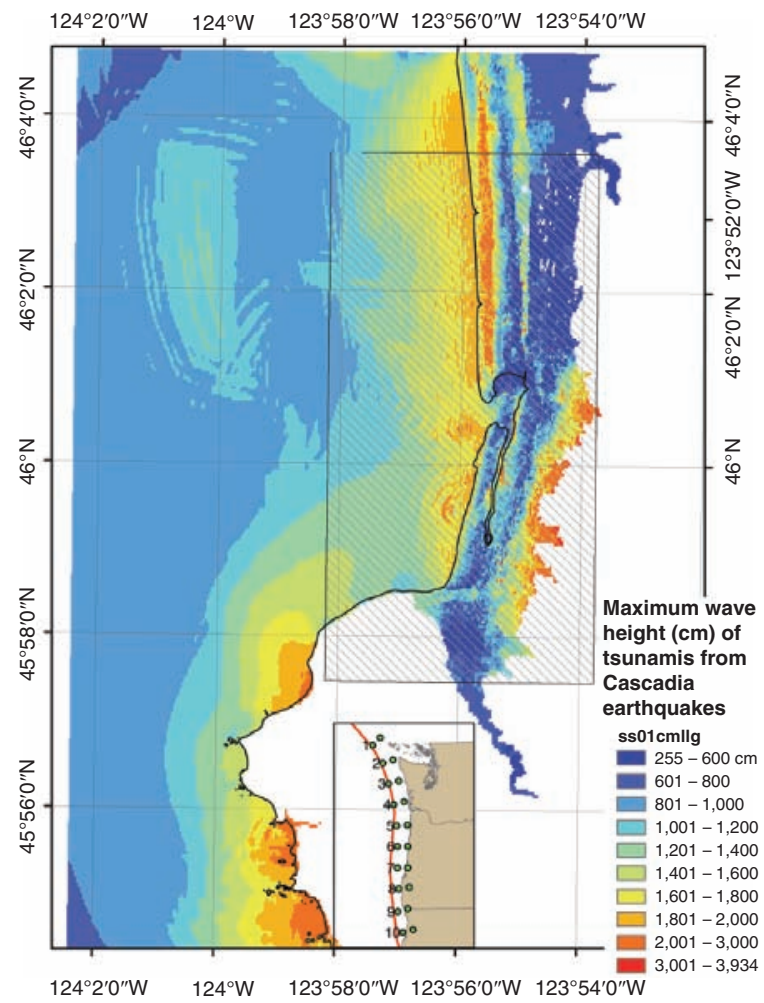

(b)

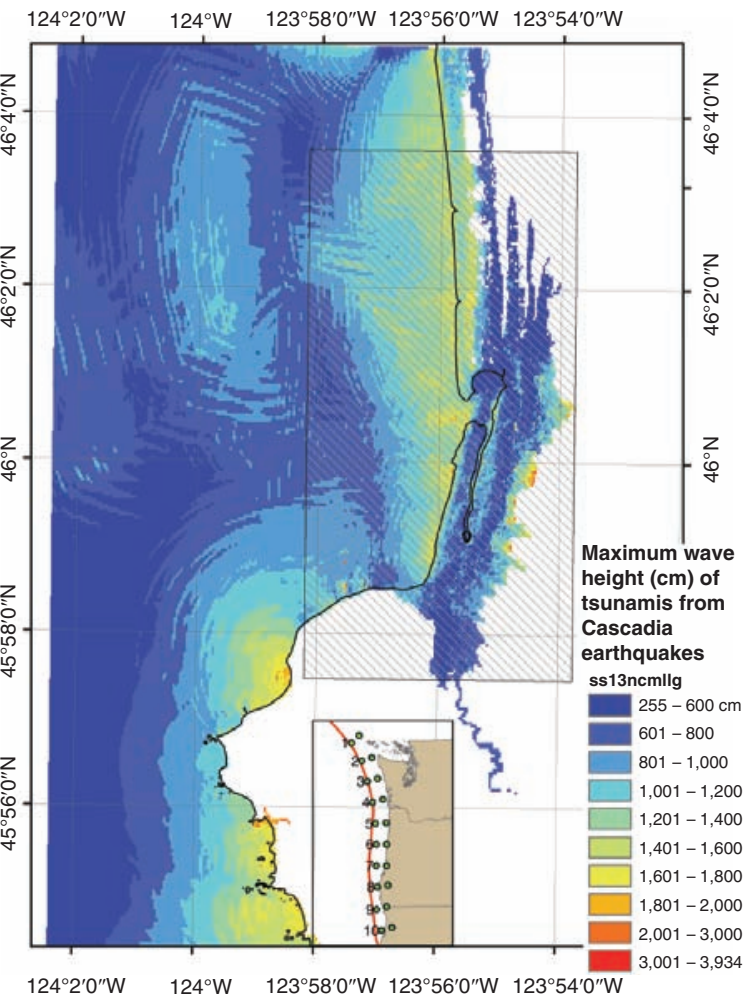

(c)

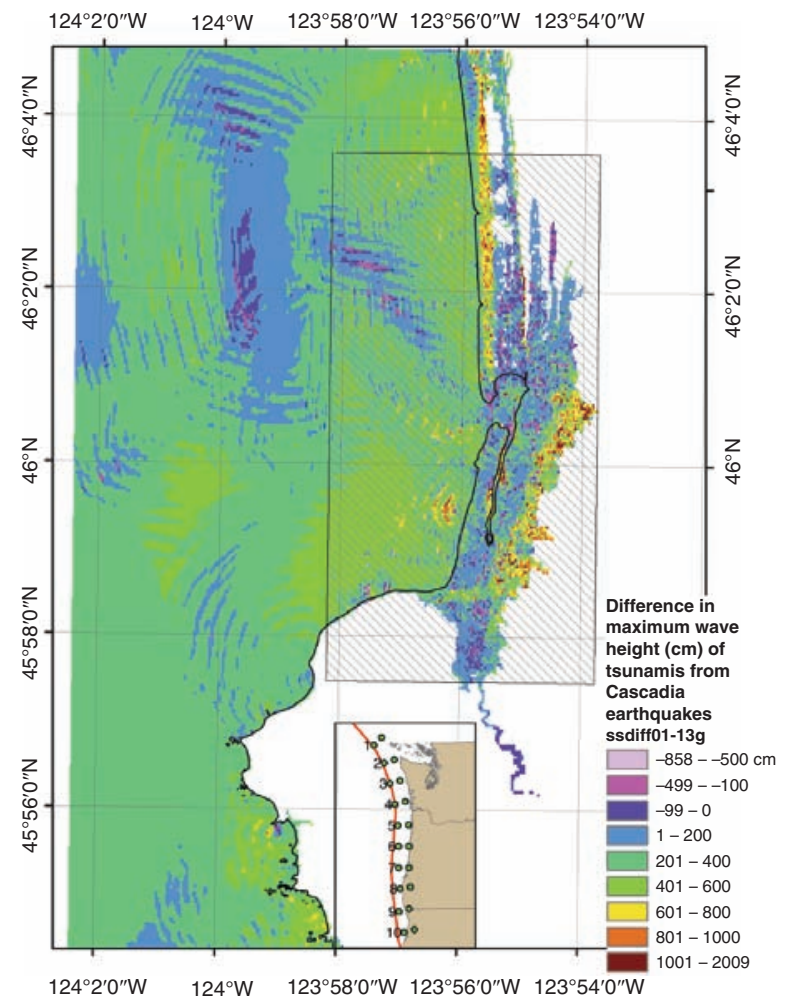

Figure 28: Comparison of inundation maps using (a) the distributed slip source described in this study with (b) the uniform slip source (Model 1A) described by Priest et al. (1997). Map (c) is the difference of wave heights between (a) and (b). 



\section{Evaluating Tsunami Impact Metrics}

SUNAMIS CAN GENERATE large onshore currents that can cause dramatic
damage to structures and move large objects far inland. The 26 Decem-
ber 2004 Indian Ocean megatsunami demonstrated tsunami impact on structures in a rather dramatic fashion. Historic examples of large tsunamis setting large objects in motion abound. The most notorious is the myth of the USN Watery, the ship moved by the 1868, Arica, Chile tsunami 2 miles inland and then moved back to shore during the 1877 Arica tsunami so that the ship could sail on. Actually, the ship was indeed transported inland, but the 1877 tsunami just moved it closer to the shoreline, where it still rests. During the 26 December 2004 megatsunami, at least two similar-size barges were moved inland in Banda Aceh and Lhok Nga in North Sumatra.

As a measure of what even a small tsunami can do, consider the 1994 Mindoro Philippines tsunami. In an area where the vertical inundation heights did not exceed $3 \mathrm{~m}$ ( $10 \mathrm{ft}$ ), the generated tsunamis floated a 6000 ton generating barge, broke its mooring lines, and carried it 1 mile inland down the Baruyan River. The impact of tsunamis on structures can be observed in detail in Discovery Channel's production "Tidal Wave" (1998). The estimation of impact forces and currents is still an art and far less understood than hydrodynamic evolution and inundation computations. In what follows, different methods and formulae in the literature are described, although none has been truly validated by comparisons with field data.

In terms of assessing FIRM $V$-zones (zones identifying velocities exceeding certain thresholds or areas of 100-year coastal floods), in addition to inundation zones, it is useful to evaluate different combinations of flow parameters. We name them impact metrics or damage indicators, in an effort to determine a single hazard zone that helps identify areas where structural safety needs to be considered in greater detail. For example, existing formulations recommended in FEMA's Coastal Construction Manual rely on riverine flooding results, and the flow velocity and forces inferred through largely empirical relationships involving only the flow depth. Tsunami flow patterns can be counterintuitive even for fairly simple topographies of a plane beach as in Banda Aceh. During the 2004 megatsunami, particle image velocimeter techniques helped identify flow velocities $3 \mathrm{~km}$ inland, which suggest that the larger the depth the larger the velocity. Further, the topography of Seaside is quite unique, particularly because of the presence of the sand-spit within the broader Seaside bay, which is fronted by another sandspit. The setting is as different from the canonical geometry of a one-dimensional wave climbing up a sloping beach, described by Synolakis (1987), as one can be. As shown 
recently by Carrier et al. (2003), even for the simple geometry of the canonical problem, the highest velocity does not occur at the same location as the highest inundation depth, and the location of the region of highest velocity depends on the incoming wave, hence on the particular scenario under study.

We will describe here existing formulations to calculate forces on structures to help motivate our choices of combinations of flow parameters, acceleration, velocity, depth, amplitude, and front velocity that may be relevant in tsunami $V$-zone assessment. Not unexpectedly, perhaps, the momentum flux parameter appears to be the most useful for engineering applications in identifying regions where the flow forces may possibly be larger than otherwise anticipated from existing formulations. The present inundation results for Seaside for specific far-field and near-field inundation events as discussed in this report have guided this choice of the boundaries of the $V$-impact zone.

\subsection{Forces on Structures}

In principle, the calculation of wave forces on structures involves the integration of the pressure and of the shear force over the exposed area of the structure during the wave motion. To understand the development of the damage metrics, we consider first the simplest possible geometry, which involves the calculation of the instantaneous wave force at time $t$ on a cylindrical pile of radius $R$, in the direction of the wave propagation. Given a pressure $p(R, \theta, z, t)$ and a tangential shear stress $\tau_{r \theta}(R, \theta, z, t)$, then the force is given by

$$
F_{T}(t)=\int_{0}^{\eta_{p}+h_{p}} \int_{0}^{2 \pi} p(\theta, z, t) R \cos \theta d \theta d z+\int_{0}^{\eta_{p}+h_{p}} \int_{0}^{2 \pi} \tau_{r \theta}(\theta, z, t) R \sin \theta d \theta d z .
$$

Here, $\eta_{p}$ and $h_{p}$ are the local amplitude and undisturbed water depth at the pile, respectively, with the assumption that they do not vary significantly over the pile diameter, hence their dependence on the radius $R$ is not shown in the arguments. Tsunamis are long waves, and indeed the flow parameters do not vary significantly over small distances, such as those typically encountered in coastal structures.

In practice, for all but the simplest steady flows, determining either the pressure or the tangential shear stresses through calculation of the velocity gradients is impossible at this state of knowledge, as it involves solution of the Navier-Stokes equation. Shallow-water wave (SW) equations used in inundation mapping are depth-averaged approximations of the Navier-Stokes equations for inviscid flow, and there are no velocity gradients perpendicular to the axis of the pile, that is, there is no depth variation. The classic simplification is to consider a mass coefficient $C_{M}$ that incorporates some of the dynamic pressure effects, and a drag coefficient $C_{D}$ which in turn accounts for the form drag that results from flow separation and incorporates all the effects of the viscous forces on the cylinder. In terms of these coefficients, the force on a cylinder is given by

$$
\vec{F}_{T}(t)=\int_{0}^{\eta_{p}+h_{p}} \pi C_{M} \rho R^{2} \frac{d \vec{V}}{d t} d z+\int_{0}^{\eta_{p}+h_{p}} C_{D} \rho R \vec{V}|\vec{V}| d z .
$$


Here $\vec{V}$ is the instantaneous horizontal velocity in the direction of wave motion, while $d \vec{V} / d t$ is the instantaneous water particle acceleration. Clearly $\vec{F}$ is a vector in the same direction as the velocity vector $\vec{V}$, hence, again the force given by (7.2) is in the direction of wave propagation. The absolute value is used to underscore that the force may change direction as the water particle velocity changes direction. For example, $\vec{V}=u \vec{i}+v \vec{j}$ and $V=|\vec{V}|=$ $\sqrt{u^{2}+v^{2}}$ with $u, v$ the horizontal particle velocities in $x, y$. If the flow is primarily one-dimensional and onshore, $\vec{V}=u \vec{i}$, and $u$ is positive under the crest and negative below the crest, if $x$ is pointing toward the pile. Dean and Harleman (1966) note that the expression (7.2) for the drag force was determined empirically for steady flows, yet for lack of better knowledge, the same formulation is used for strongly unsteady flows such as the impact of bores and surges. In these cases, the coefficients $C_{D}$ and $C_{M}$ have to be carefully evaluated. The variation of $C_{D}$ with the Reynolds number $R e=u D / v$ is shown in Fig. 8.2, page 344, in Ippen (1966). In the range of $10^{3}<R e<5 \times 10^{5}$, then $C_{D} \sim 1$. We note that $C_{D}$ does depend on the roughness of the cylinder, although for tsunamis a usual assumption is that the pile is hydrodynamically smooth, given the wavelength of the tsunami wave train.

There are a few cases where (7.2) can be used directly to calculate tsunami forces. As an example, consider small amplitude wave theory. This theory is irrotational, requiring that the curl of the velocity vector is zero vector $(\nabla \times \vec{V}=$ $\overrightarrow{0}$ ), an assumption which is not correct when waves are breaking. Shallow water wave theory (SW) is also irrotational, with no vertical velocity gradients perpendicular to the direction of wave propagation. However, shallow water wave theory is valid for larger amplitudes, for $L / h_{p} \gg 1$, while small amplitude theory applies when $a / h_{p} \ll 1$. Assuming that the pile is located at $x=0$, and assuming a wavenumber $k=2 \pi / L$ and celerity $\sigma / k=\sqrt{g h_{p}}$, then

$$
F_{T}(t)=-\rho g\left(\pi R^{2} a k h_{p}\right) C_{M} a \sin (\sigma t)+\rho g C_{D} a^{2} R \cos (\sigma t)|\cos (\sigma t)|,
$$

with the understanding that (7.3) is valid for small-amplitude long waves. Dean and Harleman (1966) note that the inertial force is inversely proportional to the period, while the drag force is independent of the period. Equation (7.3) might be an adequate approximation for calculating forces on piles offshore for tsunamis generated by far-field earthquakes or by landslides, that is, for tsunami wave trains with more than one wave. For tsunamis generated in the near-field, where there is not sufficient distance for a wavetrain to fully emerge, then these equations can only be used with caution.

The total moment is formally calculated from $M_{T}(t)=\int_{0}^{\eta_{p}+h_{p}} z F_{T}(t) d z$, that is, it is the first moment of the force from the ocean floor to the free surface. To the same level of approximation as (7.3), then

$$
M_{T}(t)=\frac{1}{2} \rho g C_{D} R a^{2} h_{p} \cos (\sigma t)|\cos (\sigma t)|-\frac{1}{2} \rho g C_{M} \pi R^{2} a k h_{p}^{2} \sin (\sigma t) .
$$

Note that consistent to the SW approximation, the moment is equal to the force times a moment arm of $h_{p} / 2$, given that SW implies that the force is uniform 
over the depth. Note also that the drag force does not depend on the period of the wave motion.

Impact forces on structures are calculated by different methods depending on whether or not the breaking wave forms a surge or a bore. On the vertical front face of a structure, they have been traditionally estimated using the classic formula of Cross (1967). He proposed that the force on a $b$ wide seawall is given by

$$
F_{\text {wall }}(t)=\frac{1}{2} \rho g b \eta^{2}\left(x=X_{w}, t\right)+C_{f}(t) \rho b \eta\left(x=X_{w}, t\right) C^{2}
$$

where $\eta_{w}=\eta\left(x=X_{w}, t\right)$ is the water surface elevation on the wall located at some $x=X_{w}, b$ is the width of the wall, $C$ is the surge or bore velocity and $C_{f}=\left(1+\tan ^{1.2} \theta\right)$ is a computed force coefficient. $\tan \theta$ is the slope of the front face of the bore as it impacts the wall. For practical applications, Cross suggested calculating $\eta\left(x=X_{w}, t\right)$ as if the wall were not there, that is, the bore would pass through the wall relatively unchanged. In computational terms, this implies using a numerical code without the structure present, and then using the calculated values and applying them on the structure. This may well be a good assumption if there is sufficient distance between structures. Even if it is not a good assumption for a densely built town such as Seaside, the objective here is to identify a damage metric that captures the $V$-zone and not to calculate individual forces.

$C_{f}(t)$ could be a function of time, since the front slope of the wave may change as the wave evolves. Ramsden and Raichlen (1990) reformulated the same equation and integrated laboratory measurements to calculate values for $C_{f}$ in terms of the bore strength $H / h_{p}$, the ratio of the bore height $H$ to the local depth $h_{p}$, recognizing that the wave height at the front face of the structure might be difficult to calculate a priori.

Ramsden (1993) points out that when $b / H \sim 1$, then three-dimensional effects dominate and are believed to reduce the overall force. On the other hand, when $b \ll H$, that is, the width of the wall is smaller than the effective crest length of the wave, the force is thought to be primarily the drag force. When overtopping occurs, that is, the wall height is smaller than the expected runup $R$. The resulting forces might be significantly less. Since there are no established and validated formulas for overtopping, at least this theory provides a worst-case scenario for the forces on the wall.

The limitations of calculating tsunami forces and moments from (7.3) and (7.4) are obvious when the tsunami evolves over dry land, which is the region of interest for developing high-hazard zones. One then has to rely on (7.4) using results from shallow water wave theory, with the numerical predictions for the depth-averaged $u$ and $v$, substituted directly into (7.2) with $V^{2}=u^{2}+v^{2}$.

Calculating the $x-y$ tsunami current distributions and magnitudes and their time variation is possible using numerical solutions of the SW equations and was done in this study. However, harbor resonances effects, breakwaters, and seawalls with characteristic sizes smaller than the grid spacing are transparent to the numerical computations. For example, a typical grid size $\Delta x, \Delta y \sim 100 \mathrm{~m}$ (333 ft) will miss all coastal structures smaller than $100 \mathrm{~m}$, unless the grid is positioned appropriately. This is not as simple as it appears, 
for numerical grids are calculated so as to model the hydrodynamic evolution correctly by attempting to maintain a constant number of grid points per wavelength as the wavelength changes.

Recently, Hughes (2004) revisited the radiation stress parameter $S_{x x}$ perpendicular to the wave motion per unit wavelength as proposed by LonguetHiggins and Stewart (1964),

$$
S_{x x}=\frac{1}{L} \int_{0}^{L} \int_{0}^{h_{p}+\eta(x)}\left(p_{d}+\rho u^{2}\right) d z d x,
$$

$p_{d}$ is the dynamic pressure and $u$ the horizontal particle velocity. The radiation stress is averaged over one wave period. For small amplitude wave theory and a periodic wave of the form $\eta(x, t)=a \sin (k x-\sigma t)$, then

$$
S_{x x}=\frac{1}{2} \rho g a^{2}\left(\frac{1}{2}+\frac{2 k h_{p}}{\sinh 2 k h_{p}}\right) .
$$

Hughes (2004) proposed the momentum flux parameter

$$
M_{t}(x, t)=\int_{0}^{h_{p}+\eta(x)}\left(p_{d}+\rho u^{2}\right) d z,
$$

as characterizing the flow kinematics better than other parameters. He noted that at the front surface of a perfectly reflecting seawall, $M_{t}$ is the instantaneous dynamic force. Note that rewriting the momentum flux parameter $M_{t}(x, t)$ for SW waves, that is, if one performs the integration in (7.8), one obtains

$$
M_{t}(x, t)=p_{d}\left(\eta_{p}+h_{p}\right)+\rho u^{2}\left(\eta_{p}+h_{p}\right) .
$$

Observing that the instantaneous dynamic pressure gradient in $z$ reflects the instantaneous fluid acceleration in $z$, equation (7.9) is reminiscent of the force equation for the total force on a pile. Rewriting (7.3) for shallow water waves where both $\vec{V}$ and $d \vec{V} / d t$ are depth-independent, then

$$
\vec{F}_{T}(t)=C_{M} \rho R^{2} \frac{d \vec{V}}{d t}\left(\eta_{p}+h_{p}\right)+C_{D} \rho R \vec{V}|\vec{V}|\left(\eta_{p}+h_{p}\right) .
$$

All earlier results have been developed for steady state flows, and are usually applied to calculate forces on piles and coastal structures subject to storm waves. Tsunamis are transient waves. For the purpose of determining tsunami impact zones, and consistent with both (7.9) and (7.10), we conjecture that tsunami forces can be thought of as consisting of two parts, an inertial component (proportional to depth times acceleration) and another due to the dynamic effects of the moving flow (proportional to depth times velocity squared). Once the accelerations and current velocities are known, drag $C_{D}$ and inertial mass $C_{M}$ coefficients can be determined for the specific shapes of structures, depending on the zone boundaries. Damage metrics of use in planning and possibly zoning, must reflect the distribution of the force over the entire impacted area and identify areas of exceptional force. Therefore, the following parameters are of interest in assessing tsunami impact: 
- the flow depth $h=\eta_{p}+h_{p}$,

- the current speed $V^{2}=u^{2}+v^{2}$,

- the acceleration $d \vec{V} / d t$,

- the inertial component $h d \vec{V} / d t$,

- and the momentum flux $h V^{2}$.

Since $V$-zones must reflect the hazards, we use the detailed inundation computations for both near-field and far-field scenario events that may impact Seaside to make detailed calculations of the four different damage metrics over the entire region, and compared their distributions. We note that while the tsunami evolves in the surf zone, the speed of the front decreases as the depth decreases. However, the flow is accelerating. In this case, the relevant velocity is the depth-averaged flow velocity. Once the tsunami hits the initial shoreline, the front suddenly accelerates. This phenomenon was explicit in many earlier investigations (Synolakis, 1987), but only recognized after Sumatra 2004. It appears to be one of the reasons why tsunami victims appear mesmerized into inaction, as they are seen in countless videos from the 2004 tsunami to watch the tsunami front approaching. They seem to expect that it will continue moving on dry land with a similar diminishing speed (Synolakis and Bernard, 2006). $V$-zones must reflect the largest velocity, i.e., the flow velocity offshore, and the velocity of the moving tsunami front on dry land.

While one might have expected that regions of large flow depths might correlate with regions of large velocities, this is not always the case. For example, as a tsunami evolves over dry land, the flow depth decreases up to the point of maximum runup, and the velocity of the shoreline tip becomes zero. Here, both $h$ and $V$ are small. During rundown, the flow depth remains small, but the current speed can be substantial, leading to higher $h V^{2}$ values in regions of the flow field that are unexpected, as suggested in a simple onedimensional setting by Carrier et al. (2003). The acceleration $d \vec{V} / d t$ may diminish as the wave runs up, but may be substantial during rundown.

The distribution of the above four parameters for both near-field and farfield events for Seaside suggests that while individual differences exist among the different scenario events, the momentum flux represents the most suitable damage indicator. In contrast to what one might have expected based on 1dimensional considerations for overland flow over a narrow spit of land, flow velocities appear to correlate well with inundation depths over the two sand spits in Seaside. Hence, the momentum flux shows a similar distribution as the inundation depths and currents. While small-scale differences exist, overall, the inertial component appears to have a similar geographical distribution as the momentum flux. We therefore recommend that the momentum flux be used as a determinant for the $V$-zone.

We note that our results are based on calculating the parameter $V^{2} / g h$, where $h$ is the entire depth. During the calculation of tsunami propagation and inundation, this parameter was calculated every time step, allowing direct construction of a map of its distribution of maximum values to guide the $V$ zone. We recommend that all future inundation mapping studies monitor this parameter, in addition to archiving $u, v, \eta$ for all times. We also recommend 
that, whenever possible, the moving front velocities be monitored and that the normalized momentum flux parameter $V^{2} / g h$ be calculated using the front velocity. The higher of the two values, the one based on the flow velocity and the other based on the front velocity, should be employed in the maps. Maps of the $V$-zone can then be used to identify areas of higher risk, where a detailed analysis using time histories of $u, v, \eta$ at the specific locations would be useful. 



\section{Results}

\subsection{0-Year Tsunami Map}

$\mathrm{U}$ SING THE METHODS DESCRIBED above, Fig. 29 and Plate $1 \mathrm{~b}$ show the tsunami wave heights, including tides, that are met or exceeded at an annual probability of $P=0.01$. For brevity, we will call this the 100-year tsunami map. A common feature in all the maps is an increase in the offshore wave height as the water depth decreases toward the outer coast. This is a direct effect of shoaling of the long waves. Inside the estuary, the hydrodynamics are more complex. For the 100-year tsunami map, there is little inundation of the developed areas in the study region. The region of coastal dunes south of the estuary mouth (that is, along the Promenade) are high enough in elevation to block most of the far-field tsunamis. Although a few of the far-field earthquake scenarios resulted in significant areas of inundation (for example, Source 3, Table 6, where the 1964 Alaska earthquake occurred), the 100-year tsunami map shows little inundation because the average interevent times for these earthquakes are substantially longer than 100 years.

As a sensitivity test to see what effect our choice of segmentation models for Aleutian-Alaska Subduction Zone earthquakes has on the 100-year tsunami map, we compare the results in Fig. 29 with a similar map in which only Segmentation Model 1, which includes the 1964 source region (Fig. 13), is used (Fig. 30b). (Correspondingly, the weight for Segmentation Model 1 was changed from 0.5 to 1.0.) Figure 30a is the 100-year map shown in Fig. 29. Although there is a slight increase in the wave heights using just Model 1 for Aleutian-Alaska earthquakes, there is no significant increase in regions that are inundated by the tsunamis.

\subsection{0-Year Tsunami Map}

In a similar manner, the 500-year tsunami map was constructed and represents wave heights that are met or exceeded at an annual probability of $P=0.002$ (Fig. 31, Plate 1c). In stark contrast to the 100-year tsunami map, the 500-year tsunami map shows large regions of inundation with significant wave heights throughout Seaside. The 500 -year tsunami map is dominated by the tsunami generated by a local Cascadia Subduction Zone earthquake. For reference, the region of inundation indicated by the 500-year tsunami map includes most of the localities where tsunami deposits from the 1700 Cascadia tsunami were found (Fig. 10).

Because the 500-year tsunami map is dominated by local Cascadia tsunamis, uncertainties in the corresponding earthquakes are likely to have a 


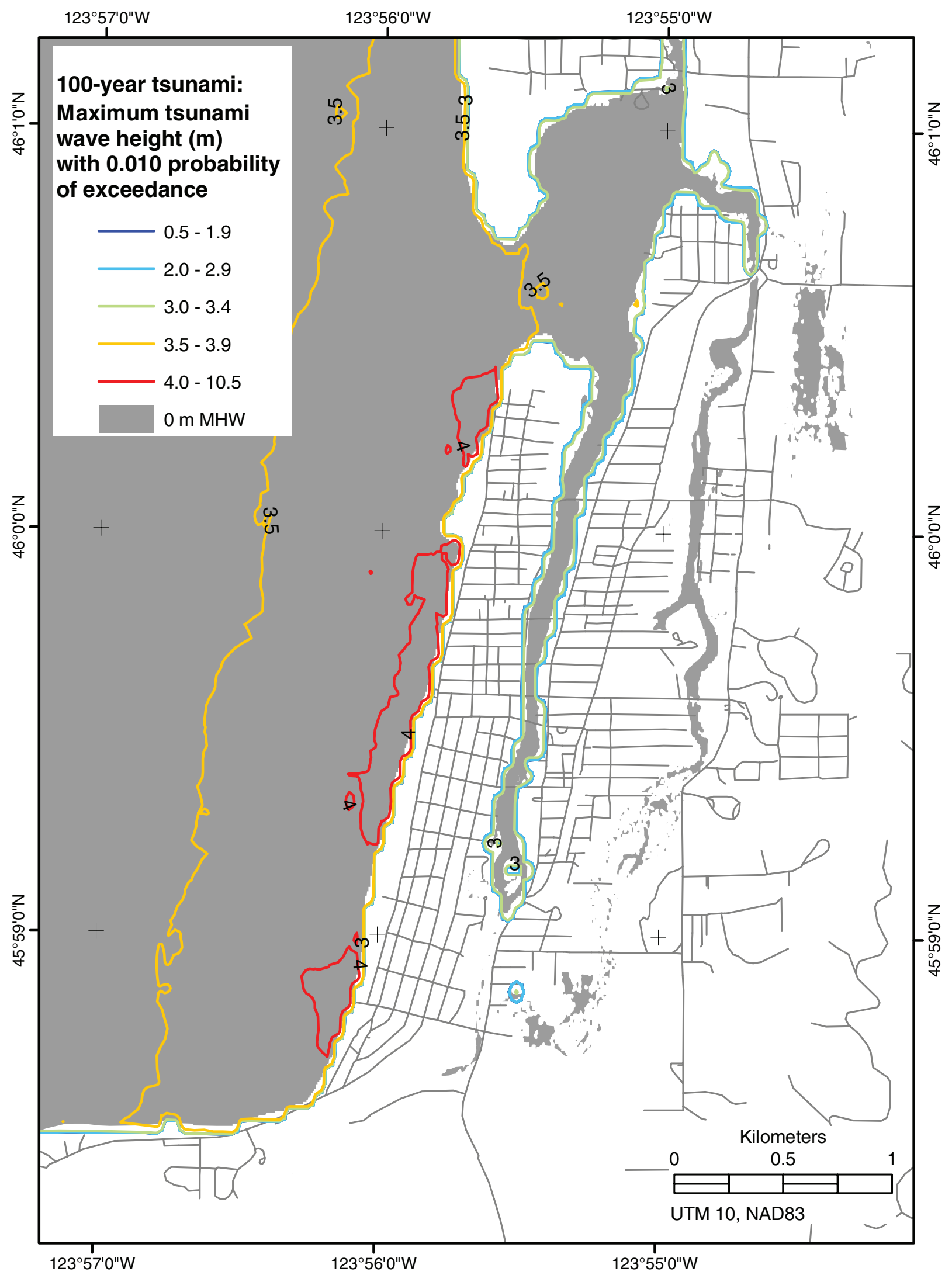

Figure 29: Tsunami wave heights $(\mathrm{m})$ with a $1 \%$ annual probability of exceedance. Wave heights include the effects of tides. 
large influence. Some of the epistemic uncertainties associated with these earthquakes are discussed in Geist (2005) and in the section below. In Fig. 32, we explore how uncertainty in the mean inter-event time for these earthquakes affects the 500-year tsunami map. Figure 32a is the 500-year map shown in Fig. 31. Two other estimates for mean inter-event times, 477 years and 610 years, that fit the paleoseismic observations (Fig. 17) are shown in Fig. 32b and 32c, respectively. The shorter mean inter-event time (477 years, Fig. 32b) results in significant changes in the 500-year tsunami map because it crosses the threshold of the exceedance probabilities being mapped (500 years). In contrast, increasing the mean inter-event time to 610 years (Fig. 32c) results in little change in the 500-year tsunami map. It is evident that it will be important to gather more accurate age dates of Cascadia Subduction Zone earthquakes to constrain the mean inter-event times shown in Fig. 17. 


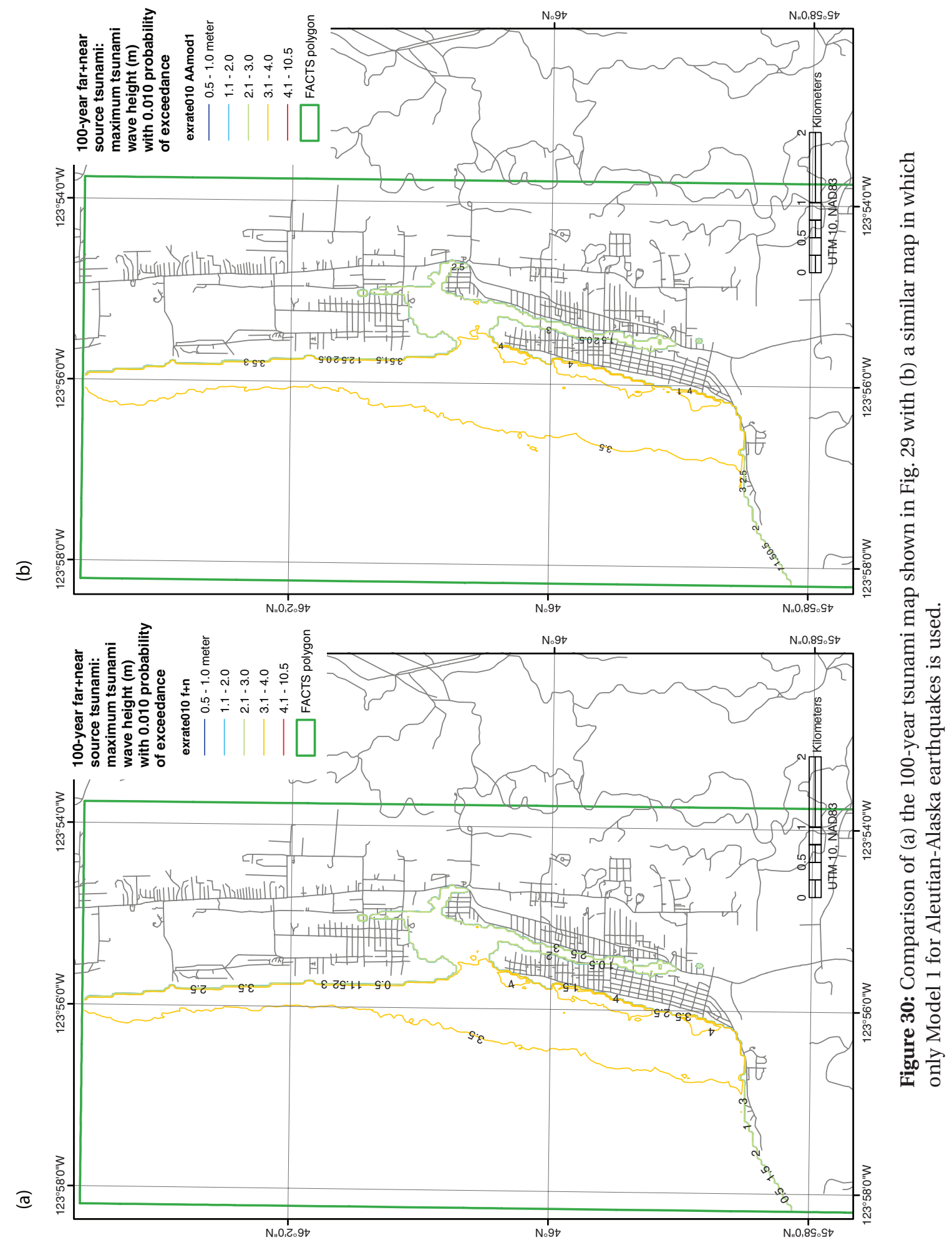




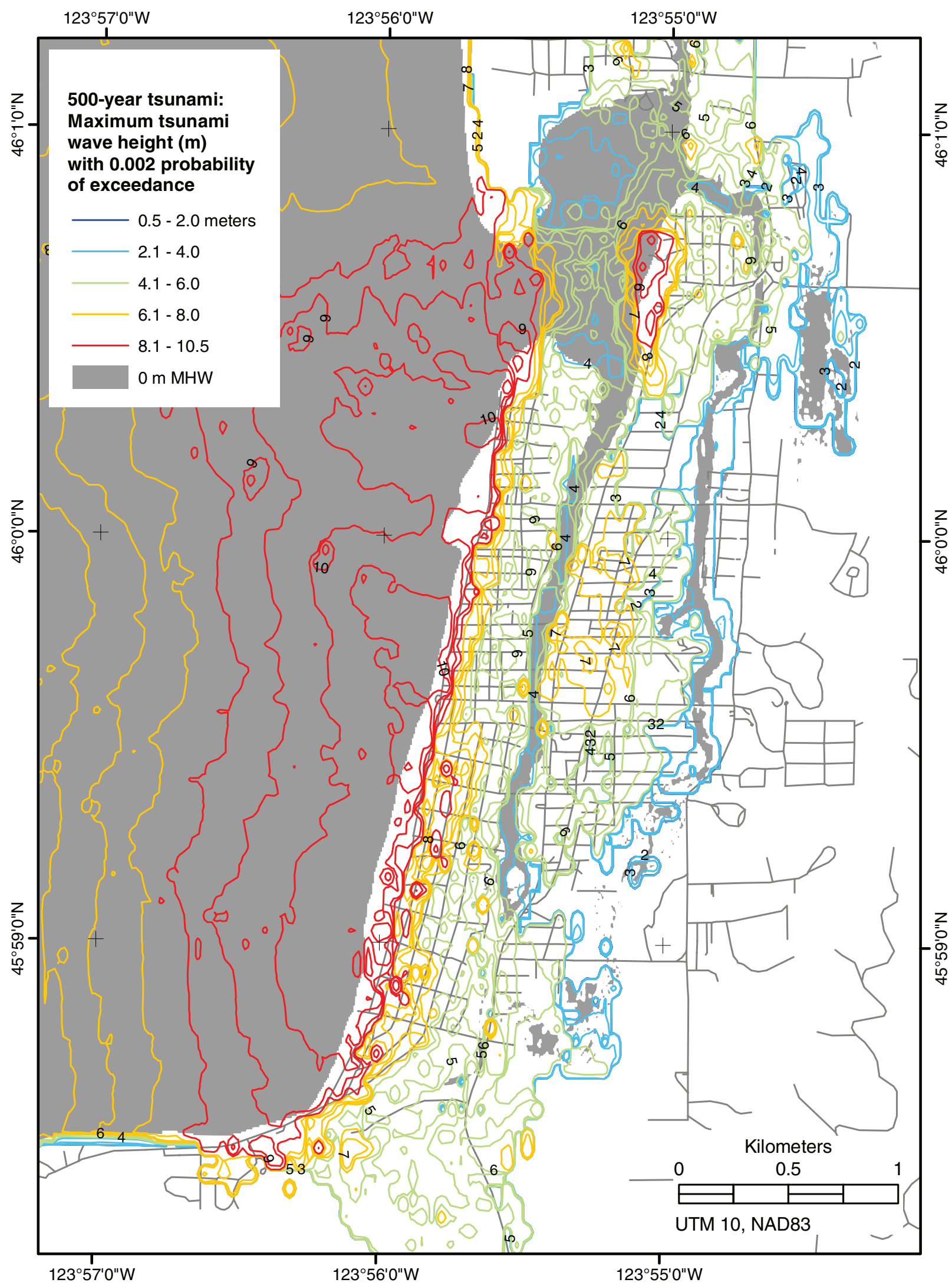

Figure 31: Tsunami wave heights $(\mathrm{m})$ with a $0.2 \%$ annual probability of exceedance. Wave heights include the effects of tides. 


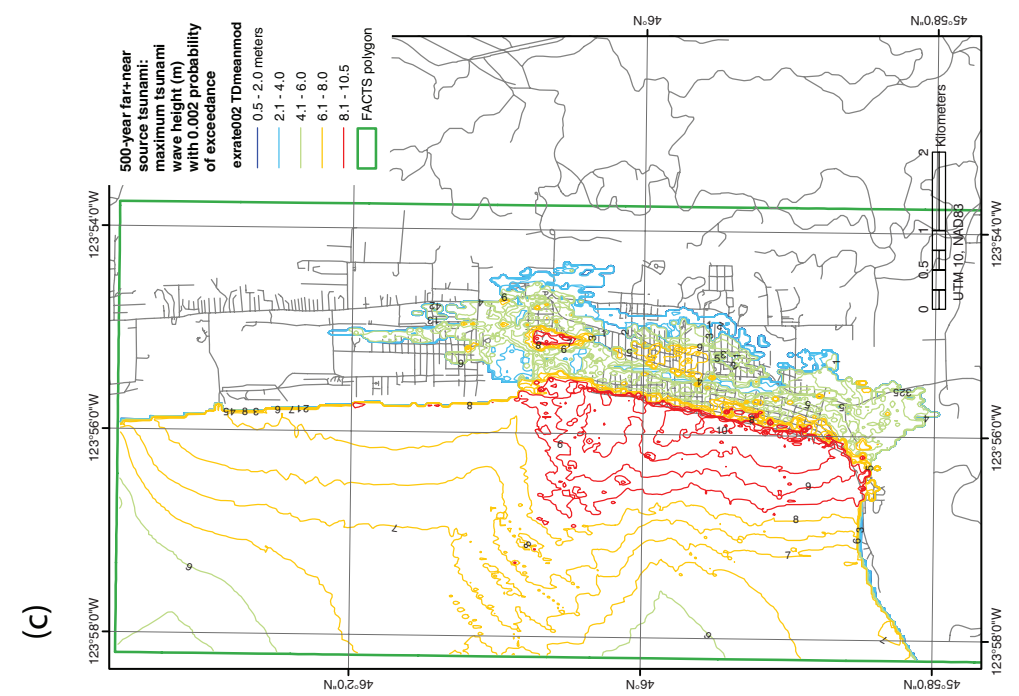

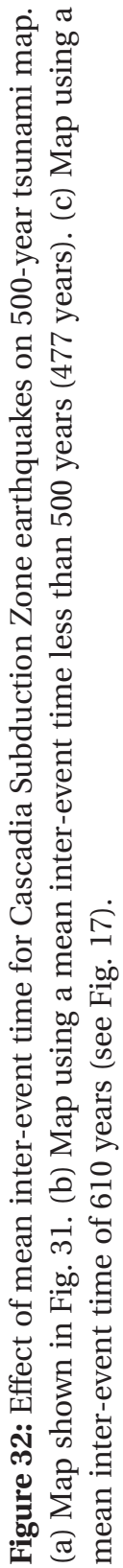

త
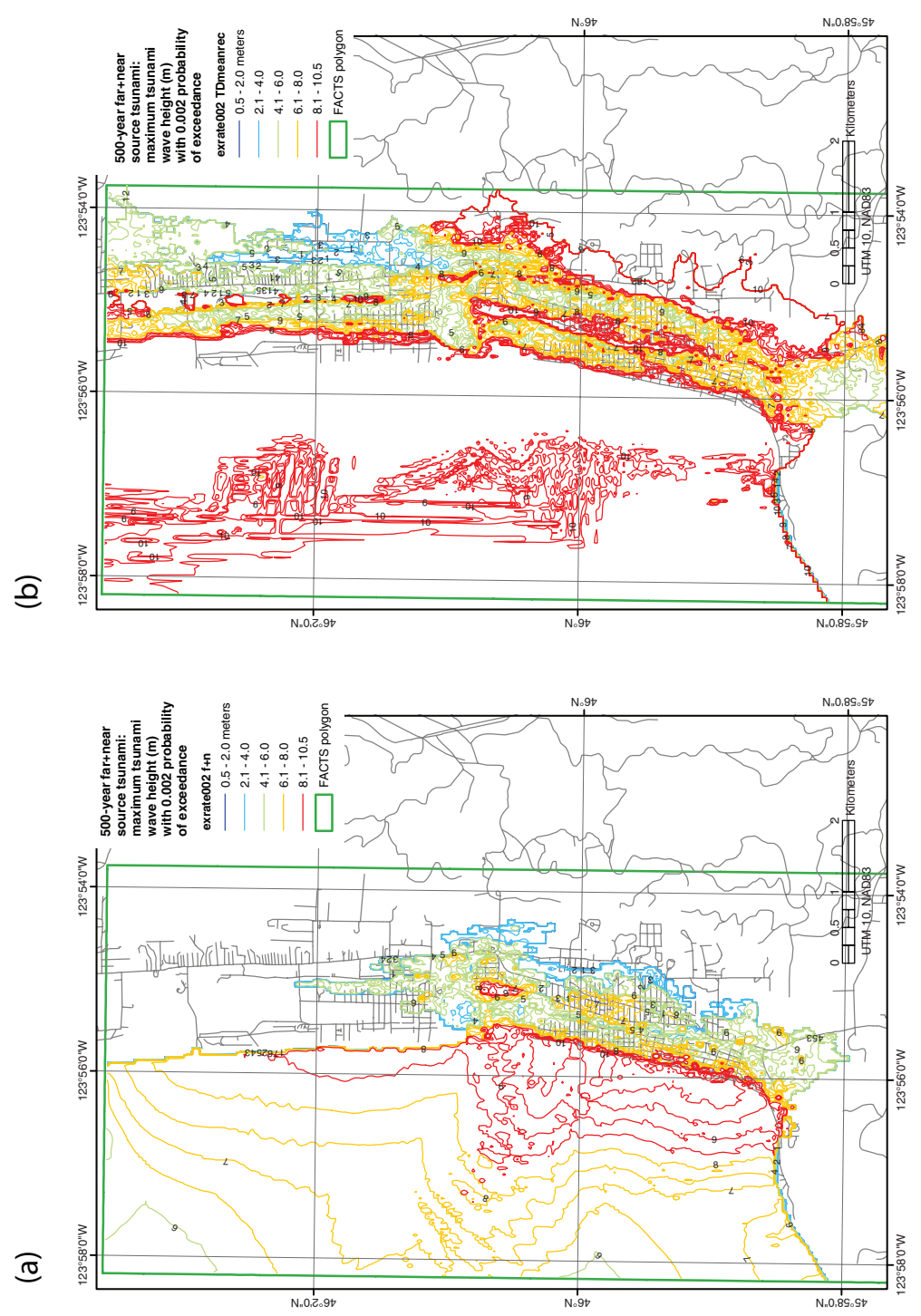


\section{Discussion: Resolvable Issues Through Future Research}

\subsection{Tsunami Earthquakes}

LTHOUGH NOT INCLUDED as part of this study, it is important to note
the possibility of tsunami earthquakes (Kanamori, 1972; Kanamori
and Kikuchi, 1993; Polet and Kanamori, 2000). These earthquakes typically rupture the shallowest part of the interplate thrust near the trench and characteristically have a slow rupture velocity. Although we know of subduction zones where they have occurred (Aleutian, Kuril, Japan, Peru, Nicaragua), it is unclear how ubiquitous they are or whether or not their downdip rupture extent overlaps with that of typical subduction zone earthquakes. It is especially difficult to assign average return times for these earthquakes, though a minimum return time can be estimated from the characteristic amount of slip during a tsunami earthquake and the relative plate convergence velocity.

One possible scenario for tsunami earthquakes for the Cascadia Subduction Zone is that they occur by rupture on a shallow splay fault near the deformation front (Geist and Yoshioka, 1996; Priest et al., 1997; Satake et al., 2003). The possibility of rupture propagation onto splay faults is an area of active research (for example, Kame et al., 2003). For now, it is difficult to quantify how likely this scenario is.

\subsection{Smaller Cascadia Subduction Zone Earthquakes}

Inclusion of earthquakes that have a magnitude smaller than the idealized characteristic earthquake magnitude will likely affect the results of the probabilistic calculations. Much of the recent paleoseismic research suggests that not all of the subduction zone earthquakes preceeding the 1700 event ruptured the entire length of the subduction zone. However, we have neither sufficient information for the paleoseismic record nor information from recorded seismicity to determine what the distribution of earthquake magnitudes is for Cascadia. One of the main questions we addressed during the beginning of this study was "Do we model earthquakes of $\mathrm{M}<9$ and alternative rupture models in addition to characteristic $M=9$ earthquakes?" Depending on the exact form of the frequency-magnitude distribution, the inclusion of smaller earthquakes will tend to increase the tsunami hazard for the $0.01 \mathrm{yr}^{-1}$ recurrence rate and decrease the tsunami hazard for the $0.002 \mathrm{yr}^{-1}$ rate (Geist and Parsons, 


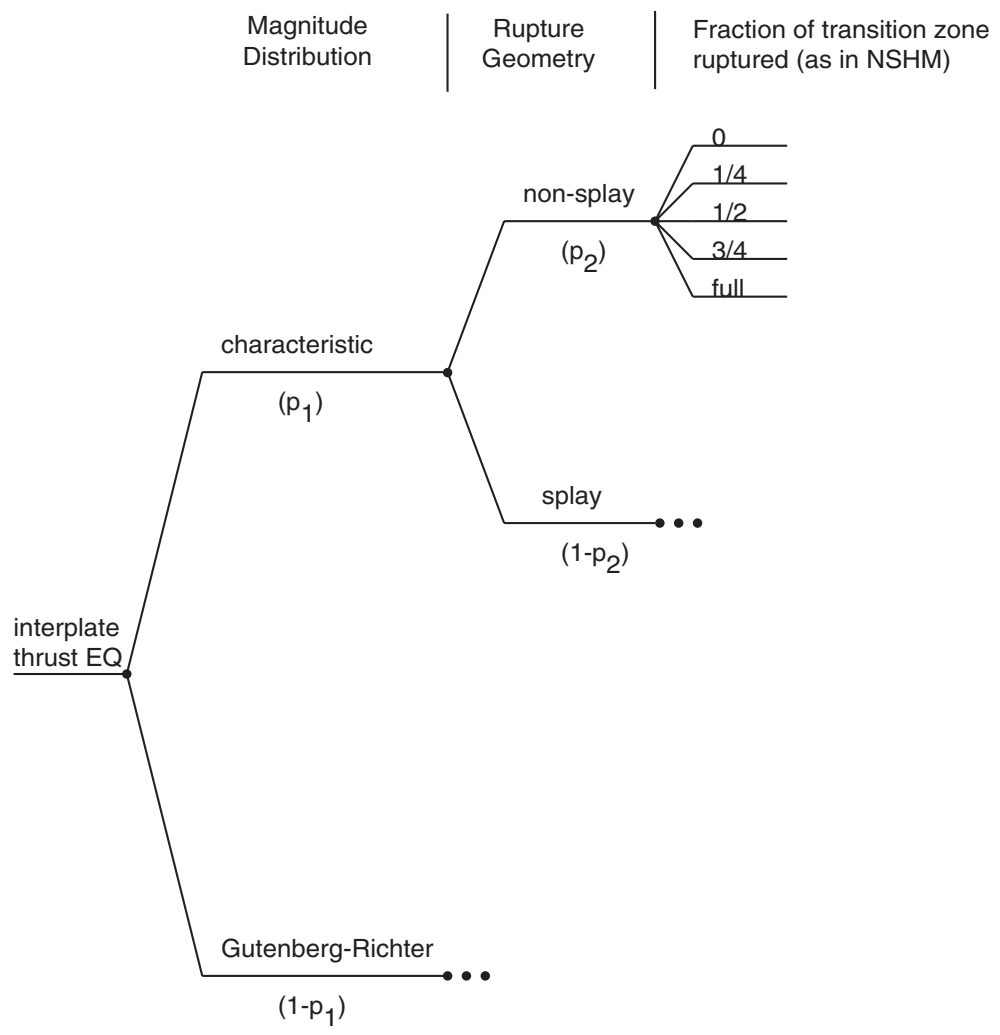

Figure 33: Sample logic tree to include the effects of epistemic uncertainties for local subduction zone earthquakes. The ellipses indicate replication of the branches from the top level.

2005). It is important to emphasize, however, that it is currently quite difficult to get reliable recurrence rates for the smaller Cascadia earthquakes from paleoseismic studies to build such a distribution, thus adding a significant amount of uncertainty to the calculations. Instead, we have focused on sources of uncertainty that we can quantify with some degree of confidence: influence of tides (Appendix E) and natural variability in slip distribution.

\subsection{Other Sources of Epistemic Uncertainty}

In any probabilistic study, the distinction between epistemic and aleatory uncertainties is made because they are handled in different ways in the probability calculations. Epistemic uncertainties are typically incorporated using logic trees, whereas aleatory uncertainties, such as the tidal stage at tsunami arrival and slip distribution at the source, are handled through direct integration in the rate calculations (Appendix E). Variation in parameters such as rupture width and whether or not splay faults are ruptured also has a demonstrated effect on local tsunami runup (Priest et al., 1997). A sample logic tree that includes many of the sources of epistemic uncertainty is given in Fig. 33. As displayed, this would involve a total of 20 branches. The total number of model runs would be dependent on both the number of branches and the 
sample size for the G-R distribution branch—in any case, the number would be excessive. Even just considering the characteristic distribution branch, if 12 model runs are needed to capture the uncertainty from slip distribution patterns, then a total of $10 \times 12=120$ model runs would be needed according to the scheme above. Clearly, some judicious choices need to be made to reduce this computational load. As possible options for future studies, one can reduce the number of branches (for example, just considering two rupture widths) or randomly sample the different branches of a more complete logic tree. 



\section{Recommendations}

HIs PILOT STUDY was motivated by the previous finding (Chowdhury et al.,
2005) that the current methodology for including tsunami information

L on Federal Insurance Rate Maps is inadequate, because it does not include advances of the last few decades in tsunami science and tsunami hazard assessment. The study has integrated advances of the last few decades in the scientific understanding, tools, and methods available for geophysical and tsunami hazard assessment to develop a Probabilistic Tsunami Hazard Assessment (PTHA) methodology, and has applied this methodology to the community of Seaside, Oregon. The resulting products, including 100- and 500-yr tsunami hazard maps and a comprehensive GIS database, represent a major advance in tsunami hazard assessment methodology.

The PTHA must now be applied to other Cascadia Subduction Zone communities, and refined and adapted to other tsunami regimes as part of a formal FEMA/NOAA/USGS partnership in a systematic, cost-effective, national effort to upgrade the FEMA series of Federal Insurance Rate Maps. To this end, we make the following recommendations:

\subsection{Scientific/Technical Recommendations}

- Include all reasonable epistemic and aleatory sources of uncertainty in each Probabilistic Tsunami Hazard Assessment, using the best available science.

- Utilize tsunami hydrodynamic models that meet NOAA standards, to ensure consistency of Federal agency products.

- Test all earthquake and tsunami models by extensive field studies to gather and exploit all possible paleogeography and paleotsunami data, historical tsunami measurements, eyewitness reports, and other types of field observations.

- Develop and maintain a comprehensive GIS database of all field data, model results, and a comprehensive site- and source-specific tsunami/ earthquake bibliography for the region as an essential and invaluable analysis and product development tool.

- Publish a report for each PTHA project that documents procedures, data sources, and results, that includes a bibliography, and that is reviewed for consistency with FEMA standards.

- Publish PTHA results either as a separate Federal Insurance Rate Map, or include PTHA information as separate, tsunami-specific items on FIRMs. In either case, include: (a) the 100-year and 500-year events, (b) tsunami- 
specific $V$-zones, (c) measurements available for the worst case historical and/or paleo-tsunami events, and (d) the "Credible Worst-Case Scenario" event.

\subsection{Policy/Programmatic Recommendations}

- Establish a formal FEMA/NOAA/USGS partnership to address national needs for tsunami hazard assessment products in a federally consistent and cost-effective manner.

- Apply PTHA to additional Cascadia Subduction Zone communities as NOAA inundation models are completed.

- Conduct pilot studies to adapt PTHA to other tsunami regimes in the Pacific, Caribbean, Atlantic, and Gulf, using a preliminary assessment of uncertainty.

- Apply PTHA to additional Pacific, Caribbean, Atlantic, and Gulf communities as the corresponding pilot studies and NOAA inundation models are completed.

- Establish a systematic maintenance and improvement program to integrate scientific and technical advances into the PTHA methodology.

\section{Acknowledgments}

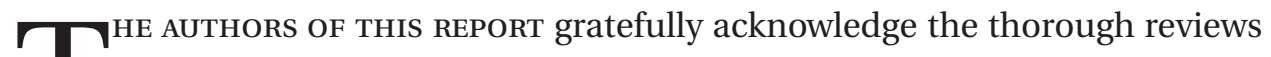
and constructive comments by Frederic Raichlen and Robert Dean. High-resolution fault geometry for the Cascadia interplate thrust was generously provided by Kelin Wang. NOAA/PMEL contribution number 2975. 


\section{References}

Abe, K., 1979, Size of great earthquake of 1837-1974 inferred from tsunami data. Journal of Geophysical Research, 84, 1561-1568.

Anderson, J.G., and J.N. Brune, 1999, Probabilistic seismic hazard analysis without the ergodic assumption. Seismological Research Letters, 70, 19-28.

Atwater, B.F., and E. Hemphill-Haley, 1997, Recurrence intervals for great earthquakes of the past 3,500 years at northeastern Willapa Bay, Washington. U.S. Geological Survey, Professional Paper 1576, 108 pp.

Atwater, B.F, M.P. Tuttle, E.S. Schweig, C.M. Rubin, D.K. Yamaguchi, and E. HemphillHaley, 2004, Earthquake recurrence inferred from paleoseismology. Developments in Quaternary Science, 1, 331-350.

Barrientos, S.E., and S.N. Ward, 1990, The 1960 Chile earthquake: Inversion for slip distribution from surface deformation. Geophysical Journal International, 104, 589-598.

Bourgeois, J., C. Petroff, H. Yeh, V. Titov, C.E. Synolakis, B. Benson, J. Kuroiwa, J. Lander, and E. Norabuena, 1999, Geologic setting, field survey and modeling of the Chimbote, northern Peru, tsunami of 21 February 1996. Pure and Applied Geophysics, 154(3/4), 513-540.

Carrier, G.F., T.T. Wu, and H. Yeh, 2003, Tsunami runup and drawdown on a plane beach. Journal of Fluid Mechanics, 475, 79-99.

Chowdhury, S., E. Geist, F. González, R. MacArthur, and C. Synolakis, 2005, Tsunami Hazards. FEMA Coastal Flood Hazard Analysis and Mapping Guidelines Focused Study Report, February 2005, 42 pp.

Cifuentes, I.L., 1989, The 1960 Chilean earthquakes. Journal of Geophysical Research, $94,665-680$.

Cifuentes, I.L., and P.G. Silver, 1989, Low-frequency source characteristics of the Great 1960 Chilean earthquake. Journal of Geophysical Research, 94, 643-663.

Combellick, R.A., 1992, Paleoseismicity of the upper Cook Inlet region, Alaska. In Wadati Conference on Great Subduction Earthquakes, Fairbanks, Alaska, 97-98.

Cornell, C.A., 1968, Engineering seismic risk analysis. Bulletin of the Seismological Society of America, 58, 1583-1606.

Cross, R.H., 1967, Tsunami surge forces. Journal of the Waterways and Harbors Division, A.C.E., 93, 201-231.

Darienzo, M.E., and C.D. Peterson, 1995, Magnitude and frequency of subduction zone earthquake along the northern Oregon coast in the past 3,000 years. Oregon Geology, 57, 3-12.

Darienzo, M.E., C.D. Peterson, and C. Clough, 1994, Stratigraphic evidence for great subduction-zone earthquake at four estuaries in northern Oregon. Journal of Coastal Research, 10, 850-876.

Dean, R.G., and D.R.F. Harleman, 1966, Interaction of structures and waves. In Estuary and Coastline Hydrodynamics, Ippen, A.T. (ed.), McGraw-Hill Book Co., 341-403.

Downes, G.L., and M.W. Stirling, 2001, Groundwork for development of a probabilistic tsunami hazard model for New Zealand. In International Tsunami Symposium 2001, Seattle, Washington, 293-301.

Fiedorowicz, B.K., 1997, Geologic evidence of historic and prehistoric tsunami inundation at Seaside, Oregon. M.S. Thesis, Portland State University, 197 pp. 
Fiedorowicz, B.K., and C.D. Peterson, 2002, Tsunami deposit mapping at Seaside, Oregon, USA. In Geoenvironmental mapping: Methods, theory, and practice, Bobrowski, P.T. (ed.), Lisse, The Netherlands, A.A. Balkema Publishers, 629-648.

Flück, P., R.D. Hyndman, and K. Wang, 1997, Three-dimensional dislocation model for great earthquakes of the Cascadia subduction zone. Journal of Geophysical Research, 102, 20,539-20,550.

Frankel, A.D., C.S. Mueller, T. Barnhard, D.M. Perkins, E.V. Leyendecker, N. Dickman, S. Hanson, and M. Hopper, 1996, National seismic-hazard maps. Documentation, June 1996: U.S. Geological Survey, Open-File Report 96-532, 41 pp.

Frankel, A.D., M.D. Petersen, C.S. Mueller, K.M. Haller, R.L. Wheeler, E.V. Leyendecker, R.L. Wesson, S.C. Harmsen, C.H. Cramer, D.M. Perkins, and K.S. Rukstales, 2002, Documentation for the 2002 Update of the National Seismic Hazard Maps: U.S. Geological Survey, Open-File Report 02-420, 33 pp.

Garcia, A.W., and J.R. Houston, 1975, Type 16 Flood Insurance Study: Tsunami Predictions for Monterey and San Francisco Bays and Puget Sound. U.S. Army Engineer Waterways Experiment Station, Technical Report H-75-17, 263 pp.

Geist, E.L., 2002, Complex earthquake rupture and local tsunamis. Journal of Geophysical Research, 107, doi: 10.1029/2000JB000139.

Geist, E.L., 2005, Local Tsunami Hazards in the Pacific Northwest from Cascadia Subduction Zone Earthquakes. U.S. Geological Survey Professional Paper 1661B, 17 pp.

Geist, E.L., and R. Dmowska, 1999, Local tsunamis and distributed slip at the source. Pure and Applied Geophysics, 154, 485-512.

Geist, E.L., and T. Parsons, 2005, Probabilistic analysis of tsunami hazards. Natural Hazards, 37(3), 277-314.

Geist, E.L., and S. Yoshioka, 1996, Source parameters controlling the generation and propagation of potential local tsunamis along the Cascadia margin. Natural Hazards, 13, 151-177.

Gelfenbaum, G., and B.E. Jaffe, 2003, Erosion and sedimentation from the 17 July 1998 Papua New Guinea tsunami. Pure and Applied Geophysics, 60, 1969-1999.

Gilpin, L.M., and G. Carver, 1992, Paleoseismicity of the SW extent of the 1964 Alaskan earthquake rupture zone, Kodiak Islands, Alaska. In Wadati Conference on Great Subduction Earthquakes, Fairbanks, Alaska, 99-100.

González, F.I., K. Satake, E.F. Boss, and H.O. Mofjeld, 1995, Edge wave and nontrapped modes of the 25 April 1992 Cape Mendocino tsunami. Pure and Applied Geophysics, 144, 409-426.

González, F.I., V.V. Titov, H.O. Mofjeld, A.J. Venturato, S. Simmons, R. Hansen, R.A. Combellick, R.K. Eisner, D. Hoirup, B. Yanagi, S. Yong, M. Darienzo, G.R. Priest, G. Crawford, and T. Walsh, 2005, Progress in NTHMP hazard assessment. Natural Hazards, 35, 89-110.

Herrero, A., and P. Bernard, 1994, A kinematic self-similar rupture process for earthquakes. Bulletin of the Seismological Society of America, 84, 1216-1228.

Houston, J.R., 1980, Joint occurrences in coastal flooding-discussion. J. Waterw. Port Coast. Ocean Div. ASCE, 106(1), 138-139.

Houston, J.R., and A.W. Garcia, 1974, Type 16 Flood Insurance Study: Tsunami Predictions for Pacific Coastal Communities. U.S. Army Engineer Waterways Experiment Station, Technical Report H-74-3.

Houston, J.R., and A.W. Garcia, 1978, Type 16 Flood Insurance Study: Tsunami Predictions for the West Coast of the Continental United States. U.S. Army Engineer Waterways Experiment Station, Technical Report H-78-26.

Hughes, S.A., 2004, Estimation of wave run-up on smooth, impermeable slopes using the wave momentum flux parameter. Coastal Engineering, 51, 1085-1104.

Ippen, A.T., 1966, Estuary and Coastline Hydrodynamics. McGraw-Hill Book Co., 744 pp. 
Jaffe, B.E., and G. Gelfenbaum, 2002, Using tsunami deposits to improve assessment of tsunami risk. In Solutions to Coastal Disasters '02, ASCE, 836-847.

Jaffe, B.E., G. Gelfenbaum, D. Rubin, R. Peters, R. Anima, M. Swensson, D. Olcese, L. Bernales, J. Gomez, and P. Riega, 2003, Tsunami deposits: Identification and interpretation of tsunami deposits from the June 23, 2001 Peru tsunami. In International Conference on Coastal Sediments 2003, World Scientific Publishing Corp., $13 \mathrm{pp}$.

Johnson, J.M., and K. Satake, 1999, Asperity distribution of the 1952 Great Kamchatka earthquake and its relation to future earthquake potential in Kamchatka. Pure and Applied Geophysics, 154, 541-553.

Johnson, J.M., K. Satake, S.R. Holdahl, and J. Sauber, 1996, The 1964 Prince William Sound earthquake: Joint inversion of tsunami and geodetic data. Journal of Geophysical Research, 101, 523-532.

Kame, N., J.R. Rice, and R. Dmowska, 2003, Effects of prestress state and rupture velocity on dynamic fault branching. Journal of Geophysical Research, 108(B5) ESE 13-11-13-21.

Kanamori, H., 1972, Mechanism of tsunami earthquakes. Physics of the Earth and Planetary Interiors, 6, 346-359.

Kanamori, H., and M. Kikuchi, 1993, The 1992 Nicaragua earthquake: A slow earthquake associated with subducted sediments. Nature, 361, 714-716.

Kelsey, H.M., R.C. Witter, and E. Hemphill-Haley, 2002, Plate-boundary earthquakes and tsunamis of the past 5500 years, Sixes River estuary, southern Oregon. Geological Society of America Bulletin, 114, 298-314.

Kobayashi, N., A.K. Otta, and I. Roy, 1987, Wave reflection and runup on rough slopes. ASCE, J. Waterways, Port, Coastal and Ocean Engineering, 113(3), 282-298.

Leendertse, J.J., 1967, Aspects of Computational Model for Long-Period Water Wave Propagation. The Rand Corp. RM-5294-PR, 179 pp.

Leonard, L.J., R.D. Hyndman, and S. Mazzotti, 2004, Coseismic subsidence in the 1700 great Cascadia earthquake: Coastal estimates versus elastic dislocation models. Geological Society of America Bulletin, 116, 655-670.

Lin, I., and C.C. Tung, 1982, A preliminary investigation of tsunami hazard. Bulletin of the Seismological Society of America, 72, 2323-2337.

Linde, A.T., and P.G. Silver, 1989, Elevation changes and the Great 1960 Chilean earthquake: Support for aseismic slip. Geophysical Research Letters, 16, 1305-1308.

Liu, P.L.F., Y.S. Cho, S.B. Yoon, and S.N. Seo, 1995, Numerical simulations of the 1960 Chilean tsunami propagation and inundation at Hilo, Hawaii. In Tsunami: Progress in Prediction, Disaster Prevention and Warning, Tsuchiya, Y., and N. Shuto, (eds.), Kluwer Academic Publishers, 99-115.

Longuet-Higgins, M.S., and R.W. Stewart, 1964, Radiation stress in water waves: A physical discussion, with applications. Deep-Sea Research, 11, 529-552.

Matthews, M.V., W.L. Ellsworth, and P.A. Reasenberg, 2002, A Brownian model for recurrent earthquakes. Bulletin of the Seismological Society of America, 92, 22332250.

Mofjeld, H.O., F.I. González, E.N. Bernard, and J.C. Newman (2000): Forecasting the heights of later waves in Pacific-wide tsunamis. Natural Hazards, 22, 71-89.

Mofjeld, H.O., F.I. González, V.V. Titov, A.J. Venturato, and J.C. Newman, in press, Effects of tides on maximum tsunami wave heights: Probability distributions. Journal of Atmospheric and Oceanic Technology.

Mofjeld, H.O., F.I. González, V.V. Titov, A.J. Venturato, and J.C. Newman (2006): Effects of tides on maximum tsunami wave heights: Probability distributions. Journal of Atmospheric and Oceanic Technology (in press).

Mofjeld, H.O., A.J. Venturato, F.I. González, and V.V. Titov, 2004, Background tides and sea level variations at Seaside, Oregon. NOAA, Technical Memorandum OAR PMEL-126, 15 pp. 
Morton, R., G. Gelfenbaum, and B.E. Jaffe (2006): Physical criteria for distinguishing sandy tsunami and storm deposits using modern examples, Journal of Sedimentary Geology, Special Issue on Tsunami Deposits (in press).

Nanayama, F., K. Satake, R. Furukawa, K. Shimokawa, B.F. Atwater, K. Shigeno, and S. Yamaki, 2003, Unusually large earthquakes inferred from tsunami deposits along the Kuril trench. Nature, 424, 660-663.

National Research Council (NRC), 2000, Risk Analysis and Uncertainty in Flood Damage Reduction Studies. Washington, DC, National Academy Press, 202 pp.

Natural Disaster Research, I., 2001, Probabilistic Tsunami Hazard Analysis: Aguadilla, Puerto Rico. Sea Grant College Program, University of Puerto Rico, Project R-122$1-97,28 \mathrm{pp}$.

Nishenko, S.P., 1991, Circum-Pacific seismic potential: 1989-1999. Pure and Applied Geophysics, 135, 169-259.

Ogata, Y., 1999, Estimating the hazard of rupture using uncertain occurrence times of paleoearthquakes. Journal of Geophysical Research, 104, 17,995-18,014.

Parsons, T., 2004, Recalculated probability of $M \geq 7$ earthquakes beneath the Sea of Marmara, Turkey. Journal of Geophysical Research, 109, B05304, doi: 10.1029/ 2003JB002667.

Parsons, T., submitted, Significance of stress transfer in time-dependent earthquake probability calculations.

Peregrine, D.H., 1966, Calculation of the development of an undular bore. Journal of Fluid Mechanics, 22(2), 321-330.

Peters, B., B.E. Jaffe, G. Gelfenbaum, and C. Peterson, 2003, Cascadia tsunami deposit database. U.S. Geological Survey, Open-File Report 03-13, 19 pp.

Petersen, M.D., C.H. Cramer, and A.D. Frankel, 2002, Simulations of seismic hazard for the Pacific Northwest of the United States from earthquakes associated with the Cascadia subduction zone. Pure and Applied Geophysics, 159, 2147-2168.

Peterson, C.D., 1993, Field trip guide to Cascadia paleoseismic evidence along the northern Oregon coast: Evidence of subduction zone seismicity in the central Cascadia margin. Oregon Geology, 55, 99-114.

Peterson, C.D., B.E. Jaffe, and B. Peters, 2004, Estimating uncertainty and frequency of high-velocity paleotsunami inundation from geologic records in back barrier settings, test locality Cannon Beach, Oregon (abs.). Eos, Transactions American Geophysical Union, 85(47), Supplement, F1038.

Pinegina, T.K., J. Bourgeois, L. Bazanova, I.V. Melekestsev, and O.A. Braitseva, 2003, A millennial-scale record of Holocene tsunamis on the Kronotskiy Bay coast, Kamchatka, Russia. Quaternary Research, 59, 36-47.

Polet, J., and H. Kanamori, 2000, Shallow subduction zone earthquakes and their tsunamigenic potential. Geophysical Journal International, 142, 684-702.

Priest, G.R., E. Myers, A.M. Baptista, P. Fleuck, K. Wang, R.A. Kamphaus, and C.D. Peterson, 1997, Cascadia subduction zone tsunamis: Hazard mapping at Yaquina Bay, Oregon. State of Oregon, Department of Geology and Mineral Industries, Open-File Report O-97-34, 144 pp.

Ramsden, J.D., 1993, Tsunamis: Forces on a vertical wall caused by long waves, bores, and surges on a dry bed. Pasadena, California, California Institute of Technology, Ph.D. Thesis, 279 pp.

Ramsden, J.D., and F. Raichlen, 1990, Forces on vertical wall caused by incident bores. Journal of Waterway, Port, Coastal, and Ocean Engineering, 116, 592-613.

Rikitake, T., and I. Aida, 1988, Tsunami hazard probability in Japan. Bulletin of the Seismological Society of America, 78, 1268-1278.

Ruff, L.J., and H. Kanamori, 1983, The rupture process and asperity distribution of three great earthquakes from long-period diffracted P-waves. Physics of the Earth and Planetary Interiors, 31, 202-230. 
Salgado, I., A. Eipert, B.F. Atwater, M. Shishikura, and M. Cisternas, 2003, Recurrence of giant earthquakes inferred from tsunami sand sheets and subsided soils in southcentral Chile (abs.). Geological Society of America Abstracts with Programs, 35(6), 584.

Satake, K., K. Wang, and B.F. Atwater, 2003, Fault slip and seismic moment of the 1700 Cascadia earthquake inferred from Japanese tsunami descriptions. Journal of Geophysical Research, 108(B11), ESE 7-1-7-17.

Scholz, C.H., 1990, The mechanics of earthquakes and faulting. Cambridge, Cambridge University Press, 439 pp.

Schwartz, S.Y., 1999, Noncharacteristic behavior and complex recurrence of large subduction zone earthquakes. Journal of Geophysical Research, 104, 23,111-23,125.

Senior Seismic Hazard Analysis Committee (SSHAC), 1997, Recommendations for Probabilistic Seismic Hazard Analysis: Guidance on Uncertainty and Use of Experts. U.S. Nuclear Regulatory Commission, Main Report NUREG/CR-6372 UCRLID-122160 Vol. 1, 256 pp.

Soloviev, S.L., 1970, Recurrence of tsunamis in the Pacific. In Tsunamis in the Pacific Ocean, Adams, W.M. (ed.), Honolulu, East-West Center Press, 149-163.

Sornette, D., L. Knopoff, Y.Y. Kagan, and C. Vanneste, 1996, Rank-ordering statistic of extreme events: Application to the distribution of large earthquakes. Journal of Geophysical Research, 101, 13,883-13,893.

Synolakis, C.E., 1987, The runup of solitary waves. Journal of Fluid Mechanics, 185, 523-545.

Synolakis C.E., and E.N. Bernard, 2006, Tsunami science before and beyond Boxing Day 2004. Phil. Trans. Roy. Soc. A, 364(1845), doi: 10.1098/rsta.20, 2231-2265.

Takahashi, T., 1996, Benchmark Problem 4. The 1993 Okushiri tsunami-Data, Conditions and Phenomena. In Long wave runup models, Yeh, H., P. Liu, and C. Synolakis (eds.), World Scientific Publishing Co. Pte. Ltd., Singapore, 384-403.

Tanioka, Y., and F.I. González, 1998, The Aleutian earthquake of June 10, 1996 (Mw 7.9) ruptured parts of both the Andreanof and Delarof segments. Geophysical Research Letters, 25, 2245-2248.

Tetra Tech Inc., 1981, Coastal Flooding Storm Surge Model. Federal Emergency Management Agency, Part 1: Methodology.

Titov, V.V., and F.I. González, 1997, Implementation and testing of the Method of Splitting Tsunami (MOST) model. NOAA Tech Memo. ERL PMEL-112, 11 pp.

Titov, V.V., F.I. González, E.N. Bernard, M.C. Eble, H.O. Mofjeld, J.C. Newman, and A.J. Venturato, 2005, Real-time tsunami forecasting: Challenges and solutions. In Developing Tsunami-Resilient Communities, The National Tsunami Hazard Mitigation Program, E. Bernard (ed.), Nat. Haz., 35(1), 40-58.

Titov, V.V., H.O. Mofjeld, F.I. González, and J.C. Newman, 1999, Offshore forecasting of Alaska-Aleutian subduction zone tsunamis in Hawaii. NOAA Tech. Memo. ERL PMEL-114, 22 pp.

Titov, V.V., and Synolakis, C.E., 1995, Modeling of breaking and nonbreaking long wave evolution and runup using VTCS-2. Journal of Waterways, Ports, Coastal and Ocean Engineering, 121(6), 308-316.

Titov, V.V., and C.E. Synolakis, 1996, Numerical modeling of 3-D long wave runup using VTCS-3. In Long wave runup models, World Scientific Publishing Co. Pte. Ltd., Singapore, pp. 242-248.

Titov, V.V., and C.E. Synolakis, 1997, Extreme inundation flows during the HokkaidoNansei-Oki tsunami. Geophysical Research Letters, 24, 11, 1315-1318.

Titov, V.V., and C.E. Synolakis, 1998, Numerical modeling of tidal wave runup. Journal of Waterways, Ports, Coastal and Ocean Engineering, 124(4), 157-171.

Tsunami Focused Study Team, 2005, Tsunami Hazards-FEMA Coastal Flood Hazard Analysis and Mapping Guidelines Focused Study Report, 42 pp. (PDF at http: //www.fema.gov/plan/prevent/fhm/frm_cfsumrpt.shtm) 
Van Dorn, W.G. 1984, Some tsunami characteristics deducible from tide records. Journal of Physical Oceanography, 14(2), 353-363.

Venturato, A.J., 2005, A digital elevation model for Seaside, Oregon: Procedures, data sources, and analyses. NOAA Tech. Memo. OAR PMEL-129, 21 pp.

Ward, S.N., 1982, Earthquake mechanisms and tsunami generation: The Kurile Islands event of 13 October 1963. Bulletin of the Seismological Society of America, 72, 759777.

Ward, S.N., 1994, A multidisciplinary approach to seismic hazard in southern California. Bulletin of the Seismological Society of America, 84, 1293-1309.

Ward, S.N., 2001, Landslide tsunami. Journal of Geophysical Research, 106, 11,20111,215 .

Wesson, R.L., A.D. Frankel, C.S. Mueller, and S.C. Harmsen, 1999, Probabilistic Seismic Hazard Maps of Alaska. U.S. Geological Survey, Open-File Report 99-36, 20 pp.

Witter, R.C., H.M. Kelsey, and E. Hemphill-Haley, 2003, Great Cascadia earthquakes and tsunamis of the past 6700 years, Coquille River estuary, southern coastal Oregon. Geological Society of America Bulletin, 115, 1289-1306.

Wong, F.L., A.J. Venturato, and E.L. Geist (2006): Seaside, Oregon, Tsunami Pilot StudyŮModernization of FEMA Flood Hazard Maps: GIS Data: U.S. Geological Survey Digital Series, in review.

Yeh, H., V.V. Titov, V. Gusiakov, E. Pelinovsky, V. Khramushin, and V. Kaistrenko, 1995, The 1994 Shikotan earthquake tsunami. Pure and Applied Geophysics, 144(3/4), 569-593. 


\title{
APPENDICES
}

\author{
A: Background tides and sea level variations at Seaside, Oregon \\ B: A digital elevation model for Seaside, Oregon \\ C: Summary of eyewitness observations from 1964 Alaska Tsunami in Seaside, Oregon \\ D: Location of sites used in this study and presence of 1964, 1700, and older tsunami deposits \\ E: Incorporating tides into probability calculations \\ F: Determining earthquake recurrence rates \\ G: Surface and area calculation for the 100-year and 500-year floods
}





\section{Appendix A: NOAA Technical Memorandum OAR PMEL- 126, "Background tides and sea level variations at Seaside, Oregon" by H.O. Mofjeld et al.}

NOAA Technical Memorandum OAR PMEL-126

\section{BACKGROUND TIDES AND SEA LEVEL VARIATIONS AT SEASIDE, OREGON}

Harold O. Mofjeld ${ }^{1}$

Angie J. Venturato ${ }^{2}$

Frank I. González ${ }^{1}$

Vasily V. Titov ${ }^{2}$

${ }^{1}$ Pacific Marine Environmental Laboratory Seattle, WA

2 Joint Institute for the Study of the Atmosphere and Ocean (JISAO)

University of Washington, Seattle, WA

Pacific Marine Environmental Laboratory

Seattle, WA

September 2004

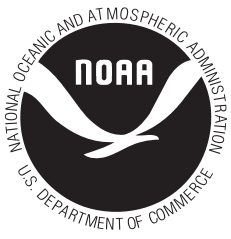




\section{NOTICE}

Mention of a commercial company or product does not constitute an endorsement by NOAA/OAR. Use of information from this publication concerning proprietary products or the tests of such products for publicity or advertising purposes is not authorized.

Contribution No. 2736 from NOAA/Pacific Marine Environmental Laboratory

For sale by the National Technical Information Service, 5285 Port Royal Road Springfield, VA 22161 


\section{Contents}

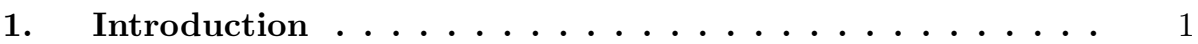

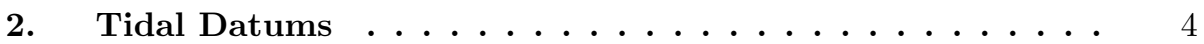

3. Tidal Harmonic Constants . . . . . . . . . . . . 6

4. Water Level Probability Distributions . . . . . . . . 6

4.1 Observed Background Water Levels Near Seaside . . . . . . . 6

4.2 Predicted Background Water Levels at Seaside . . . . . . . . 10

5. Sea Level Trends . . . . . . . . . . . . . . . . . . . . 12

6. Joint Probability Methods Versus Direct Calculations . . . 12

7. Summary and Conclusions . . . . . . . . . . . . . 13

8. Acknowledgments . . . . . . . . . . . . . . 14

\section{List of Figures}

1 Map showing Seaside and relevant tide stations . . . . . . . . . . 2

2 Sample time series of observed water levels near Seaside . . . . . . . 3

3 Probability density functions from observed water levels . . . . . . 8

4 Exceedance probabilities from observed water levels . . . . . . . . 9

$5 \quad$ Same as Fig. 4 but with logarithm of exceedance probability . . . . $\quad 9$

$6 \quad$ Probability density functions at South Beach and Seaside . . . . . . 11

$7 \quad$ Same as Fig. 7 but with logarithm of exceedance probability . . . . 11

\section{List of Tables}

1 Type of tide $=(\mathrm{O} 1+\mathrm{K} 1) /(\mathrm{M} 2+\mathrm{S} 2)$ and sequence of tide $=$

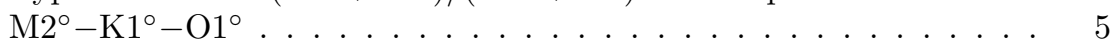

$2 \quad \mathrm{M} 2$ and $\mathrm{K} 1$ tidal harmonic constants in the Cascadia region . . . . . 5

3 Tidal datums relative to MLLW . . . . . . . . . . . . . . 5

4 Tidal harmonic constants at Seaside, Toke Point, and South Beach . 7

5 Percentage heights and ranges from observed water levels . . . . . . 10

6 Observed sea level trends in the Cascadia region . . . . . . . . . . . 13 
This page is intentionally left blank. 


\title{
Background tides and sea level variations at Seaside, Oregon
}

\author{
Harold O. Mofjeld ${ }^{1}$, Angie J. Venturato ${ }^{2}$, Frank I. González ${ }^{1}$, and Vasily V. Titov ${ }^{2}$
}

\section{Introduction}

The purpose of this technical memorandum is to provide a summary of the tides and other sea level variations at Seaside, Oregon, the site for the FEMA FIRM Tsunami Pilot Study. Because the tidal range is so large along the U.S. West Coast, the tides and other sea level variations have a significant effect on tsunami runup heights and inundation. For this reason, Houston and Garcia (1978) used predicted tides when computing the 100- and 500year tsunami runup heights for the previous tsunami Flood Insurance Rate Maps (FIRMs).

Since Seaside is not served by a long-term tide station, many tidal quantities that are relevant to tsunami mapping must be estimated by other means. The results presented here are based on inferences from NOAA tide stations in the region and from the Eastern North Pacific ENPAC 2003 tide model of Spargo (2003) and Spargo et al. (in press). Tidal datums are available inside the mouth of the Necanicum River from water level observations taken during Nov 1971-Sept 1972; as we will see, there are substantial differences between these and the inferred coastal datums. The locations of the tide stations are shown in Fig. 1.

NOAA has designated the 19-year period 1983-2001 as the official U.S. National Tide Datum Epoch, and we have used observations from this NTDE when these were available. It is fortunate that the time series of water levels observed during this NTDE contain the largest El Niño events of the Twentieth Century (1982-1983 and 1997-1998), as well as representative distributions of other water level variations. This allows a useful comparison between observed and predicted tides in the region.

This technical memorandum is organized into examples of tidal time series to give a general characterization of the tides in the region (this section), tidal datums to provide information to develop digital elevation models and compare with tsunami amplitudes (Section 2), tidal harmonic constants that can be used for tidal prediction (Section 3), probability distributions including the average time the water level is at or above various heights (Section 4), interseismic sea level trends (Section 5), next steps to include background water levels in the estimation of 100- and 500-yr tsunami heights at Seaside area (Section 6), and conclusions on estimates of tides and other background water levels at Seaside (Section 7).

The examples of observed water levels in Fig. 2 show that within the central Cascadia region containing Seaside, the tides have very similar temporal patterns with some variation in amplitude between the tide stations.

\footnotetext{
${ }^{1}$ NOAA/Pacific Marine Environmental Laboratory, 7600 Sand Point Way NE, Seattle, WA 98115-6349

${ }^{2}$ Joint Institute for the Study of the Atmosphere and Ocean (JISAO), University of Washington, Box 354235, Seattle, WA 98195-4235
} 

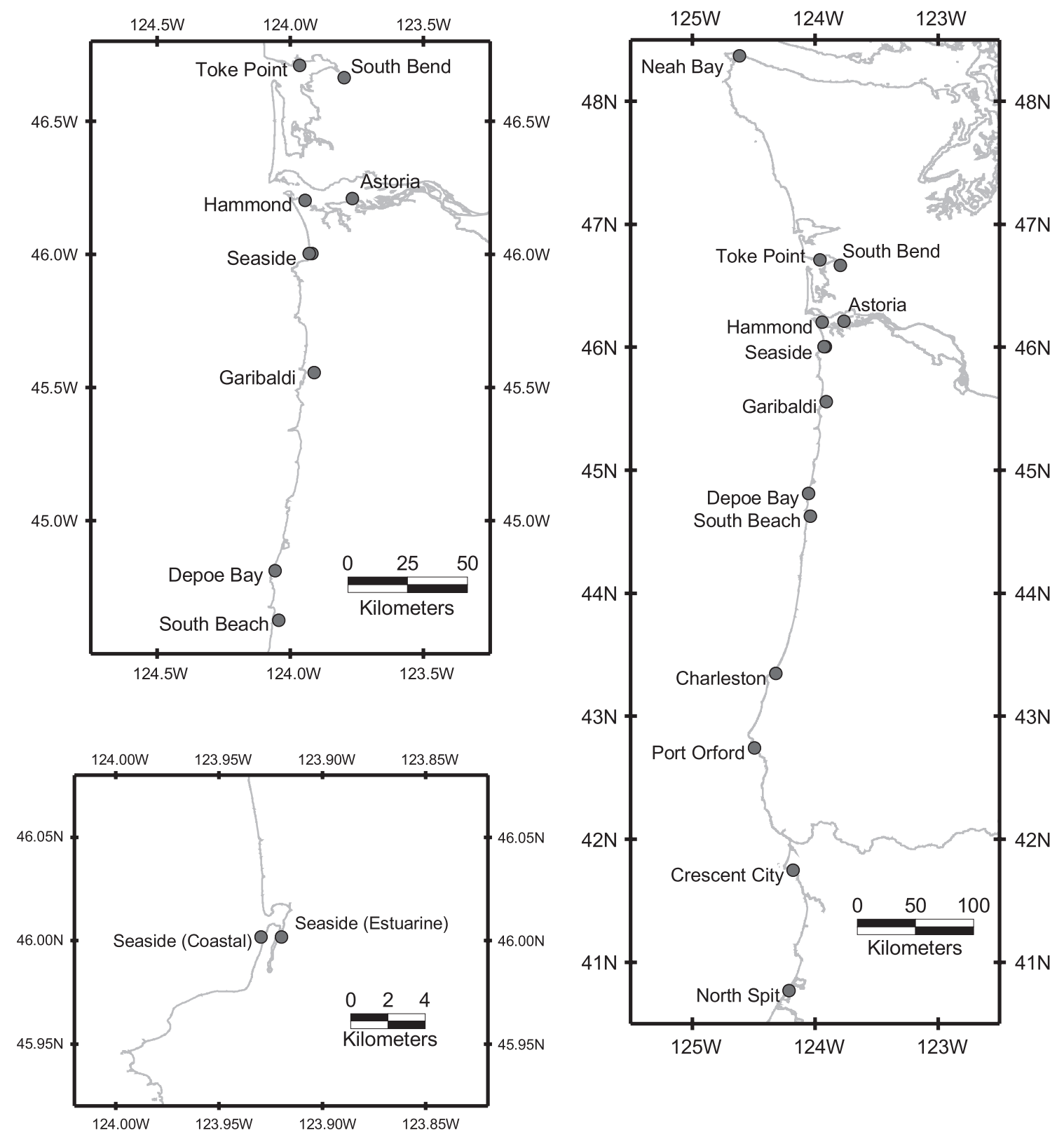

Figure 1: Map of the Central Cascadia region showing the locations of Seaside and relevant tide stations. 

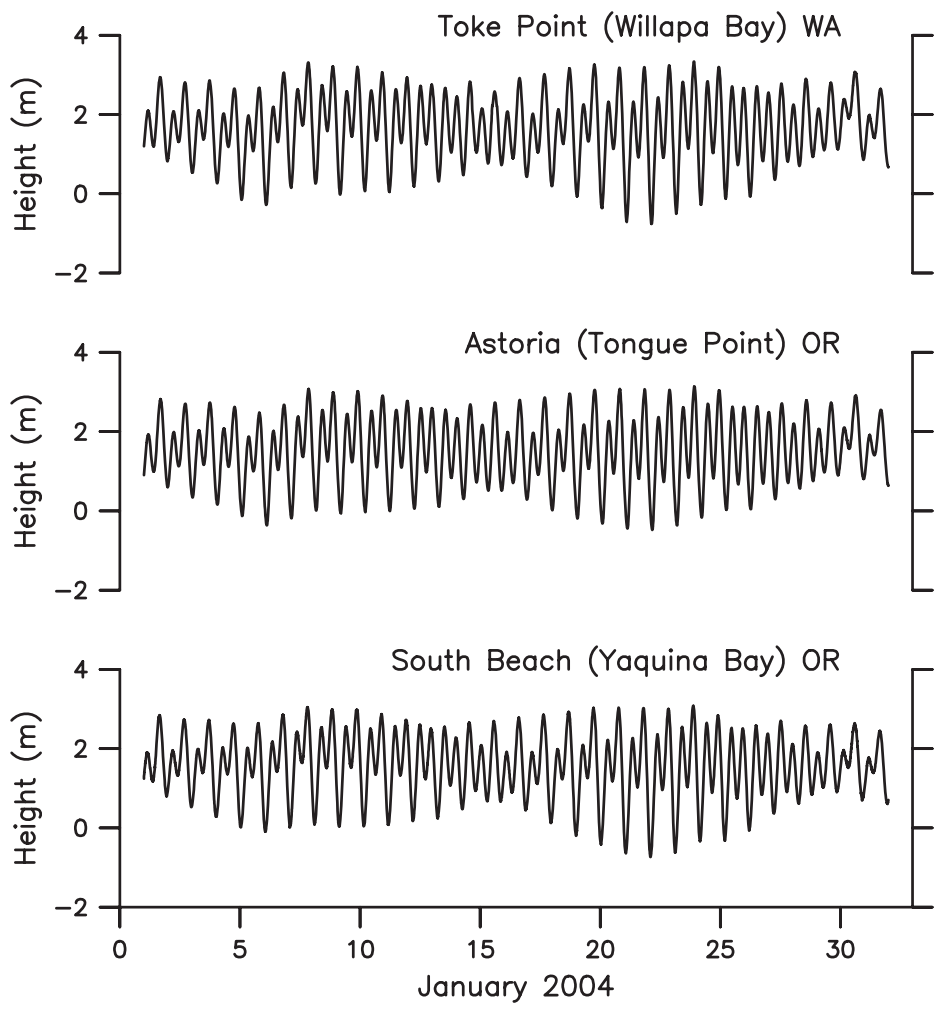

Figure 2: Sample time series of observed water levels at the three nearest long-term tide stations to Seaside.

These tides are mixed semidiurnal (Table 1). Substantial differences (Fig. 2) occur between successive low waters; lesser differences occur between successive high waters; and low and high waters follow the sequence LLW, LHW, HLW, HHW. Both the amplitude and shape of the daily tidal curve are modulated (Fig. 2) over fortnightly (two-week) and monthly time scales. The northward increase (Table 2) of the harmonic constant amplitudes and phase lags is consistent with northward propagating tidal waves that turn northwestward in the Cascadia region. Descriptions of the tidal modeling and dynamics in this region, as well as references to previous work, are given by Mofjeld et al. (1995), Foreman et al. (2000), Myers and Baptista (2001), Spargo (2003), and Spargo et al. (in press).

Observations and tidal theory show that the amplitudes and shapes of the daily tidal curve vary throughout the month due to variations in the lunar phase (new moon, first quarter...), declination (meridional angle off the equator), and parallax (distance from the earth). Significant modulations of the tides also occur on seasonal (solstitial-equinoctal and solar parallax) and interannual (18.6-year lunar nodal) time scales. For the latter reason, tidal datums (like those in the next section) are ideally computed from 19 years of observations (e.g., NTDE 1983-2001). 
Mofjeld et al.

\section{Tidal Datums}

For the Tsunami Pilot Study, tidal datums are relevant in two ways. The first is in developing the digital elevation model (DEM) for the tsunami inundation model. The second is in providing a succinct summary of height scales for background water levels to compare with tsunami wave heights. Tidal datums are for the NTDE 1983-2001, computed from observations during this period or adjusted vertically to be consistent with it (details documented at NOAA's www.co-ops.nos.noaa.gov website).

Table 3 gives the official tidal datums for stations in the region surrounding Seaside as reported by NOAA/NOS/CO-OPS (National Ocean Service/Center for Operational Oceanographic Products and Services) and NOAA/NGS (National Geodetic Survey). For Seaside itself, three sets of datums are shown. The first set of coastal datums at Seaside were obtained by the harmonic constant datum method (Mofjeld et al., 2004) using harmonic constants from the ENPAC 2003 tide model. The other set of coastal datums at Seaside were linearly interpolated in latitude from the observed datums at Hammond and Garibaldi (Fig. 1), the closest stations to Seaside. The third set of Seaside datums are based on 11 months (Nov 1971-Sept 1972) of water level observations at the 12th Avenue Bridge over the Necanicum River.

The coastal datums obtained by the two different methods are in relatively good agreement. For instance, the values of MHW relative to MLLW (important when merging water depth and land elevation data) agree within $0.2 \mathrm{~m}$. However, there is a significant difference (Table 3) between the coastal datums and those inside the shallow river mouth. Of particular interest is the 0.76-0.96 m difference for MHW which is relevant to merging water depth and land elevation data to form the digital elevation model for tsunami modeling. It is worth noting that reduced tidal ranges often occur in bays with restrictive inlets (e.g., Kjerfve and Knoppers, 1991).

The larger difference (Table 3 ) between MLLW and the geodetic datum NAVD 88 observed inside the river mouth is also consistent with restricted tidal exchange through the inlet, especially near low tide when more water is retained in the estuary than would occur with free exchange. This hypothesis is corroborated by a personal communication from Maria Little (NOAA/NOS/CO-OPS) in which she reports that a water level station at the Seaside Sewage Plant $\left(46^{\circ} 0.4^{\prime} \mathrm{N}, 123^{\circ} 55.1^{\prime} \mathrm{W}\right)$, just inside the river mouth, showed "...damping of the high waters and flat low waters, caused by a distortion of the tide signal. There are no Accepted Values [of tidal datums] for this station." The tidal exchange may additionally be affected by the changing nature of the river mouth as observed over the past 30 years. The variations in the river mouth will be discussed in a technical memorandum by Angie Venturato (in preparation). A high-resolution non-linear tide model would be needed to fully understand the relationship between the tides on the open coast at Seaside and those inside the Necanicum River mouth. 
Table 1: Type of tide $=(\mathrm{O} 1+\mathrm{K} 1) /(\mathrm{M} 2+\mathrm{S} 2)$ and sequence of tide $=\mathrm{M} 2^{\circ}-\mathrm{K}^{\circ}-\mathrm{O} 1^{\circ}$ at the nearest long-term tide stations to Seaside and inferred values for the open coast at Seaside. The Type of Tide is mixed semidiurnal when the amplitude ratio is between 0.25 and 1.5 .

\begin{tabular}{lcc}
\hline Station & Type & $\begin{array}{c}\text { Sequence } \\
\text { (deg) }\end{array}$ \\
\hline Toke Point & 0.563 & 127.2 \\
Astoria & 0.549 & 126.4 \\
Coastal Seaside & 0.611 & 130.7 \\
South Beach & 0.621 & 132.4 \\
\hline
\end{tabular}

Table 2: M2 and K1 tidal harmonic constants observed at coastal and estuarine tide stations in the Cascadia region. These are the largest semidiurnal and diurnal constituents, respectively.

\begin{tabular}{|c|c|c|c|c|c|c|}
\hline \multirow[b]{2}{*}{ Station } & \multirow[b]{2}{*}{$\begin{array}{c}\text { Latitude } \\
\text { (deg) }\end{array}$} & \multirow[b]{2}{*}{$\begin{array}{l}\text { Longitude } \\
\text { (deg) }\end{array}$} & \multicolumn{2}{|c|}{ M2 } & \multicolumn{2}{|c|}{ K1 } \\
\hline & & & $\begin{array}{c}\text { Amp } \\
\text { H (m) }\end{array}$ & $\begin{array}{c}\text { Lag } \\
\text { G (deg) }\end{array}$ & $\begin{array}{c}\text { Amp } \\
H(m)\end{array}$ & $\begin{array}{c}\text { Lag } \\
\text { G (deg) }\end{array}$ \\
\hline Neah Bay & 48.3683 & 124.6167 & 0.787 & 246.3 & 0.497 & 248.3 \\
\hline Toke Point & 46.7083 & 123.9650 & 0.981 & 253.7 & 0.435 & 251.1 \\
\hline South Bend & 46.6633 & 123.7983 & 1.124 & 259.7 & 0.428 & 254.8 \\
\hline Astoria & 46.2083 & 123.7667 & 0.945 & 264.2 & 0.403 & 256.2 \\
\hline Coastal Seaside & 46.0017 & 123.9300 & 0.960 & 229.1 & 0.463 & 238.2 \\
\hline Depoe Bay & 44.8100 & 124.0583 & 0.890 & 225.0 & 0.438 & 235.0 \\
\hline South Beach & 44.6250 & 124.0433 & 0.902 & 231.1 & 0.443 & 237.7 \\
\hline Charleston & 43.3450 & 124.3217 & 0.818 & 225.3 & 0.401 & 235.2 \\
\hline Port Orford & 42.7400 & 124.4967 & 0.750 & 216.5 & 0.428 & 231.2 \\
\hline Crescent City & 41.7450 & 124.1833 & 0.714 & 212.2 & 0.390 & 228.2 \\
\hline North Spit & 40.7667 & 124.2167 & 0.710 & 220.0 & 0.411 & 236.1 \\
\hline
\end{tabular}

Table 3: Tidal datums relative to MLLW at tide stations in the region surrounding Seaside. The coastal Seaside datums were linearly interpolated in latitude using the datums at Hammond and Garibaldi. Also shown are the maximum and minimum observed heights at the tide station (where available) and the geodetic datums NGVD 29 and NAVD 88.

\begin{tabular}{|c|c|c|c|c|c|c|}
\hline Station & Hammond & $\begin{array}{l}\text { Coastal } \\
\text { Seaside }\end{array}$ & $\begin{array}{l}\text { Coastal } \\
\text { Seaside }\end{array}$ & $\begin{array}{c}\text { Estuarine } \\
\text { Seaside }\end{array}$ & Garibaldi & $\begin{array}{l}\text { South } \\
\text { Beach }\end{array}$ \\
\hline Source: & Observed & Model & Interpolated & Observed* & Observed & Observed \\
\hline Latitude & 46.2017 & 46.0017 & 46.0017 & 46.0017 & 45.5550 & 44.6250 \\
\hline Longitude & 123.9450 & 123.9300 & 123.9300 & 123.9200 & 123.9117 & 123.0433 \\
\hline To Entrance & $\begin{array}{c}7 \mathrm{~km} \\
(\mathrm{~m})\end{array}$ & $\begin{array}{c}0 \mathbf{k m} \\
(\mathbf{m})\end{array}$ & $\begin{array}{c}0 \mathbf{k m} \\
(\mathbf{m})\end{array}$ & $\begin{array}{c}2 \mathrm{~km} \\
(\mathrm{~m})\end{array}$ & $\begin{array}{c}2 \mathrm{~km} \\
(\mathrm{~m})\end{array}$ & $\begin{array}{c}4 \mathrm{~km} \\
(\mathrm{~m})\end{array}$ \\
\hline Max Obs & 3.45 & & & & 3.60 & 3.73 \\
\hline MHHW & 2.54 & 2.74 & 2.52 & 1.77 & 2.48 & 2.54 \\
\hline MHW & 2.33 & 2.51 & 2.31 & 1.55 & 2.26 & 2.33 \\
\hline MTL & 1.36 & 1.47 & 1.35 & 0.84 & 1.35 & 1.38 \\
\hline MSL & 1.34 & 1.46 & 1.34 & 0.83 & 1.33 & 1.36 \\
\hline MLW & 0.39 & 0.44 & 0.39 & 0.12 & 0.40 & 0.42 \\
\hline NGVD29 & & & & 0.23 & 1.16 & 1.26 \\
\hline NAVD 88 & -0.01 & \multicolumn{2}{|c|}{-0.03 to 0.02} & -0.88 & 0.10 & 0.23 \\
\hline MLLW & 0.00 & 0.00 & 0.00 & 0.00 & 0.00 & 0.00 \\
\hline Min Obs & -0.90 & & & & -0.88 & -1.07 \\
\hline
\end{tabular}

*Maria Little, NOAA/NOS/CO-OPS, personal communication 


\section{Tidal Harmonic Constants}

Tidal predictions rely on harmonic constants (HCs) that are specific to the location of interest. For the open coast at Seaside $\left(46^{\circ} 00.1^{\prime} \mathrm{N}, 123^{\circ} 55.8^{\prime} \mathrm{W}\right)$, the HCs for the O1, K1, N2, M2, and S2 constituents were computed from the ENPAC 2003 tide model. The minor diurnal and semidiurnal HCs (Table 4) were inferred from South Beach amplitude ratios and phase differences using the method outlined by Schureman (1976). The long period HCs are based on those at South Beach. The higher frequency tides $(2 \mathrm{SM} 2, \ldots)$ are set to zero amplitude because of lack of information. However, they are likely to be small because the continental shelf west of Seaside is narrow and deepens relatively rapidly; this limits greatly the shallow water effects that generate such constituents. Also shown for comparison are observed HCs at Toke Point and South Beach (Fig. 1). The 37 constituents in Table 4 are the same as those used by NOAA for its official tidal predictions.

\section{Water Level Probability Distributions}

Probability distributions serve to characterize the general behavior of background water levels in terms of the duration of time spent at various ranges of height. To apply this method, the probability distribution functions (pdfs) are computed from observed tide gage records when these are available, or from predicted tides.

\subsection{Observed Background Water Levels Near Seaside}

Shown in Fig. 3 are the observed pdfs at Toke Point, Astoria, and South Beach (Fig. 1). The pdfs were computed by first interpolating the verified hourly observations to 15-minute values using cubic interpolation. The 15minute time interval was chosen to allow accurate estimates for the heights of the individual high and low tides that may not be resolved with 1-hr sampling. The height values in the time series were binned using a $0.1 \mathrm{~m}$ height interval for each bin to form a histogram for each station. The histograms were then renormalized so that the total (sum) over the full range of heights is unity (1.0), as required by probability theory.

Figure 3 shows that the pdfs at the three stations tend to be large around the frequently occurring high and low water stands, when the height is changing slowly, but much smaller at the extreme ranges that occur only rarely in time. The pdfs at these stations are very similar. The slight upward displacement of the upper Toke Point and Astoria curves relative to the South Beach pdf is due to the slightly larger tidal ranges at these two stations. The shapes of the pdf curves are somewhat different near the central peaks (pdf $>0.3$ ); but overall, the pdfs have very similar shapes and widths (Table 5) and similar maximum values. This is expected since the distances between the stations are small compared with the alongshore variations in tides in the Cascadia region (Mofjeld et al., 1995; Foreman et al., 2000; Myers and Baptista, 2001; Spargo, 2003; Spargo et al., in press). The same should therefore be true on the open coast of Seaside since it is located between 
Table 4: Tidal harmonic constants (37 constituents) and the mean relative to MLLW for the open coast at Seaside and at the Toke Point and South Beach tide stations.

\begin{tabular}{|c|c|c|c|c|c|c|}
\hline \multirow{2}{*}{$\begin{array}{l}\text { Station: } \\
\text { Location: } \\
\text { Constituent }\end{array}$} & \multicolumn{2}{|c|}{$\begin{array}{c}\text { Toke Point } \\
46.7083,123.9650\end{array}$} & \multicolumn{2}{|c|}{$\begin{array}{c}\text { Coastal Seaside } \\
46.0017,123.9300\end{array}$} & \multicolumn{2}{|c|}{$\begin{array}{c}\text { South Beach } \\
44.6250,124.0433\end{array}$} \\
\hline & $\begin{array}{c}\text { Amplitude } \\
\text { H (m) }\end{array}$ & $\begin{array}{l}\text { Phase Lag } \\
\text { G (deg) }\end{array}$ & $\begin{array}{c}\text { Amplitude } \\
\mathbf{H}(\mathrm{m})\end{array}$ & $\begin{array}{l}\text { Phase Lag } \\
\text { G (deg) }\end{array}$ & $\begin{array}{l}\text { Amplitude } \\
\mathbf{H}(\mathbf{m})\end{array}$ & $\begin{array}{c}\text { Phase Lag } \\
\text { G (deg) }\end{array}$ \\
\hline mean & 1.458 & & 1.441 & & 1.358 & \\
\hline SA & 0.158 & 289.8 & 0.123 & 281.6 & 0.123 & 281.6 \\
\hline SSA & 0.000 & 0.0 & 0.019 & 258.7 & 0.019 & 258.7 \\
\hline MM & 0.000 & 0.0 & 0.027 & 174.7 & 0.027 & 174.7 \\
\hline MSF & 0.000 & 0.0 & 0.000 & 0.0 & 0.000 & 0.0 \\
\hline MF & 0.024 & 161.8 & 0.019 & 155.0 & 0.019 & 155.0 \\
\hline 2Q1 & 0.006 & 221.0 & 0.007 & 202.2 & 0.007 & 204.3 \\
\hline Q1 & 0.047 & 230.2 & 0.050 & 216.7 & 0.048 & 213.4 \\
\hline RHO & 0.011 & 208.7 & 0.011 & 212.4 & 0.010 & 213.8 \\
\hline $\mathrm{O} 1$ & 0.264 & 235.4 & 0.288 & 220.2 & 0.269 & 221.0 \\
\hline M1 & 0.016 & 270.3 & 0.016 & 252.2 & 0.015 & 250.7 \\
\hline P1 & 0.136 & 249.2 & 0.144 & 235.5 & 0.137 & 234.2 \\
\hline $\mathrm{S} 1$ & 0.006 & 40.7 & 0.012 & 20.4 & 0.012 & 20.4 \\
\hline K1 & 0.435 & 251.1 & 0.463 & 238.2 & 0.443 & 237.7 \\
\hline J1 & 0.023 & 267.6 & 0.029 & 256.8 & 0.027 & 255.0 \\
\hline OO1 & 0.016 & 292.6 & 0.016 & 276.4 & 0.015 & 273.1 \\
\hline $2 \mathrm{~N} 2$ & 0.022 & 204.6 & 0.022 & 178.2 & 0.021 & 183.2 \\
\hline MU2 & 0.008 & 253.2 & 0.016 & 197.2 & 0.015 & 201.1 \\
\hline N2 & 0.198 & 229.7 & 0.196 & 203.7 & 0.187 & 207.2 \\
\hline NU2 & 0.044 & 228.6 & 0.038 & 206.1 & 0.036 & 209.5 \\
\hline M2 & 0.981 & 253.7 & 0.960 & 229.1 & 0.902 & 231.1 \\
\hline LAM2 & 0.009 & 269.3 & 0.006 & 241.2 & 0.006 & 243.8 \\
\hline L2 & 0.033 & 266.3 & 0.026 & 243.6 & 0.024 & 246.4 \\
\hline $\mathrm{T} 2$ & 0.017 & 270.5 & 0.015 & 250.6 & 0.014 & 253.8 \\
\hline $\mathrm{S} 2$ & 0.261 & 284.4 & 0.269 & 255.2 & 0.244 & 258.6 \\
\hline R2 & 0.002 & 285.6 & 0.002 & 255.2 & 0.002 & 258.6 \\
\hline K2 & 0.071 & 279.6 & 0.070 & 247.4 & 0.066 & 250.2 \\
\hline 2SM2 & 0.000 & 0.0 & 0.000 & 0.0 & 0.003 & 63.5 \\
\hline $2 \mathrm{MK} 3$ & 0.005 & 64.3 & 0.000 & 0.0 & 0.000 & 0.0 \\
\hline M3 & 0.000 & 0.0 & 0.000 & 0.0 & 0.000 & 0.0 \\
\hline MK3 & 0.004 & 10.9 & 0.000 & 0.0 & 0.004 & 172.3 \\
\hline MN4 & 0.006 & 335.6 & 0.000 & 0.0 & 0.005 & 164.8 \\
\hline M4 & 0.014 & 352.6 & 0.000 & 0.0 & 0.013 & 189.0 \\
\hline MS4 & 0.009 & 30.5 & 0.000 & 0.0 & 0.007 & 229.5 \\
\hline $\mathrm{S} 4$ & 0.000 & 0.0 & 0.000 & 0.0 & 0.000 & 0.0 \\
\hline M6 & 0.009 & 45.3 & 0.000 & 0.0 & 0.008 & 300.7 \\
\hline S6 & 0.000 & 0.0 & 0.000 & 0.0 & 0.000 & 0.0 \\
\hline M8 & 0.000 & 0.0 & 0.000 & 0.0 & 0.000 & 0.0 \\
\hline
\end{tabular}




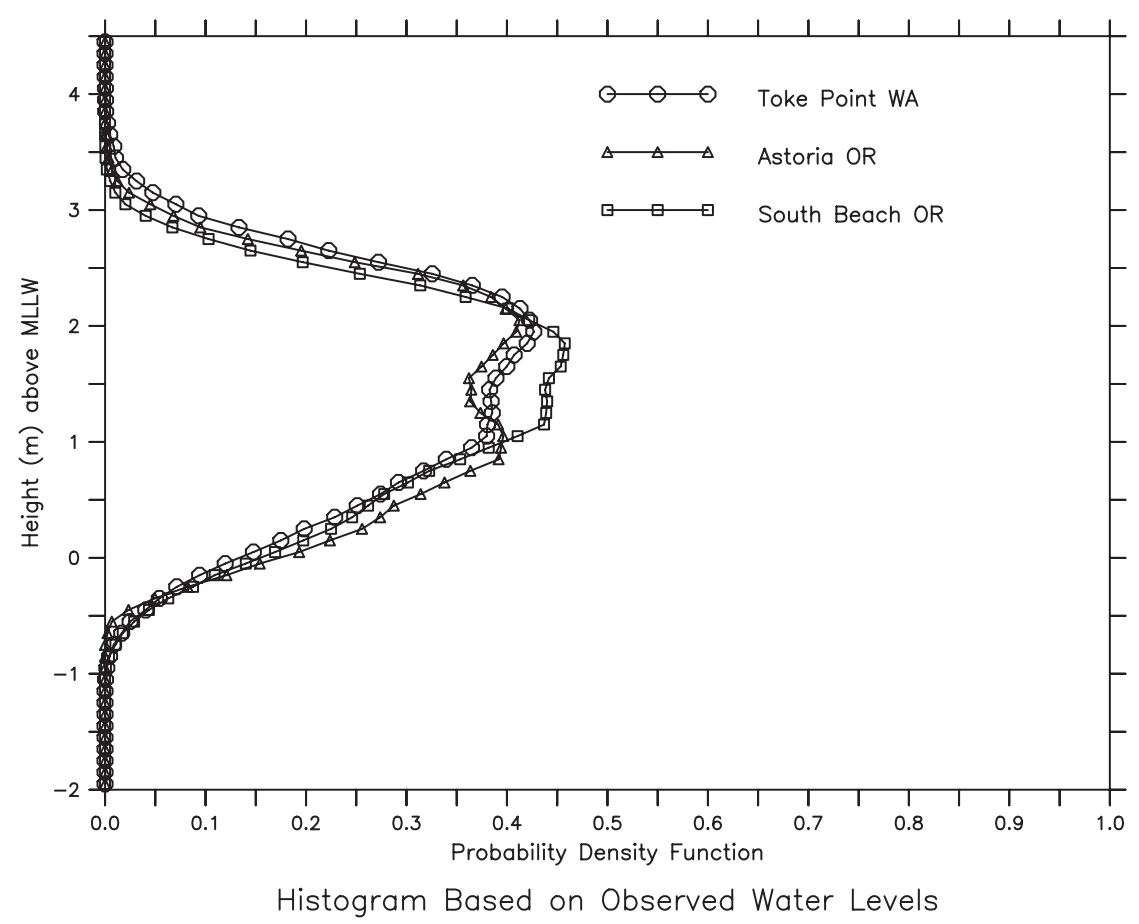

Figure 3: Probability density functions computed from observed water levels at the nearest long-term tide stations to Seaside.

these tide gage stations. Other differences in the pdfs are presumably due in part to local tidal dynamics within the three bays where the tide gages are located and to different inlet effects on the tides in these bays.

Integrating the pdfs (Fig. 3) downward in height gives the cumulative exceedance probability $\mathrm{P}(\eta)$, where $\eta$ is the height above MLLW. $\mathrm{P}(\eta)$ represents the fraction of the time, on average, that the water level is above the height $\eta$. As shown in Fig. 4, the exceedance probabilities decrease approximately linearly with increasing height $\eta$ from MLLW $(\eta=0)$ to $\mathrm{P}=0.1$ (10\% probability of exceedance). The differences in $\mathrm{P}$ between the three tide stations increases upward in height to a $0.19 \mathrm{~m}$ difference between Toke Point and South Beach at $\mathrm{P}=0.1$.

The values of $\mathrm{P}$ at larger heights are relevant to the exceedance probabilities of observed storm surges. When plotted on a $\log (\mathrm{P})$ scale, the exceedance curves (Fig. 5) take an asymptotic form that can be fit to extreme value distributions. Like the tsunami probability distributions, additional calculations using time series of storm surges, especially their duration in time, need to be performed before distributions like those in Fig. 5 can be used to determine event heights for various recurrence intervals (Pugh, 1987, 2004).

The percentage heights and ranges shown in Table 5, as well as the magnitudes of the tidal datums given in Table 3, indicate that tides are large enough to have important effects on the height probabilities of tsunamis at Seaside. The percentage height ranges (Table 5) for the three stations are 


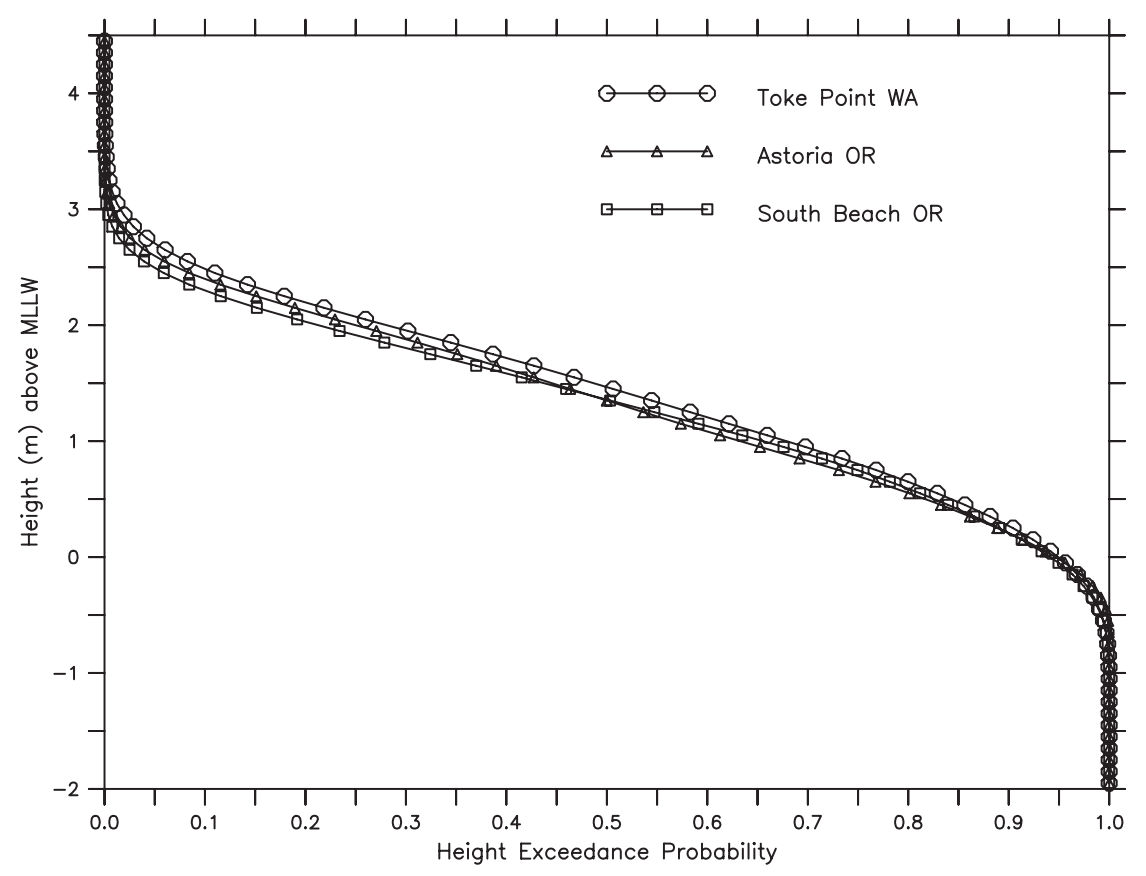

Histogram Based on Observed Water Levels

Figure 4: Exceedance probabilities computed from observed hourly water levels at the nearest long-term tide stations to Seaside.

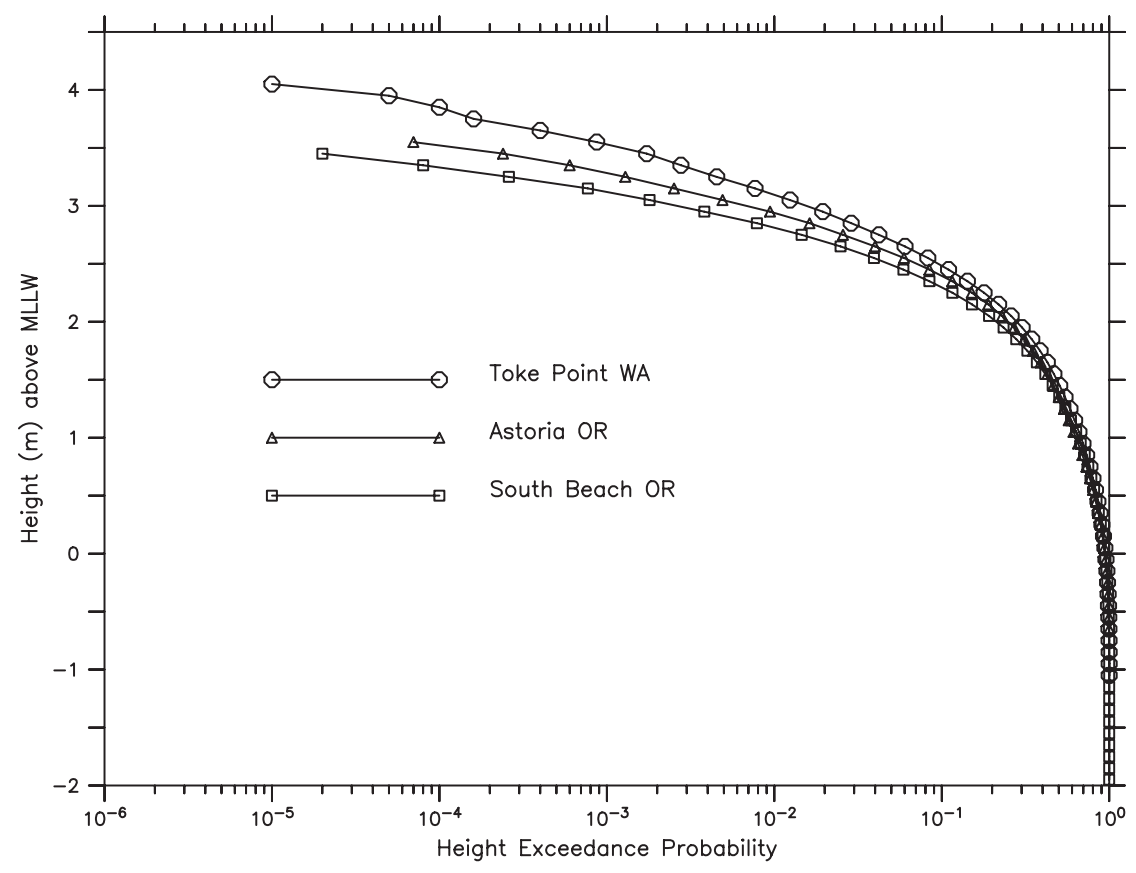

Histogram Based on Observed Water Levels

Figure 5: Same as Fig. 4 but with the logarithm of exceedance probability plotted against height. 
Table 5: Percentage heights and ranges, based on the probability distribution functions derived from observed water levels during the National Tidal Datum Epoch 1983-2001. For a given percentage probability, a random background water level will occur within the height range between the upper and lower bounds.

\begin{tabular}{|c|c|c|c|c|c|}
\hline \multirow{2}{*}{$\begin{array}{l}\text { Station } \\
\text { Bounds (\%): }\end{array}$} & \multirow[b]{2}{*}{$\begin{array}{c}50 \% \text { Height } \\
(\mathrm{m})\end{array}$} & \multicolumn{4}{|c|}{ Height Ranges } \\
\hline & & $\begin{array}{l}50 \% \\
(\mathrm{~m})\end{array}$ & $\begin{array}{l}80 \% \\
(\mathrm{~m})\end{array}$ & $\begin{array}{l}90 \% \\
(\mathrm{~m})\end{array}$ & $\begin{array}{c}98 \% \\
(\mathrm{~m})\end{array}$ \\
\hline Toke Point & 1.47 & & & & \\
\hline Upper & & 2.00 & 2.30 & 2.50 & 2.82 \\
\hline Lower & & 0.70 & 0.21 & -0.05 & -0.46 \\
\hline Range & & 1.30 & 2.09 & 2.55 & 3.28 \\
\hline Astoria & 1.35 & & & & \\
\hline Upper & & 2.00 & 2.40 & 2.60 & 2.94 \\
\hline Lower & & 0.70 & 0.21 & -0.02 & -0.33 \\
\hline Range & & 1.30 & 2.19 & 2.62 & 3.27 \\
\hline South Beach & 1.36 & & & & \\
\hline Upper & & 2.07 & 2.49 & 2.71 & 3.10 \\
\hline Lower & & 0.80 & 0.27 & -0.01 & -0.45 \\
\hline Range & & 1.27 & 2.22 & 2.72 & 3.55 \\
\hline
\end{tabular}

very similar, differing by less than $0.2 \mathrm{~m}$ for probabilities of $90 \%$ or less. Hence, these statistics are spatially uniform within a few tenths of a meter at Toke Point, Astoria, and South Beach. By implication, the same is true along the open coast at Seaside.

\subsection{Predicted Background Water Levels at Seaside}

Houston and Garcia (1978) used predicted tides to compute the effects of background water level fluctuations on the 100- and 500-year tsunami exceedance heights along the West Coast. Since observed water levels are available at only a limited number of sites along the West Coast and these are typically within embayments, there is an issue as to whether predicted tides can be used for the next generation of tsunami flood maps.

As a measure of the differences between the observed and predicted water levels that might occur at Seaside, a comparison between these was made for the water levels at South Beach. These are then compared with the predicted tides at Seaside. The pdf and exceedance probabilities were computed from 19-year (NTDE 1983-2001) time series of hourly tidal predictions (cubic interpolated to 15-minute values to be consistent with the procedures used on the observed time series). The South Beach and Seaside harmonic constants used to generate the predictions are shown in Table 4 . The height exceedance probabilities in Figs. 6 and 7 provide a measure of how much error would occur on average by using predicted rather than observed water levels for Seaside, since both South Beach and Seaside are located within the same meteorological and oceanographic regimes. The differences in the Seaside curves relative to those for South Beach are primarily due to the larger tidal range at Seaside, as seen in Figs. 3 and 5 for Astoria and Toke Point.

From the standpoint of probabilities (Figs. 6 and 7), there is very close 


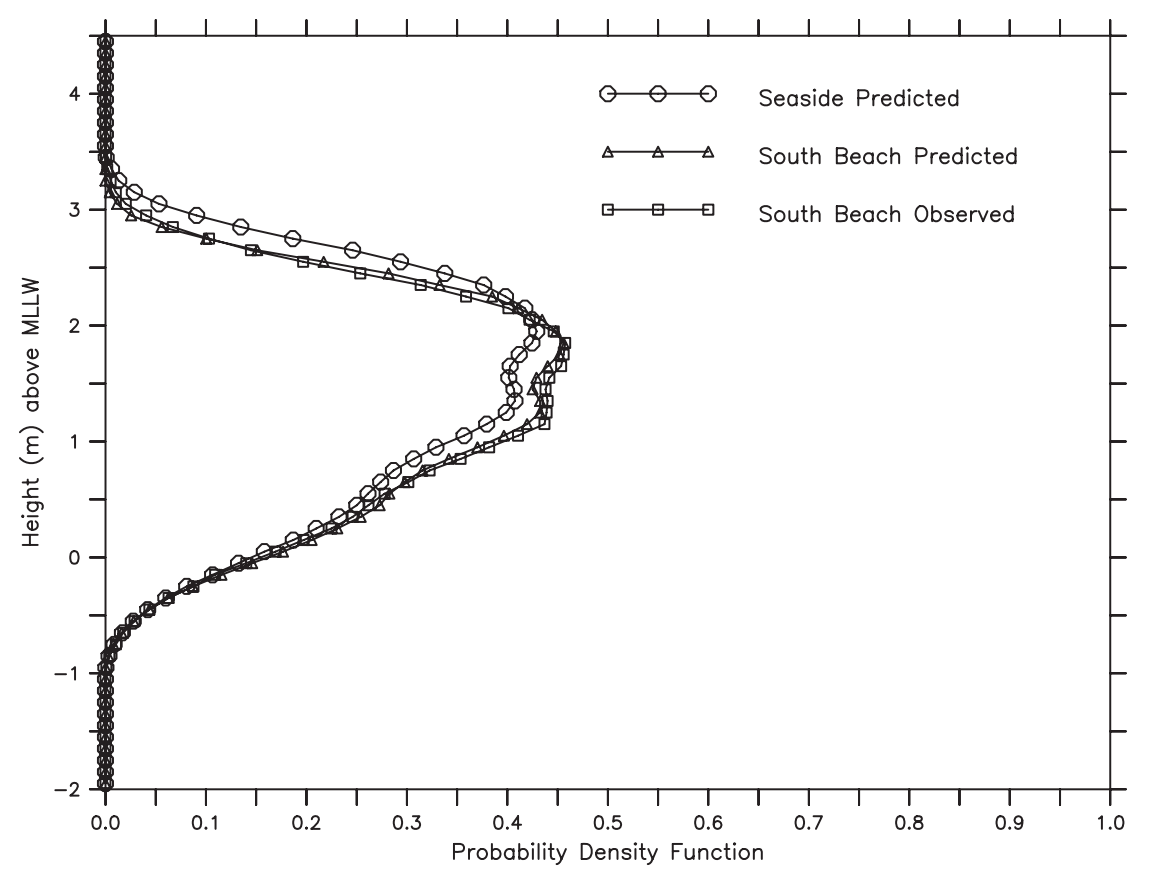

Figure 6: Probability density functions (pdfs) computed from predicted water levels at South Beach and Seaside. Also shown is the pdf computed from the observed water levels at South Beach.

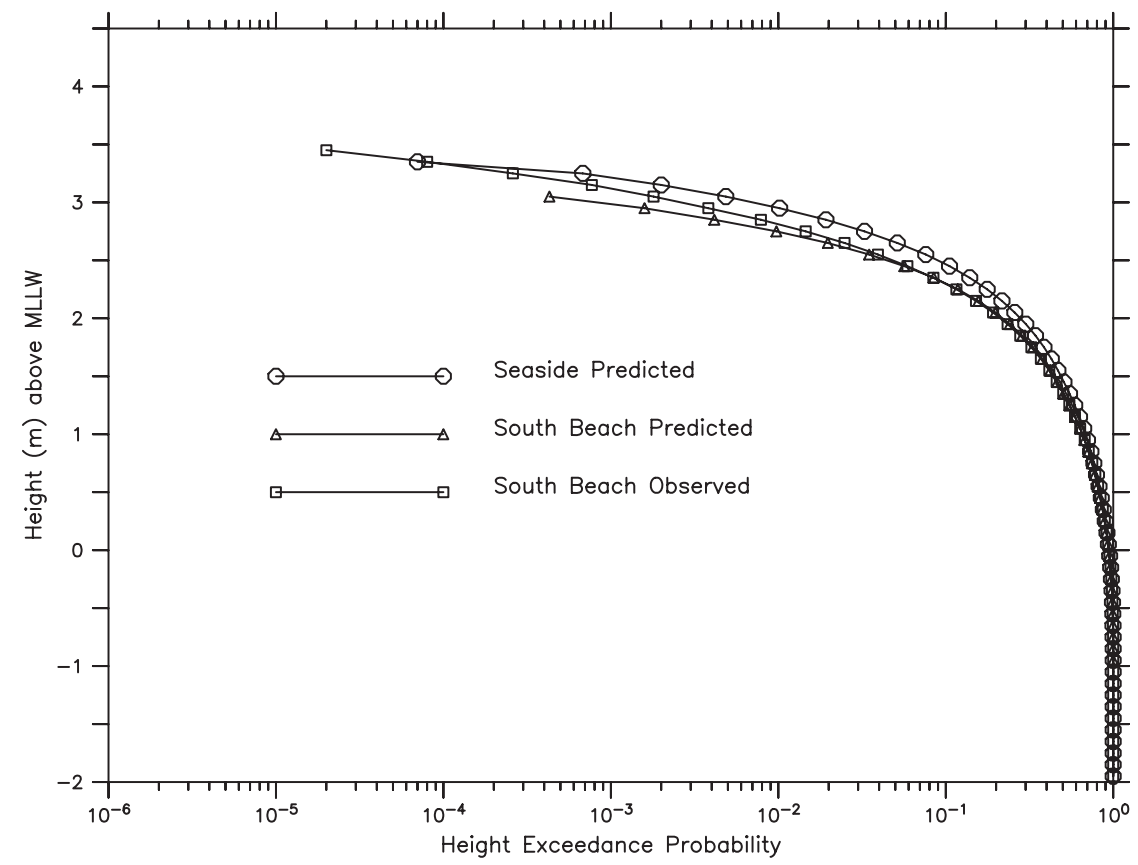

Figure 7: Same as Fig. 6 but with the logarithm of exceedance probability plotted against height. 
agreement between the observations and predictions for South Beach. The minor differences that do exist (Figs. 6 and 7) are due primarily to the storm surges and other non-tidal water level fluctuations that are not included in the tidal predictions. These give rise to the greater heights at low exceedance probabilities (Fig. 7). However, there is a very low probability that the maximum wave in a tsunami will arrive at Seaside at the same time as a winter storm, occurring during a major El Niño, than at lower heights where there is a very close match between the observed and predicted tides.

\section{Sea Level Trends}

When presenting the broad spectrum of coastal water levels, it is appropriate to also include a discussion of sea level trends. This is true even though they are not immediately relevant to the specific issues of computing 1percentage-annual-chance and 0.2-percentage-annual-chance quantities that are FEMA's definitions for the 100- and 500-yr exceedance values, respectively.

The sea level trends (Table 6 ) in the Cascadia region vary considerably between long-term tide stations. This indicates different vertical ground movement in the vicinity of the tide gages that are significant in magnitude compared with the present $\sim 1.4 \mathrm{~mm} / \mathrm{yr}$ of global sea level rise (Intergovernmental Panel on Climate Change (IPCC), 2001; Pugh, 2004). The upward ground movement at Neah Bay and Crescent City (Fig. 1) is large enough

to overwhelm oceanic sea level rise and produce negative trends that are significant at the $95 \%$ confidence level. In contrast, the observed trend at South Beach indicates continuing subsidence of the land near the tide gage.

The variation in trends (Table 6) along the length of Cascadia shows that the interseismic tectonic processes presently affecting relative sea level also vary with location along the coast. Given this variability, it is difficult to estimate the sea level trend at Seaside based solely on the observed trends elsewhere in the region. The observed trends at other sites serve as placing some bounds of the Seaside trend and, taken together with other information from GPS observations and geological interpretation, may help to further constrain estimates of the interseismic Seaside trend. There is also the important issue of coseismic ground movement (subsidence or uplift) during regional Cascadia Subduction Zone earthquakes.

\section{Joint Probability Methods Versus Direct Calculations}

One method for including tides and other water level fluctuations in the probability estimates of coastal flooding is via the joint probability method (JPM) described by, e.g., Tawn and Vassie (1991) and Pugh (1987, 2004). This method convolves (integrates their product over height) the pdf of the background water levels at a given coastal location with the pdf of modeled storm surges to get the total exceedance probability. The revised method (Tawn and Vassie, 1991) adjusts the probabilities to take into account the 
Table 6: Observed sea level trends at tide stations in the Cascadia region. Shown are trends in relative sea level, which are the sum of the separate vertical movements of the water and the land. Note that the uncertainty in the trend decreases with increasing series length.

\begin{tabular}{lcccccc}
\hline Station & $\begin{array}{c}\text { Trend } \\
(\mathbf{m m} / \mathbf{y r})\end{array}$ & $\begin{array}{c}\text { Stnd. Dev. } \\
(\mathbf{m m} / \mathbf{y r})\end{array}$ & $\begin{array}{c}\mathbf{9 5 \%} \mathbf{C ~ I} \\
(\mathbf{m m} / \mathbf{y r})\end{array}$ & Start & End & $\begin{array}{c}\text { Length } \\
\text { (years) }\end{array}$ \\
\hline Neah Bay & -1.41 & 0.22 & 0.43 & 1934 & 1999 & 66 \\
Toke Point & 2.82 & 1.05 & 2.06 & 1973 & 1999 & 27 \\
Astoria & -0.16 & 0.24 & 0.47 & 1925 & 1999 & 75 \\
South Beach & 3.51 & 0.73 & 1.43 & 1967 & 1999 & 33 \\
Charleston & 1.74 & 0.87 & 1.71 & 1970 & 1999 & 30 \\
Crescent City & -0.48 & 0.23 & 0.45 & 1933 & 1999 & 67 \\
\hline
\end{tabular}

non-random nature of the tides and the persistence in time (redundancy) of both the tides and the additional flooding event (e.g., storm surge), as well as possible non-linear interactions between tsunamis and the tides. A major issue in applying the revised JPM method to the tsunami problem would be finding the redundancy factors for the model tsunamis and background water levels.

An alternative to this method is that of Houston and Garcia (1978), in which each model tsunami is slid along the time series of background water levels. Since the time series of the model tsunamis are relatively short compared to the duration of significant waves in observed tsunamis, the model time series need to be extended in time. This can be done by assuming exponential amplitude decay, which Mofjeld et al. (2000) have shown matches closely the observed decay of Pacific tsunamis.

\section{Summary and Conclusions}

For tides on the open coast at Seaside, Oregon, a comparison has been made of predictions based on the ENPAC 2003 tide model of Spargo (2003) and Spargo et al. (in press) with the observed and predicted water levels at long-term tide stations in the region. This comparison shows there is close agreement for many of the tidal quantities that are relevant to probabilistic tsunami mapping. This is fortunate, since Seaside is not served by a long-term tide station. The tidal datums inferred from the model harmonic constants and those interpolated from observed values at Hammond and Garibaldi (Fig. 1) are found to be within $0.05 \mathrm{~m}$ for $\mathrm{MHW}$ relative to MLLW. Having an accurate estimate of this height difference is essential for generating the digital elevation model (DEM) for tsunami modeling. There are substantial differences between the coastal datums at Seaside and those observed within the Necanicum River, possibly due to restricted tidal exchange through the river mouth.

Close agreement exists between probability distributions at the long-term South Beach station and those at the Seaside open coast. This is due in part to the proximity of the South Beach station to the coast and the free tidal exchange through the inlet to Yaquina Bay. Conversely, the comparison 
of tidal quantities at Toke Point, Astoria, and South Beach (Fig. 1) reveals greater differences, probably at least partly due to local tidal dynamics in the bays where these tide stations are located. However, the exceedance curves

from all the tide stations are very close to each other and, by implication, to that on the outer coast at Seaside. These results also suggest that predicted tides should be adequate when linearly combining coastal tsunami heights with background water levels to estimate probabilities.

The goal of the Tsunami Pilot Study is to develop methods that can be applied to probabilistic tsunami hazard assessment and mapping along the U.S. West Coast. The analyses and comparison outlined in this technical memorandum, together with the distribution of long-term tide stations along the Coast, suggest that the methods used here will work effectively to characterize background water levels at other locations where direct long-term water level observations are not available.

\section{Acknowledgments}

The authors wish to thank Maria Little (NOAA/NOS/Center for Operational Oceanographic Products and Services), Emily Spargo, Ed Myers (NOAA/NOS/Coastal Survey Development Laboratory), and Mike Foreman (Fisheries and Oceans Canada/Institute of Ocean Sciences) for providing datums, harmonic constants, and other useful tidal information.

\section{References}

Foreman, M.G.G., W.R. Crawford, J.Y. Cherniawsky, R.F. Henry, and M.R. Tarbotton (2000): A high-resolution assimilating tidal model for the northeast Pacific Ocean. J. Geophys. Res., 105 (C12), 28,629-28,651.

Houston, J.R., and A.W. Garcia (1978): Type 16 Flood Insurance Study: Tsunami predictions for the West Coast of the Continental United States. USACE USACE Waterways Experimental Station Tech. Rprt H-78-26.

Intergovernmental Panel on Climate Change (IPCC) (2001): Climate Change 2001: Impacts, Adaptation and Vulnerability. Cambridge Univ. Press, 1032 pp.

Kjerfve, B., and B.A. Knoppers (1991): Tidal choking in a coastal lagoon. In Tidal Hydrodynamics, B.B. Parker (ed.), Wiley, 169-181.

Mofjeld, H.O., F.I. González, E.N. Bernard, and J.C. Newman (2000): Forecasting the heights of later waves in Pacific-wide tsunamis. Nat. Hazards, 22, 71-89.

Mofjeld, H.O., F.I. González, M.C. Eble, and J.C. Newman (1995): Ocean tides in the continental margin off the Pacific Northwest Shelf. J. Geophys. Res., 100 (C6), 10,789-10,800.

Mofjeld, H.O., A.J. Venturato, F.I. González, V.V. Titov, and J.C. Newman (2004): The harmonic constant datum method: Options for overcoming datum discontinuities at mixed-diurnal tidal transitions. J. Atmos. Oceanic Tech., 21, 95-104.

Myers, E.P., and A.M. Baptista (2001): Inversion for tides in the Eastern North Pacific Ocean. Adv. Water. Resour., 24(5), 505-519.

Pugh, D.T. (1987): Tides, Surges and Mean Sea-Level. Wiley, 472 pp.

Pugh, D.T. (2004): Changing Sea Levels: Effects of Tides, Weather and Climate. Cambridge Univ. Press, 265 pp.

Schureman, P. (1976): Manual of Harmonic Analysis and Prediction of Tides. C\&GS Spec. Publ. No. 98, U.S. Government Printing Office, 317 pp. 
Spargo, E., J. Westerink, R. Luettich, and D. Mark (2004): Developing a tidal constituent database for the Eastern North Pacific Ocean. In Proceedings of the 8th International Conference on Estuarine and Coastal Modeling, Monterey, CA, 3-5 November 2003, in press.

Spargo, E.A. (2003): Using a Finite Element Model of the Shallow Water Equations to Model Tides in the Eastern North Pacific Ocean. M.S. Thesis, University of Notre Dame, 224 pp.

Tawn, J.A., and J.M. Vassie (1991): Recent improvements in the joint probability method for estimating extreme sea levels. In Tidal Hydrodynamics, B.B. Parker (ed.), Wiley, 813-828.

Venturato, A.J. (in preparation): A digital elevation model for Seaside, Oregon: Procedures, data sources, and analyses. NOAA Tech. Memo. 



\section{Appendix B: NOAA Technical Memorandum OAR PMEL- 129, "A digital elevation model for Seaside, Oregon: Proce- dures, data sources, and analyses" by A.J. Venturato.}

NOAA Technical Memorandum OAR PMEL-129

\section{A DIGITAL ELEVATION MODEL FOR SEASIDE, OREGON: PROCEDURES, DATA SOURCES, AND ANALYSES}

Angie J. Venturato

Joint Institute for the Study of the Atmosphere and Ocean (JISAO)

University of Washington, Seattle, WA

Pacific Marine Environmental Laboratory

Seattle, WA

November 2005

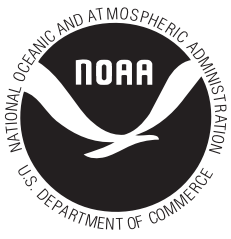




\section{NOTICE}

Mention of a commercial company or product does not constitute an endorsement by NOAA/OAR. Use of information from this publication concerning proprietary products or the tests of such products for publicity or advertising purposes is not authorized.

Contribution No. 2812 from NOAA/Pacific Marine Environmental Laboratory

For sale by the National Technical Information Service, 5285 Port Royal Road

Springfield, VA 22161 


\section{Contents}

1. Introduction .................... 1

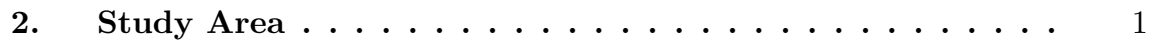

3. Methodology ................. 3

3.1 Data Sources and Processing ........... . . 3

3.1.1 Shoreline . . . . . . . . . . . . . 3

3.1.2 Bathymetry ................. 5

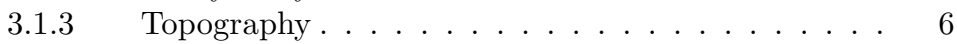

3.2 DEM Development . . . . . . . . . . . . . . . 10

3.3 Quality Assurance .. . . . . . . . . . . . . . . 10

3.4 Historical shoreline analysis . . . . . . . . . . . . . . . 13

4. Summary and Conclusions ............... 14

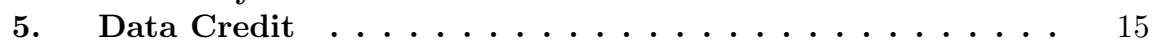

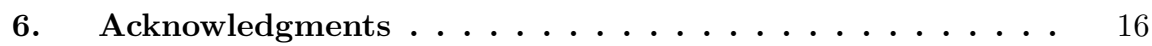

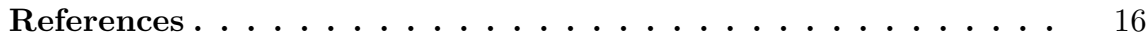

\section{List of Figures}

1 Study area of the FEMA FIRM project for Seaside, Oregon. . . . . . 2

2 Estimated contours used to correct vertical datums to Mean High

Water. . . . . . . . . . . . . . . . 4

3 Shoreline vector analysis . . . . . . . . . . . . . 4

4 Estimated depth surface of the Necanicum River estuarine region. . 6

5 Coverage areas of bathymetric data sources used in the DEM . . . . 7

6 Coverage area of topographic data sources used in DEM development 7

7 Topographic data analyses . . . . . . . . . . . . . . . . 9

8 Steps of DEM development: (a) bathymetric grid, (b) topographic grid, and (c) merged grid. . . . . . . . . . . . . . . . . . . 11

9 Spatial density distribution . . . . . . . . . . . . . . . . 11

10 Historical shoreline depicting the apparent Mean High Water line based on orthophotography obtained from the University of Oregon

11 Accretion and erosion trends of the Necanicum River mouth over a 55-year period. . . . . . . . . . . . . . . . 14

\section{List of Tables}

1 Parameters set by the modeler for the high-resolution DEM. . . . . . 3

2 Shoreline data sources. . . . . . . . . . . . . 5

3 Bathymetric data sources from the National Ocean Service . . . . . 5

4 Topographic data sources . . . . . . . . . . . . . 8

5 Comparison of NGS vertical control points with the DEM . . . . . . 12

6 Estimate of total DEM error. . . . . . . . . . . . . . . 15 
This page is intentionally left blank. 


\title{
A Digital Elevation Model for Seaside, Oregon: Procedures, Data Sources, and Analyses
}

\author{
Angie J. Venturato ${ }^{1}$
}

\section{Introduction}

As part of a probabilistic tsunami hazard assessment pilot study to modernize Flood Insurance Rate Maps for the Federal Emergency Management Agency (González et al., 2004), the NOAA Center for Tsunami Inundation Mapping Efforts (TIME) developed a digital elevation model (DEM) for the purpose of modeling tsunami inundation for Seaside, Oregon. The finite-difference inundation model requires a series of nested computational elevation grids to simulate tsunami generation, propagation, and inundation in the region of interest (Fig. 1). To properly simulate the non-linear wave dynamics of inundation, a high-resolution DEM merging land and seafloor elevations is required (González et al., 2005). A merged DEM with a resolution of $1 / 3$ arc-seconds (approximately 10 meters) was developed for the Seaside, Oregon area. This technical memorandum provides a summary of the data sources and methodology used.

\section{Study Area}

The study area covers the coastal communities of Seaside and Gearhart in Clatsop County, Oregon. The Seaside-Gearhart area has a population of 6900 based on 2000 U.S. Census data, with a projected growth rate of $13 \%$ within the next decade (Clatsop County, 2005). The area's economy is primarily based on tourism with tens of thousands of visitors during the peak summer season (Oregon Coast Visitors Association, personal communication). Several tourist accommodations line the promenade, a 2-mile concrete boardwalk along the ocean beachfront.

Seaside is part of the Clatsop Plains, which is a low-lying coastal area from the Columbia River to Tillamook Head abutted on the east side by the hills of the Oregon Coast Range (Fig. 1b). Soils consist primarily of sand dune ridges and silt loam (USDA Natural Resources Conservation Service, 1994). The sand ridges run parallel to the ocean shore due to littoral accretion from the Columbia River (Fiedorowicz, 1997). Beachgrass and shrubs along sand ridges and Sitka spruce inland are the main vegetation types outside of urban areas (Oregon Natural Heritage Program, 1999).

The Necanicum River flows through the center of Seaside where it joins the Neawanna and Neacoxie Creeks, forming an estuary bay before draining into the Pacific Ocean (Fig. 1c). The Necanicum River bar-built estuary has a low water volume with a watershed of approximately 225 square kilometers (Oregon Ocean-Coastal Management Program, 2000).

\footnotetext{
${ }^{1}$ Joint Institute for the Study of Atmosphere and Ocean (JISAO), University of Washington, Box 354235, Seattle, WA 98195-6349
} 

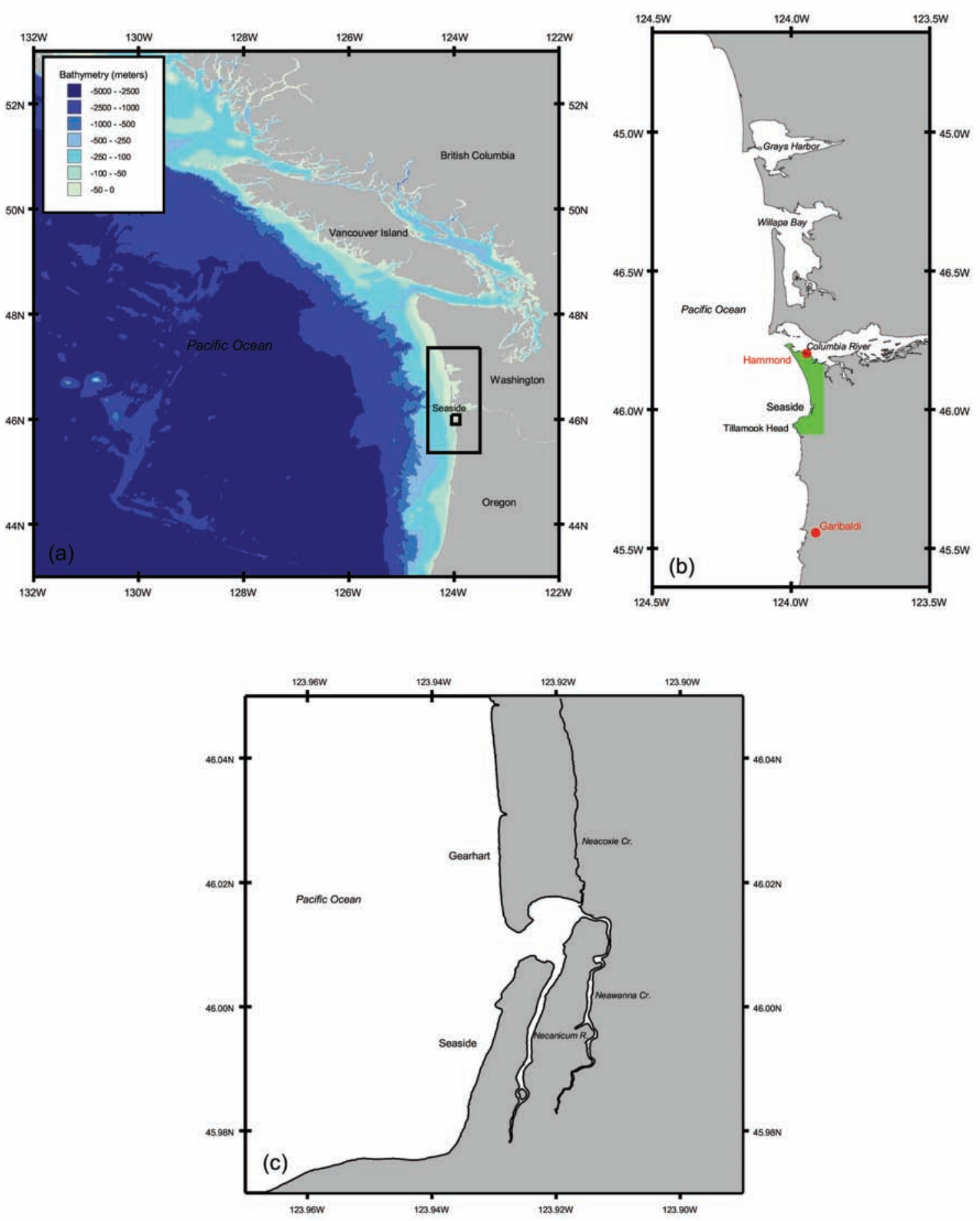

Figure 1: Study area of the FEMA FIRM project for Seaside, Oregon. (a) The nested grids used by the model. (b) Display of the Columbia River littoral cell with associated NOS water-level stations. (c) Details of the study region. 


\section{Methodology}

The modeler set parameters for the grid based on input requirements for the inundation model (Table 1). Other criteria, such as obtaining the best available data, were also established in the planning process using recommended practices from prior inundation modeling efforts (González et al., 2005). Data processing, grid assembly, and quality assurance are described in the following subsections.

\subsection{Data Sources and Processing}

Bathymetric, topographic, shoreline, control, and orthophotographic data were obtained from various government agencies. The primary data sources were obtained from the U.S. Geological Survey (USGS), NOAA National Ocean Service (NOS), and the Oregon Geospatial Data Clearinghouse (OGDC). Datasets were converted into formats compatible with ESRI ArcView GIS ${ }^{\circledR} 3.3$.

Data sets were corrected to the common data framework established by modeler parameters. The ArcView Projection Utility was used to convert projected horizontal coordinates and datums to geographic coordinates and NAD83. Vertical datum transformation was applied based on the methodology described in Mofjeld et al. (2004). A vertical datum surface was developed using linearly interpolated values from official NOS datums at Hammond and Garibaldi, Oregon and a historical tertiary NOS water-level station in the Necanicum River estuary (Fig. 2).

\subsubsection{Shoreline}

Vector data representing the Mean High Water line were collected from the NOAA Shoreline Data Explorer and OGDC (Table 2). Significant discrepancies were found when comparing datasets (Fig. 3a). Orthorectified photographs conducted in 2000 by the National Aerial Photography Program (NAPP) were obtained from OGDC to perform a visual analysis (Table 2). A

Table 1: Parameters set by the modeler for the high-resolution DEM.

\begin{tabular}{ll}
\hline Pilot study site & Seaside, Oregon \\
Coverage area & West boundary: -124.04 \\
& East boundary: -123.89 \\
& North boundary: 46.08 \\
& South boundary: 45.90 \\
Coordinate system & Geographic decimal degrees \\
Horizontal datum & North American Datum of 1983 (NAD83) \\
Vertical datum & Mean High Water \\
Vertical units & Meters \\
Grid resolution & $1 / 3$ arc-seconds \\
Grid format & ASCII raster grid \\
\hline
\end{tabular}




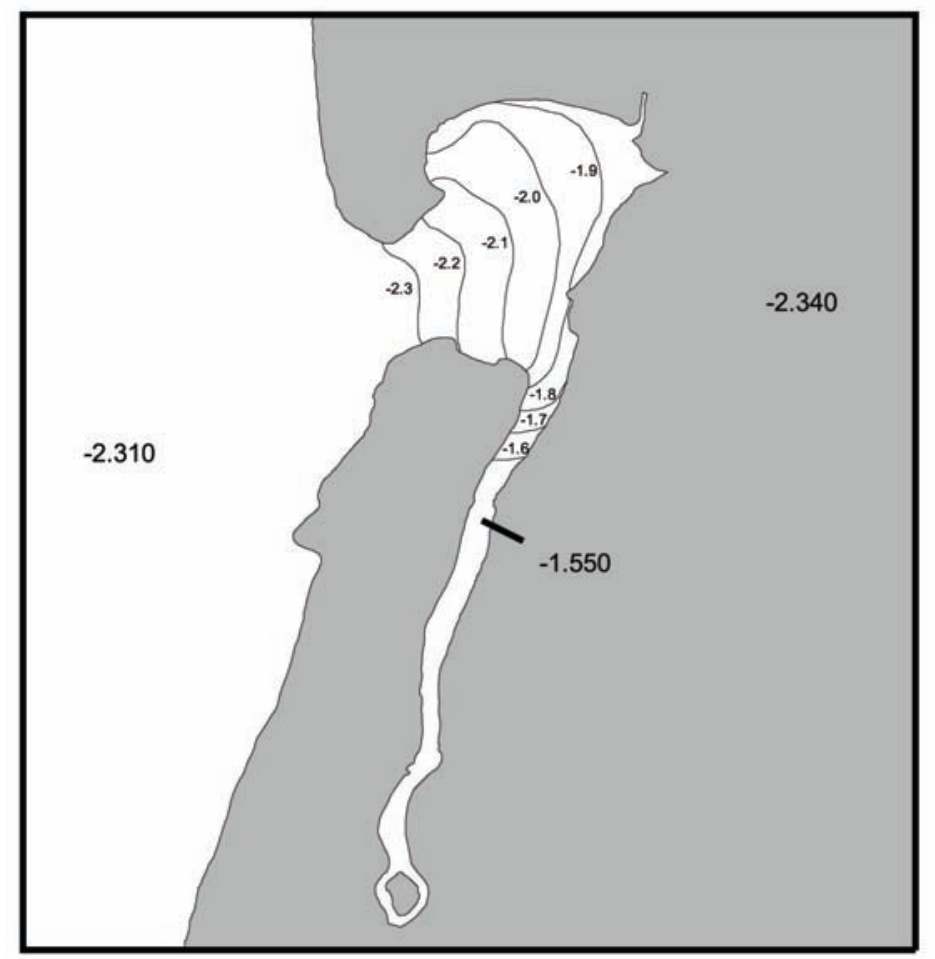

Figure 2: Estimated contours used to correct vertical datums to Mean High Water. Values are based on Mofjeld et al. (2004).
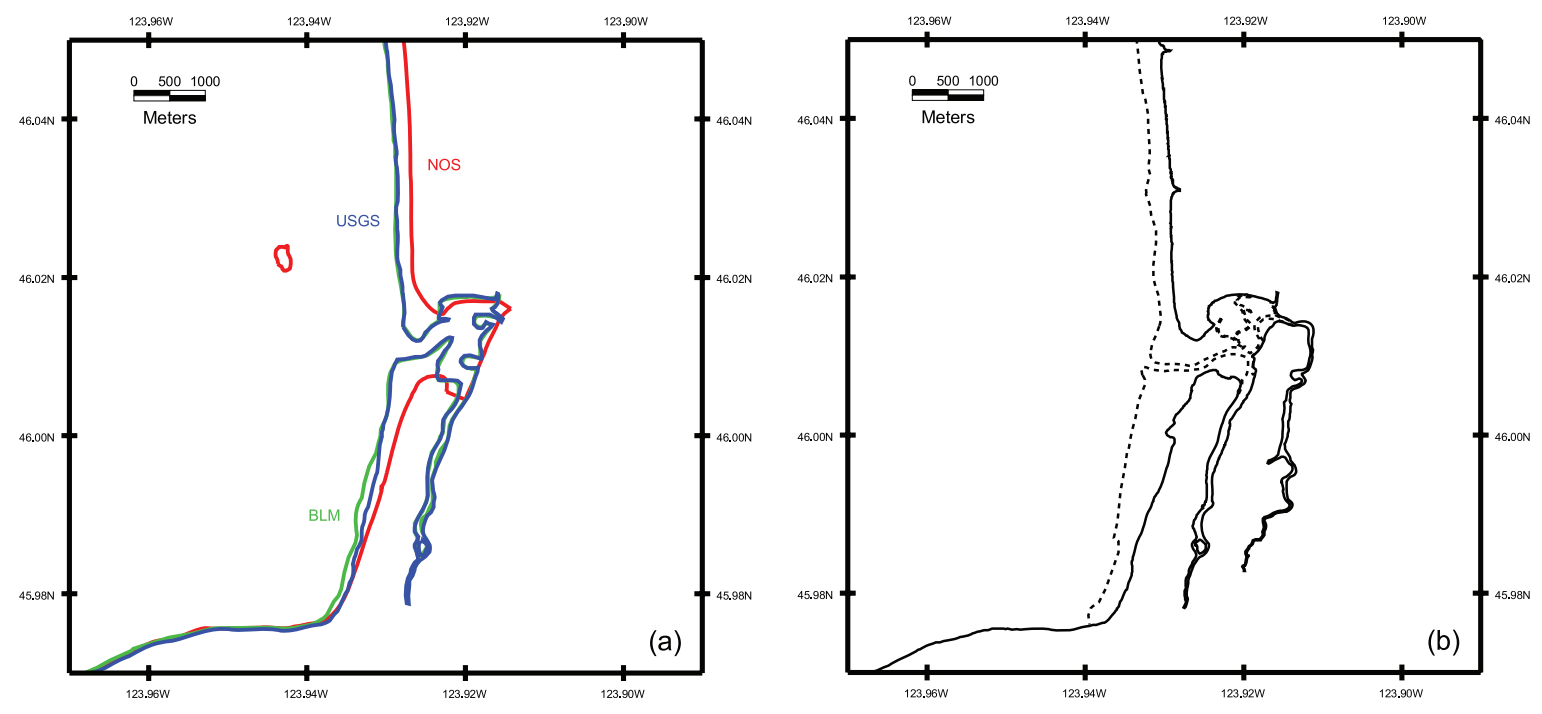

Figure 3: Shoreline vector analysis. (a) Shoreline vectors from the Bureau of Land Management (BLM) in green, National Ocean Service (NOS) in red, and U.S. Geological Survey (USGS) in blue. (b) Corrected shoreline vectors used in DEM development. The dashed line represents apparent Mean Lower Low Water based on recent orthophotos. The solid line represents Mean High Water. 
Table 2: Shoreline data sources.

\begin{tabular}{lccc}
\hline \multicolumn{1}{c}{ Source } & Survey(s) & Year & Scale \\
\hline NOAA Shoreline Data Explorer & OR43C04 & 1926 & $1: 20,000$ \\
USGS Hydrographic Vectors & $45123 \mathrm{~h} 8$ & 1973 & $1: 24,000$ \\
& $46123 \mathrm{a} 8$ & & \\
Bureau of Land Management & Various & 1999 & $1: 24,000$ \\
National Aerial Photography Program & $45123 \mathrm{~h} 8$ & 2000 & $1: 24,000$ \\
& $46123 \mathrm{a} 8$ & & \\
\hline
\end{tabular}

Table 3: Bathymetric data sources from the National Ocean Service. No survey data were available for the Necanicum River region.

\begin{tabular}{llccc}
\hline \multicolumn{1}{c}{ Source } & Survey & Year & Scale & Spatial Resolution \\
\hline NOSHDB & H04611 & 1926 & $1: 20,000$ & $50-200 \mathrm{~m}$ \\
NOSHDB & H04612 & 1926 & $1: 20,000$ & $50-200 \mathrm{~m}$ \\
NOSHDB & H04635 & 1926 & $1: 40,000$ & $50-200 \mathrm{~m}$ \\
NOSHDB & H08417 & 1958 & $1: 20,000$ & $50-200 \mathrm{~m}$ \\
LDART & Spring 1998 & 1998 & N/A & $5 \mathrm{~m}$ \\
\hline
\end{tabular}

resulting shoreline file with vectors representing both Mean High Water and Mean Lower Low Water was created using the Bureau of Land Management (BLM) vectors with revisions made based on photography (Fig. 3b). Polygonal files representing water and land were derived from data corresponding to the Mean High Water line.

\subsubsection{Bathymetry}

Bathymetric datasets consisted of four hydrographic surveys obtained from the NOS Hydrographic Database (NOSHDB) and LIDAR data from the NOS Coastal Services Center (CSC) (Table 3). Various Federal, State, and local agencies were contacted for recorded depth information on the Necanicum River estuary, yielding no results. Tom Horning of Horning Geosciences provided an estimated depth based on field observations (personal communication). This estimation was combined with limited LIDAR data within the intertidal zone to develop an estimated depth surface for the estuary (Fig. 4).

NOSHDB surveys were conducted using a single-beam digital echo sounder or lead line sounding method. The database processing system converted sounding depths to NAD83 and corrected meters using the National Geodetic Survey (NGS) NADCON software and Carter's tables (Carter, 1980), respectively. The accuracy of these surveys is difficult to determine. Accuracy standards were not established until 1965, and the values were digitized from hand-drawn maps. The surveys within the immediate vicinity of Seaside were based on the North American Datum of 1913, which required an 


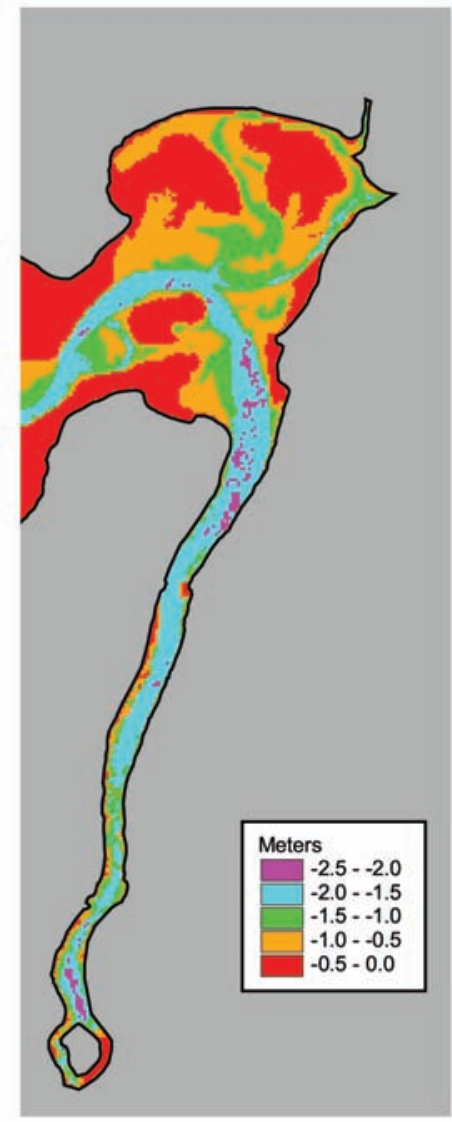

Figure 4: Estimated depth surface of the Necanicum River estuarine region.

additional transformation based on a single pair of datum shift values before applying NADCON (National Geophysical Data Center, 2004).

LIDAR data were obtained using the CSC LIDAR Data Retrieval Tool (LDART) to cover the intertidal zone. The Topography section provides details on these data.

Approximately 75,000 bathymetric points were selected from the surveys and surface model with recent data superseding older data in overlapping areas. Four anomalous points were removed from the selection. Spatial polygons were created to display selected coverage areas (Fig. 5) within the area of interest. $95 \%$ of the project area was covered by NOS survey soundings of variable density.

\subsubsection{Topography}

LIDAR data from LDART, a 10-meter DEM from the USGS National Elevation Dataset (NED), and a 10-meter DEM used in prior tsunami hazard modeling (Priest et al., 1998) were obtained as topographic datasets. Fifteen 


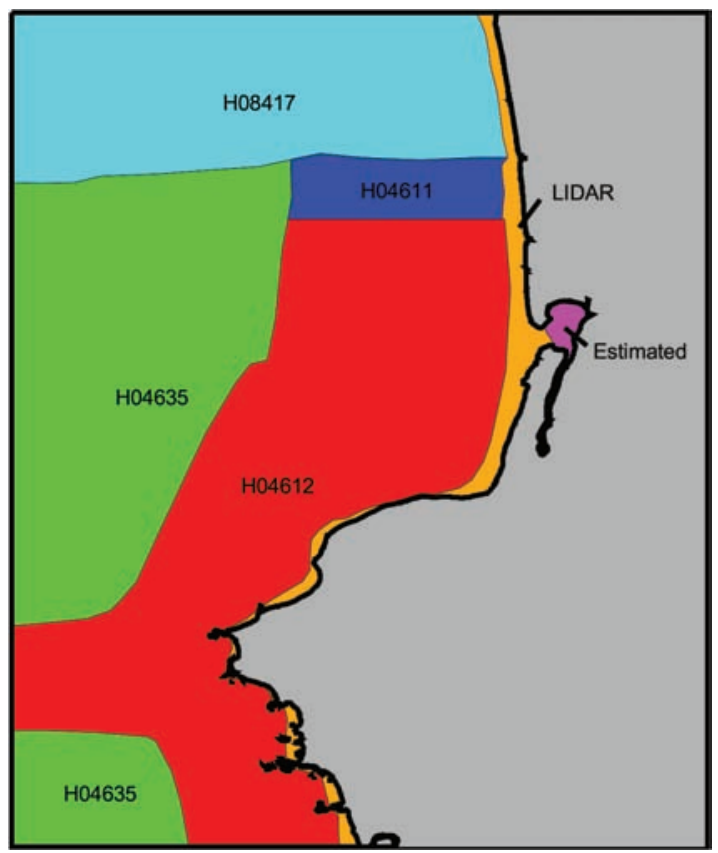

Figure 5: Coverage areas of bathymetric data sources used in the DEM. The Necanicum River region was estimated from limited LIDAR data and estimates from Horning (see Fig. 4). The coverage areas were clipped to the study area boundaries for display purposes; however, the selected data sources extend beyond the boundary to avoid interpolation edge errors during grid development.

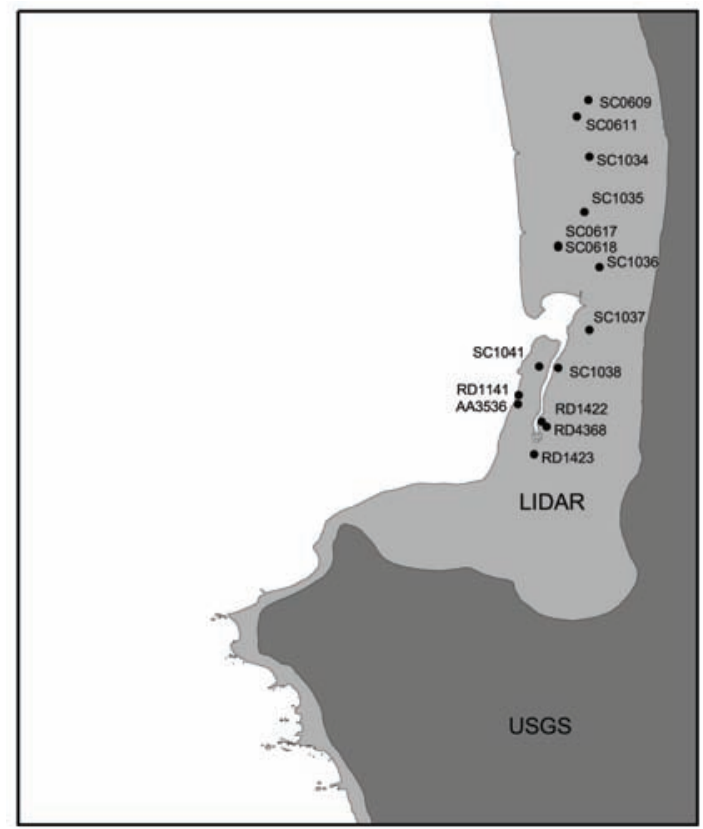

Figure 6: Coverage area of topographic data sources used in DEM development (clipped to boundary for display). Vertical control points are depicted by identification number. 
Table 4: Topographic data sources. The associated root mean square (RMS) error is based on source metadata and NGS control point comparison.

\begin{tabular}{|c|c|c|c|c|c|c|}
\hline Source & Survey & Year & $\begin{array}{c}\text { Spatial } \\
\text { Resolution }\end{array}$ & $\begin{array}{c}\text { Horizontal } \\
\text { RMS Error } \\
\text { based on } \\
\text { metadata } \\
\end{array}$ & $\begin{array}{c}\text { Vertical } \\
\text { RMS Error } \\
\text { based on } \\
\text { metadata }\end{array}$ & $\begin{array}{c}\text { Vertical } \\
\text { RMS Error } \\
\text { based on } \\
\text { comparison }\end{array}$ \\
\hline LDART & Spring 1998 & 1998 & $5 \mathrm{~m}$ & $0.80 \mathrm{~m}$ & $0.15 \mathrm{~m}$ & $0.21 \mathrm{~m}$ \\
\hline LDART & Fall 1997 & 1997 & $5 \mathrm{~m}$ & $0.80 \mathrm{~m}$ & $0.15 \mathrm{~m}$ & $0.37 \mathrm{~m}$ \\
\hline $\begin{array}{l}\text { David C. Smith } \\
\text { \& Associates, Inc. }\end{array}$ & 1996 & 1996 & $10 \mathrm{~m}$ & $\mathrm{~N} / \mathrm{A}$ & $\mathrm{N} / \mathrm{A}$ & $0.77 \mathrm{~m}$ \\
\hline USGS NED & $\begin{array}{l}45123 \mathrm{~h} 8 \\
46123 \mathrm{a} 8\end{array}$ & 1973 & $10 \mathrm{~m}$ & $15 \mathrm{~m}$ & $15 \mathrm{~m}$ & $1.24 \mathrm{~m}$ \\
\hline
\end{tabular}

vertical survey control datasheets were collected from NGS for comparison with each dataset (Fig. 6). Table 4 provides information on each dataset.

The LIDAR surveys were conducted as part of the Airborne Topographic Mapper Mission to cover coastal areas. The data were collected at low tide using a pulsed laser with a wavelength of 550 nanometers. Quality assessment of the survey data is limited to internal consistency checks with filtering to remove outliers of first returns. A detailed analysis of the LIDAR data was made to remove vegetation by selecting points with the highest likelihood of being on the surface. This analysis was conducted using Spatial Analyst and 3D Analyst (Fig. 7b). Rectified orthophotos were used to remove points representing apparent vegetation or structures (Fig. 7c) to create a corrected LIDAR dataset.

The USGS NED DEM was developed in 1999. The dataset was derived using bilinear interpolation of hypsography and hydrography contours based on surveys conducted in 1973. The majority of the Seaside area is below the hypsography contour interval of 25 feet $(7.6 \mathrm{~m})$. A comparative analysis of the USGS data with the corrected LIDAR survey data revealed significant differences in these low-lying areas. The USGS DEM was edited to select only those values above the 250 -foot contour and outside of the boundary of the available LIDAR data. Further edits were made to contours derived from the USGS DEM to remove boundary discrepancies (Fig. 7d).

David C. Smith and Associates, Inc., developed the 10-meter DEM used in prior tsunami hazard modeling. It was based on 1996 orthorectified aerial photography. DEM values did not compare well with LIDAR or USGS data (Fig. 7e). Comparison with control data along the coast also showed an average error of $3 \mathrm{~m}$. Since little information was available on the development procedure for this dataset, it was not considered a viable input option.

The corrected 1998 LIDAR survey and USGS NED DEM data were selected as final input for the DEM (Fig. 6). LIDAR covered approximately $45 \%$ of the project area. 

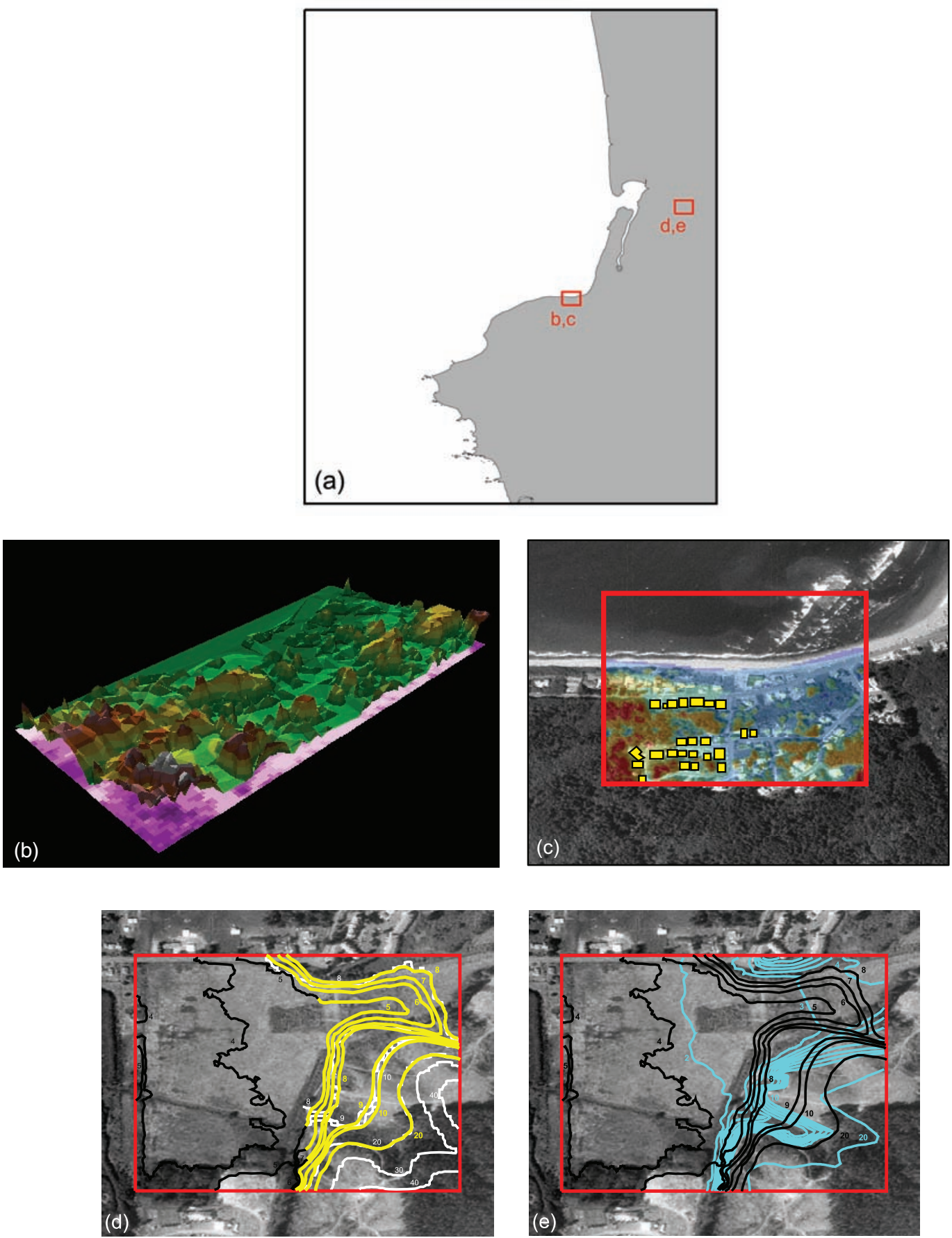

Figure 7: Topographic data analyses. (a) Red boxes depict sample areas as detailed in associated panels. (b) Analysis of LIDAR data using 3D Analyst with $2 \mathrm{~m}$ vertical exaggeration. Peaks suggest possible vegetation or infrastructure. (c) LIDAR data is corrected to remove vegetation and infrastructure using orthophotography as a reference. Polygons (yellow boxes) representing buildings are drawn to select and remove data values that do not represent the "bald earth." (d) Contour comparison of LIDAR (black) and USGS NED (white) data along the boundary of the LIDAR survey. A vector file (yellow) is created to correct disparities between datasets with reference to orthophotography. (e) Contour comparison of corrected data (black) with DEM used in prior tsunami hazard modeling efforts (blue). 


\subsection{DEM Development}

A simple method of Delauney triangulation and natural neighbor interpolation was used to build the DEM. Delauney triangulation, also known as the triangular irregular network (TIN) method, constructs a surface of continuous non-overlapping triangles based on mass points and breaklines. A TIN maintains data values within the range of vertices and will not extend beyond boundaries. Its main disadvantage is the creation of triangular plateaus due to all vertices having the same elevation value. This usually occurs when using contours as an input. The inputs for this study consisted primarily of mass points.

Natural neighbor interpolation helps create a smoother raster grid by using an areal weighting scheme on the nearest TIN vertices to the output raster cell. Other methods such as spline interpolation with tension or inverse distance weighting are also viable options, but were not investigated.

DEM development consisted of three steps: building the bathymetric grid, building the topographic grid, and then merging the two grids into the final DEM (Fig. 8). This process was chosen based on modeler requirements to ensure a definitive distinction between land (positive) and water (negative) values. Zero or near-zero values cause anomalies in the inundation model. Consequently, all land values were restricted to $\geq 0.01 \mathrm{~m}$ and all water values to $\leq-0.01 \mathrm{~m}$.

The bathymetric grid was built using selected bathymetric data and the land polygon (with a value of $-0.01 \mathrm{~m}$ ) as input for the interpolation. The resulting grid was clipped to the water polygon. The topographic grid used selected topographic data sources and the water polygon (with a value of $0.01 \mathrm{~m}$ ) as input and then clipped to the land polygon in the same manner. Spatial analysis was used to find problem areas, which were corrected by re-interpolating after removing anomalous points or adding supplementary points and contours.

The topographic and bathymetric grids were merged into a final DEM and analyzed for consistency. Any null values were set to $0.01 \mathrm{~m}$. The DEM was exported to an ASCII raster grid and distributed to the modeler.

\subsection{Quality Assurance}

The quality of the DEM is difficult to determine. A number of different factors contribute to cumulative DEM error, including inherent error within the various selected data sources, conversion error, error due to interpolation of spatially varying data sources, and error due to subjective interpretation. An attempt to quantify some of these factors is provided below.

Inherent errors in the data sources are provided in the Data Sources and Processing section. The spatial density of selected bathymetry and topography data show high-density in low-lying and intertidal areas with sparse data offshore (Fig. 9). Offshore values of the DEM are based on interpolation of distant data points, whereas near-shore values are based on data points that support the requested $1 / 3$ arc-second resolution.

Horizontal datum conversions were primarily made using NADCON trans- 

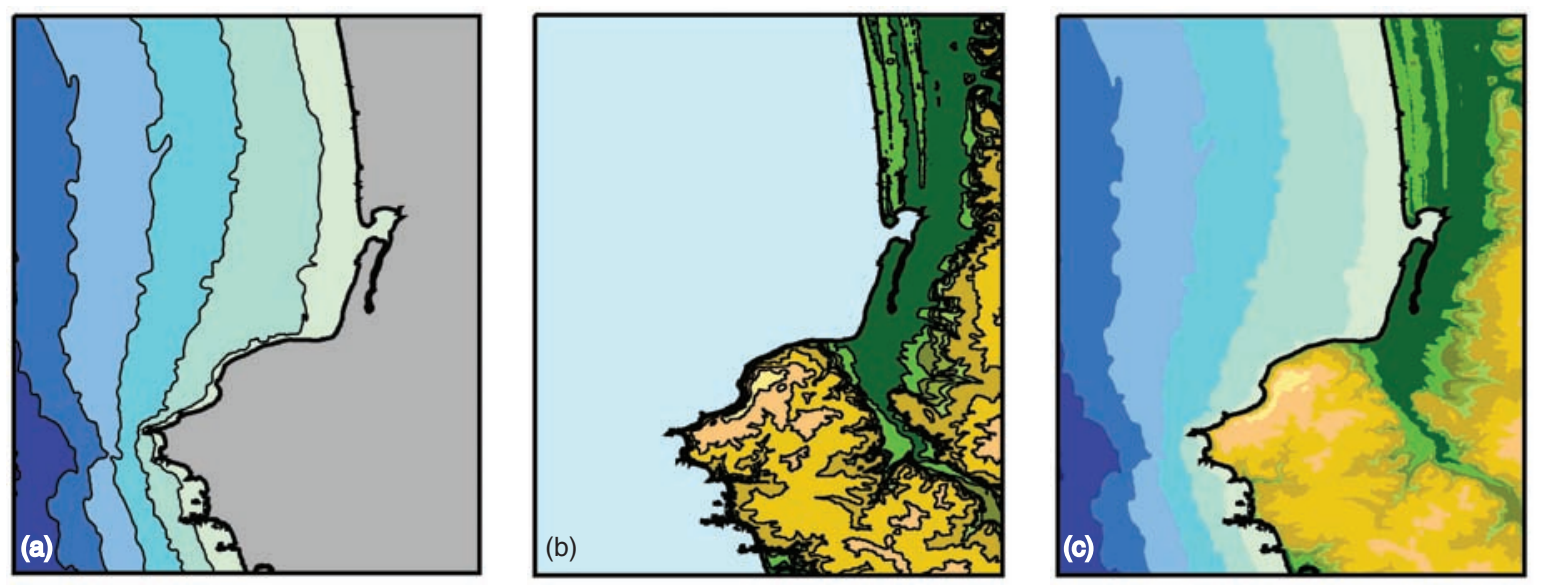

Figure 8: Steps of DEM development: (a) bathymetric grid, (b) topographic grid, and (c) merged grid.

(a)
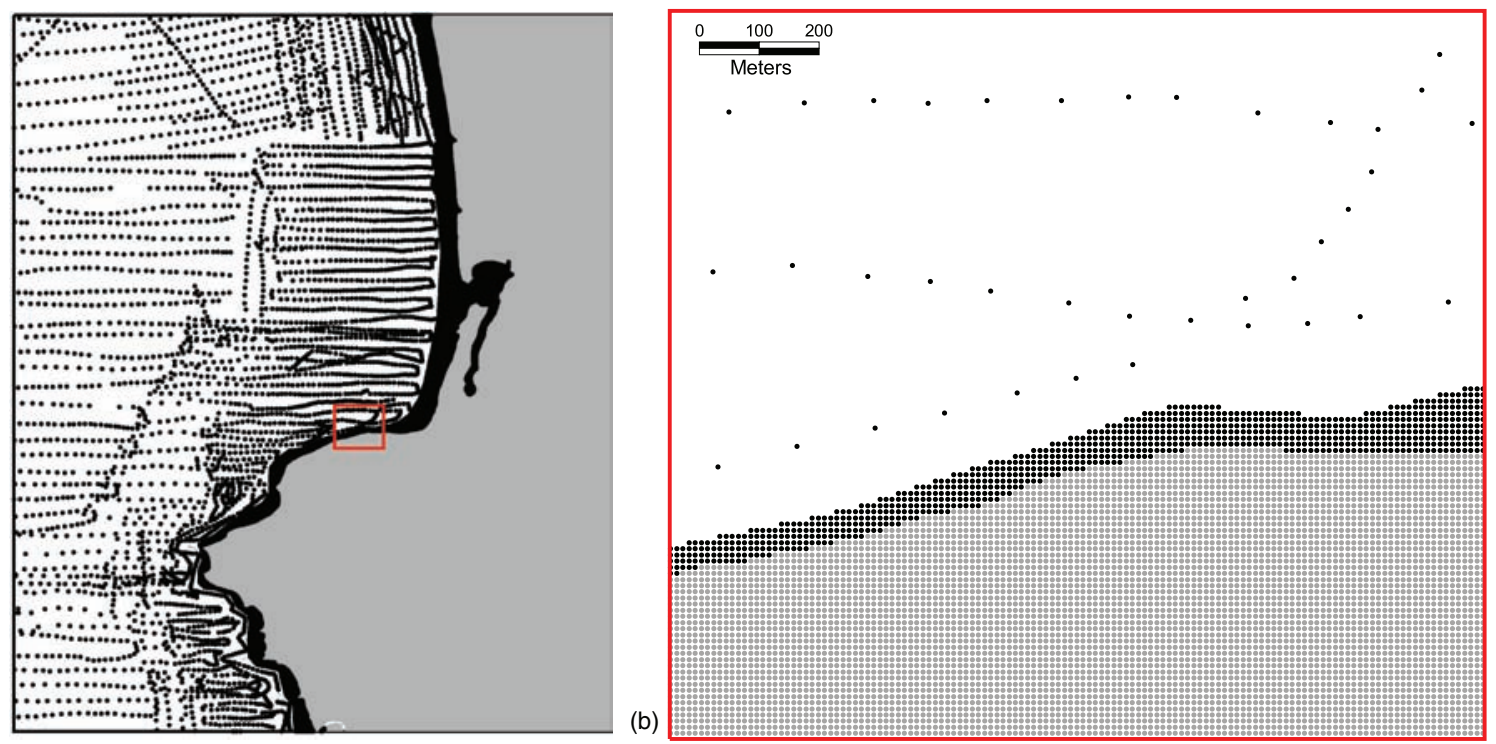

Figure 9: Spatial density distribution. (a) Spatial density of selected bathymetric (black) and topographic (gray) data sources. Red box depicts (b) detailed display of distribution. The topographic data had a much higher density (ranging from 5-10 m) than the bathymetric data (ranging from 5-200 m). 
formation, which is based on a minimum-curvature model (Dewhurst, 1990). The conversion from NAD27 to NAD83 introduces uncertainty of $0.15 \mathrm{~m}$ at a $67 \%$ confidence level. Converting from older North American datums to NAD83 leads to a conversion error of $0.20 \mathrm{~m}$ (National Geodetic Survey, 2004).

Converting from a map projection to geographic coordinates also introduces error. A few data sources were in Oregon Lambert Projection or Oregon State Plane Projection. The conversion error for both of these projections is $0.10 \mathrm{~m}$ (Snyder, 1987).

Vertical datum conversion based on the interpolation of tidal and geodetic datums obtained from NOS tidal benchmarks produced an error of $0.05 \mathrm{~m}$ (Mofjeld et al., 2004). Additional vertical control error was created based on estimating the interaction between the open coast and the Necanicum River estuary. The estuarine region is not well defined (see Bathymetry section 3.1.2); thus, the vertical datum surface (Fig. 2) does not account for the possibility of a deltaic sill affecting tidal circulation. This may add a vertical error of up to $0.35 \mathrm{~m}$ within the estuary.

Assessing the quality of the DEM was based on comparison with vertical control and source data. Vertical control data existed only for land elevation values, yielding a RMS error of $0.135 \mathrm{~m}$ (Fig. 6, Table 5). A direct difference between bathymetric source data and the DEM yielded a RMS error of $0.01 \mathrm{~m}$.

Subjective interpretation may also introduce error. The construction of shoreline and contours based on disparate sources are two of the primary components that could affect DEM quality. Descriptions of these data provided in the methodology section provide some guidance on the quality of the interpretation.

Table 5: Comparison of NGS vertical control points with the DEM. Average error was $0.404 \mathrm{~m}$ with a RMS error of $0.135 \mathrm{~m}$. See Fig. 6 for a spatial display of the control points.

\begin{tabular}{cccccc}
\hline $\begin{array}{c}\text { Control } \\
\text { Point }\end{array}$ & Latitude & Longitude & $\begin{array}{c}\text { Control } \\
\text { Elevation }(\mathbf{m})\end{array}$ & $\begin{array}{c}\text { DEM } \\
\text { Elevation }(\mathbf{m})\end{array}$ & $\begin{array}{c}\text { Absolute } \\
\text { Difference }(\mathbf{m})\end{array}$ \\
\hline AA3536 & -123.929722 & 45.993056 & 8.210 & 7.715 & 0.495 \\
RD1141 & -123.929551 & 45.995082 & 7.297 & 6.990 & 0.307 \\
RD1422 & -123.924444 & 45.989167 & 5.490 & 5.374 & 0.116 \\
RD1423 & -123.926111 & 45.981944 & 6.074 & 5.992 & 0.082 \\
RD4368 & -123.923333 & 45.988056 & 5.640 & 5.232 & 0.408 \\
SC0609 & -123.914167 & 46.060278 & 8.152 & 8.923 & 0.771 \\
SC0611 & -123.916698 & 46.056681 & 20.911 & 20.494 & 0.417 \\
SC0617 & -123.920805 & 46.028119 & 11.834 & 11.754 & 0.080 \\
SC0618 & -123.920833 & 46.027778 & 9.562 & 9.881 & 0.319 \\
SC1034 & -123.913889 & 46.047778 & 6.190 & 6.764 & 0.574 \\
SC1035 & -123.915000 & 46.035556 & 6.964 & 8.292 & 1.328 \\
SC1036 & -123.911667 & 46.023333 & 7.095 & 7.043 & 0.052 \\
SC1037 & -123.913889 & 46.009444 & 4.164 & 4.185 & 0.021 \\
SC1038 & -123.920833 & 46.001111 & 6.103 & 5.683 & 0.420 \\
SC1041 & -123.925000 & 46.001389 & 5.362 & 4.697 & 0.665 \\
\hline
\end{tabular}




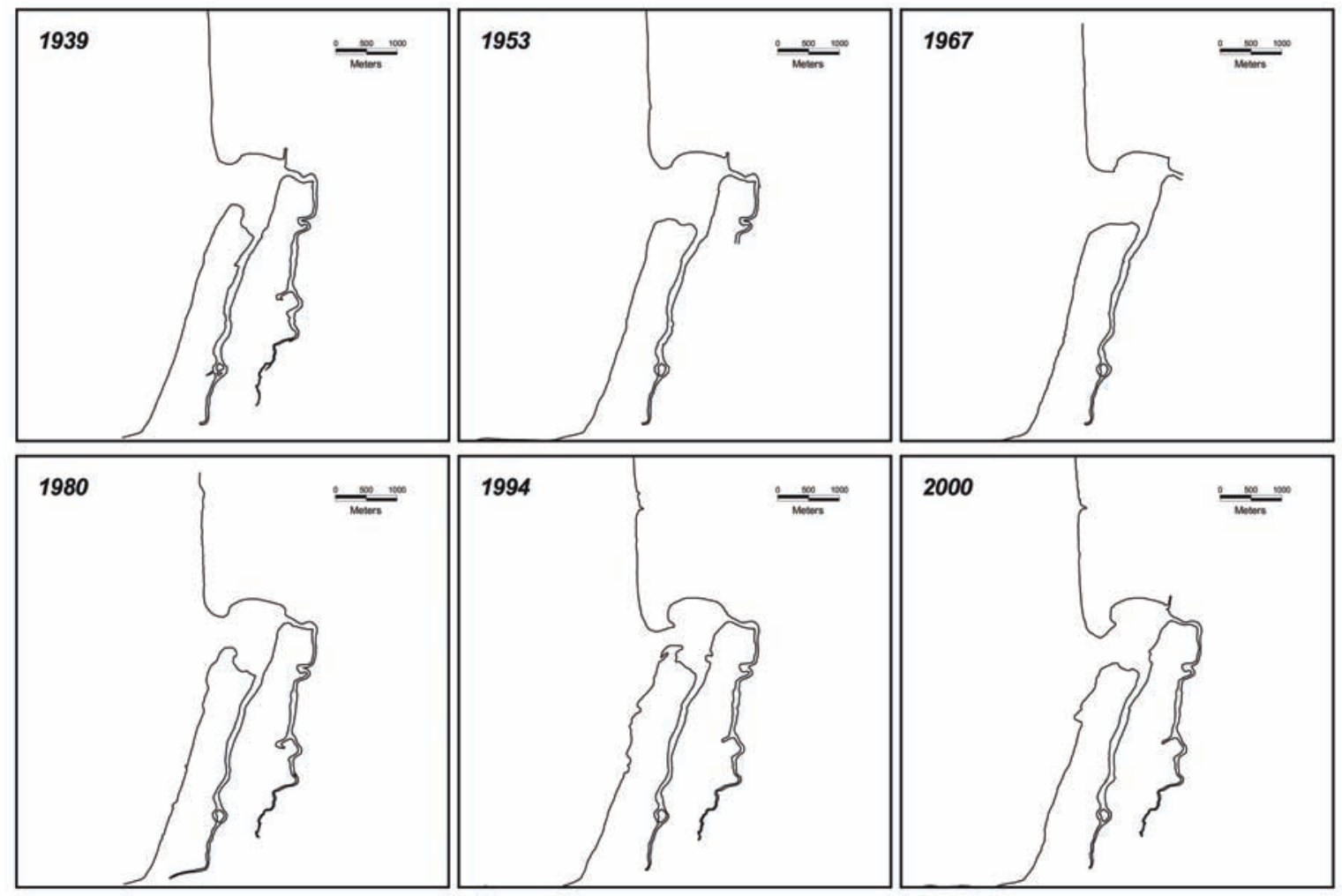

Figure 10: Historical shoreline depicting the apparent Mean High Water line based on orthophotography obtained from the University of Oregon. The northern outer coast has an accretion rate of approximately 45 meters every 14 years. The southern outer coast varies little over the same period.

\subsection{Historical shoreline analysis}

The discovery of significant shoreline differences with source data and recent aerial photography from 1996 and 2000 led to an analysis of historical shoreline for the Seaside area. Past aerial photographs were obtained from the University of Oregon. Apparent mean high water and mean lower low water were digitized and georeferenced in ArcGIS $\odot$.

The resulting files show a very dynamic shoreline pattern likely due to the Seaside area residing within the Columbia River littoral cell. A general trend of accretion averaging $3.2 \mathrm{~m} / \mathrm{y}$ on the outer coast north of the Necanicum River mouth is apparent (Fig. 10). These values nearly match the historical accretion rates of the Clatsop Plains sub-cell, which averages $3.3 \mathrm{~m} / \mathrm{y}$ (Woxell, 1998).

There is also a cyclic pattern seen within the Necanicum River mouth (Fig. 11). The northern extent of the mouth shows an accretion rate of approximately $7 \mathrm{~m} / \mathrm{y}$ since 1939 . The southern extent varies between accretion and erosion over an estimated 15-year cycle. Over 55 years, the mouth span ranged from $300-800 \mathrm{~m}$ width. 


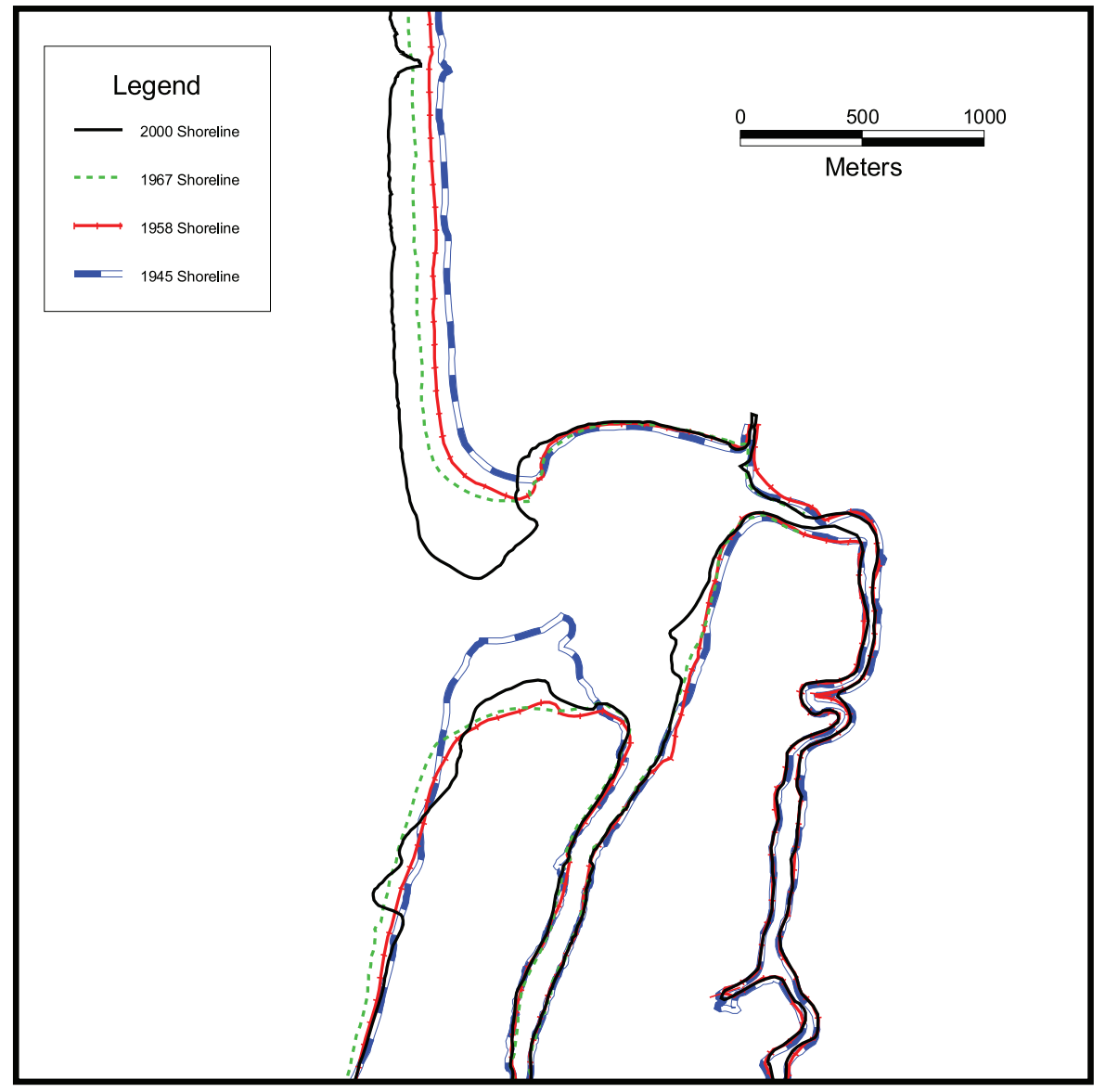

Figure 11: Accretion and erosion trends of the Necanicum River mouth over a 55 -year period.

\section{Summary and Conclusions}

A digital elevation model consisting of merged bathymetry and topography and covering the Seaside, Oregon region was built for use in a tsunami inundation model as part of a FEMA FIRM Pilot Study. The DEM consisted of disparate data sources from various Federal, State, and local agencies. Data were collected and processed according to requested parameters. Best available data were selected as input for the grid. A simple interpolation method based on Delauney triangulation and a natural neighborhood filter was used to build the DEM.

The DEM was analyzed for quality by making comparisons with input data sources and vertical control points. Total DEM error is difficult to quantify due to subjective factors in development; however, an estimated total error range is provided in Table 6 . The methodology described in this report helps provide a qualitative assessment of the DEM.

The DEM provides a snapshot of a dynamic region. Varying shoreline 
Table 6: Estimate of total DEM error. These estimates are based on a quantitative assessment of the DEM. The total error is sum of the quantitative values. Subjective interpretation adds unknown error to the DEM.

\begin{tabular}{lcc}
\hline \multicolumn{1}{c}{ Error Type } & $\begin{array}{c}\text { Horizontal Error Range } \\
\text { (meters) }\end{array}$ & $\begin{array}{c}\text { Vertical Error Range } \\
\text { (meters) }\end{array}$ \\
\hline Projection/Datum conversion & $0.35-0.45$ & $0.05-0.40$ \\
Comparison with vertical control & & $0.14-1.33$ \\
Comparison with original data sources & $0.80-10$ & $0.01-1.24$ \\
Total known quantitative error & $1.15-10.45$ & $0.20-2.97$ \\
\hline
\end{tabular}

patterns may affect maximum credible tsunami inundation. Further analysis and subsequent updates are necessary to ensure accurate tsunami hazard assessments.

The inherent uncertainty based on disparate data sources and the dynamic nature of the shoreline led to a set of recommendations to improve the DEM. These recommendations are listed below in no particular order:

- New bathymetric multibeam surveys should be conducted for the Necanicum River and the offshore region of northern Oregon. This could significantly reduce error in the DEM by providing greater spatial density and better information on the current state of the seafloor.

- Recent 2002 LIDAR surveys should be used to update the topography and intertidal zone. Given the dynamic nature of the shoreline, these data could also be used to further analyze Columbia River littoral exchange patterns. Ideally, data with vegetation already removed would be available to reduce processing time.

- A high-resolution tidal model to explore the tidal relationship between the Necanicum River estuary and open ocean should be developed. Tertiary tide gages should be installed to provide a recent observational record of current tidal trends, thereby reducing vertical datum conversion errors.

- The latest orthophotos and high-resolution vectors representing Mean High Water to more accurately depict the shoreline should be obtained. New false-color orthoimagery is being collected by the State of Oregon (Oregon Geospatial Enterprise Office, 2005).

- Different interpolation schemes should be tested to assess the best method for the inundation model.

\section{Data Credit}

David C. Smith and Associates, Inc. (1996): 10-meter DEM. Portland, Oregon. 
NOAA Coastal Services Center (2004): Aircraft Laser/GPS Mapping of Coastal Topography, LDART. Charleston, South Carolina. http: //www.csc.noaa.gov/lidar/

NOAA National Geodetic Survey (2004): Vertical Geodetic Control Data. Silver Spring, Maryland. http://www.ngs.noaa.gov/

NOAA National Geodetic Survey (2004): OR43C04 1926 Shoreline, Shoreline Data Explorer. Silver Spring, Maryland. http://www.ngs . noaa.gov/newsys_ims/shoreline/

NOAA National Geophysical Data Center (2002): NOS Hydrographic Database, GEODAS Version 4.1.18. Boulder, Colorado. http:// ngdc.noaa.gov/

NOAA National Ocean Service (2004): Regional Water-Level Station Benchmarks. Silver Spring, Maryland. http://tidesandcurrents. noaa.gov/benchmarks/

Oregon Bureau of Land Management (2001): Oregon Watershed Boundaries. Portland, Oregon. Data obtained through the Oregon Geospatial Data Clearinghouse. http://www.gis.state.or.us/

USGS EROS Data Center (1973): Hydrographic Vectors. Sioux Falls, South Dakota. Data obtained through the Oregon Geospatial Data Clearinghouse. http://www.gis.state.or.us/

USGS EROS Data Center (1999): National Elevation Dataset. Sioux Falls, South Dakota. http://gisdata.usgs.net/ned/

USGS National Aerial Photography Program (2002): 2000 Digital Orthophoto Quads. Reston, Virginia. Data obtained through the Oregon Geospatial Data Clearinghouse. http://www.gis.state.or.us/

\section{Acknowledgments}

This research is funded in part by the Federal Emergency Management Agency Map Modernization Program. This publication is partially funded by the Joint Institute for the Study of the Atmosphere and Ocean (JISAO) under NOAA Cooperative Agreement No. NA17RJ1232, Contribution \#1136.

The author thanks George Priest (Oregon Department of Geology and Mineral Industries), Tom Horning (Horning Geosciences), Colin Kelly (University of Oregon), Kirk Waters (NOAA Coastal Services Center), and Harold Mofjeld (NOAA Pacific Marine Environmental Laboratory) for assistance with data sources and processing.

\section{References}

Carter, D.J.T. (1980): Echo-Sounding Correction Tables, third edition. Hydrographic Department, Ministry of Defence, Taunton Somerset. 
Clatsop County (2005): Clatsop County Community Profile. Clatsop County Community Development, Astoria, Oregon.

Dewhurst, W.T. (1990): NADCON-The application of minimum-curvaturederived surfaces in the transformation of positional data from North American Datum of 1927 to the North American Datum of 1983. NOAA Tech. Memo. NOS NGS-50, National Ocean Survey, 30 pp.

Fiedorowicz, B.K. (1997): Geologic evidence of historic and prehistoric tsunami inundation at Seaside, Oregon. M.S. thesis, Portland State University.

González, F.I., E. Geist, C. Synolakis, and V.V. Titov (2004): Probabilistic tsunami hazard assessment: the Seaside, Oregon pilot study. In 2004 Fall AGU Conference Proceedings, OS22B-04.

González, F.I., V.V. Titov, H.O. Mofjeld, A.J. Venturato, R.S. Simmons, R. Hansen, R. Combellick, R.K. Eisner, D.F. Hoirup, B.S. Yanagi, S. Yong, M. Darienzo, G.R. Priest, G.L. Crawford, and T.J. Walsh (2005): Progress in NTHMP hazard assessment. Nat. Hazards, 35(1), 89-110.

Mofjeld, H.O., A.J. Venturato, F.I. González, and V.V. Titov (2004): Background tides and sea level variations at Seaside, Oregon. NOAA Tech. Memo. OAR PMEL-126, NOAA/Pacific Marine Environmental Laboratory, 15 pp.

National Geodetic Survey (2004): NADCON Version 2.10 Documentation. Boulder, CO.

National Geophysical Data Center (2004): GEODAS Help Manual. National Geophysical Data Center, Marine Geology and Geophysics Department, Boulder, CO.

Oregon Geospatial Enterprise Office (2005): 2005 Orthoimagery Update. http: //www . oregon.gov/DAS/IRMD/GEO/.

Oregon Natural Heritage Program (1999): Oregon GAP analysis project-A geographic approach to planning for biological diversity. Oregon Department of Fish and Wildlife, Portland, OR, 168 pp.

Oregon Ocean-Coastal Management Program (2000): Oregon Coastal Atlas. http: //www. coastalatlas.net/.

Priest, G.R., E. Myers, A. Baptista, R.A. Kamphaus, B.K. Fiedorowicz, C.D. Peterson, and T.S. Horning (1998): Tsunami Hazard Map of the Seaside-Gearhart Area, Clatsop County, Oregon. IMS-3, Scale 1:12,000, Oregon Department of Geology and Mineral Industries, Portland, OR.

Snyder, J.P. (1987): Map Projections-A working manual. USGS Professional Paper $1395,383 \mathrm{pp}$.

USDA Natural Resources Conservation Service (1994): Soil survey of Clatsop County, Oregon, OR007. U.S. Department of Agriculture, Portland, OR, 189 pp.

Woxell, L.K. (1998): Prehistoric beach accretion rates and long-term response to sediment depletion in the Columbia River Littoral System, USA. M.S. thesis, Portland State University, Portland, OR, 113 pp. 



\section{Appendix C. Summary of eyewitness observations from 1964 Alaska Tsunami in Seaside, Oregon (compiled by Tom Horning)}

The 1964 Good Friday Alaska far-field tsunami struck Seaside on Friday, March 27, at 11:35 PM, approximately $1 \mathrm{hr}$ before an approximate $+5.4 \mathrm{ft}$ MLLW high tide. It took about $4 \mathrm{hr}$ for the tsunami to reach Seaside from its source area near Prince William Sound, arriving 15 min after the wave struck Neah Bay, Washington, and 5 min before it reached Crescent City, California. The first surge caused the greatest damage. A second surge probably occurred prior to $1 \mathrm{AM}$, but caused significantly less damage. Surges continued for at least $12 \mathrm{hr}$. Surf was exceptionally low, averaging about $3 \mathrm{ft}$ high, at a time of year when 8 to $20 \mathrm{ft}$ waves are common. The moon was full on a balmy windless night and the night sky was cloudless, permitting good illumination. Damage totaled \$276,000 from flooded homes, damaged bridges, and ruined cars. Two houses were damaged beyond repair. Evacuation sirens were not blown until the first surge was spreading through neighborhoods and up rivers. The decision to evacuate the city was withheld until urgent radio messages from the Mendocino County (California) sheriff's office were received recommending evacuation of the coast. One fatal heart attack occurred during the sirens.

\section{C1. Initial Drawdown}

The first surge was preceded by a negative phase that drew down the tide to an inferred elevation of less than minus $2 \mathrm{ft}$ MLLW. The Necanicum River was observed at two locations to be lower and narrower than ever seen before. Near the Avenue A bridge, the river was observed to be only about $45 \mathrm{ft}$ wide in a 135$\mathrm{ft}$-wide channel that is always filled with water, even during tides of minus 2.0 $\mathrm{ft}$ MLLW. A police observer crossing the river at the 12th Avenue Bridge during his evacuation claims that the mud bottom of the river was visible. These observations have not been corroborated. Sand flats in the bay were exposed immediately prior to the beginning of the first surge, according to another police observer along the north side of the bay. The flats normally would have been covered by the high tide. 


\section{C2. First Surge on the Beach}

Few people observed the first surge arriving on the ocean beach on the west side of Seaside. Near the Cove, at the south end of town, the ocean was seen to withdraw and develop a trough-like depression about 1200 yards west of the beach. Beyond the trough, the ocean rose higher than normal, as judged by the elevation of breakers along the boulder beach of Tillamook Head. As the trough deepened, small breakers between the trough and Seaside diminished until the ocean surface became smooth and glassy, apparently as water withdrew off the strand. Large waves then surged past observers on Tillamook Head and toward the beach, much like 20 -ft winter storm waves. It appears that the first surge arrived along the Cove as a breaking bore, in contrast to its more passive arrival farther to the north, perhaps due to effects from the headland. The water surged over the cobble berm and passed between houses south of Avenue W, carrying large driftwood against houses and filling basements with water.

According to newspaper accounts in the Seaside Signal, the arrival of the first surge on the beach near Broadway, midway between Tillamook Head and the river mouth, was characterized by waves running up the beach, followed by additional waves rapidly overtaking the first, all of which chased strollers off the beach. There are no eyewitness reports of a prior drawdown of the ocean along this part of the beach, but it probably occurred, based on the reduction of water elevation observed in the estuary. Apparently, a bore advanced onto the beach near 12th Avenue, just south of the estuary at the north end of town, because the police observer there heard the roar of very loud surf, felt an anomalous strong wind from the west, and observed wads of foam blowing over his head from out of the darkness. At this point, he departed in haste, sped eastward across the 12th Avenue Bridge, and observed the unusual drawdown of the river, apparently beating the incoming tsunami to the Necanicum River.

Runup elevations along the ocean front ranged from 19 to $23 \mathrm{ft}$ NGVD. Allowing for about $3.4 \mathrm{ft}$ between MLLW and $0.0 \mathrm{ft}$ NGVD, and given that the tide was predicted to be at $4.9 \mathrm{ft}$ MLLW $(+1.5 \mathrm{ft}$ NGVD) at the 12th Avenue Bridge at that time, the first surge was from about 17 to $21 \mathrm{ft}$ in height (there is some question as to MLLW versus NGVD in the Seaside area). Water crossed the ocean front Promenade at 12th and 9th Avenues, at Broadway and Avenue A, at locations where elevations ranged from 20 to $23 \mathrm{ft}$. It rose to $19.5 \mathrm{ft}$ at Avenue S, but did not cross the boardwalk. There is an anecdotal account of foam on the boardwalk one or two blocks farther to the north. Water was observed flowing down 12th Avenue and Broadway, perhaps 6 inches deep, for a distance of about one block. One eyewitness directly observed water less than 6 inches deep quietly flowing onto the Promenade near Avenue A. To the west, the ocean surface was glassy with minor roiling "like a full glass of water just poured"; free of significant foam and without any expression of the prevailing $3 \mathrm{ft}$ surf. The water stood for "a few moments," and then withdrew rapidly into the moonlit darkness to well beyond standard low tide. Abundant debris, small logs, sticks, and other detritus were left on the concrete walk of the Promenade and in front yards. Larger stumps and logs were stranded on access ramps to the beach, several feet below the Promenade surface. 
Water flowed onto Ocean Vista Drive south of Avenue W, near the Cove, establishing runup at about $21 \mathrm{ft}$ NGVD. Accounts are inconsistent as to whether water crossed Sunset Boulevard along the south side of the Cove. From the most conservative accounts, water appears to have risen to at least $19 \mathrm{ft}$ NGVD. Possibly it may have been 2 to $3 \mathrm{ft}$ higher and may have carried large logs and boulders onto the road, which some observers remember blocking the road. One neighbor noted that the ocean surface was largely free of foam and appeared ready to break over the berm, but then withdrew into the night. Confusion arises with memories for residents of this area after 30 to 40 years, because winter storms frequently have surged onto the road and into the marshes on the lee side of the cobble berm on which the road is built. There are no newspaper accounts of debris on this road, nor do emergency responders and public works employees recall clearing debris. In general, it appears that runup generally may have been limited south of Avenue $S$, as compared to points farther north along the beach. In part, this can be explained by direct observation that the tsunami water readily drained into the rounded cobble deposits that underlie the south part of Seaside, in contrast to less permeable dune sands and organic soils farther to the north. This enhanced drainage prevented more extensive inundation of the upland terrain in the southern part of the city.

\section{C3. Surge Enters the Bay}

The primary surge apparently entered the estuary as waves propelled by a rapid rise in sea level, but it became focused as a series of bores within the narrow confines of the river channels. Observers along the east side of the bay, at Mason Street and 25th Avenue, recount that water elevations rose over a period of several minutes, allowing time to evacuate. Card-players near 24th Avenue heard the growl of cobbles in the river channel west of their house, like a distant jet engine, and observed wild and chaotic conditions in the estuary with waves and foam moving incomprehensively in the moonlight. Water and foam barely surmounted the forested dune on which their residence was built, establishing runup at about $21 \mathrm{ft}$ NGVD from about 20th to 24th Avenues.

\section{C4. Surge Enters Neawanna Creek and Venice Park Neighborhood}

An observer at 26th Avenue and Queen Street observed a bore heading straight toward his house up the lower channel of Neawanna Creek. The family dog first heard the dull roar of the water. The family had less than 1 min to evacuate upstairs before water and 5-ft diameter driftwood logs crashed through the west side of their house, filling it $7 \mathrm{ft}$ deep, pushing out the back wall, and carrying away their cars. The surge banked against Highway 101 north of the Neawanna Creek Bridge, partly flooding over it, depositing sand on the highway and running between houses to the east. The surge spread back to the southwest, inundating the eastern two-thirds of the Venice Park neighborhood 
under 1 to $3 \mathrm{ft}$ of water from 24th to 26th Avenues, and lapping onto a low dune ridge on the west side of the neighborhood. Freezers, coolers, furniture, and spewing propane tanks were consistently found southwest of their homes of origin. Similarly, large driftwood logs floated into the neighborhood on southwesterly directed currents. Several families put their children into attic spaces and onto roofs to avoid the swift rise of water. Surges constrained by dense forest vegetation and brush along narrow roads rose as high as $7 \mathrm{ft}$, only to drop to less than $3 \mathrm{ft}$ in open intersections. Many heard the evacuation sirens and stepped out of their homes to find swift currents in the streets. Several mobile homes were swept into the highways or into the river. In this neighborhood, static water runup averaged about $12.5 \mathrm{ft}$ NGVD, or about 2.5 $\mathrm{ft}$ higher than the elevation of highest flooding due to storm surge in the following 40 years. Surges locally increased runup by 6 to 12 in, primarily near the river channel.

It is likely that runup was increased a small amount by debris dams lodged against bridges. Runup elevations upstream from the Neawanna Creek (Hwy 101) Bridge were about $1.5 \mathrm{ft}$ lower than in Venice Park, below the blockage. Pilings beneath the Seattle, Portland, and Spokane train trestle, just upstream from the Highway 101 Bridge, were washed away by the floodwaters, leaving the ties and rails, which hung as a suspension bridge between the riverbanks. Apparently, debris dams against the pilings forced water to accelerate near the bed of the river, and this washed away sand into which the pilings had been driven, allowing them to be swept away with the logjam.

Heavy foam and strong, groaning currents were observed by evacuees who crossed the 12th Avenue Bridge over Neawanna Creek, but residents along the river bank at the bridge did not observe evidence of flooding out of the flood plain. Between 12th Avenue and Broadway, water did not rise any higher than typical winter floods. Runup in this vicinity appears not to have been higher than about $9 \mathrm{ft}$ NGVD. There is very little evidence of the extent of flooding south of Broadway due to the absence of damage. Water is inferred to have flooded at least to the Avenue S Bridge, primarily within the channel. In general, flooding affected marshland of the Neawanna Creek drainage for a distance of about 1 mile upstream from the bay.

\section{C5. Surge in the Necanicum River}

Inundation within the Necanicum River extended from its mouth more than 2 miles upstream to at least the ninth fairway of the Seaside Golf Course, just south of Avenue U. An eye-witness between Broadway and Avenue A observed multiple bores advancing over the nearly empty river bottom, each about $2 \mathrm{ft}$ high and each followed by another within 10 to $30 \mathrm{sec}$, until the 14-ft-deep river channel was filled flush to the edge of its banks by a final 4 -ft culminating bore. The culminating bore was observed sweeping up the Necanicum Channel near 4th Avenue beneath a thick mantle of dense foam, essentially as a quiet plateau of water moving at about 10 miles per hour. The bore struck the main timber decking of the abandoned 4th Avenue Bridge and tore it from its pilings with the sound of "giant eggshells cracking." The decking broke into multiple pieces 
and floated upstream, the largest to lodge beneath the east end of the First Avenue Bridge and tip up to erect a cofferdam to the on-rushing water. As a result, water and foam were directed beneath the west end of the bridge and beyond. Water flowed over the bridge railings and flooded westward across First Avenue and Necanicum Boulevard, filling parking lots and streets, and blocking evacuation by many who thought it would be a safer crossing than farther down stream. Water was several inches deep in Broadway west of the river. Foam was as high as $7 \mathrm{ft}$ along the sides of buildings along North Edgewood, apparently having been skimmed off by the deck of the Broadway Bridge. As the foam broke down later, only silt from the river was left in the streets, in contrast to beach and bay sands in neighborhoods closer to the river mouth.

Debris from the 4th Avenue Bridge, or large driftwood, continued upstream beneath the Broadway Bridge to the First Avenue Bridge, where it struck the bridge railings and knocked them into the street. Swift currents, possibly with the assistance of debris dams, swept two sets of pilings from beneath the Avenue G Bridge, farther to the south. The concrete decking of the bridge fortunately was able to span the gap and support the loads of evacuating cars without collapsing. Low areas on the west side of the river flooded with several inches of water from about Avenue I to about Avenue $\mathrm{N}$, and as far west as South Downing Street.

Water and/or foam stood on the decks of all bridges from 12th Avenue to Avenue G. Runup reached more than $14 \mathrm{ft}$ NGVD at 12th Avenue, about $13 \mathrm{ft}$ at 1st Avenue, and about $12 \mathrm{ft}$ at Avenue A. Water entered the first floor of the hospital at Avenue S, flooding only several inches deep and establishing runup at about $10.5 \mathrm{ft}$. Runup reached $9.8 \mathrm{ft}$ NGVD on the ninth green of the golf course at Avenue U. Runup near bridges tended to be higher than farther from the channel, apparently because of surges and splashing related to higher velocities in the channels.

\section{C6. A Second Surge}

There are few recollections of the second surge of the Good Friday tsunami and no reference to it can be found in the news clippings from that event. Hearsay accounts of disaster responders suggest that barrels had moved about the Venice Park neighborhood during the night by waves; however, large driftwood logs were not affected and no residents of the neighborhood noticed anything unusual. The primary observation of a second surge was made at the Seaside Golf Course, where the owner observed, at about 1:30 AM, that a slightly lower runup debris line had formed on the ninth green well after the first surge had withdrawn.

An eyewitness who saw bores moving up the Necanicum channel later moved to the north side of the estuary in Gearhart. There he saw what must have been the second surge enter the estuary. Easily visible in the moonlight, he saw multiple waves pouring into the bay from the ocean to strike the east side of the bay near the high school, between 17th and 24th Avenues. The waves rebounded and met oncoming surges to amplify and explode upward 
higher than the homes along the shore. Runup was as high as $21 \mathrm{ft}$ NGVD in this area, or nearly $8 \mathrm{ft}$ higher than runup to the north or south. One homeowner adjacent to the amplification zone observed that driftwood logs had floated into her glass-enclosed patio without any damage to the panes, implying gentle forces at the extreme edge of the runup. She also reported that considerable rock fill along the shore had been washed away and, further, that the bank had slumped enough to break irrigation pipes in the lawn and distort some walls in the house a tiny amount. Another resident at 24th Avenue estimated that the waves eroded the 15 - $\mathrm{ft}$-high bank of dune sand by about $10 \mathrm{ft}$.

\section{C7. Sand and Debris Deposits}

Although significant sand was transported by the tsunami into marshes and neighborhoods, there was little evidence of intense channel erosion or scouring. Noticeable scouring occurred only along shorelines where rock fill projected into the bay. These projections allowed eddying, which created shallow depressions of less than $2 \mathrm{ft}$ deep and no more than $70 \mathrm{ft}$ long and $15 \mathrm{ft}$ wide. Sand deposition tended to occur along topographic shelves, such as riverbanks and yards, where water velocities slowed abruptly. Streets and wide level fields tended not to accumulate much sand, but yards adjacent to streets could accumulate up to 14 inches of sand. Sand suspended in 30 to 36 inches of water was able to settle out in houses to form layers of about 2 to 3.5 inches thick. Many ghost shrimp (Callianassa californiensis) were transported from the sand flats and river bottoms into yards and streets with the sand. The shrimp probably were sucked from their burrows by Venturi forces, rather than excavated by erosion, as their burrows can be more than $2 \mathrm{ft}$ deep and such extensive erosion was generally not visible. However, significant erosion in sandy river channels could have occurred. Many fish were stranded as the water withdrew. Worms came to the surface of the ground to escape the salt water.

\section{C8. Surges for Twelve Hours}

Several surges entered the estuary the next day. They were perhaps as much as 2 to $4 \mathrm{ft}$ high and appeared as rapid increases in the tide that took about $10 \mathrm{~min}$ to peak. Water sped up the main river channels at speeds of 5 to 10 miles per hour. Standing waves with breaking crests stood perhaps 2 to $3 \mathrm{ft}$ high. Logs riding in on the water rose out of the water as they crossed the waves, slapping the water surface as they came back down. Stumps rolled and tumbled in the rapidly moving water. As water spilled out of the channels and onto the sand flats, it spread outward at a moderate walking pace without cessation as dark turbulent sand-filled water several inches deep, crossing about 150 yards in under $2 \mathrm{~min}$. Shoaling occurred over sand bars in the channels and bores were observed as far up the Necanicum River as Broadway. 


\section{C9. Wrap-Up}

Had the first surge arrived during low tide, much of the damage in Seaside would most likely not have occurred, as later surges in the tsunami train were apparently smaller than the earliest ones. It is important to note that had the tide, the first surge, or the ocean surf of that day been higher, the damage in Seaside would have resulted in significantly greater property damage. Water would have poured across the Promenade and into the core of town, flowing down nearly all streets. Many homes would have been swept from their foundations and many lives could have been lost. Large numbers of people evacuated across bridges and roads that were already flooded or were adjacent to raging rivers. Had the water been any higher, many would have been washed into deep, swift water, and most likely would have drowned.

This account of the 1964 tsunami in Seaside is based on interviews with over 75 people, personal observations, at least four sets of excellent photos, and clippings from various newspapers. 



\section{Appendix D. Location of sites used in this study and presence of 1964, 1700, and older tsunami deposits}

\begin{tabular}{|c|c|c|c|c|c|c|c|}
\hline Source & Site \# & UTM_X (NAD 83) & UTM_Y (NAD 83) & Date & 1964 & 1700 & Older \\
\hline Jaffe et al., this study & SS6-04-1 & 428207.00000 & 5092839.00000 & $06 / 24 / 04$ & yes & no & no \\
\hline Jaffe et al., this study & SS6-04-2 & 428244.00000 & 5092869.00000 & $06 / 24 / 04$ & yes & $?$ & no \\
\hline Jaffe et al., this study & SS6-04-3 & 428095.00000 & 5092851.00000 & $06 / 24 / 04$ & no & no & no \\
\hline Jaffe et al., this study & SS6-04-4 & 428094.00000 & 5092851.00000 & $06 / 24 / 04$ & no & no & no \\
\hline Jaffe et al., this study & SS6-04-5 & 428401.00000 & 5092858.00000 & $06 / 25 / 04$ & yes & yes & no \\
\hline Jaffe et al., this study & SS6-04-6 & 428401.00000 & 5092858.00000 & $06 / 25 / 04$ & no & no & no \\
\hline Jaffe et al., this study & SS6-04-7 & 428653.00000 & 5092807.00000 & $06 / 25 / 04$ & no & no & no \\
\hline Jaffe et al., this study & SS6-04-8 & 428683.00000 & 5092799.00000 & $06 / 25 / 04$ & no & yes & no \\
\hline Jaffe et al., this study & SS6-04-9 & 428742.00000 & 5092818.00000 & $06 / 25 / 04$ & no & yes & no \\
\hline Jaffe et al., this study & SS6-04-10 & 428757.00000 & 5092818.00000 & $06 / 25 / 04$ & no & yes & yes \\
\hline Jaffe et al., this study & SS6-04-11 & 428757.00000 & 5092828.00000 & $06 / 25 / 04$ & no & yes & no \\
\hline Jaffe et al., this study & SS6-04-12 & 429043.00000 & 5093031.00000 & $06 / 25 / 04$ & no & yes & no \\
\hline Jaffe et al., this study & SS6-04-13 & 429043.00000 & 5093026.00000 & $06 / 25 / 04$ & no & no & no \\
\hline Jaffe et al., this study & SS6-04-14 & 429288.00000 & 5095951.00000 & $06 / 26 / 04$ & yes & no & no \\
\hline Jaffe et al., this study & SS6-04-15 & 429297.00000 & 5095165.00000 & $06 / 26 / 04$ & yes & no & no \\
\hline Jaffe et al., this study & SS6-04-16 & 429294.00000 & 5095174.00000 & $06 / 26 / 04$ & yes & no & no \\
\hline Jaffe et al., this study & SS6-04-17 & 429289.00000 & 5095197.00000 & $06 / 26 / 04$ & yes & no & no \\
\hline Jaffe et al., this study & SS6-04-18 & 429297.00000 & 5095197.00000 & $06 / 26 / 04$ & yes & no & no \\
\hline Jaffe et al., this study & SS6-04-19 & 429279.00000 & 5095204.00000 & $06 / 26 / 04$ & yes & no & no \\
\hline Jaffe et al., this study & SS6-04-20 & 429273.00000 & 5095213.00000 & $06 / 26 / 04$ & yes & no & no \\
\hline Jaffe et al., this study & SS6-04-21 & 428595.00000 & 5094778.00000 & $06 / 26 / 04$ & yes & no & no \\
\hline Jaffe et al., this study & SS6-04-22 & 428139.00000 & 5092869.00000 & $06 / 27 / 04$ & no & yes & no \\
\hline Jaffe et al., this study & SS6-04-23 & 429663.00000 & 5094968.00000 & $06 / 27 / 04$ & no & no & yes \\
\hline Jaffe et al., this study & SS6-04-24 & 429506.00000 & 5094739.00000 & $06 / 27 / 04$ & no & yes & yes \\
\hline Jaffe et al., this study & SS6-04-25 & 429261.00000 & 5095231.00000 & $06 / 27 / 04$ & yes & yes & no \\
\hline Jaffe et al., this study & SS6-04-26 & 429303.00000 & 5095155.00000 & $06 / 27 / 04$ & yes & yes & no \\
\hline Jaffe et al., this study & SS9-04-30 & 428773.00000 & 5092845.00000 & $09 / 24 / 04$ & no & yes & yes \\
\hline Jaffe et al., this study & SS9-04-31 & 428808.00000 & 5093005.00000 & $09 / 24 / 04$ & no & yes & no \\
\hline Jaffe et al., this study & SS9-04-32 & 428736.00000 & 5092992.00000 & $09 / 24 / 04$ & no & no & no \\
\hline Jaffe et al., this study & SS9-04-33 & 428756.00000 & 5092500.00000 & $09 / 24 / 04$ & no & yes & no \\
\hline Jaffe et al., this study & SS9-04-34 & 429660.00000 & 5094931.00000 & $09 / 24 / 04$ & no & yes & no \\
\hline Jaffe et al., this study & SS9-04-35 & 429647.00000 & 5094894.00000 & $09 / 24 / 04$ & no & yes & no \\
\hline Jaffe et al., this study & SS9-04-36 & 429647.00000 & 5095033.00000 & $09 / 24 / 04$ & no & yes & no \\
\hline Jaffe et al., this study & SS9-04-37 & 427301.00000 & 5091607.00000 & $09 / 25 / 04$ & no & no & yes \\
\hline Jaffe et al., this study & SS9-04-38 & 427288.00000 & 5091519.00000 & $09 / 25 / 04$ & no & no & yes \\
\hline
\end{tabular}


Tsunami Pilot Study Working Group—Seaside, Oregon Tsunami Pilot Study

\begin{tabular}{|c|c|c|c|c|c|c|c|}
\hline Source & Site \# & UTM_X (NAD 83) & UTM_Y (NAD 83) & Date & 1964 & 1700 & Older \\
\hline Jaffe et al., this study & SS9-04-39 & 427363.00000 & 5091396.00000 & $09 / 25 / 04$ & no & no & yes \\
\hline Jaffe et al., this study & SS9-04-40 & 427402.00000 & 5091267.00000 & $09 / 25 / 04$ & no & no & yes \\
\hline Jaffe et al., this study & SS9-04-41 & 427495.00000 & 5091107.00000 & $09 / 25 / 04$ & no & no & yes \\
\hline Jaffe et al., this study & SS9-04-42 & 429272.00000 & 5096272.00000 & $09 / 25 / 04$ & yes & yes & yes \\
\hline Jaffe et al., this study & SS9-04-43 & 428744.00000 & 5092758.00000 & $09 / 26 / 04$ & no & yes & no \\
\hline Jaffe et al., this study & SS9-04-44 & 428761.00000 & 5092819.00000 & $09 / 26 / 04$ & no & yes & no \\
\hline Jaffe et al., this study & SS9-04-45 & 428890.00000 & 5092944.00000 & $09 / 26 / 04$ & no & yes & yes \\
\hline Jaffe et al., this study & SS9-04-46 & 429182.00000 & 5093416.00000 & $09 / 26 / 04$ & no & yes & yes \\
\hline Jaffe et al., this study & SS9-04-47 & 429181.00000 & 5093445.00000 & $09 / 26 / 04$ & no & yes & no \\
\hline Jaffe et al., this study & SS9-04-48 & 429165.00000 & 5093502.00000 & $09 / 26 / 04$ & no & yes & no \\
\hline Jaffe et al., this study & SS9-04-49 & 429002.00000 & 5094032.00000 & $09 / 26 / 04$ & no & no & no \\
\hline Jaffe et al., this study & SS9-04-50 & 429433.00000 & 5094076.00000 & $09 / 26 / 04$ & no & yes & no \\
\hline Jaffe et al., this study & SS9-04-51 & 429216.00000 & 5094168.00000 & $09 / 26 / 04$ & no & yes & no \\
\hline Jaffe et al., this study & SS9-04-52 & 428466.00000 & 5093918.00000 & $09 / 27 / 04$ & yes & no & no \\
\hline Jaffe et al., this study & SS9-04-53 & 428466.00000 & 5093918.00000 & $09 / 27 / 04$ & yes & no & no \\
\hline Jaffe et al., this study & SS9-04-54 & 428540.00000 & 5094150.00000 & $09 / 27 / 04$ & yes & no & no \\
\hline Jaffe et al., this study & SS9-04-55 & 428576.00000 & 5094279.00000 & $09 / 27 / 04$ & yes & no & no \\
\hline Jaffe et al., this study & SS9-04-56 & 428609.00000 & 5094400.00000 & $09 / 27 / 04$ & yes & no & no \\
\hline Jaffe et al., this study & SS9-04-57 & 428752.00000 & 5092329.00000 & $09 / 27 / 04$ & no & yes & no \\
\hline Jaffe et al., this study & SS9-04-58 & 428695.00000 & 5092256.00000 & $09 / 27 / 04$ & no & yes & no \\
\hline Jaffe et al., this study & SS9-04-59 & 428330.00000 & 5091895.00000 & $09 / 27 / 04$ & no & yes & no \\
\hline Jaffe et al., this study & SS9-04-60 & 429307.00000 & 5093988.00000 & $09 / 27 / 04$ & no & yes & no \\
\hline Jaffe et al., this study & SS9-04-61 & 429196.00000 & 4.00000 & $09 / 27 / 04$ & no & $?$ & no \\
\hline Jaffe et al., this study & SS9-04-62 & 429260.00000 & 1.00000 & $09 / 27 / 04$ & no & ? & no \\
\hline Jaffe et al., tl & SS9-04-63 & 429288.00000 & 5094387.00000 & $09 / 27 / 04$ & no & ? & no \\
\hline Jaffe et al., this study & SS9-04-64 & .00000 & 5094168.00000 & $09 / 27 / 04$ & no & yes & no \\
\hline Jaffe et al., this s & SS9-04-65 & .00000 & 5094260.00000 & $09 / 27 / 04$ & no & $?$ & no \\
\hline Jaffe & SS9-04-66 & 000 & .00000 & $09 / 27 / 04$ & no & ? & no \\
\hline Jaffe & SS9-04-67 & 000 & 2.00000 & $09 / 27 / 04$ & no & ? & no \\
\hline Jaff & SS9-04-68 & 000 & 00000 & $09 / 27 / 04$ & no & ? & no \\
\hline al., this study & SS9-04-69 & 000 & 00000 & $09 / 27 / 04$ & no & ? & no \\
\hline Jaff & $9-04-70$ & 000 & 000 & $09 / 28 / 04$ & no & ? & no \\
\hline & 9-04-71 & 000 & 000 & $09 / 28 / 04$ & no & yes & no \\
\hline & & & 000 & $09 / 28$ & yes & no & no \\
\hline et al., this study & $9-04-73$ & 000 & 000 & $09 / 29 / 04$ & no & yes & no \\
\hline Jaffe et al., this study & $9-04-74$ & 000 & 000 & $09 / 30 / 04$ & no & yes & no \\
\hline Jaffe et al., this study & $9-04-75$ & & 000 & $09 / 30 / 04$ & no & yes & no \\
\hline Jaffe et al., this study & SS9-04-76 & & 000 & $09 / 30 / 04$ & no & yes & no \\
\hline Fedorowitcz and Peterson, 1997 & & & 467 & $07 / 18 / 96$ & no & no & no \\
\hline Fedorowitcz and Peterson, 1997 & SSX_II & & & $07 / 18 / 96$ & no & no & no \\
\hline Fedorowitcz and Peterson, 1997 & SSX_III & & & $07 / 18 / 96$ & yes & no & no \\
\hline Fedorowitcz and Peterson, 1997 & SSX_IV & & & $07 / 18 / 96$ & yes & no & no \\
\hline Fedorowitcz and Peterson, 1997 & SSX_V & 429131.15 & 096467.21602 & $07 / 18 / 96$ & yes & no & no \\
\hline Fedorowitcz and Peterson, 1997 & SSX_VI & & 096441.21622 & $07 / 18 / 96$ & yes & no & no \\
\hline Fedorowitcz and Peterson, 1997 & SSX_VII & 429127.15135 & 5096416.21670 & $07 / 18 / 96$ & yes & no & no \\
\hline Fedorowitcz and Peterson, 1997 & SSX_VIII & 429124.15157 & 5096393.21701 & $07 / 18 / 96$ & yes & no & no \\
\hline Fedorowitcz and Peterson, 1997 & SSX_IX & 429122.15180 & 5096368.21734 & $07 / 18 / 96$ & yes & no & no \\
\hline Fedorowitcz and Peterson, 1997 & SSX_X & 429121.15227 & 5096319.21802 & $07 / 18 / 96$ & yes & no & no \\
\hline Fedorowitcz and Peterson, 1997 & SSX_XI & 429119.15223 & 5096323.21795 & $07 / 18 / 96$ & yes & no & no \\
\hline Fedorowitcz and Peterson, 1997 & SSX_XII & 429118.14988 & 5096570.21450 & $07 / 18 / 96$ & yes & no & no \\
\hline Fedorowitcz and Peterson, 1997 & SSX_XIII & 429115.15009 & 5096548.21479 & $07 / 18 / 96$ & yes & no & no \\
\hline Fedorowitcz and Peterson, 1997 & SSX_XIV & 429111.15034 & 5096522.21513 & $07 / 19 / 96$ & yes & no & no \\
\hline
\end{tabular}




\begin{tabular}{|c|c|c|c|c|c|c|c|}
\hline Source & Site \# & UTM_X (NAD 83) & UTM_Y (NAD 83) & Date & 1964 & 1700 & Older \\
\hline Fedorowitcz and Peterson, 1997 & SSX_XV & 429108.15058 & 5096497.21546 & $07 / 19 / 96$ & no & no & no \\
\hline Fedorowitcz and Peterson, 1997 & SSX_XVI & 29091.15006 & 5096551.21460 & $07 / 18 / 96$ & no & no & no \\
\hline Fedorowitcz and Peterson, 1997 & SSX_XVII & 9087.15029 & 096527.21491 & $07 / 18 / 96$ & yes & no & no \\
\hline Fedorowitcz and Peterson, 1997 & SSX_XVIII & 9083.15054 & 5096501.21524 & $07 / 18 / 96$ & no & no & no \\
\hline Fedorowitcz and Peterson, 1997 & SSX_XIX & 9079.15078 & 5096476.21557 & $07 / 18 / 96$ & yes & no & no \\
\hline Fedorowitcz and Peterson, 1997 & SSX_XX & 29104.15081 & 5096472.21578 & $07 / 19 / 96$ & no & no & no \\
\hline Fedorowitcz and Peterson, 1997 & SSX_XXI & 29100.15105 & 5096447.21610 & $07 / 19 / 96$ & yes & no & no \\
\hline Fedorowitcz and Peterson, 1997 & SSX_XXII & 429096.15128 & 5096423.21641 & $07 / 19 / 96$ & yes & no & no \\
\hline Fedorowitcz and Peterson, 1997 & SSX_XXIII & 429092.15152 & 5096398.21674 & $07 / 19 / 96$ & yes & no & no \\
\hline Fedorowitcz and Peterson, 1997 & SSX_XXIV & 429085.15045 & 5096510.21513 & $07 / 19 / 96$ & no & no & no \\
\hline Fedorowitcz and Peterson, 1997 & SSX_XXV & 429085.15198 & 5096350.21737 & $07 / 19 / 96$ & no & no & no \\
\hline Fedorowitcz and Peterson, 1997 & SSX_XXVI & 429089.15219 & 5096328.21770 & 07/19/96 & no & no & no \\
\hline Fedorowitcz and Peterson, 1997 & SSX_XXVII & 429116.15253 & 5096292.21836 & $07 / 19 / 96$ & no & no & no \\
\hline Fedorowitcz and Peterson, 1997 & SSX_XXVIII & 429114.15270 & 5096274.21860 & $07 / 19 / 96$ & yes & no & no \\
\hline Fedorowitcz and Peterson, 1997 & SSW_I & 429415.15956 & 50955 & $07 / 27 / 96$ & no & no & no \\
\hline Fedorowitcz and Peterson, 1997 & SSW_II & 5982 & 088 & $07 / 27 / 96$ & yes & no & no \\
\hline orowitcz and Peterson, 1997 & SSW_III & & 129 & $07 / 27 / 96$ & yes & no & no \\
\hline eterson, 1997 & SSW_IV & & & $27 / 96$ & no & no & no \\
\hline terson, 1997 & SSW_V & & 200 & $27 / 96$ & yes & no & no \\
\hline erson, 1997 & $N_{-} \mathrm{VI}$ & & 184 & $7 / 96$ & yes & no & no \\
\hline orowitcz and Peterson, 1997 & SSW_VII & & 225 & 7/96 & yes & no & no \\
\hline erson, 1997 & SSW_VIII & & & & yes & no & no \\
\hline on, 1997 & SSW_IX & & & & yes & no & no \\
\hline on, 1997 & SSW_X & & & & yes & no & no \\
\hline on, 1997 & SSW_XI & & & & yes & no & no \\
\hline 997 & SSW_XII & & & & no & no & no \\
\hline 997 & SSW_XIII & & & /96 & yes & no & no \\
\hline & SSW_XIV & & & & yes & no & no \\
\hline & SSW_XV & & & 07 & yes & no & no \\
\hline & SSW & & & & yes & no & no \\
\hline & SSW_XVII & & & /96 & yes & no & no \\
\hline & $\mathrm{SSW}_{-}$ & & & /96 & yes & no & no \\
\hline & & & & & yes & no & no \\
\hline & XX & & & /96 & yes & no & no \\
\hline & SSW & & & /96 & yes & no & no \\
\hline & SSW & & & /96 & yes & no & no \\
\hline & SSW & & & /96 & yes & no & no \\
\hline & $\mathrm{SSW}_{-}$ & & & /96 & no & no & no \\
\hline & XXV & & & /96 & no & no & no \\
\hline & $\mathrm{SSW}_{-}$ & & & /96 & no & no & no \\
\hline & SSW_XXVII & & & /96 & yes & no & no \\
\hline & SSW_XXVIII & & & $07 / 30 / 96$ & yes & no & no \\
\hline & SSW_XXIX & & & $07 / 30 / 96$ & no & no & no \\
\hline Fedorowitcz and Peterson, 1997 & SSW_XXX & & & $07 / 30 / 96$ & no & yes & no \\
\hline Fedorowitcz and Peterson, 1997 & SSW 712 & 429224.16817 & 094147.24199 & $06 / 20 / 96$ & no & yes & no \\
\hline Fedorowitcz and Peterson, 1997 & SSW 713 & & 4209 & $06 / 20 / 96$ & no & yes & no \\
\hline Fedorowitcz and Peterson, 1997 & SSW 714 & 429229.16732 & 5094730.24073 & $06 / 21 / 96$ & no & no & no \\
\hline Fedorowitcz and Peterson, 1997 & SSW 715 & & 5094729.24091 & $06 / 21 / 96$ & no & yes & no \\
\hline Fedorowitcz and Peterson, 1997 & SSW 716 & 429145.16594 & 5094880.23819 & $06 / 21 / 96$ & no & yes & no \\
\hline Fedorowitcz and Peterson, 1997 & SSW 717 & 429148.16635 & 5094837.23880 & $06 / 21 / 96$ & no & yes & no \\
\hline Fedorowitcz and Peterson, 1997 & SSW 718 & 429300.16419 & 5095057.23660 & $06 / 21 / 96$ & yes & no & no \\
\hline Fedorowitcz and Peterson, 1997 & SSW 719 & 429287.16397 & 5095081.23619 & $06 / 21 / 96$ & yes & no & no \\
\hline
\end{tabular}


Tsunami Pilot Study Working Group—Seaside, Oregon Tsunami Pilot Study

\begin{tabular}{|c|c|c|c|c|c|c|c|}
\hline Source & Site \# & UTM_X (NAD 83) & UTM_Y (NAD 83) & Date & 1964 & 1700 & Older \\
\hline Fedorowitcz and Peterson, 1997 & SW 720 & 429272.16391 & 5095088.23601 & $06 / 21 / 96$ & yes & no & no \\
\hline Fedorowitcz and Peterson, 1997 & SSW 721 & 29275.16 & 5093559.23 & $06 / 21 / 96$ & no & yes & no \\
\hline Fedorowitcz and Peterson, 1997 & SSW 722 & 429401.16034 & 95461.23159 & $6 / 22 / 96$ & yes & no & no \\
\hline Fedorowitcz and Peterson, 1997 & SSW 723 & 429318.16131 & 095362.23248 & $6 / 22 / 96$ & yes & no & no \\
\hline Fedorowitcz and Peterson, 1997 & SSW 724 & 429306.16121 & 95372.23227 & $6 / 22 / 96$ & yes & no & no \\
\hline Fedorowitcz and Peterson, 1997 & SSW 725 & 42929 & 095165.23509 & $6 / 22 / 96$ & yes & no & no \\
\hline Fedorowitcz and Peterson, 1997 & SSW 726 & 42924 & & 6/22/96 & yes & yes & no \\
\hline Fedorowitcz and Peterson, 1997 & SSW 727 & 429086.16 & 094001.23978 & $6 / 22 / 96$ & no & no & no \\
\hline Fedorowitcz and Peterson, 1997 & SSW 72 & 428786.15 & 762 & $06 / 22 / 96$ & no & no & no \\
\hline Fedorowitcz and Peterson, 1997 & SSW 72 & 42861 & 323 & $06 / 25 / 96$ & no & yes & yes \\
\hline Fedorowitcz and Peterson, 1997 & SSW 73 & 42857 & 50 & $06 / 25 / 96$ & no & yes & yes \\
\hline Fedorowitcz and Peterson, 19? & SSN 73 & 428 & 69 & /96 & yes & $?$ & no \\
\hline Fedorowitcz and Peterson, 1997 & SSN 732 & 42826 & 25 & /96 & no & yes & no \\
\hline Fedorowitcz and Peterson, 1997 & SSS 733 & 42976 & 69 & $06 / 26$ & no & no & no \\
\hline Fedorowitcz and Peterson, 19 & SSS 734 & 4297 & 25 & /96 & no & yes & no \\
\hline Fedorowitcz and Peterson, 1997 & SSW 735 & 428810.15618 & 274 & 06/26/96 & no & yes & no \\
\hline Fedorowitcz and Peterson, 1997 & SSW 736 & 42884 & 459 & $06 / 26 / 96$ & no & yes & yes \\
\hline Fedorowitcz and Peterson, 1997 & SSN 737 & 428261.16010 & 093022.22527 & $06 / 27 / 96$ & yes & $?$ & no \\
\hline Fedorowitcz and Peterson, 1997 & SSN 738 & 42826 & 22589 & $06 / 27 / 96$ & yes & no & no \\
\hline Fedorowitcz and Peterson, 1997 & SSN 739 & 42825 & 2603 & $06 / 27 / 96$ & yes & no & no \\
\hline Fedorowitcz and Peterson, 1997 & SSN 740 & 42823 & 093062.22554 & $06 / 28 / 96$ & yes & no & no \\
\hline Fedorowitcz and Peterson, 1997 & SSN 741 & 42822 & 492 & $06 / 28 / 96$ & yes & no & no \\
\hline Fedorowitcz and Peterson, 1997 & SSN 742 & 42817 & 413 & $06 / 28 / 96$ & yes & no & no \\
\hline Fedorowitcz and Peterson, 1997 & SSN 743 & 42826 & 636 & $06 / 28 / 96$ & yes & no & no \\
\hline on, 1997 & SSN 744 & 428 & & $28 / 96$ & yes & yes & no \\
\hline terson, 1997 & SSN 745 & 428 & & $28 / 96$ & yes & yes & no \\
\hline terson, 1997 & SSN 746 & 428 & & 28/96 & yes & yes & no \\
\hline on, 1997 & SSN 747 & 428 & & 8/96 & yes & no & no \\
\hline Id Peterson, 1997 & SSN 748 & 428 & & 8/96 & yes & yes & no \\
\hline on, 1997 & SSN 749 & 428 & & $/ 96$ & yes & yes & no \\
\hline Fedorowitcz and Peterson, 1997 & SSN 750 & 4284( & 2955 & $06 / 29 / 96$ & yes & no & no \\
\hline d Peterson, 1997 & SSX 75 & 69 & & 9/96 & yes & no & no \\
\hline Fedorowitcz and Peterson, 1997 & SSX 752 & .15053 & 1552 & $06 / 29 / 96$ & yes & no & no \\
\hline Fedorowitcz and Peterson, 1997 & SSX 753 & 3.15031 & 096525.21522 & $06 / 29 / 96$ & yes & no & no \\
\hline Fedorowitcz and Peterson, 1997 & SSX 754 & 8.15019 & 096538.21507 & $06 / 29 / 96$ & yes & no & no \\
\hline Fedorowitcz and Peterson, 1997 & SSW 755 & 1.16595 & 093821.23822 & $07 / 02 / 96$ & no & no & no \\
\hline Fedorowitcz and Peterson, 1997 & SSW 756 & 429126.16610 & 093843.23847 & $07 / 02 / 96$ & no & yes & no \\
\hline Fedorowitcz and Peterson, 1997 & SSW 757 & 42921 & 093921.23976 & $07 / 02 / 96$ & no & yes & no \\
\hline orowitcz and Peterson, 1997 & SSN 758 & 428447.16330 & 093450.23064 & $07 / 03 / 96$ & yes & no & no \\
\hline witcz and Peterson, 1997 & SSN 759 & 42845 & 084 & $07 / 03 / 96$ & yes & no & no \\
\hline Fedorowitcz and Peterson, 1997 & SSN 760 & 428326.16182 & 5093252.22796 & $07 / 03 / 96$ & no & no & no \\
\hline Fedorowitcz and Peterson, 1997 & SSN 761 & 428356.16043 & 5093061.22623 & $07 / 03 / 96$ & yes & no & no \\
\hline Fedorowitcz and Peterson, 1997 & SSW 762 & 429145.16461 & 5093626.23646 & $07 / 03 / 96$ & no & yes & no \\
\hline Fedorowitcz and Peterson, 1997 & SSW 763 & 429150.16446 & 5093604.23627 & $07 / 03 / 96$ & no & yes & no \\
\hline Fedorowitcz and Peterson, 1997 & SSW 764 & 429198.16475 & 5093646.23696 & 07/03/96 & no & yes & no \\
\hline Fedorowitcz and Peterson, 1997 & SSW 765 & 429197.16460 & 5093624.23674 & 07/03/96 & no & yes & no \\
\hline Fedorowitcz and Peterson, 1997 & SSW 766 & 429191.16448 & 5093607.23654 & $07 / 10 / 96$ & no & yes & no \\
\hline Fedorowitcz and Peterson, 1997 & SSW 767 & 429207.16429 & 5093579.23636 & $07 / 11 / 96$ & no & no & no \\
\hline Fedorowitcz and Peterson, 1997 & SSW 768 & 429274.16404 & 5093541.23638 & $07 / 11 / 96$ & no & yes & no \\
\hline Fedorowitcz and Peterson, 1997 & SSX 769 & 429114.15045 & 5096510.21531 & $07 / 11 / 96$ & yes & no & no \\
\hline Fedorowitcz and Peterson, 1997 & SSX 770 & 429125.15141 & 5096409.21679 & $07 / 11 / 96$ & yes & no & no \\
\hline Fedorowitcz and Peterson, 1997 & SSX 771 & 429105.15113 & 5096439.21625 & 07/11/96 & yes & no & no \\
\hline
\end{tabular}




\begin{tabular}{|c|c|c|c|c|c|c|c|}
\hline Source & Site \# & UTM_X (NAD 83) & UTM_Y (NAD 83) & Date & 1964 & 1700 & Older \\
\hline Fedorowitcz and Peterson, 1997 & SSX 772 & 429097.15077 & 5096477.21567 & $07 / 11 / 96$ & yes & no & no \\
\hline Fedorowitcz and Peterson, 1997 & SSX 773 & 29081.15052 & 5096503.21520 & $07 / 11 / 96$ & yes & no & no \\
\hline Fedorowitcz and Peterson, 1997 & SSX 774 & 9086.15026 & 096530.21486 & $07 / 11 / 96$ & yes & no & no \\
\hline Fedorowitcz and Peterson, 1997 & SSW 775 & 29306.16642 & 5093893.23999 & $07 / 12 / 96$ & no & yes & no \\
\hline Fedorowitcz and Peterson, 1997 & SSW 776 & 29275.16646 & 5093898.23986 & $07 / 12 / 96$ & no & $?$ & no \\
\hline Fedorowitcz and Peterson, 1997 & SSW 777 & 429292.16645 & 5093897.23995 & $07 / 12 / 96$ & no & yes & no \\
\hline Fedorowitcz and Peterson, 1997 & SSW 778 & 429306.16696 & 5093973.24077 & $07 / 12 / 96$ & no & $?$ & no \\
\hline Fedorowitcz and Peterson, 1997 & SSW 779 & 429326.16694 & 5093970.24085 & $07 / 12 / 96$ & no & ? & no \\
\hline Fedorowitcz and Peterson, 1997 & SSW 780 & 429239.16918 & 5094296.24353 & $07 / 12 / 96$ & no & no & no \\
\hline Fedorowitcz and Peterson, 1997 & SSW 781 & 429142.16963 & 5094492.24356 & $07 / 12 / 96$ & no & yes & no \\
\hline Fedorowitcz and Peterson, 1997 & SSW 782 & 429180.16248 & 5093314.23361 & $07 / 12 / 96$ & no & no & no \\
\hline Fedorowitcz and Peterson, 1997 & SSW 783 & 429237.16239 & 5093299.23380 & $07 / 12 / 96$ & no & no & no \\
\hline Fedorowitcz and Peterson, 1997 & SSW 784 & 428750.15733 & 5092602.22405 & $07 / 13 / 96$ & no & yes & yes \\
\hline Fedorowitcz and Peterson, 1997 & SSW 785 & 428775.15735 & 5092602.22420 & $07 / 13 / 96$ & no & no & no \\
\hline Fedorowitcz and Peterson, 1997 & SSW 786 & 428827.15736 & 5092599.22449 & $07 / 13 / 96$ & no & no & no \\
\hline Fedorowitcz and Peterson, 1997 & SSW 787 & 428825.15793 & 50926 & $07 / 13 / 96$ & no & yes & yes \\
\hline erson, 1997 & SSW 788 & 4288 & 549 & $13 / 96$ & no & yes & yes \\
\hline dorowitcz and Peterson, 1997 & SSW 789 & 336 & 2592 & $3 / 96$ & no & yes & yes \\
\hline orowitcz and Peterson, 1997 & SSW 790 & & 680 & $3 / 96$ & no & yes & yes \\
\hline erson, 1997 & SSW 791 & & 236 & $7 / 96$ & no & no & no \\
\hline Fedorowitcz and Peterson, 1997 & SSW 792 & 247 & 327 & $7 / 96$ & no & yes & no \\
\hline erson, 1997 & SSW 7 & & & 07 & no & yes & no \\
\hline erson, 1997 & $\mathrm{SSW}^{-}$ & & 993 & & no & no & no \\
\hline on, 1997 & SSW & & & 5/96 & no & yes & no \\
\hline on, 1997 & SSW & & & & no & yes & no \\
\hline , 1997 & SSW & & & & no & yes & no \\
\hline 1, 1997 & SSW & & & /96 & no & yes & yes \\
\hline , 1997 & SSW & & & /96 & no & $?$ & no \\
\hline 997 & SSW & & & /96 & no & yes & no \\
\hline & SSW & & & 196 & no & no & no \\
\hline & SSW & & & 1/96 & no & no & no \\
\hline & & & & 196 & no & no & no \\
\hline & & & & & no & no & no \\
\hline son, 1997 & SSW & & & 1/96 & no & no & no \\
\hline vitcz and Peterson, 1997 & SSW & & & 1/96 & no & no & no \\
\hline & & & & 196 & no & no & no \\
\hline & SSW & & & 196 & no & no & no \\
\hline & & & & /96 & no & no & no \\
\hline & & & & $/ 96$ & no & no & no \\
\hline & SSW & & & $/ 96$ & no & no & no \\
\hline & SSW & & & /96 & no & yes & no \\
\hline & & & & /96 & no & yes & no \\
\hline Fedorowitcz and Peterson, 1997 & SSW 8 & & & 1/96 & no & yes & yes \\
\hline Fedorowitcz and Peterson, 1997 & & & & $07 / 31 / 96$ & no & no & no \\
\hline Fedorowitcz and Peterson, 1997 & SSW 8 & 428937.16204 & 093259.23164 & $07 / 31 / 96$ & no & no & no \\
\hline Fedorowitcz and Peterson, 1997 & SSW 817 & & 5092568.22383 & 08/07/96 & no & no & no \\
\hline Fedorowitcz and Peterson, 1997 & SSW 818 & 428856.15710 & 5092558.22426 & $08 / 07 / 96$ & no & yes & yes \\
\hline Fedorowitcz and Peterson, 1997 & SSW 819 & & 5093000.23050 & 08/07/96 & no & no & no \\
\hline Fedorowitcz and Peterson, 1997 & SSW 820 & 429259.16160 & 5093182.23279 & 08/07/96 & no & no & no \\
\hline Fedorowitcz and Peterson, 1997 & SSW 821 & 429241.16121 & 5093125.23213 & 08/07/96 & no & no & no \\
\hline Fedorowitcz and Peterson, 1997 & SSW 822 & 428927.16009 & 5092980.22884 & 08/07/96 & no & yes & no \\
\hline Fedorowitcz and Peterson, 1997 & SSW 823 & 428945.16003 & 5092971.22886 & $08 / 07 / 96$ & no & yes & no \\
\hline
\end{tabular}




\begin{tabular}{|c|c|c|c|c|c|c|c|}
\hline Source & Site \# & UTM_X (NAD 83) & UTM_Y (NAD 83) & Date & 1964 & 1700 & Older \\
\hline Fedorowitcz and Peterson, 1997 & SSW 824 & 429051.15989 & 5092943.22922 & $08 / 07 / 96$ & no & no & no \\
\hline Fedorowitcz and Peterson, 1997 & SSW 825 & 29049.16048 & 5093029.23005 & $08 / 07 / 96$ & no & yes & no \\
\hline Fedorowitcz and Peterson, 1997 & SSN 826 & 27303.14815 & 91572.20470 & $08 / 07 / 96$ & no & no & yes \\
\hline Fedorowitcz and Peterson, 1997 & SSN 827 & 427272.14763 & 5091511.20388 & $08 / 08 / 96$ & no & yes & yes \\
\hline Fedorowitcz and Peterson, 1997 & SSW 828 & 428439.15262 & 091982.21598 & $08 / 08 / 96$ & no & yes & yes \\
\hline Fedorowitcz and Peterson, 1997 & SSW 829 & 428446.15293 & 5092024.21644 & $08 / 08 / 96$ & no & yes & no \\
\hline Fedorowitcz and Peterson, 1997 & SSW 830 & 428405.15230 & 5091943.21538 & $08 / 08 / 96$ & no & yes & yes \\
\hline Fedorowitcz and Peterson, 1997 & SSW 831 & 428335.15215 & 5091933.21484 & $08 / 08 / 96$ & no & no & yes \\
\hline Fedorowitcz and Peterson, 1997 & SSW 832 & 428277.15175 & 5091887.21402 & $08 / 08 / 96$ & no & yes & yes \\
\hline Fedorowitcz and Peterson, 1997 & SSW 833 & 428676.15398 & 5092138.21900 & $08 / 08 / 96$ & no & yes & no \\
\hline Fedorowitcz and Peterson, 1997 & SSW 834 & 428690.15427 & 5092177.21948 & $08 / 08 / 96$ & no & yes & no \\
\hline Fedorowitcz and Peterson, 1997 & SSW 835 & 428692.15459 & 5092222.21993 & $08 / 08 / 96$ & no & yes & yes \\
\hline Fedorowitcz and Peterson, 1997 & SSW 836 & 428692.15493 & 5092269.22040 & 08/09/96 & no & yes & no \\
\hline Fedorowitcz and Peterson, 1997 & SSW 837 & 428704.15474 & 5092241 & 08/09/96 & no & yes & no \\
\hline Fedorowitcz and Peterson, 1997 & SSW 838 & 428676 & 5092271 & 08/09/96 & no & yes & no \\
\hline orowitcz and Peterson, 1997 & SSW 839 & 42871 & 068 & 08/09/96 & no & yes & no \\
\hline erson, 1997 & SSW & 40 & 124 & 08/09/96 & no & yes & no \\
\hline eterson, 1997 & SSW & & 138 & 08/09/96 & no & no & no \\
\hline erson, 1997 & SSW & 67 & 174 & $08 /$ & no & no & no \\
\hline on, 1997 & SSW & & 237 & 08 & no & yes & no \\
\hline Id Peterson, 1997 & SSW & & 314 & $08 /$ & no & yes & no \\
\hline son, 1997 & & & & & no & no & no \\
\hline a, 1997 & SSW & & & & no & no & no \\
\hline n, 1997 & SSW & & & & no & yes & no \\
\hline a, 1997 & SSW & & & & no & no & no \\
\hline 997 & SSXa & & & & yes & no & no \\
\hline 1997 & SSXa & & & & yes & yes & no \\
\hline 997 & SSXa & & & $08 /$ & yes & ? & no \\
\hline & SSXa & & & $08 /$ & yes & no & no \\
\hline 997 & SSX & & & $08 /$ & yes & yes & no \\
\hline & SSX & & & $08 /$ & yes & yes & no \\
\hline & & & & $4 / 96$ & yes & ? & no \\
\hline & & & & & yes & no & yes \\
\hline & SS $\Sigma$ & & & $08 / 15 / 96$ & no & no & no \\
\hline erson, 1997 & SSXa & & & $08 / 15 / 96$ & yes & $?$ & no \\
\hline & SSN & & & $08 / 15 / 96$ & yes & no & no \\
\hline & & & & /96 & yes & no & no \\
\hline & & & & $/ 96$ & yes & no & no \\
\hline & & & & $/ 96$ & yes & no & no \\
\hline & & & & $/ 96$ & yes & no & no \\
\hline & & & & $/ 96$ & yes & no & no \\
\hline & & & & /96 & no & no & no \\
\hline & & & & /96 & no & yes & no \\
\hline & & & & $08 / 16 / 96$ & no & yes & no \\
\hline Fedorowitcz and Peterson, 1997 & SSS 868 & & & $08 / 16 / 96$ & no & yes & no \\
\hline Fedorowitcz and Peterson, 1997 & SSN 869 & & & $08 / 16 / 96$ & yes & no & no \\
\hline Fedorowitcz and Peterson, 1997 & SSN 870 & 428887.16343 & 5095155.23291 & $08 / 16 / 96$ & yes & no & no \\
\hline Fedorowitcz and Peterson, 1997 & SSN 871 & & 5094963.23423 & $08 / 16 / 96$ & yes & no & no \\
\hline Fedorowitcz and Peterson, 1997 & SSS 872 & 429638.16593 & 5094855.24126 & $08 / 16 / 96$ & no & no & yes \\
\hline Fedorowitcz and Peterson, 1997 & SSS 873 & 429676.16484 & 5094970.23990 & $08 / 16 / 96$ & no & no & yes \\
\hline Fedorowitcz and Peterson, 1997 & SSS 874 & 429699.16377 & 5095084.23847 & $08 / 16 / 96$ & no & yes & no \\
\hline Fedorowitcz and Peterson, 1997 & SSS 875 & 429677.16255 & 5095216.23654 & $08 / 17 / 96$ & no & yes & no \\
\hline
\end{tabular}




\begin{tabular}{lccccccc}
\hline Source & Site \# & UTM_X (NAD 83) & UTM_Y (NAD 83) & Date & 1964 & 1700 Older \\
\hline Fedorowitcz and Peterson, 1997 & SSS 876 & 429506.16700 & 5094748.24200 & $08 / 17 / 96$ & no & yes & yes \\
Fedorowitcz and Peterson, 1997 & SSN 877 & 428173.15573 & 5092439.21891 & $08 / 23 / 96$ & no & yes & no \\
Fedorowitcz and Peterson, 1997 & SSN 878 & 428201.15567 & 5092427.21896 & $08 / 23 / 96$ & no & no & no \\
Fedorowitcz and Peterson, 1997 & SSS 879 & 429681.15870 & 5095628.23092 & $08 / 23 / 96$ & no & yes & no \\
Fedorowitcz and Peterson, 1997 & SSS 880 & 429704.15832 & 5095668.23051 & $08 / 23 / 96$ & no & yes & no \\
Fedorowitcz and Peterson, 1997 & SSS 881 & 429670.15803 & 5095700.22987 & $08 / 23 / 96$ & no & yes & no \\
Fedorowitcz and Peterson, 1997 & SSN 882 & 428337.15890 & 5092854.22405 & $08 / 23 / 96$ & no & yes & no \\
Fedorowitcz and Peterson, 1997 & SSN 883 & 428353.15892 & 5092855.22416 & $08 / 23 / 96$ & yes & yes & no \\
Fedorowitcz and Peterson, 1997 & SSN 884 & 428326.15888 & 5092851.22396 & $08 / 23 / 96$ & no & yes & no \\
Fedorowitcz and Peterson, 1997 & SSS 885 & 429553.16868 & 5094567.24474 & $08 / 23 / 96$ & no & no & no \\
Fedorowitcz and Peterson, 1997 & SSS 886 & 429503.16870 & 5094568.24445 & $08 / 23 / 96$ & no & $?$ & no \\
Fedorowitcz and Peterson, 1997 & SSS 887 & 429483.16868 & 5094571.24430 & $08 / 24 / 96$ & no & yes & no \\
Fedorowitcz and Peterson, 1997 & SSS 888 & 429459.16867 & 5094574.24413 & $08 / 24 / 96$ & no & $?$ & no \\
Fedorowitcz and Peterson, 1997 & SSS 889 & 429505.16844 & 5094595.24409 & $08 / 22 / 96$ & no & yes & no \\
Fedorowitcz and Peterson, 1997 & SSW 890 & 428193.15121 & 5091827.21290 & $08 / 22 / 96$ & no & yes & yes \\
\hline UTM: Universal Transverse Mercar
\end{tabular}

UTM: Universal Transverse Mercator coordinates in North American Datum 1983, zone 10, in meters yes = tsunami deposit of specified age present

no = tsunami deposit of specific age not present

? = evidence for tsunami origin for deposit of specified age inconclusive 



\section{Appendix E. Incorporating tides into probability calculations}

Including tides in the probability calculation is essentially a source of aleatory uncertainty, because it is unknown at what tidal stage the tsunami wavetrain will arrive at Seaside (Mofjeld et al., 1997; Mofjeld et al., in press). First, consider the far-field case where only one rupture scenario (magnitude, slip, area) is considered per source region $(j)$. For each tsunami amplitude $A_{j}$ (corresponding to each $j$ source), the tides produce a probability density function $f(y, A)$ that describes the distribution in height of the maximum waves, where $y$ is the total wave height, including tsunami and tidal amplitudes. To get the exceedance rate for the $j$ th source as a function of $y$, we integrate the corresponding probability density function (PDF) as follows:

$$
F_{j}\left(y, A_{j}\right) \equiv \int_{y}^{\infty} f\left(y^{\prime}, A\right) d y^{\prime} .
$$

To get an explicit form for $F(y, A)$, a Gaussian distribution (Mofjeld et al., in press) is a reasonable approximation to the PDF:

$$
f(y, A)=B \exp \left[-\left(y-\eta_{0}\right)^{2} / 2 \sigma^{2}\right], B^{-1}=\sqrt{2} \pi \sigma,
$$

where

$$
\eta_{0}(A)=A+\mathrm{MSL}+C(\mathrm{MHHW}-\mathrm{MSL}) \exp \left[-\alpha\left(A / \sigma_{0}\right)^{\beta}\right]
$$

and

$$
\sigma(A)=\sigma_{0}-C^{\prime} \sigma_{0} \exp \left[-\alpha^{\prime}\left(A / \sigma_{0}\right)^{\beta^{\prime}}\right] .
$$

The parameters $C, \alpha, \beta, C^{\prime}, \alpha^{\prime}$, and $\beta^{\prime}$ are specific to the tides at a given location (see Appendix A). The integral $F(y, A)$ is then

$$
F(y, A)=\frac{1}{2} \operatorname{erfc}\left[\left(y-\eta_{0}\right) / \sqrt{2} \sigma\right], \operatorname{erfc}(z) \equiv 1-\operatorname{erf}(z) .
$$

Here, $\operatorname{erf}(z)=(2 / \sqrt{\pi}) \int_{0}^{z} \exp \left(-t^{2}\right) d t$ is the standard form of the error function.

The rate at which $y^{\prime} \geq y$ for a given source $\left(\lambda_{j}\right)$ is the mean recurrence rate of that design earthquake $\left(v_{j}\right)$ multiplied by $F_{j}$ :

$$
\lambda_{j}\left(y^{\prime} \geq y\right)=v_{j} F_{j}\left(y^{\prime} \geq y\right) .
$$

If for all source regions there is only one design earthquake per region, then the aggregate exceedance rate would be (since we are dealing with discrete regions):

$$
\lambda\left(y^{\prime} \geq y\right)=\sum_{j} \lambda_{j}\left(y^{\prime} \geq y\right) .
$$


The exceedance probability at Seaside, assuming that the arrival times are Poissonian, is

$$
P\left(y^{\prime}>y\right)=1-e^{-\lambda T},
$$

where $T$ is the exposure time of interest (1 year).

Next, consider just the local case where a distribution of tsunami amplitudes is obtained from multiple slip distributions available for a specified magnitude, average slip, area. If $p\left(A_{\text {local }}\right)$ is the PDF for local tsunami amplitudes, then

$$
E_{\text {local }}\left(y^{\prime} \geq y\right)=\int_{0}^{\infty} p\left(A_{\text {local }}\right) F\left(y, A_{\text {local }}\right) d A .
$$

$p\left(A_{\text {local }}\right)$ can be determined from a normalized histogram as in Mofjeld et al. (in press) or by approximation to a Gaussian distribution, similar to $f(y, A)$. Inclusion of multiple realizations for local rupture (aleatory uncertainty of the source) is discussed further in Section 5.2, "Source Specification," for Cascadia subduction zone earthquakes below. It follows that the local exceedance rate is given by

$$
\lambda_{\text {local }}\left(y^{\prime} \geq y\right)=v_{\text {local }} E_{\text {local }}\left(y^{\prime} \geq y\right) .
$$

Therefore, the "Grand Total" exceedance rate (local + far field) can be given by

$$
\lambda\left(y^{\prime} \geq y\right)=\lambda_{\text {local }}\left(y^{\prime} \geq y\right)+\sum_{j}^{\text {far-field }} \lambda_{j}\left(y^{\prime} \geq y\right) .
$$

The objective, of course, is to find $y$ corresponding to $\lambda=0.01 \mathrm{yr}^{-1}$ and $\lambda=$ $0.002 \mathrm{yr}^{-1}$.

\section{References}

Mofjeld, H.O., M.G.G. Foreman, and A. Ruffman, 1997, West Coast tides during Cascadia subduction zone tsunamis. Geophysical Research Letters, 24, 2215-2218.

Mofjeld, H.O., F.I. González, V.V. Titov, A.J. Venturato, and J.C. Newman, in press, Effects of tides on maximum tsunami wave heights: Probability distributions. Journal of Atmospheric and Oceanic Technology. 


\section{Appendix F. Determining earthquake recurrence rates}

For each earthquake, a set of source parameters must be chosen that determines the initial condition for propagation modeling. Earthquake magnitude is the primary parameter that links other source parameters such as rupture area and average amount of slip. Unlike deterministic modeling in which recurrence rates are not considered, probabilistic modeling requires the determination of recurrence rate for each source used in inundation modeling. Recurrence rates can be determined from frequency-magnitude distributions as follows.

\section{F1. Characteristic vs. Gutenberg-Richter}

A persistent controversy in seismology is whether the frequency-magnitude distribution for earthquakes follows a characteristic model at the largest magnitudes or a modified Gutenberg-Richter (G-R) distribution. Although broad generalizations are not always accurate, observational seismology tends to support the modified G-R model, whereas paleoseismology studies tend to follow, at least implicitly, the characteristic model. Figure F-1a, modified from Wesnousky (1994), shows the two models for both the discrete and cumulative form, where $\mathrm{M}_{\mathrm{a}}$ is the magnitude of the largest aftershock for the characteristic distribution. Note that for both models, smaller earthquakes follow a power-law scaling relationship. In Wesnousky's (1994) conception that is typical for paleoseismic studies, there is a significant gap in intermediate earthquake magnitudes between $\mathrm{M}_{\mathrm{a}}$ and $\mathrm{M}_{\max }$ for the characteristic model such that a given fault typically ruptures in $\mathrm{M}_{\max }$ earthquakes with the rest of the distribution $\mathrm{M}<\mathrm{M}_{\mathrm{a}}$ representing foreshocks, aftershocks, and background seismicity. In contrast, the G-R model predicts a power-law scaling relationship that is valid for all magnitudes up to $\mathrm{M}_{\max }$.

Both models are often employed in the development of the USGS National Seismic Hazard Maps. For example, in the seismic hazard maps for Alaska (Wesson et al., 1999) the Aleutian segment of the Pacific-North American interplate thrust is characterized by a G-R distribution for $\mathrm{M}=7-9.2$, whereas the Prince William Sound segment (1964 source region) is characterized by both a G-R distribution $(\mathrm{M}=7-8)$ and a characteristic rupture model $(\mathrm{M}=9.2)$ with an average return time of 750 years derived from paleoseismology studies (400500 years estimated by Bartsch-Winkler and Schmoll, 1992). For earthquakes along the Cascadia interplate thrust, the National Seismic Hazard Maps use two different models that are equally weighted (Frankel et al., 2002): (1) a $\mathrm{M}=9.0$ characteristic earthquake with an average repeat time of 500 years 
(a)

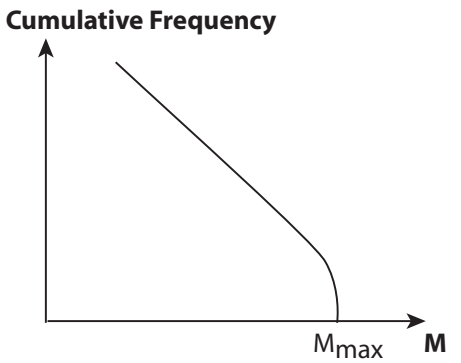

Gutenberg-Richter Distribution

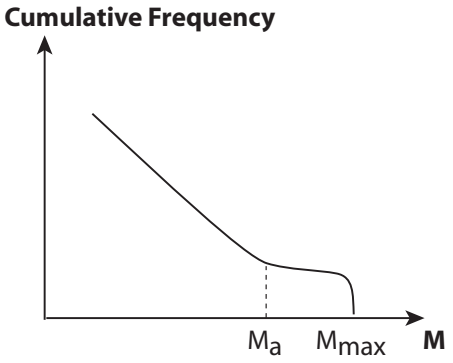

Characteristic Distribution (b)

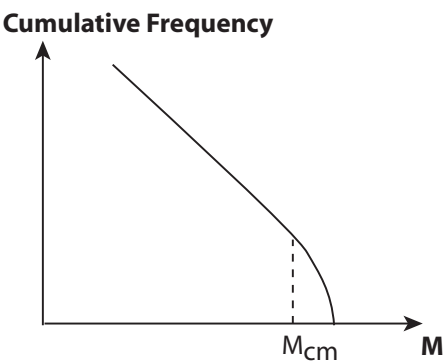

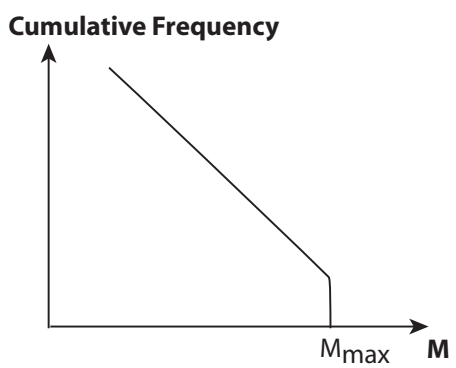

Tapered Gutenberg-Richter Distribution Characteristic Distribution

Figure F1: Characteristic and Gutenberg-Richter earthquake distributions as described in different studies: (a) Wesnousky (1994); (b) Kagan (2002a).

and (2) a series of $M=8.3$ earthquakes that fill the seismogenic region of the interplate thrust every 500 years, resulting in a repeat time of 110 years for a $\mathrm{M}=8.3$ earthquake to occur anywhere in the seismic zone. A G-R distribution is not used for Cascadia interplate thrust earthquakes. It should be stressed, however, that the paleoseismic data used in characteristic earthquake models needs to be carefully analyzed with respect to the possible magnitude range that geologic markers represent and to account for open intervals in calculating average repeat times (Parsons, 2004, submitted) (see also Savage, 1991; Schwartz, 1999 for specific concerns regarding the characteristic model).

A different definition of characteristic and Gutenberg-Richter models is presented more recently by Kagan (2002a) as shown in Fig. F1b. The characteristic distribution is a power-law distribution truncated at the characteristic magnitude (cumulative form). This is similar to Wesnousky's (1994) definition of Gutenberg-Richter distribution (Fig. Fla) and hence is an obvious source of confusion. The other distributions shown above are modified GutenbergRichter distributions where there is an accelerating fall-off in earthquake recurrence rates with increasing magnitude. The tapered Gutenberg Richter and Gamma distributions have a "soft" corner magnitude, whereas the characteristic and truncated Pareto (also called truncated Gutenberg-Richter because the 
probability density distribution is truncated) have "hard" cutoff magnitudes (Kagan, 2002b).

For tsunamis, we are primarily concerned with establishing recurrence rates for large magnitude earthquakes that occur at the tail of these distributions. The distributions derived by Kagan are statistically more defensible using observed seismicity and seismic moment balances (Bird and Kagan, submitted; Kagan, 2002a; Pisarenko and Sornette, 2004; Sornette and Sornette, 1999). Even so, there is substantial uncertainty in establishing recurrence rates at the distribution tails because of a lack (thankfully) of very large magnitude earthquakes (hence, the reason there are multiple distributions).

\section{F2. Modified G-R Distributions}

The original form of the G-R distribution is

$$
\log N(m)=a-b m,
$$

where $N(m)$ is the number of earthquakes with magnitude $\geq m$ and $a$ and $b$ are scaling parameters. The parameter $a$ is often associated with the seismic activity of a particular region and $b$ is the power-law exponent of scaling. Kagan (2002a), Sornette and Sornette (1999), and other earlier studies indicate that source finiteness requires that there must be an upper bound to the G-R distribution (Equation 1). This leads to the modified G-R distributions described by Kagan (2002a) and shown in Fig. F1b.

In a simplified version involving the truncated G-R distribution, Ward (1994) derives an expression for the average repeat time for earthquakes of magnitude $m$ :

$$
T(m)=\left[\frac{b}{1.5+b}\right] \frac{10^{(1.5+b) m_{\max }+9.5}}{\dot{M}_{s}\left[10^{b m_{\max }}-10^{b m}\right]},
$$

where $\dot{M}_{s}$ is the seismic moment release rate in Nm/yr. Note that the $a$ value (Equation 1) does not appear in this expression. The seismic activity is determined by $\dot{M}_{s}$ as described below. Recurrence rates calculated from (2) are associated with a sharp distribution corner with a hard cutoff at $m_{\max }$.

An equivalent expression for the tapered G-R (TGR) distribution can be derived from Kagan (2002b, eqn. 7):

$$
T\left(M_{0}\right)=\left[\frac{1}{1-\beta}\right] \frac{M_{0}^{\beta} M_{\mathrm{cm}}^{1-\beta}}{\dot{M}_{s}} \Gamma(2-\beta) \xi_{m},
$$

where $\beta=\frac{2}{3} b, \Gamma$ is the gamma function and $\xi_{m}=\exp \left(M_{0} / M_{\mathrm{cm}}\right) . M_{0}$ and $M_{\mathrm{cm}}$ are given in $\mathrm{Nm}$ (corresponding magnitudes $m_{0}$ and $m_{\mathrm{cm}}$ are given by $m=$ $\frac{2}{3} \log M-6.0$ ). Similar expressions can be derived for the other distributions.

\section{F3. Seismic Moment Conservation}

The seismic moment rate $\dot{M}_{s}$ in Equations (2) and (3) can be determined for a particular seismic zone from historic earthquakes, as long as the catalog 
contains the largest seismic moment events. Otherwise, $\dot{M}_{s}$ can be determined from fault slip rates $\left(\dot{s}_{\text {geol }}\right)$ and estimates of geometric parameters. The formula for geologically determined $\dot{M}_{S}$ is given below (Ward, 1994):

$$
\dot{M}_{s}=\mu L H_{s} \dot{s}_{\text {geol }}
$$

where $\mu$ is the shear modulus, $L$ is the fault length, and $H_{s}$ is the effective seismogenic thickness. The latter parameter is the most difficult to estimate because it involves determination of the base of seismicity (transition from unstable to stable frictional properties) and the seismic coupling coefficient $(\chi)$ that accounts for the portion of fault movement that occurs aseismically. Studies by Bird and Kagan (submitted), Kagan (2002b), and Ward (1994) all seek to ensure that the seismic moment rates are consistent with plate tectonic rates and physical parameters.

\section{F4. Seismic Zonation}

In calculating frequency-magnitude distributions, a seismic zonation scheme is used such that the scaling parameters can be considered more or less uniform. For example, the zonation scheme used by Ward (1994) for evaluating onshore seismic hazards in southern California entailed defining 66 regions with definable characteristics. For the purpose of the tsunami pilot study, much larger zones need to be considered. For far-field sources, the FlinnEngdahl regions are probably most suitable. Kagan (1997) and Sornette and Sornette (1999) determine $b$-values, moment rate, and corner magnitudes for Flinn-Engdahl regions relevant to far-field tsunamis. In a later paper, Kagan (2002b) considers smaller circum-Pacific seismic zones defined by McCann et al. (1979) and Nishenko (1991). For the smaller zones, however, the statistics are not as reliable and accommodation for interacting zones (cf., Ward, 1994) needs to be included for larger earthquakes that span multiple zones.

A question may be raised as to whether the estimated scaling parameters are applicable for the subset of tsunamigenic earthquakes. The earthquakes analyzed by Kagan $(1997 ; 2002 \mathrm{~b})$ are in the depth range of $0-70 \mathrm{~km}$, though most are in the $0-40 \mathrm{~km}$ range. The primary condition that limits the transfer of seismic to tsunami energy is deformation that occurs onshore rather than offshore. This effect should be accounted for in existing tsunami propagation models that use realistic bathymetry and topography over the source region.

\section{F5. Approach Used in This Study}

As outlined above, there are several choices of frequency-magnitude distributions that one could choose to determine earthquake recurrence rates. Whereas the scaling and recurrence rates of small earthquakes are usually well defined, the tail of the distribution is difficult to constrain with statistical confidence (Pisarenko and Sornette, 2004). Unfortunately, it is the large earthquakes that exist at the distribution tail that are of primary interest for far-field tsunami studies. 
One possible approach is to calculate inundation maps based on $\mathrm{M}_{\max }$, some of which have historic precedent, such as the 1964 Alaska, 1960 Chile, 1957 Aleutian, and 1700 Cascadia earthquakes. This serves the dual purpose of constraining the aggregate 0.01 or 0.002 annual probability from high returnperiod events and using these historic events for model validation. However, how do we establish the return period for these events? Sykes and Quittmeyer (1981) use the time-predictable model (Shimazaki and Nakata, 1980) to estimate recurrence rates for large earthquakes in most of the regions of interest. Murray and Segall (2002), however, recently call into question the time-predictable model. As another option, we can use characteristic rates for the 1964 Alaska source and 1700 Cascadia source regions (similar to the National Seismic Hazard Maps) estimated from paleoseismology and use a modified G-R distribution for other regions defined by Flinn-Engdahl zonation. If characteristic sources are used, however, it would be most consistent to also use historic and paleoseismic studies for other regions, such as Japan, that are considerably more complex (e.g., Nanayama et al., 2003; Rikitake, 1999; Utsu, 1984). This also introduces the previously mentioned problems in using paleoseismic data to establish recurrence rates for specific earthquake magnitudes. A third approach would be to simply use a modified G-R distribution for all regions that are constrained by plate tectonic/fault slip rates. In this case, the seismic moment rate for the Cascadia interplate thrust would have to be derived from fault slip rates (Equation 4 ) and an assumed $b$-value. In contrast to the paleoseismic/characteristic earthquake approach, both the magnitude and recurrence rates are well defined, though there is significant uncertainty in estimating recurrence rates for the largest earthquakes.

\section{F6. Summary}

One of the obvious difficulties with specifying far-field sources for this and any tsunami probability study is obtaining accurate estimates for $\mathrm{M}_{\max }$ and the associated recurrence rates for each source region. Several problematic examples include wide variations in the estimated seismic moment for the 1957 Andreanof earthquake (Boyd et al., 1995) and differences between tsunami and seismic estimates for events such as the 1952 Kamchatka and 1960 Chile earthquakes. One way to incorporate these uncertainties is to estimate a reasonable distribution of source parameters and run additional models to determine the effect on inundation at Seaside. Given the time constraint of the pilot study, however, we rely on sensitivity studies such as Titov et al. (1999) to determine if and how this type of analysis should proceed.

Finally, an example of how these sources may combine for determining the 100-year and 500-year inundation zones is given below. If we assume a timeindependent (Poissonian) probability model and that the largest inundation zone will be from a $\mathrm{M}=9$ Cascadia earthquake with an average return time of 500 years, then the Cascadia earthquake alone (along with its variations) will determine the 500-year tsunami flood at Seaside. Suppose, furthermore, that the four largest inundation zones at Seaside were from a $\mathrm{M}=9.0$ Cascadia event (500 yr), a $\mathrm{M}=9.2$ Gulf of Alaska event (750 yr), a $\mathrm{M}=8.8$ Kamchatka event (300 
yr), and a $\mathrm{M}=9.5$ Chile event (300 yr) Then, the 100-year tsunami flood would be where the inundation zones from all four of these earthquakes overlap (i.e., $\frac{1}{500}+\frac{1}{750}+\frac{1}{300}+\frac{1}{300}=\frac{1}{100}$ ). These numbers are approximate for the purposes of the example. Also, the combination of events constraining the 100-year flood may change when time-dependent probabilities are considered.

\section{F7. References}

Bartsch-Winkler, S., and H.R. Schmoll, 1992, Utility of radiocarbon-dated stratigraphy in determining late Holocene earthquake recurrence intervals, upper Cook Inlet region, Alaska. Geological Society of America Bulletin, 104, 684-694.

Bird, P., and Y.Y. Kagan, submitted, Plate-tectonic analysis of shallow seismicity: Apparent boundary width, beta-value, corner magnitude, coupled lithosphere thickness, and coupling in seven tectonic settings. Bulletin of the Seismological Society of America.

Boyd, T.M., E.R. Engdahl, and W. Spence, 1995, Seismic cycles along the Aleutian arc: Analysis of seismicity from 1957 through 1991. Journal of Geophysical Research, 100, 621-644.

Frankel, A.D., M.D. Petersen, C.S. Mueller, K.M. Haller, R.L. Wheeler, E.V. Leyendecker, R.L. Wesson, S.C. Harmsen, C.H. Cramer, D.M. Perkins, and K.S. Rukstales, 2002, Documentation for the 2002 Update of the National Seismic Hazard Maps. U.S. Geological Survey, Open-File Report 02-420, 33 pp.

Kagan, Y.Y., 1997, Seismic moment-frequency relation for shallow earthquakes: Regional comparison. Journal of Geophysical Research, 102, 2835-2852.

Kagan, Y.Y., 2002a, Seismic moment distribution revisited: I. Statistical Results. Geophysical Journal International, 148, 520-541.

Kagan, Y.Y., 2002b, Seismic moment distribution revisited: II. Moment conservation principle. Geophysical Journal International, 149, 731-754.

McCann, W.R., S.P. Nishenko, L.R. Sykes, and J. Krause, 1979, Seismic gaps and plate tectonics: Seismic potential for major boundaries. Pure and Applied Geophysics, $117,1082-1147$.

Murray, J., and P. Segall, 2002, Testing time-predictable earthquake recurrence by direct measurement of strain accumulation and release. Nature, 419, 287-291.

Nanayama, F, K. Satake, R. Furukawa, K. Shimokawa, B.F. Atwater, K. Shigeno, and S. Yamaki, 2003, Unusually large earthquakes inferred from tsunami deposits along the Kuril trench. Nature, 424, 660-663.

Nishenko, S.P., 1991, Circum-Pacific seismic potential: 1989-1999. Pure and Applied Geophysics, 135, 169-259.

Parsons, T., 2004, Recalculated probability of M 7 earthquakes beneath the Sea of Marmara, Turkey. Journal of Geophysical Research, 109(B5), B05304, doi: 10.1029/ 2003JB002667.

Parsons, T., submitted, Significance of stress transfer in time-dependent earthquake probability calculations.

Pisarenko, V.F., and D. Sornette, 2004, Statistical detection and characterization of a deviation from the Gutenberg-Richter distribution above magnitude 8. Pure and Applied Geophysics, 161, 839-864.

Rikitake, T., 1999, Probability of a great earthquake to recur in the Tokai district, Japan: Reevaluation based on newly-developed paleoseismology, plate tectonics, tsunami study, micro-seismicity and geodetic measurements. Earth Planets Space, 51, 147157.

Savage, J.C., 1991, Criticism of some forecasts of the National Earthquake Prediction Evaluation Council. Bulletin of the Seismological Society of America, 81, 862-881. 
Schwartz, S.Y., 1999, Noncharacteristic behavior and complex recurrence of large subduction zone earthquakes. Journal of Geophysical Research, 104, 23,111-23,125.

Shimazaki, K., and T. Nakata, 1980, Time-predictable recurrence model for large earthquakes. Geophysical Research Letters, 7, 279-282.

Sornette, D., and A. Sornette, 1999, General theory of the modified Gutenberg-Richter law for large seismic moments. Bulletin of the Seismological Society of America, 89, 1121-1130.

Sykes, L.R., and R.C. Quittmeyer, 1981, Repeat times of great earthquakes along simple plate boundaries. In Earthquake Prediction: An International Review, Simpson, D.W., and P.G. Richards (eds.), Washington, D.C., American Geophysical Union, 217-247.

Titov, V.V., H.O. Mofjeld, F.I. González, and J.C. Newman, 1999, Offshore forecasting of Hawaiian tsunamis generated in Alaskan-Aleutian subduction zone. Pacific Marine Environmental Laboratory (PMEL), NOAA Technical Memorandum ERL PMEL-114, 26 pp.

Utsu, T., 1984, Estimation of parameters for recurrence models of earthquakes. Bulletin of the Earthquake Research Institute, 59, 53-66.

Ward, S.N., 1994, A multidisciplinary approach to seismic hazard in southern California. Bulletin of the Seismological Society of America, 84, 1293-1309.

Wesnousky, S.G., 1994, The Gutenberg-Richter or characteristic earthquake distribution, which is it? Bulletin of the Seismological Society of America, 84, 1940-1959.

Wesson, R.L., A.D. Frankel, C.S. Mueller, and S.C. Harmsen, 1999, Probabilistic Seismic Hazard Maps of Alaska. U.S. Geological Survey, Open-File Report 99-36, 20 pp. 



\section{Appendix G. Surface and area calculation for the 100-year and 500-year floods}

The results of the probabilistic tsunami hazard analysis (PTHA) are grids of probability values for a series of tsunami wave heights in $0.5-\mathrm{m}$ increments from $0.5 \mathrm{~m}$ to $10.5 \mathrm{~m}$. The cell size is defined by the near-field tsunami source models and is 0.000558 degree in geographic coordinates or approximately $60 \mathrm{~m}$ in projected coordinates. The cell values were exported from PTHA as $x y z$ (longitude, latitude, probability) values and reformatted as ArcGIS grids. The grid for each wave height was contoured with an interval of $0.2 \%$ or 0.002 probability (Figs. Gla-c). The $1.0 \%$ contours for each wave height were merged into one file representing an annual probability of exceedance of $1.0 \%$ or the 100 -year tsunami (Fig. G1d). The $0.2 \%$ contours were similarly merged to represent the annual probability of exceedance of $0.2 \%$ or the 500 -year tsunami (Fig. Gle).

The wave height contours overlap or are closely spaced (sub-pixel separation) in coastal and inshore areas (Fig. G2d). The overlaps of the 100-year contours were clarified in the plate that accompanies this report by selective labeling, but overlaps for the 500-year contours are more complex and were processed to smooth the surface, taking into account the maximum wave height values at grid cell resolution (Fig. G2d-f).

Several ArcGIS surface interpolation methods were tested (with the overlapping and nonoverlapping contours separated or combined) to isolate one that most closely reproduced the maximum grid values. Combining contour data from the non-overlapping area and the extracted maximum points from the overlapping area in the TOPOGRID tool provided final wave heights with a standard deviation $0.25 \mathrm{~m}$ around the maximum PTHA wave heights. The TOPOGRID command is an interpolation method designed for the creation of digital elevation models (DEMs) (Hutchinson, 1993) from both line and point input.

Each of the 500-year wave height contours was converted to a grid, the grids were merged by descending wave height to capture the maximum value in each grid cell. The maximum grid values were converted to points and clipped to the overlap area for input to TOPOGRID (Fig. G2b). Contours that do not overlap are clipped and input to TOPOGRID as line features without modification. Contours of the resulting grid are used in the final representation of these flood surfaces (Fig. G2c, Plate 1). 
(a)

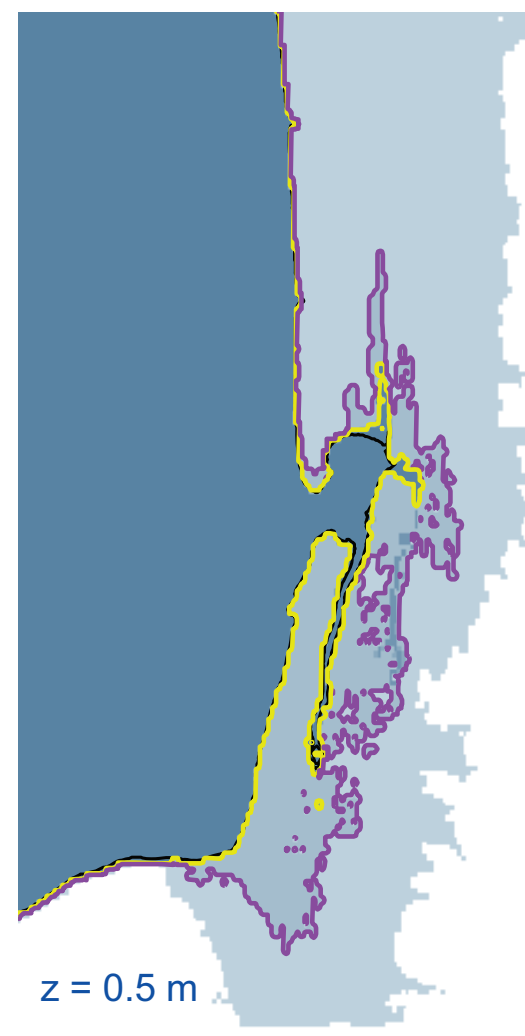

(b)

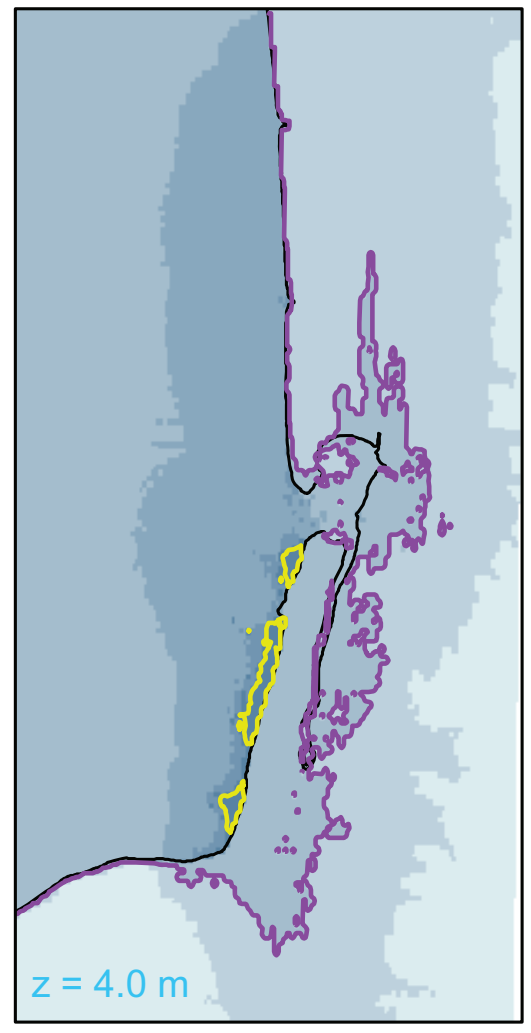

(d)

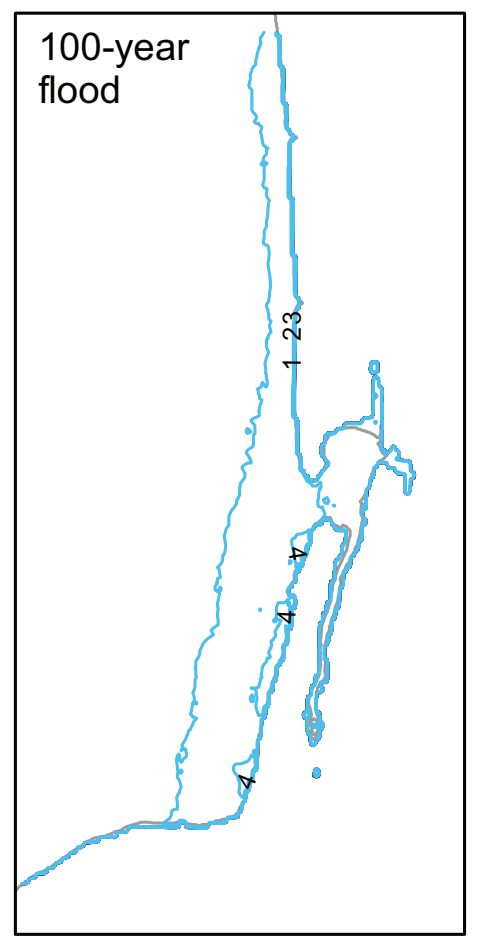

(c)

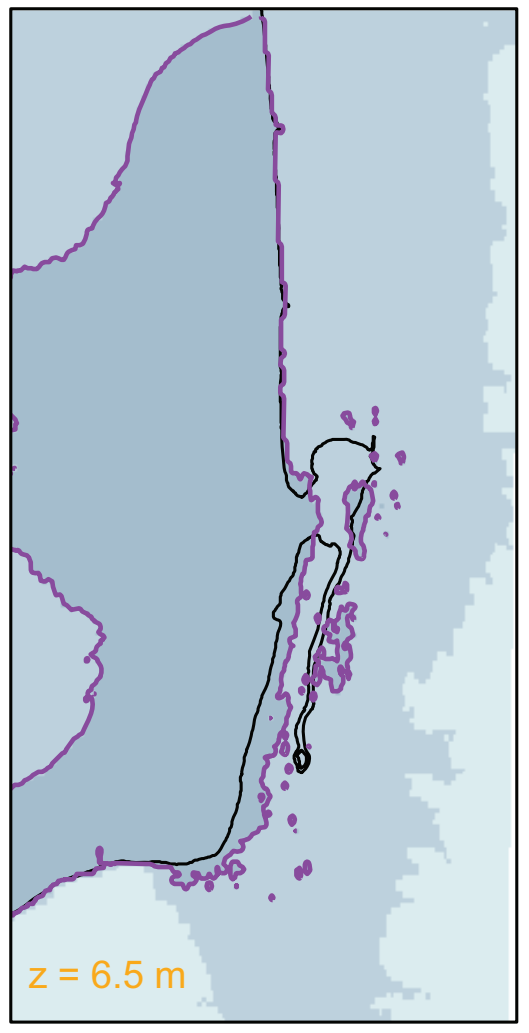

(e)

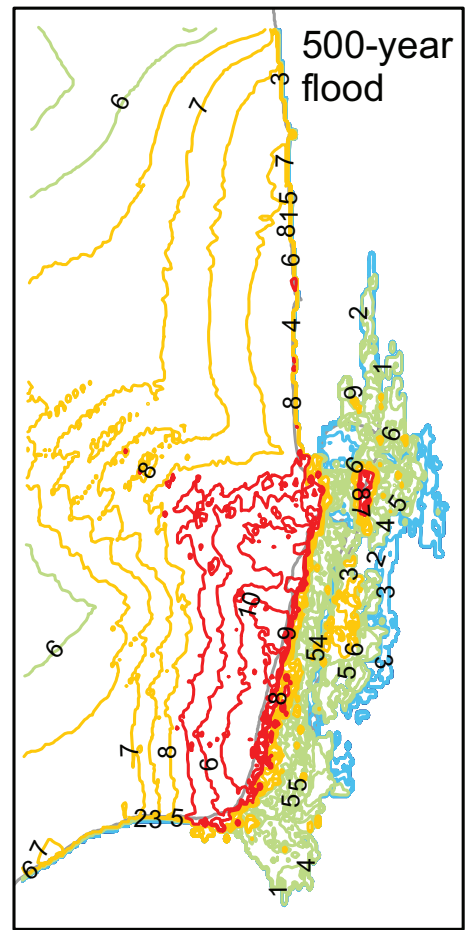

Figure G1: Probability grids from probabilistic tsunami hazard analysis (PTHA) for selected wave heights (a) $0.5 \mathrm{~m}$, (b) $4.0 \mathrm{~m}$, and (c) $6.5 \mathrm{~m}$ with the 0.002 and 0.010 contours where they exist. 100-year (d) and 500-year (e) flood maps of wave heights compiled from 0.010 and 0.002 probability contours, respectively. 
(a)

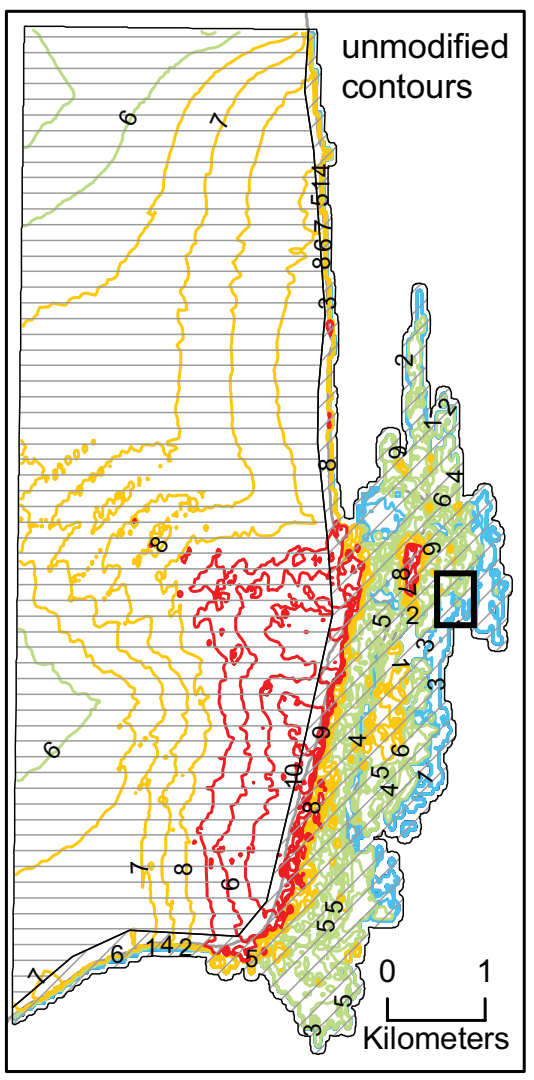

(d)

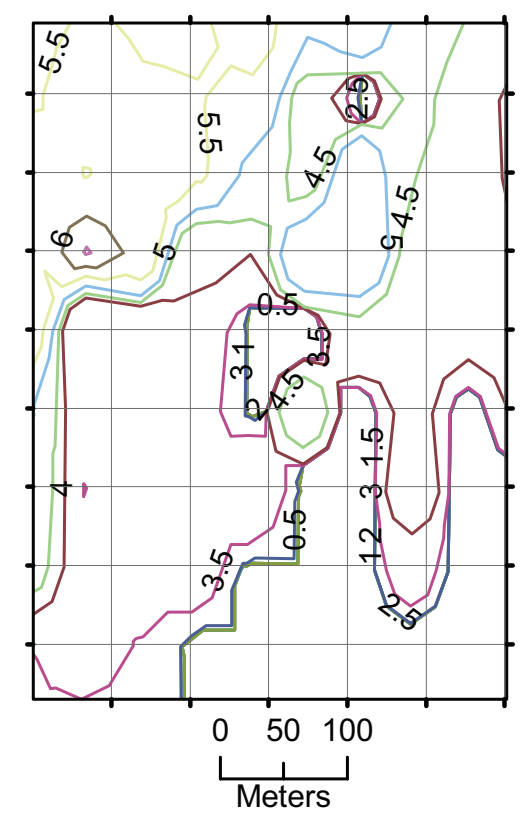

(b)

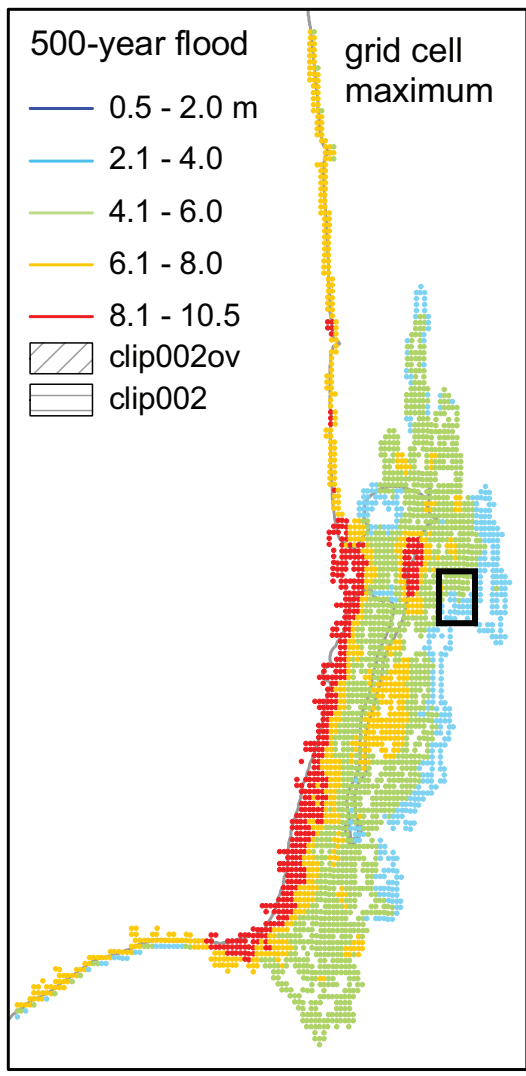

(e)

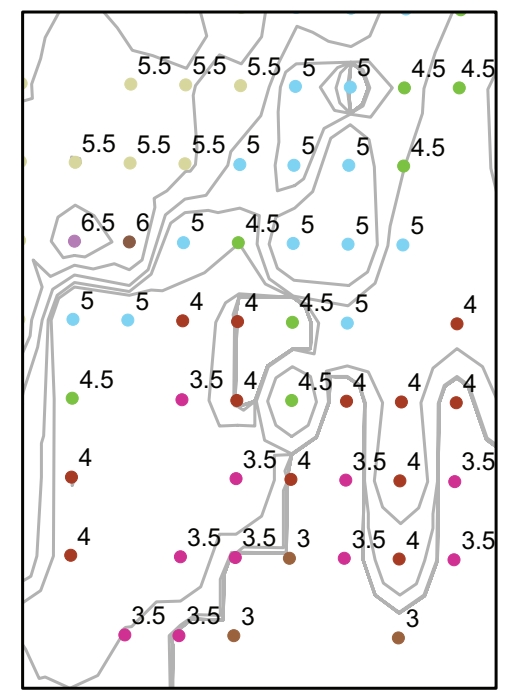

(c)

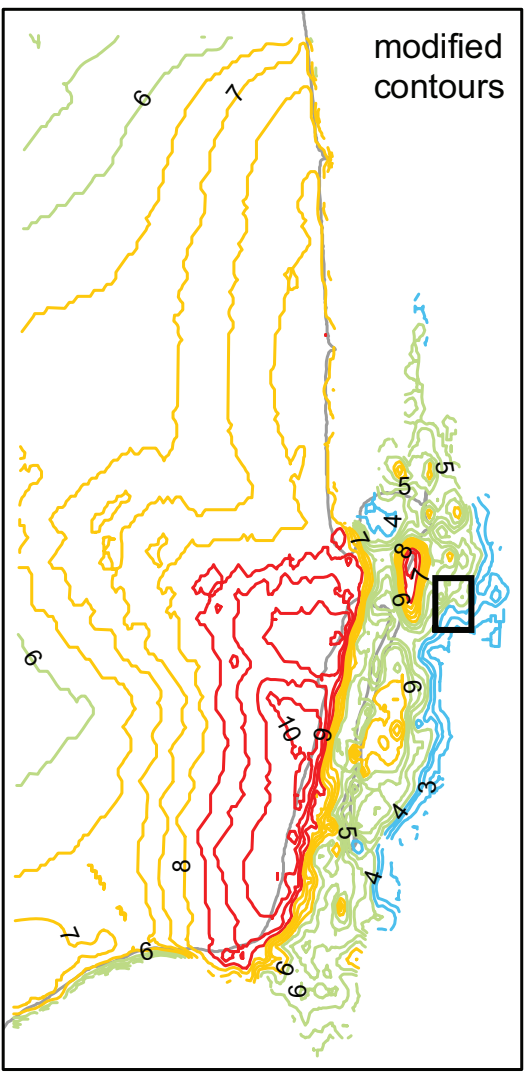

(f)

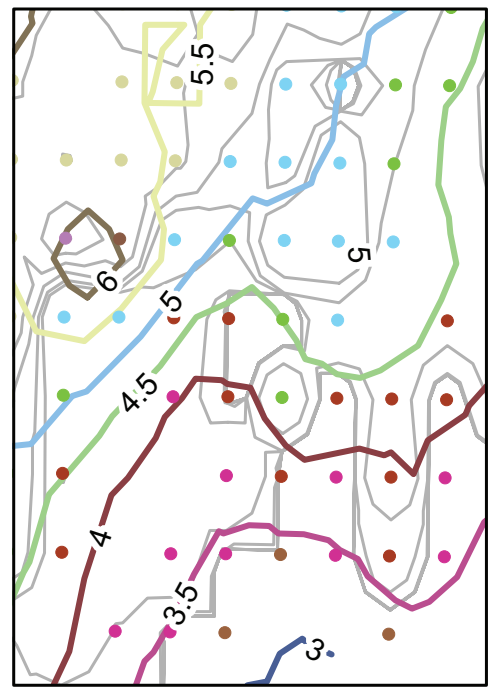

Figure G2: Maps of 500-year flood data for entire study area with accompanying enlargements of a selected area. (a) 500-year flood contours as extracted from PTHA model. Enlargement (b) shows that contours lie close together at the grid-cell level. (c) Maximum wave height values extracted for each grid cell in the inshore area. (d) Enlargement shows values for each grid cell in relation to original contours. (e) Contours recalculated by Arc TOPOGRID are generalized, but generally honor the original data (f). 
The eastern edge of the data portrays a maximum wave height of no less than $2.5 \mathrm{~m}$. This artificial thickness of water may be addressed by going to a smaller grid spacing and/or modeling finer increments of wave height exceedance from PTHA.

The extents of the 100- and 500-year maps are combined with the mean lower low water line (or_seaside1_3navd) (Venturato, 2005) to produce the tsunami-based flood zone map (Fig. G3).

\section{References}

Hutchinson, M.F., 1993, Development of a continent-wide DEM with applications to terrain and climate analysis. In Environmental Modeling with GIS, Goodchild, M.F, B.O. Parks, and L.T. Steyaert (eds.), New York, Oxford University Press, 392399.

Priest, G.R., E. Myers, A.M. Baptista, P. Fleuck, K. Wang, R.A. Kamphaus, and C.D. Peterson, 1997, Cascadia subduction zone tsunamis: Hazard mapping at Yaquina Bay, Oregon. State of Oregon, Department of Geology and Mineral Industries, Open-File Report O-97-34, 144 pp.

Venturato, A.J., 2005, A digital elevation model for Seaside, Oregon: Procedures, data sources, and analyses. NOAA Technical Memorandum OAR PMEL-129, 21 pp. 


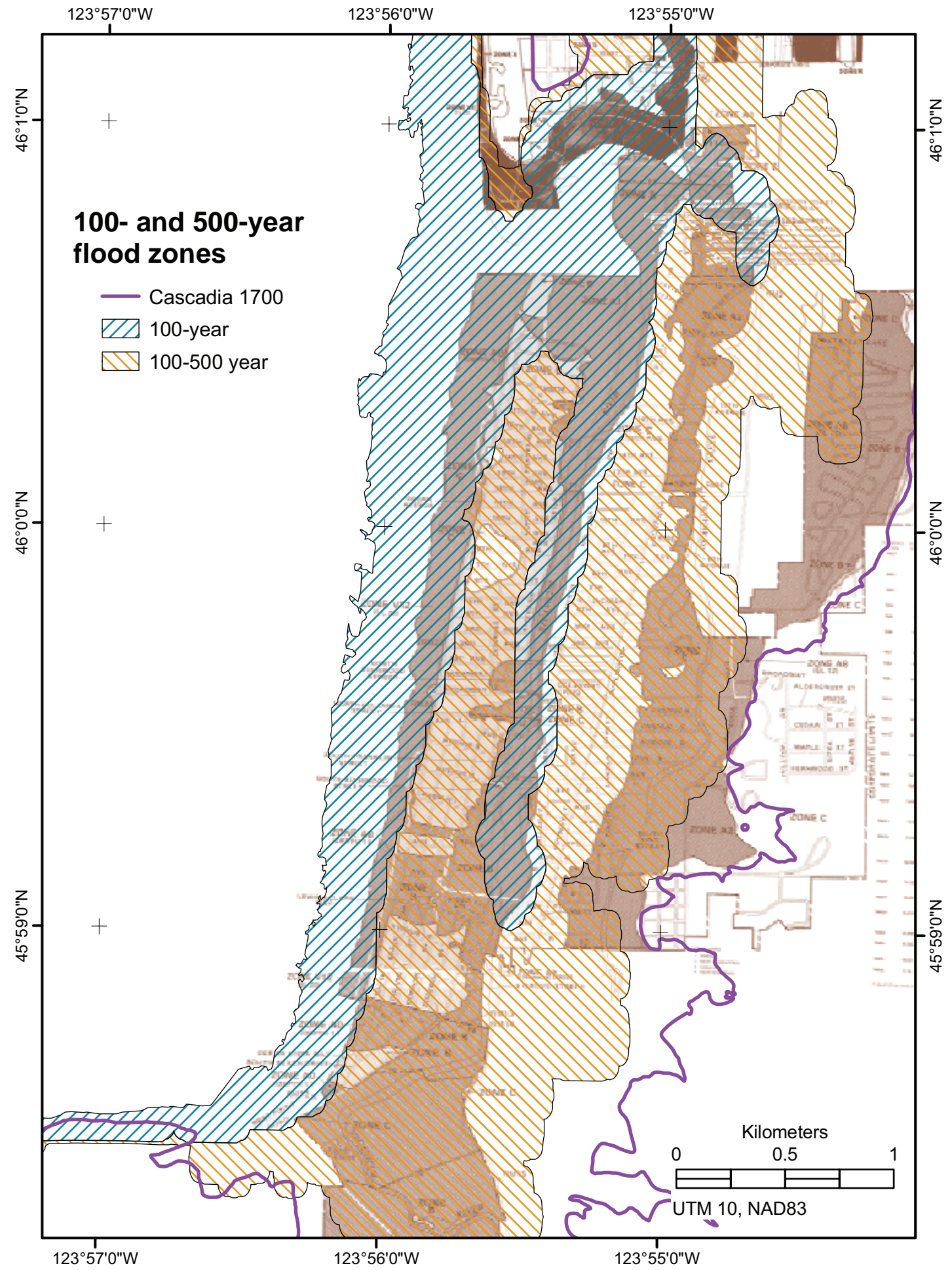

Figure G3: Map of 100- and 500-year flood zones based on PTHA overlaid on FEMA Flood Insurance Rate Maps for Seaside-Gearhart area. Seaward limit is mean lower low water (NAVD88). Landward boundary of 500-year flood zone may extend eastward because maximum wave height is $2.5 \mathrm{~m}$ at eastern edge. Line showing extent of deposits from tsunami generated by 1700 Cascadia earthquake (Priest et al., 1997) is included for comparison. 

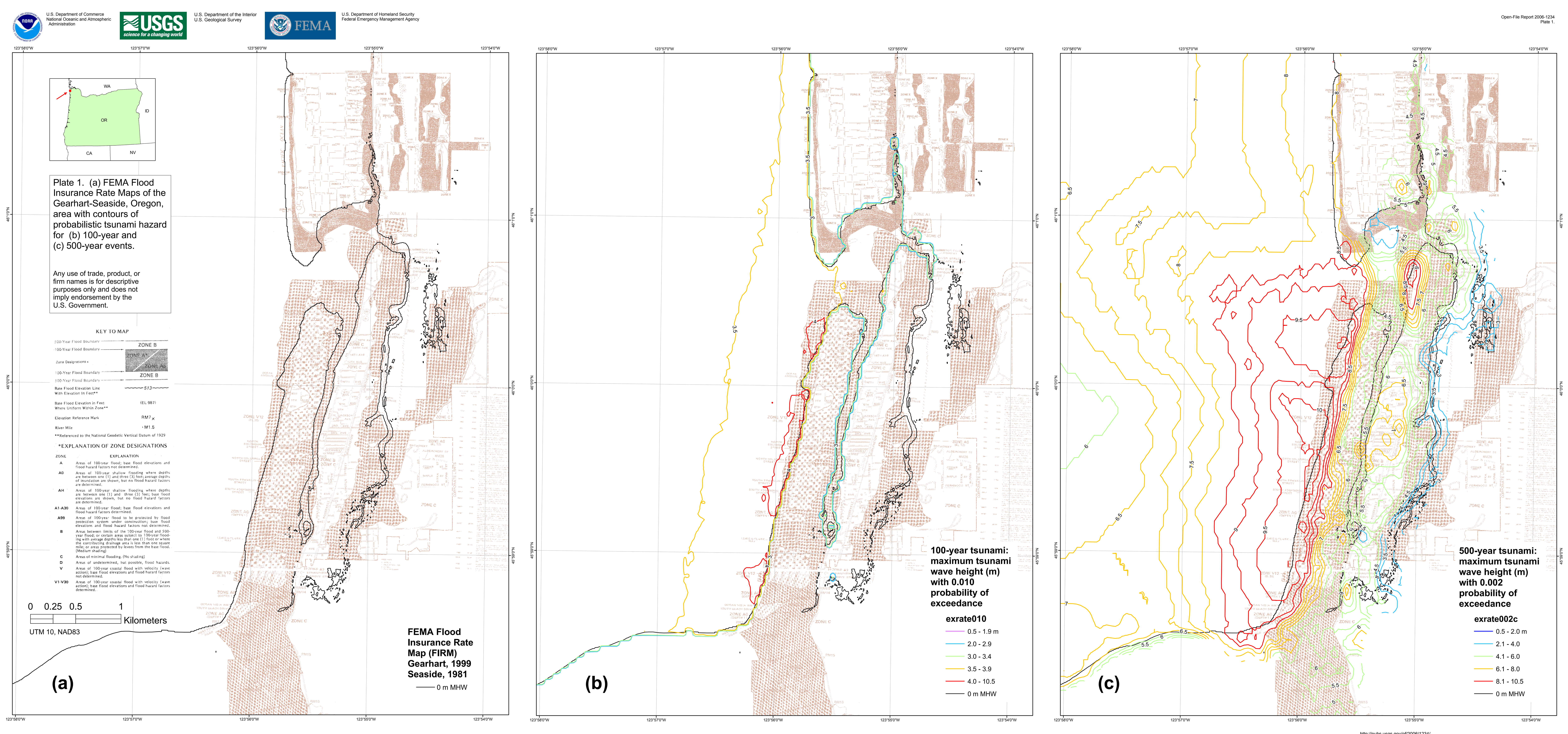